UNIVERSIDADE DE BRASÍLIA

FACULDADE DE TECNOLOGIA DEPARTAMENTO DE ENGENHARIA ELÉTRICA

\title{
ARQUITETURA DE SISTEMAS DE INFORMAÇÃO: PROPOSTA DE UM MECANISMO DE APRENDIZAGEM COM ORIENTAÇÃO METODOLÓGICA PARA APOIO À DECISÃO EM CENÁRIOS COMPLEXOS
}

ELIOMAR ARAÚJO DE LIMA

ORIENTADOR: LUÍS FERNANDO RAMOS MOLINARO

TESE DE DOUTORADO EM ENGENHARIA ELÉTRICA

PUBLICAÇÃO

BRASÍLIA/DF: FEVEREIRO - 2015 
UNIVERSIDADE DE BRASÍLIA

FACULDADE DE TECNOLOGIA

DEPARTAMENTO DE ENGENHARIA ELÉTRICA

ARQUITETURA DE SISTEMAS DE INFORMAÇÃO: PROPOSTA DE UM MECANISMO DE APRENDIZAGEM COM ORIENTAÇÃO METODOLÓGICA PARA APOIO À DECISÃO EM CENÁRIOS COMPLEXOS.

\section{ELIOMAR ARAÚJO DE LIMA}

TESE SUBMETIDA AO DEPARTAMENTO DE ENGENHARIA ELÉTRICA DA FACULDADE DE TECNOLOGIA DA UNIVERSIDADE DE BRASÍlIA COMO PARTE DOS REQUISITOS NECESSÁRIOS PARA A OBTENÇÃO DO GRAU DE DOUTOR EM ENGENHARIA ELÉTRICA.

\section{APROVADA POR:}

Prof. Luís Fernando Ramos Molinaro, Dr. (PPGEE-UnB) (Orientador)

Prof. Humberto Abdalla Júnior, Dr. (PPGEE-UnB)

(Examinador Interno)

Prof ${ }^{a}$. Daniela Fávaro Garrossini, Dra . (DI-UnB)

(Examinadora Interna)

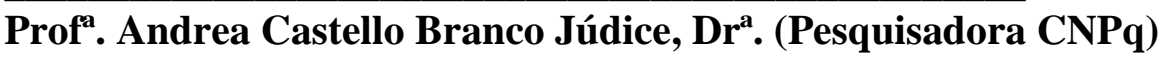

(Examinadora Externa)

Prof. Paulo Rogério Foina, Dr. (UniCEUB)

(Examinador Externo)

Prof. Fabrício Ataídes Braz, Dr. (PPGEE-UnB)

(Suplente)

BRASÍLIA/DF, 24 DE FEVEREIRO DE 2015. 


\section{FICHA CATALOGRÁFICA}

\section{LIMA, ELIOMAR ARAÚJO DE}

Arquitetura de sistemas de informação: proposta de um mecanismo de aprendizagem com orientação metodológica para apoio à decisão em cenários complexos.

278p., 210 x 297 mm (ENE/FT/UnB, Doutor, Engenharia Elétrica, 2015). Tese de Doutorado - Universidade de Brasília. Faculdade de Tecnologia. Departamento de Engenharia Elétrica.

1. Tomada de decisão

3. Estruturação de problema

5. Sistema de aprendizagem

I. ENE/FT/UnB II. Título (série)
2. Pensamento sistêmico

4. Multimetodologia

6. Multidimensionalidade

\section{REFERÊNCIA BIBLIOGRÁFICA}

LIMA, E. A. (2014). Arquitetura de sistemas de informação: proposta de um mecanismo de aprendizagem com orientação metodológica para apoio à decisão em cenários complexos. Tese de Doutorado em Engenharia Elétrica, Publicação 090/2015, Departamento de Engenharia Elétrica, Universidade de Brasília, Brasília, DF, 257p.

\section{CESSÃO DE DIREITOS}

AUTOR: Eliomar Araújo de Lima.

TÍTULO: Arquitetura de sistemas de informação: proposta de um mecanismo de aprendizagem com orientação metodológica para apoio à decisão em cenários complexos.

GRAU: Doutor ANO: 2015

É concedida à Universidade de Brasília permissão para reproduzir cópias desta tese de doutorado e para emprestar ou vender tais cópias somente para propósitos acadêmicos e científicos. O autor reserva outros direitos de publicação e nenhuma parte dessa dissertação de mestrado pode ser reproduzida sem autorização por escrito do autor.

Eliomar Araújo de Lima

SQSW Quadra 504 Bloco I, Residencial Porto Bello, Apto. 213, Sudoeste.

70.673-509 Brasília - DF - Brasil.

Tel.+556131071029/ eliomar78@gmail.com 


\section{DEDICATÓRIA}

Dedico à minha amada familia - filhas Eara e Euiza e esposa Qenata, pais Euize Eutite, avoós Chanoel e Qsoldina e sogra Chania Qosa - ao orientador da tese, Drofessor Euis Cholinaro, aos amigos e colegas. Exste é um momento especial que compartilho com vocês, gratidũo é a palaura de ordem.

Oseria ingènuo pensar que toda tese representa real avanco da Giència, mas é justo esperar que toda tese traga alguma luz para o ambiente em que foi defendida (O Yieira, 2008). 


\section{AGRADECIMENTOS}

Agradeço a todos que contribuíram para o empreendimento deste projeto de pesquisa. À comunidade acadêmica, um agradecimento ao Reitor da Universidade de Brasília que me proporcionou esta oportunidade, em nome do qual estendo os agradecimentos aos professores e alunos do Programa de Pós-Graduação em Engenharia Elétrica da Faculdade de Tecnologia.

À orientação da tese, um agradecimento especial pelas condições oferecidas e pela forma inspiradora e sincera de encaminhar as atividades acadêmicas. "Dificilmente se pode fazer uma tese contra o orientador, e nem é indicado, embora seja viável encontrar orientador pluralista e democrático a este ponto" (Demo, 2014). Agradeço, portanto, ao Professor Luis Fernando Ramos Molinaro pelos ensinamentos e forma de condução, em nome do qual estendo os agradecimentos aos demais professores, pesquisadores e estagiários do Núcleo de Multimídia e Internet.

À família, um agradecimento carinhoso por todo o suporte emocional e de inspiração. 
Pingue uma gota em um oceano de significados e note que ondas concêntricas se formam. Definir uma palavra isoladamente significa tentar agarrar essas ondas; ninguém tem mãos tão ágeis. Agora, lance duas ou três palavras de uma única vez. Padrões de interferência se formam, reforçando um ao outro aqui, e cancelandose mutuamente acolá. Alcançar o significado das palavras não é agarrar as ondas por elas originadas, mas sim perceber as interações entre essas ondulações. Isto é o que significa escutar, o que significa ler; algo incrivelmente complexo, embora os seres humanos o pratiquem no dia-a-dia; com frequência riem e choram ao mesmo tempo. Escrever, por outro lado, parece simples, pelo menos até que se tente fazê-lo (Bringhurst, 2006). 


\section{RESUMO}

\section{ARQUITETURA DE SISTEMAS DE INFORMAÇÃO: PROPOSTA DE UM MECANISMO DE APRENDIZAGEM COM ORIENTAÇÃO METODOLÓGICA PARA APOIO À DECISÃO EM CENÁRIOS COMPLEXOS}

Esta tese expressa o resultado de estudos e investigações de campo executadas ao longo dos últimos cinco anos. Aborda instrumentos típicos do pensamento sistêmico para ajudar a visualizar, analisar, modelar e estruturar projetos de engenharia e processos de mudança, utilizando-se de uma concepção construtivista. O desenvolvimento do pensamento sistêmico é um processo de aprendizagem circular que visa substituir uma abordagem reducionista por uma perspectiva holística para implicar teorias e práticas que permitam (re) desenhar políticas, estratégias e institucionalizações desejadas. Em tais contextos, ao focalizar o processo de tomada de decisão, surge o interesse desta pesquisa em buscar uma medida de compromisso em ampliar ou restringir os horizontes de avaliação para resolução de problemas em cenários complexos, utilizando-se de uma proposta de construto de visão multidimensional. A estratégia de pesquisa foi implementada com base em uma proposta de orientação metodológica, resultado da confluência da metodologia de sistemas flexíveis (SSM), do método de pesquisa-ação integral e sistêmico e das abordagens multimetodológicas, para viabilizar a obtenção de conhecimento teórico fundamento na prática. Ao todo, três projetos de pesquisa de campo foram empreendidos, um voltado para o desenvolvimento organizacional e dois para PD\&I. As análises e interpretações das ações comunicativas e de intervenções de cunho pedagógico em cada um dos projetos desencadearam reflexões avaliativas, implicando a proposta do mecanismo de aprendizagem para apoio à decisão em cenários complexos, contemplando quatro dimensões, a saber: realidade, pensamento sistêmico, viabilização e ação. $\mathrm{O}$ processo de constituição do mecanismo torna propícia a modelagem e a construção de arquiteturas de sistemas de informação. 


\section{ABSTRACT}

INFORMATION SYSTEMS ARCHITECTURE: PROPOSAL FOR A LEARNING MECHANISM WITH GUIDANCE METHODOLOGY TO SUPPORT THE DECISION IN COMPLEX SCENARIOS

This thesis expresses the result of studies and field investigations performed over the past five years. It approaches typical instruments of systems thinking to help visualize, analyze, model and structure engineering projects and change processes, using a constructivist design. The development of systems thinking is a circular process of learning to replace a reductionist approach for a holistic approach to imply theories and practices that allow (re) design policies, strategies and desired institutionalization. In such contexts, the focus of the decisionmaking process, the interest of this research to seek a compromise measure is to expand or restrict the horizons of review for troubleshooting in complex scenarios, using a proposal of multidimensional view framework. The search strategy was implemented on the basis of a proposal of methodological guidance, result of the confluence of soft systems methodology (SSM), the method of integral and systemic action research and multimethodological approaches, to facilitate the achievement of foundation theoretical knowledge in practice. In all, three field research projects were undertaken, one facing the organizational development and two for RD\&I. The analysis and interpretation of communicative actions and educational profile of interventions in each of the projects triggered reflective review, implying the proposed learning mechanism for decision support in complex scenarios, contains four dimensions, namely: reality, systems, viability and action. The mechanism formation process makes it propitious for modelling and building architectures of information systems. 


\section{SUMÁRIO}

DEDICATÓRIA ................................................................................................... IV

AGRADECIMENTOS .......................................................................................................... V

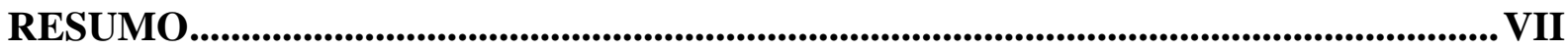

ABSTRACT .............................................................................................................. VII

LISTA DE QUADROS....................................................................................................................XII

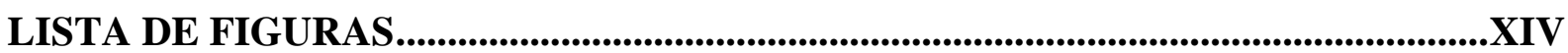

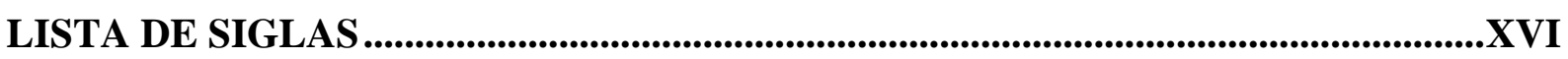

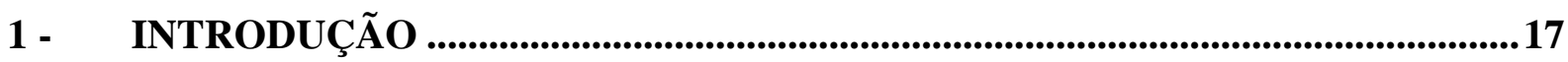

1.1 - DESCOBRINDO A SITUAÇÃO-PROBLEMA DE PESQUISA …………………......19

1.2 - EXPRESSANDO A SITUAÇÃO-PROBLEMA DE PESQUISA..................................23

2 - OBJETIVO ................................................................................................................27

2.1 - DEFININDO AS BASES DO SISTEMA DE INVESTIGAÇÃO DA TESE ……….....28

2.2 - INICIANDO A DEFINIÇÃO DAS ORIENTAÇÕES METODOLÓGICAS ................31

2.3 - VIABILIZANDO A PROPOSTA DE PESQUISA ………………………………....... 32

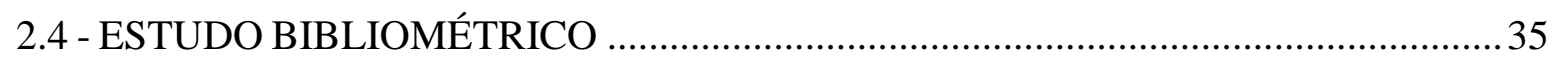

2.4.1 - Periódicos Científicos das Engenharias IV …………………………………........ 37

2.4.2 - Programas de Doutorado da Engenharia Elétrica..................................................40

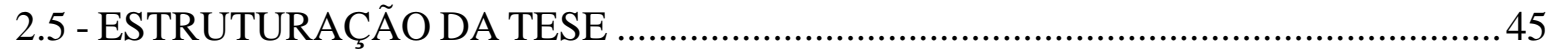

3 - FUNDAMENTOS TEÓRICOS..........................................................................48

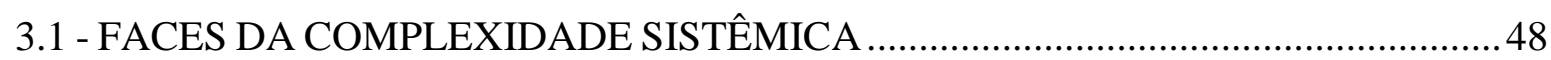

3.1.1 - Do Pensamento à Teoria e Ciências da Complexidade .........................................50

3.1.1.1 - Abordagens Complexas para o Desenvolvimento Organizacional ...................54

3.1.2 - Do Pensamento à Teoria e Prática Sistêmica.........................................................58

3.1.3 - Abordagens Sistêmicas Aplicadas às Organizações............................................... 65

3.1.3.1 - Estruturação de Problemas na Perspectiva Sistêmica ........................................ 70

3.1.3.2 - Métodos de Estruturação de Problemas ............................................................ 72

3.1.3.3 - Metodologia de Sistemas Flexíveis..................................................................

3.1.3.4 - Concepções Sistêmicas Críticas ........................................................................ 77

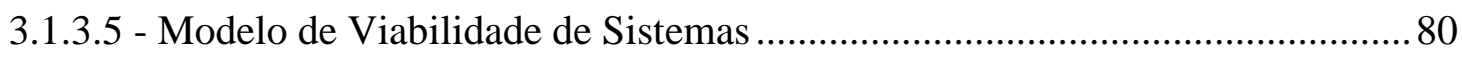

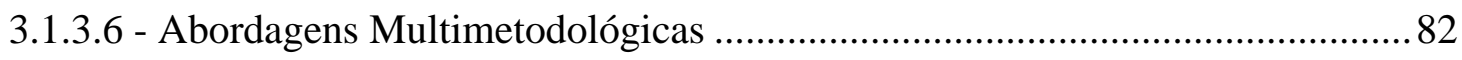

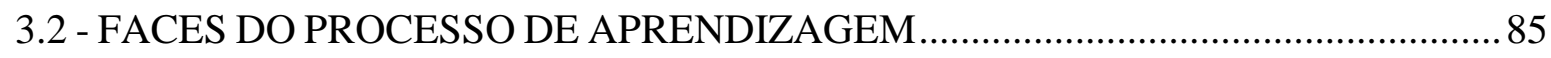

3.2.1 - Mecanismo de Aprendizagem Organizacional ..................................................... 86 
3.2.2 - Processo de Tomada de Decisão 89

3.2.3 - Apoio à Decisão em Cenários Complexos ……..................................................... 90

3.3 - ARQUITETURA DE SISTEMAS DE INFORMAÇÃO ........................................... 93

3.3.1 - Informação, Sistemas de Informação e Linguagem ............................................. 94

3.3.2 - Modelagem de Sistemas de Informação .............................................................. 98

3.3.3 - Ontologias para Sistemas de Informação ............................................................ 101

3.3.4 - Arquitetura de Sistemas de Informação ............................................................ 102

4 - METODOLOGIA...................................................................................................106

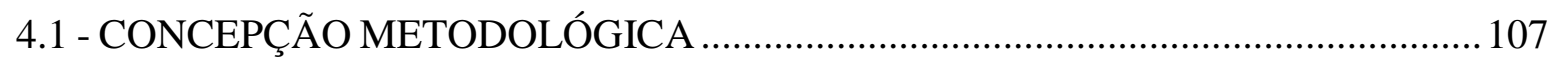

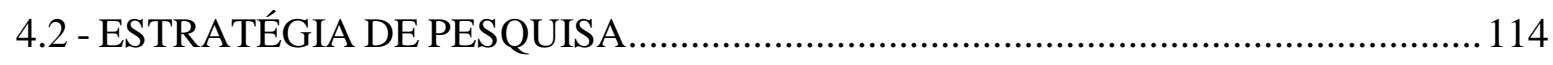

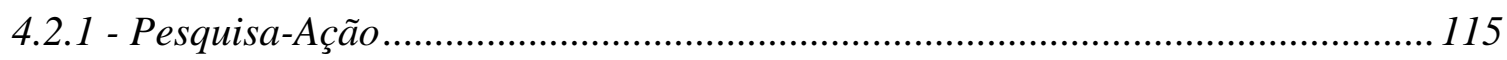

4.2.1.1 - Modos de Conceber a Articulação da Pesquisa com a Ação ........................ 118

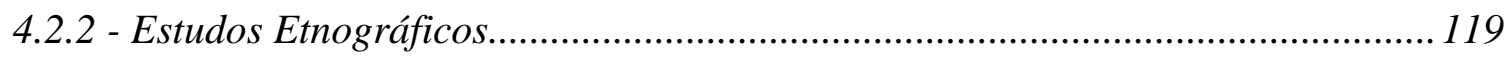

4.2.2.1 - Pesquisa-Ação-Etnográfica ....................................................................... 120

4.2.4 - Orientação Metodológica Fundamentada na Abordagem Integrada e Sistêmica

4.2.4.1 - Metodologia para Resolução de Problemas Complexos.............................. 129

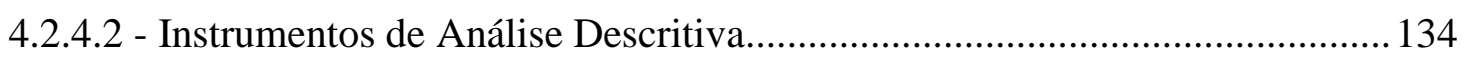

4.2.4.3 - Instrumentos de Análise Interpretativa ....................................................... 138

4.2.4.4 - Instrumentos de Coleta e Registro de Dados ............................................... 140

4.3 - OPERACIONALIZAÇÃO DA PESQUISA DE CAMPO ....................................... 143

4.3.1 - Projeto de Desenvolvimento Organizacional - Projeto Alpha ............................ 145

4.3.2 - Projeto de PD\&I - Projeto Bravo.......................................................................... 145

4.3.3 - Projeto de PD\&I - Projeto Charlie .................................................................. 146

5 - RESULTADOS E DISCUSSÃO .................................................................147

5.1 - APLICAÇÃO DOS INSTRUMENTOS DE COLETA E ANÁLISE DE DADOS .... 147

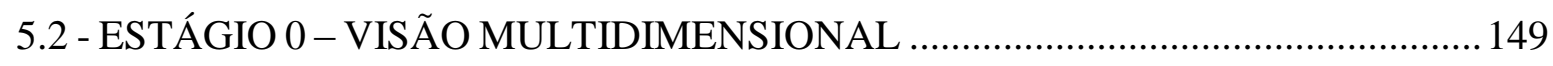

5.2.1 - Gênese do Construto de Visão Multidimensional ............................................... 149

5.2.2 - Aplicação da Seção de Policy Delphi .................................................................. 154

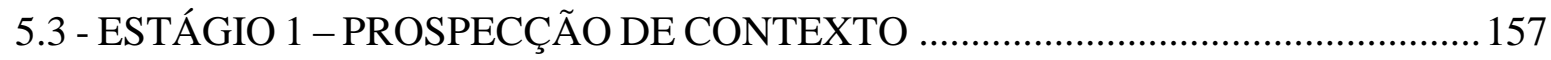

5.3.1 - Prospecção de Contexto - Projeto Alpha .......................................................... 158

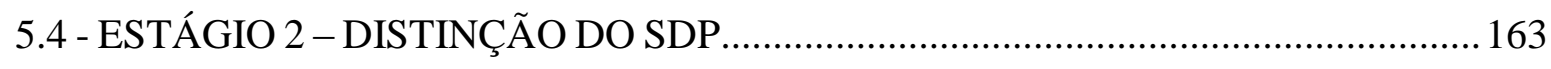

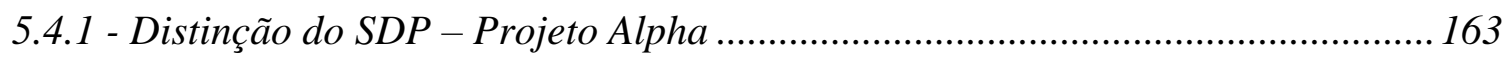


5.5 - ESTÁGIO 3 - AÇÃO PEDAGÓGICA 167

5.5.1 - Ação Pedagógica - Projeto Alpha …………………………………………...... 167

5.6 - ESTÁGIO 4 - DISCUSSÃO E AVALIAÇÃO REFLEXIVA.....................................172

5.6.1 - Constituição do Mecanismo de Aprendizagem .................................................. 174

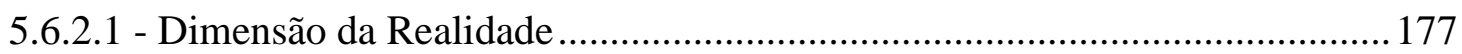

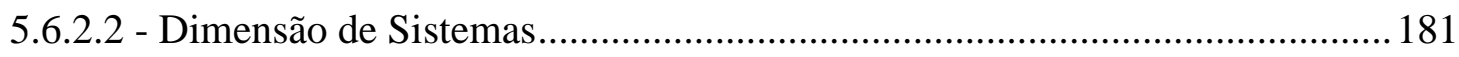

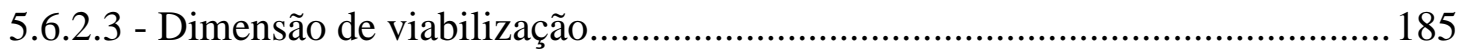

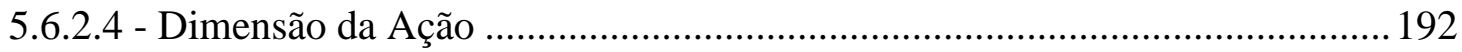

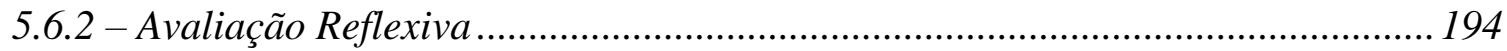

6 - CONCLUSÃO E RECOMENDAÇÕES ..........................................................198

6.1 - DAS CONTRIBUIÇÕES E LIMITAÇÕES DA PESQUISA ……………………........201

6.2 - RECOMENDAÇÕES E CONSIDERAÇÕES FINAIS ………………………….......205

REFERÊNCIAS BIBLIOGRÁFICAS ..........................................................................208

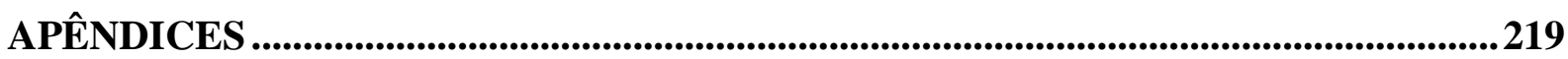

A- APÊNDICE A: ARTEFATOS DE APOIO À COMUNICAÇÃO E AO PROCESSO

DE DESENVOLVIMENTO DA TESE ..........................................................................220

B- APÊNDICE B: ARTEFATOS DO PROJETO ALPHA ..............................................226

C- APÊNDICE C: ARTEFATOS DO PROJETO BRAVO …….......................................234

D- APÊNDICE D: ARTEFATOS DO PROJETO CHARLIE .........................................248

E- APÊNDICE E: ARTEFATOS DO PROJETO DE PESQUISA .................................265

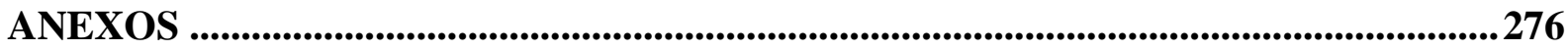

F- ANEXO A: ARTEFATOS DA HEURÍSTICA CRÍTICA SISTÊMICA ..................277 


\section{LISTA DE QUADROS}

Quadro 3.1 - Distinção das abordagens de PO tradicional e flexível ..................................... 76

Quadro 3.2 - Fatores de alavancagem de aprendizagem organizacional ................................ 88

Quadro 4.1 - Quadro-resumo entre Ciência positivista e pesquisa-ação ............................... 117

Quadro 4.2 - Mapa de atividades e recursos da orientação metodológica............................. 134

Quadro 5.1 - Aplicação dos instrumentos de coleta nas pesquisas de campo ....................... 148

Quadro 5.2 - Construto com múltiplas dimensões e parâmetros de aprendizagem ................158

Quadro 5.3 - Roteiro para iniciar os estudos de sistemas: Projeto Alpha ............................. 160

Quadro 5.4 - Definições-chave do sistema relevante: Projeto Alpha ................................... 165

Quadro 5.5 - Mudanças desejáveis e factíveis: Projeto Alpha ............................................. 168

Quadro 5.6 - Síntese dos resultados da ação executada: Projeto Alpha .................................170

Quadro 5.7 - Principais domínios linguísticos identificados nas pesquisas de campo ..........179

Quadro 5.8 - Contextos complexos das pesquisas de campo ............................................. 184

Quadro 5.9 - Status das pesquisas: Aplicação do Construto de Visão Multidimensional ......191

Quadro 5.10 - Fases do processo decisório e as dimensões do mecanismo ...........................197

Quadro A.1 - Cronograma do projeto de pesquisa .............................................................223

Quadro A.2 - Guia de tópicos para a Seção Policy Delphi .................................................224

Quadro B.1 - Aspectos da análise de fronteira de Ulrich: Projeto Alpha .............................227

Quadro B.2 - Dimensões da tipologia de rede: Projeto Alpha .............................................228

Quadro B.3 - Matriz de atribuição de responsabilidades RACI: Projeto Alpha ....................230

Quadro B.4 - Prospecção da capacidade do sistema de interesse: Projeto Alpha ..................231

Quadro B.5 - Categorias avaliativas da análise de fronteira: Projeto Alpha .........................232

Quadro C.1 - Roteiro para iniciar os estudos de sistemas: Projeto Bravo .............................235

Quadro C.2 - Definições-chave do sistema relevante: Projeto Bravo ..................................238

Quadro C.3 - Aspectos da análise de fronteira de Ulrich: Projeto Bravo ..............................239

Quadro C.4 - Dimensões da tipologia de rede: Projeto Bravo ..............................................240

Quadro C.5 - Matriz de atribuição de responsabilidades RACI: Projeto Bravo .....................242

Quadro C.6 - Prospecção da capacidade do sistema de interesse: Projeto Bravo...................243

Quadro C.7 - Categorias avaliativas da análise de fronteira: Projeto Bravo .........................245

Quadro C.8 - Síntese dos resultados da ação executada: Projeto Bravo ...............................247

Quadro D.1 - Roteiro para iniciar os estudos de sistemas: Projeto Charlie ..........................249

Quadro D.2 - Definições-chave do sistema relevante: Projeto Charlie ................................252

Quadro D.3 - Aspectos da análise de fronteira de Ulrich: Projeto Charlie ...........................253 
Quadro D.4 - Dimensões da tipologia de rede: Projeto Charlie ..........................................255

Quadro D.5 - Matriz de atribuição de responsabilidades RACI: Projeto Charlie ..................257

Quadro D.6 - Prospecção da capacidade do sistema de interesse: Projeto Charlie ...............258

Quadro D.7 - Categorias avaliativas da análise de fronteira: Projeto Charlie ......................259

Quadro D.8 - Guia de tópicos do estudo etnográfico: Projeto Charlie ..................................262

Quadro D.9 - Síntese dos resultados da ação executada: Projeto Charlie .............................264

Quadro E.1 - Roteiro para iniciar os estudos de sistemas: Projeto de Pesquisa ....................266

Quadro E.2 - Definições-chave do sistema relevante: Projeto de Pesquisa...........................268

Quadro E.3 - Aspectos da análise de fronteira de Ulrich: Projeto de Pesquisa ....................269

Quadro E.4 - Dimensões da tipologia de rede: Projeto de Pesquisa ......................................270

Quadro E.5 - Matriz de atribuição de responsabilidades RACI: Projeto de Pesquisa ...........272

Quadro E.6 - Prospecção da capacidade do sistema de interesse: Projeto de Pesquisa.........273

Quadro E.7 - Categorias avaliativas da análise de fronteira: Projeto de Pesquisa.................274

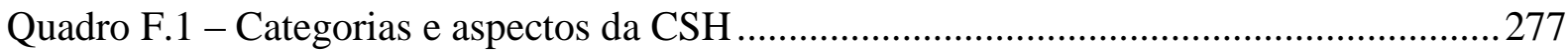

Quadro F.2 - As doze categorias críticas que compõem a heurística .................................278 


\section{LISTA DE FIGURAS}

Figura 1.1 - Constituição dos temas de interesse ………………………………………....... 18

Figura 2.1 - Esquema paradigmático para construção de um trabalho científico .......................32

Figura 2.2 - Periódicos das Engenharias IV: publicações.........................................................38

Figura 2.3 - Periódicos das Engenharias IV: tipos de pesquisa ................................................ 39

Figura 2.4 - Periódicos das Engenharias IV: temas de pesquisa..................................................39

Figura 2.5 - Doutorado em EE no Brasil: programas por região ……………………………... 40

Figura 2.6 - Teses defendidas nos programas de doutorado .....................................................40

Figura 2.7 - Teses de Doutorado por temas de interesse ..........................................................42

Figura 2.8 - Teses de Doutorado por tipos de pesquisa ..........................................................4

Figura 2.9 - Teses de Doutorado por orientação metodológica .................................................. 44

Figura 2.10 - Painel do projeto de pesquisa da tese …………………………………......... 45

Figura 2.11 - Esquema visual da pesquisa ....................................................................... 46

Figura 3.1 - Transversalidade das questões motivacionais da pesquisa ...................................50

Figura 3.2 - Processo de investigação iterativo para compreender a complexidade ................57

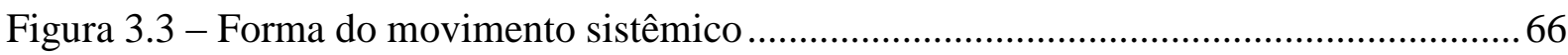

Figura 3.4 - Ciclos do processo de desenvolvimento do pensamento sistêmico ........................66

Figura 3.5 - Abordagens de investigação nos sistemas organizacionais ...................................67

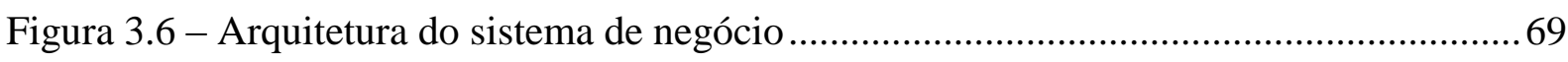

Figura 3.7 - Crítica de fronteiras ....................................................................................... 71

Figura 3.8 - Tipos de problemas e escolas de pesquisa operacional.........................................75

Figura 3.9 - $\mathrm{O}$ triângulo eterno de julgamentos de fronteira, fatos e valores ............................78

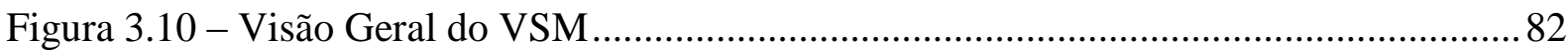

Figura 3.11 - Abordagem multimetodológica: SSM, CSH e VSM ……………………….... 85

Figura 3.12 - Modelo de avaliação de problemas de decisão complexas .................................92

Figura 3.13 - Modelo genérico de atividade de um SI.....................................................98

Figura 3.14 - Relação de forças da tecnologia, prática e teoria no SI....................................... 100

Figura 3.15 - Ontologia em destaque na concepção de um SI.................................................102

Figura 3.16 - Visão geral do framework de arquitetura corporativa de SI ............................ 105

Figura 4.1 - Dimensões epistemológica, teórica e prática .....................................................110

Figura 4.2 - Ciclo de pesquisa-ação-etnográfica para os sistemas de informação................... 121

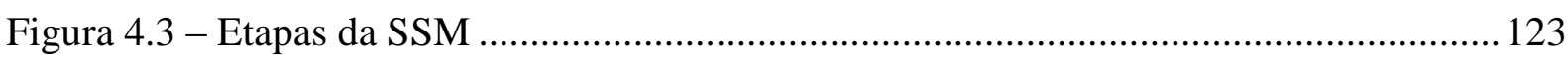

Figura 4.4 - Estrutura formalizada da SSM para o sistema de aprendizagem ........................124 
Figura 4.5 - Ciclo da pesquisa-ação: percepção e atribuição de sentido 125

Figura 4.6 - Orientação metodológica da pesquisa integrada e sistêmica 131

Figura 5.1 - Visão Multidimensional e Seção de Policy Delphi .............................................. 156

Figura 5.2 - Figura rica: Projeto Alpha ............................................................................. 162

Figura 5.3 - Mapa Cognitivo: Projeto Alpha …............................................................... 163

Figura 5.4 - Mapa Conceitual - Projeto Alpha................................................................... 166

Figura 5.5 - Modelo de viabilidade de sistemas ................................................................. 169

Figura 5.6 - Ações para melhoria da situação-problema - Projeto Alpha ............................... 172

Figura 5.7 - Visão radial do Mecanismo de Aprendizagem ............................................... 175

Figura 5.8 - Dimensão da realidade: Mecanismo de Aprendizagem .................................... 180

Figura 5.9 - Dimensão de sistemas: Mecanismo de Aprendizagem ...................................... 183

Figura 5.10 - Dimensão de viabilização: Mecanismo de Aprendizagem ............................... 186

Figura 5.11 - Sistema construído em torno do problema: Projeto Charlie ............................ 189

Figura 5.12 - Arquitetura da estratégia da REA: Projeto Charlie ........................................ 190

Figura 5.13 - Dimensão da ação: Mecanismo de Aprendizagem ......................................... 194

Figura 5.14 - Mecanismo de aprendizagem: quanto ao domínio do problema...................... 195

Figura 5.15 - Dimensões do Mecanismo em Perspectiva ..................................................... 197

Figura A.1 - Concepção metodológica da tese .....................................................................225

Figura B.1 - Perspectiva do Organograma do Órgão de Operação..........................................226

Figura C.1 - Figura rica do sistema de gestão de operações de TI: Projeto Bravo .................237

Figura D.1 - Unidades da Federação com Escritórios de Articulação ....................................248

Figura D.2 - Figura rica do ecossistema da economia criativa: Projeto Charlie ..................251

Figura D.3 - Mapa de Relações Sociais: Projeto Charlie ......................................................261 


\section{LISTA DE SIGLAS}

AHP

ARS

CATWOE

$\mathrm{CSH}$

MCDA

MCDM

MEP

PD\&I

PETI

REA

SAD

SDP

SI

SODA

SSM

TASCOI

TI

TSI

VSM
Analytic Hierarchy Process

Análise de Redes Sociais

Customers, Actors, Transformation, Weltanschauung, Owner,

Environment (Clientes, Atores, Transformação, Concepção de Mundo, Proprietário e Restrições Ambientais)

Critical Systems Heuristics (Heurística Crítica Sistêmica)

Multiple-Criteria Decision Analysis

Multiple-Criteria Decision Making

Problem Structuring Methods (Métodos de Estruturação de

Problemas)

Pesquisa, Desenvolvimento e Inovação

Planejamento Estratégico de Tecnologia da Informação

Rede de Escritórios de Articulação

Sistema de Apoio à Decisão

Sistema Determinado pelo Problema

Sistema(s) de Informação

Strategic Options Development and Analysis (Análise e

Desenvolvimento de Opções Estratégicas)

Soft Systems Methodology (Metodologia de Sistemas Flexíveis)

Transformations, Actors, Suppliers, Customers, Owners e Interveners (Transformações, Atores, Fornecedores, Clientes, Proprietários e Intervenientes)

Tecnologia da Informação

Total Systems Intervention (intervenção sistêmica total)

Viable Systems Model (Modelo de Viabilidade de Sistemas) 


\section{1 - INTRODUÇÃO}

A realidade nos parece cada vez mais virtual do que propriamente física. Muitas vezes abstrata, a realidade cibernética rompe os limites da existência humana à medida que surgem novos ambientes virtuais para simular uma dada realidade aparente. De jogos eletrônicos em rede até relacionamentos de segundas vidas, o homem se vê conectado a tudo e a todos de forma desmesurada, complexificando as suas próprias estruturas e dificultando a articulação das redes sociais.

A configuração do mundo corporativo não pode ficar alheia a esse cenário, dos tempos e movimentos aos riscos e restrições inerentes. Há uma profusão de acontecimentos e circunstâncias extraordinárias que mudam as tendências e as posições assumidas, em um vai e vem interminável. Aprender, desaprender e reaprender conceitos e paradigmas é a condição de existência contemporânea.

Penetrar nas estruturas das redes para descobrir os espaços de troca, as razões que levam às conversações, os comportamentos difusos dos atores e as conexões existentes, é mais do que necessário, é uma condição sine qua non que deve preceder qualquer atividade humana para consubstanciar o aprendizado. Já há sinais claros de esgotamento dos sistemas organizacionais, fortemente regulados pelos controles inflexíveis. Falta, portanto, mais aprendizagem e menos controle.

Durante grande parte do século passado, com o seu foco intenso em métodos de gestão científica, os especialistas têm tentado controlar os sistemas humanos de uma forma linear como se fossem máquinas, mas essa metáfora já não representa o que estamos vivenciando (Findlay e Straus, 2013).

Só resta ao pesquisador entender as realidades que se apresentam com suas nuanças, obliquidades e externalidades. Por onde começar? Qual o caminho a percorrer? O que se pretende alcançar? Se essas são as perguntas-chave, os metodologistas Martins e Theóphilo (2009, p. 107) entendem que:

O homem, visando entender a realidade, promove pesquisa - processo de estudo, construção, investigação e busca - que relaciona e confronta informações, fatos, dados e evidências visando à solução de um problema sobre a realidade social, 
[...] exerce um papel de questionamento crítico dos fundamentos e princípios das diversas ciências, [...] utilizando conceitos como teoria; orientação teórica, [...] identificando tanto o estudo dos métodos, quanto o método ou métodos empregados por uma dada ciência.

A matriz de argumentos e a discutibilidade pretendida para esta pesquisa gira em torno da definição dos temas de interesse que motivaram o pesquisador a empreendê-la. A experienciação das atividades acadêmicas, laborais e pedagógicas, desenvolvidas ao longo dos últimos oito anos, permitiu descobrir questões e situações emblemáticas sobre a função de coordenação dos especialistas em tecnologia da informação, diante de contextos de atividades humanas intensas.

São estes os temas de interesse da pesquisa: pensamento e prática sistêmica, decisão em nível de coordenação em cenários complexos e arquiteturas de sistemas de informação. A Figura 1.1 apresenta uma perspectiva visual, contendo os principais tópicos de estudo, com destaque para o processo de construção reflexiva de novos conhecimentos a partir dos marcos teóricos e das implicações sucessivas em termos práticos. Coerente com o argumento de Checkland e Holwell (1998), o ciclo de ideias teóricas levaram ao uso de ideias práticas e vice-versa, de modo que permitiu compreender e ressignificar a prática pela teoria.

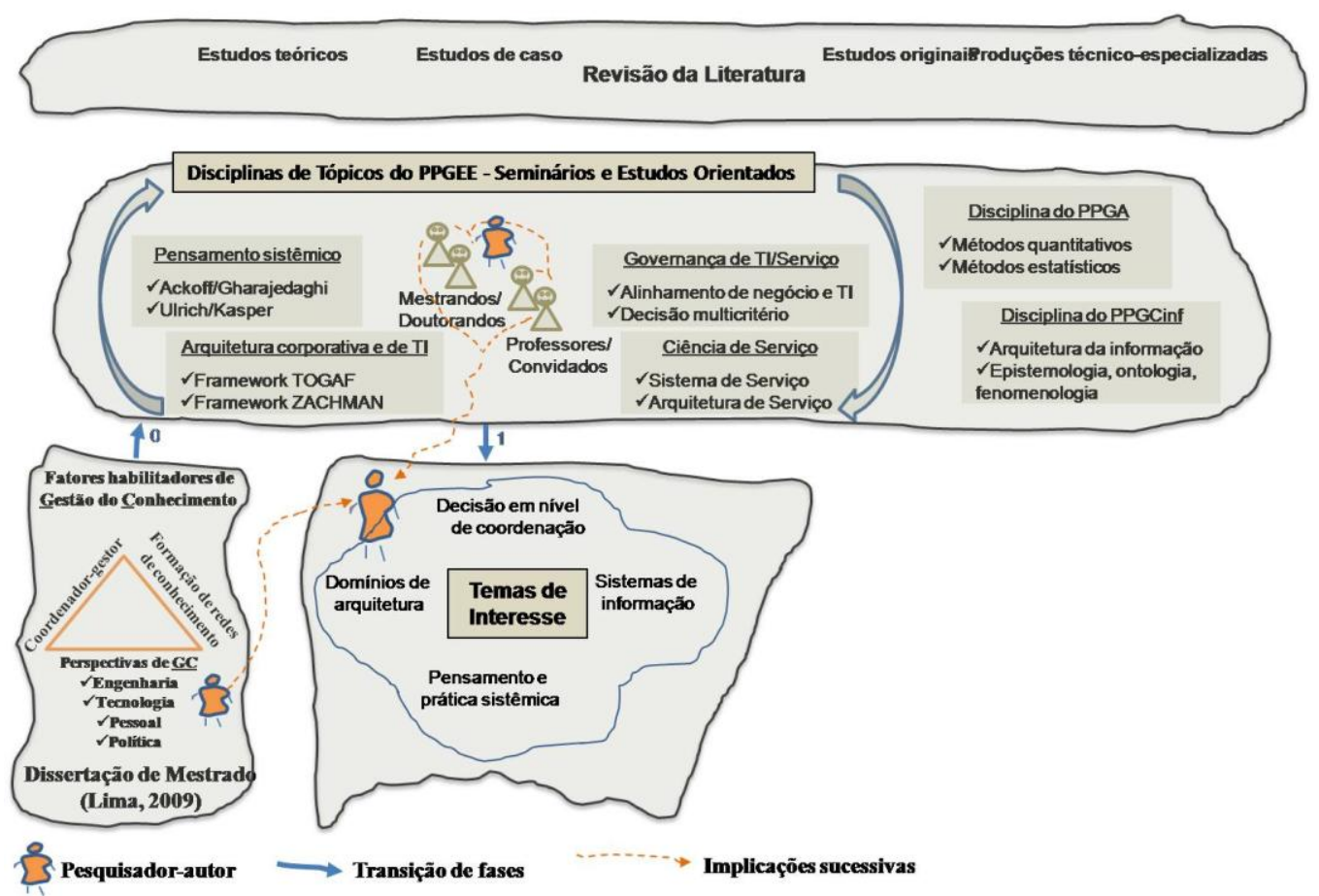

Figura 1.1 - Constituição dos temas de interesse

(O autor, 2015) 


\section{1 - DESCOBRINDO A SITUAÇÃO-PROBLEMA DE PESQUISA}

Um das grandes discussões das Ciências hoje é a capacidade de lidar com fenômenos ou problemas complexos. Todavia, a complexidade se manifesta objetiva e subjetivamente (Jackson, 2013), implicando todas as áreas do conhecimento, incluindo as Engenharias. Abordagens analíticas, baseadas nos princípios do reducionismo, da objetividade e da imparcialidade do pesquisador, dão lugar às abordagens sistêmicas, as quais se fundamentam nos princípios do holismo, da objetivação e da intersubjetividade dos pesquisadores e sujeitos da pesquisa, para tratar a complexidade sistêmica (Vasconcelos, 2002).

A princípio, a abordagem sistêmica é um contraponto ao pensamento analítico, ao pensamento cartesiano e ao pensamento mecanicista. Mas apesar disso, ela não nega as virtudes do pensamento científico, pois de fato não deixa de sê-lo, devendo então ser vista apenas como uma forma complementar ou ainda uma alternativa capaz de gerenciar as dificuldades do pensamento científico tradicional (Vasconcellos, 2013; Gharajedaghi, 2007; Moraes, 2004; Morin, 2011).

Ainda que o positivismo seja a base paradigmática predominante nas Ciências Exatas e nas Engenharias, o desejo de qualquer engenheiro ou analista de sistemas, no campo pragmático, é traduzir as demandas e necessidades da sociedade em soluções tecnológicas que viabilizem os empreendimentos e aumentem a produtividade dos negócios. Seja pela aplicação de tecnologias da informação robustas para solucionar problemas existentes, seja pelo aumento da capacidade de resposta, proporcionando maior diversidade de escolha ao cliente, entregando padrões de qualidade superiores e buscando alcançar resultados expressivos, ainda assim, poderão existir situações emblemáticas com as quais não se têm respostas tecnologicamente viáveis.

A não observância da realidade plural de um sistema de atividade humana e dos contextos ambientais aos quais está circunscrito, por exemplo, podem desencadear uma atuação desastrosa, podendo gerar impactos negativos e de difícil resolução. De acordo com Jackson (2013), em tais sistemas, os especialistas têm de lidar com uma grande diversidade de visões e opiniões das várias partes interessadas. 
Já no campo teórico, o papel do engenheiro como pesquisador não está completamente assimilado. As experienciações de Morin (2004, p.23) ajudam a refletir e aprender mais sobre as relações teórico-práticas sob uma perspectiva antropopedagógica ${ }^{1}$, a qual oferece métodos que se sobressaem melhor em contextos de desenvolvimento de pesquisas científicas não esclarecidas satisfatoriamente. Para o metodologista, os projetos de pesquisa que interessam ao pesquisador não lhe parecem sempre bem apropriados para as suas interpretações, já que ele não vê como aplicá-los facilmente em seu contexto laboral. O profissional prático, como é o caso dos engenheiros, está mais situado no plano da práxis, ou seja, fora do laboratório. Ele deve pensar levando em conta a singularidade, a espacialidade e a temporalidade, sem se esquecer de integrar seu ato na totalidade, no conjunto.

O engenheiro está exposto a situações problemáticas de menor ou maior complexidade, dependendo das condições e das restrições encontradas no contexto de atuação. Buscar soluções no espectro das tecnologias da informação para satisfazer os requisitos de negócio está longe de ser uma tarefa trivial, porque nem sempre os problemas estão bem estruturados e o dimensionamento da complexidade está condizente com o sistema organizacional.

O desafio de lidar com problemas em cenários complexos permeia as Ciências, as quais estão se ocupando cada vez mais intensamente dos problemas de decisão que afetam a atuação dos pesquisadores e profissionais, buscando refletir sobre abordagens de estruturação de problemas que possam ser aplicadas na resolução de situações não triviais, e por vezes emblemáticas.

Problemas de decisão são considerados complexos quando compreendem vários elementos ou aspectos distintos, cujas múltiplas formas possuem relações de interdependências, dificultando sua clareza e entendimento (Pereira e Fonseca, 2009). Nessas condições, a atuação do especialista, no sentido estrito da palavra, remete a uma atuação analítica, que se mostra inadequada para tratar a complexidade sistêmica (Vasconcelos, 2002).

\footnotetext{
${ }^{1}$ Perspectiva antropopedagógica - consiste na aplicação e adaptação de métodos de observação participante da antropologia e de princípios da pedagogia aberta, que é baseada na autonomia dos educandos, atualizando as propostas de investigação do tipo emancipatório (Morin, 2004).
} 
A ampliação da complexidade nos problemas em uma economia globalizada é refletida sobre setores de atividade econômica estratégicos para o país, como o setor energético e o setor de telecomunicações (Jackson, 2003). Tratar a complexidade nesses contextos exige pensar sistemicamente.

A apropriação da teoria sistêmica requer uma concepção paradigmática fundamentada nos preceitos do pensamento sistêmico holístico (Vasconcellos, 2013; Jackson, 2003). Para colocá-la em prática, a teoria sistêmica requer um esforço coletivo de todas as áreas do conhecimento, atentando-se à realidade plural que se apresenta.

Pensar os sistemas da engenharia requer um corpo de conhecimentos que vai além das disciplinas científicas que compõem o núcleo base da formação tradicional dos engenheiros no Brasil. Ao discorrer sobre o sistema enquanto objeto de estudo, Checkland (1993, p. 5) assevera que sua distinção se dá pelo fato de ser um assunto que versa sobre outros assuntos. Se por um lado não apresenta as mesmas características de uma disciplina científica, por outro pode ser aplicado no contexto de praticamente todas elas, como uma meta disciplina.

As Ciências da complexidade, a cibernética, as abordagens do pensamento sistêmico e a Tecnologia da Informação (TI), estão impactando todos os setores da economia e da sociedade há mais de meio século, viabilizando o modelo desenvolvimentista das nações e das corporações em geral. O progresso tecnológico vem ocorrendo em função do imbricamento dessas áreas do conhecimento, viabilizado pela atuação dos engenheiros e dos grupos interdisciplinares, alavancando os últimos avanços em matéria de convergência tecnológica, mobilidade e comunicação.

A TI exerce um papel fundamental de suporte e habilitador tecnológico, mas ainda hoje não é plenamente compreendida pelos líderes e gestores organizacionais. Dada a sua pertinência na conjuntura mundial, a TI é objeto de estudo das Engenharias, e em particular, é um tópico recorrente nas áreas de concentração dos programas de pósgraduação stricto sensu em engenharia elétrica no Brasil.

Ao proferir que as Engenharias necessitam mais de Ciências Sociais do que propriamente de continuar avançando enquanto Engenharias, o Professor Malcolm McCulloch, do 
Departamento de Ciências da Engenharia da Universidade de Oxford ${ }^{2}$, traz um alento importante sobre os aspectos comportamentais, sociais, culturais e de cognição humana, que deverão ser observados no processo de desenvolvimento tecnológico.

As Engenharias estão tradicionalmente orientadas ao domínio da solução de um dado problema, ou situação problemática, aplicando métodos e ferramentas apropriadas pelo corpo de conhecimento técnico, que se fundamenta nas Ciências Naturais e nos conhecimentos matemáticos. Não há, por outro lado, uma preocupação central no tocante ao domínio do problema, já que este é dado. Entretanto, Morin (2004) adverte que é no domínio do problema onde se podem observar as relações sociais e as manifestações culturais, que estão presentes nos sistemas sociotécnicos.

A realidade social vivida e vivenciada pelos profissionais da engenharia está repleta de situações problemáticas que nem sempre podem ser simplificadas, uma vez que a situação ou o problema pode estar mal definido - haja vista o que ocorre nas relações entre usuários e especialistas de TI. Demo (2014, p. 93) lembra que a realidade social não é determinada, mas condicionada, o que permite atribuir-lhe maneiras típicas, tendenciais, regulares do seu acontecer. Embora simplificar seja condição de explicar, é sempre uma questão pertinente não simplificar em excesso, forçando a realidade a artificialismos mentais.

Dietz (2010) postula que o profissional atua ora produzindo, ora coordenando. Via de regra, a função de produção é mais latente nos profissionais com conhecimento especializado, como é o caso dos engenheiros, médicos, advogados etc. A função de coordenação geralmente é relegada por razões de praticidade e porque tem potencial para desviar o foco da atividade fim. No entanto, intuitiva e regularmente o profissional destina uma fatia de tempo considerável para lidar com questões que são tipicamente de coordenação, mas que não são caracterizadas como tal.

Por exemplo, ao participar de um projeto de TI, aquele profissional se relaciona física e virtualmente com os demais membros da equipe, quer seja trocando mensagens,

\footnotetext{
${ }^{2}$ Evento promovido pela Faculdade de Tecnologia da Universidade de Brasília no segundo semestre de 2013 - 1st International Workshop on Smart Grid. Professor Malcolm McCulloch é Professor Associado da Universidade de Oxford e Diretor do Institute for Carbon and Energy Reduction in Transport (ICERT).
} 
documentos e correspondências, quer seja falando ao telefone e realizando reuniões, encontros e utilizando outros canais para viabilizar a sua atuação e a de seus pares, ou para atender as demandas solicitadas. A implicação do engenheiro como coordenador remete a uma pergunta de ordem pragmática: por que motivo o engenheiro deveria se preocupar com essa condição nova e como isso poderia afetar seus afazeres?

Ainda que exista uma predominância desse quadro na atuação laboral, cada vez mais os profissionais de TI estão sendo exigidos pelas competências transversais (Castro, 2011), o que exige assimilação e condutas pautadas pela convivência em equipe, mantendo uma comunicação interpessoal satisfatória, sendo capaz de se autogerir e se automotivar, e exercendo papel de liderança. Todos esses atributos estão associados com a função de coordenação que, em última análise, corresponde à atividade-meio que compromete uma fatia considerável do tempo de um profissional (engenheiro), imprescindível para a condução de equipes e engajamento de partes interessadas vinculadas a projetos e empreendimentos de engenharia.

\section{2 - EXPRESSANDO A SITUAÇÃO-PROBLEMA DE PESQUISA}

Iniciar grandes projetos ou desenvolver um já existente está se tornando cada vez mais complexo e difícil de navegar entre os crescentes grupos de stakeholders que contribuem para a tomada de decisão (Findlay e Straus, 2013). Os autores defendem que os gerentes de projetos precisam de uma liderança mais sofisticada, governança e abordagens para gestão das partes interessadas para ajudá-los a entender a complexidade e fornecer orientações práticas para o pensamento e a ação.

Circunstancialmente, face à exploração dos acontecimentos e dos fenômenos típicos das realidades observadas em projetos de tecnologia da informação, PD\&I e em processos de mudança empreendidos no mundo corporativo, condicionando o modelo de desenvolvimento organizacional, faz emergir situações-problema que desafiam os agentes de tomada de decisão. Por exemplo, saber avaliar cenário onde existem problemas mal ou pouco estruturados, ou mesmo não estruturados, onde o sistema de atividade humana é preponderante para alcançar os resultados pretendidos, e onde há baixa assimilação da complexidade sistêmica, pode ser esclarecedor e reflexivo para o pensar e o agir. 
Diante de tais cenários, que se confirmam cada vez mais turbulentos, com alto grau de incertezas e imprevisibilidade, as empresas competem local e globalmente em mercados diversos e com espaços de troca virtuais que requerem uma capacidade de processamento de informações sem precedentes. Sustentar-se nessas condições contextuais, na avaliação de Pereira e Fonseca (2009, p.31), depende da velocidade de assimilação das informações e da correspondente agilidade decisória proporcionada pela participação dos sistemas de informação.

A preocupação em entregar melhores resultados organizacionais coloca as tecnologias da informação no epicentro de tais discussões, seja como plataforma de suporte, seja como habilitador do desenvolvimento organizacional. Liker, Haddad e Karlin (1999) asseveram que, historicamente, a tecnologia é tratada como uma força causal determinística com impactos previsíveis. Mais recentemente, com a popularização das tecnologias da informação, há um reconhecimento da complexidade da tecnologia e sua relação com o sistema de atividade humana passa a ser bidirecional e dependente de diversos fatores contingentes.

Um aspecto fundamental nessa discussão é a apropriação tecnológica. Uma das formas de fazê-lo é por meio da terceirização de serviços de tecnologia da informação, que é uma pauta recorrente das organizações públicas e privadas (Gonzalez, Gasco e Llopis, 2006). No momento da contratação emerge uma série de condicionantes e restrições financeiras, legais, funcionais, orgânicas e processuais, que complexificam a análise de viabilidade, que tipicamente é levada a cabo para subsidiar a decisão de terceirização. Nesse cenário, reduzir o escopo de análise para questões eminentemente econômicas ou funcionais, por exemplo, pode desencadear novas situações-problema de ordem sistêmica, conforme pode ser observado em Lima, Silva e Molinaro (2013), Gonzalez, Gasco e Llopis (2006) e Silva, Lima e Molinaro (2013).

Mesmo que haja disponibilidade de meios e recursos tecnológicos, a estabilidade e a sobrevivência das organizações cada vez mais requer a ênfase nas características de adaptação e aprendizagem (Ackoff, 1979; Senge, 2013; Sterman, 2000). As organizações são sistemas intencionais que possuem metas e objetivos que precisam ser permanentemente perseguidos. Contém partes que são sistemas de atividades humanas, 
cujas necessidades devem ser satisfeitas, independentemente da plataforma tecnológica existente, pois, também são sistemas intencionais.

Mediante questões de ordem tecnológica e social, há razões para acreditar que o enriquecimento dos conhecimentos de um especialista aumenta as chances de enfrentar a complexidade dos problemas existentes (Lima, 2009; Morin, 2004). No entanto, o próprio ato de conhecer é uma questão complexa, pois todo fazer é um conhecer e todo conhecer é um fazer (Maturana e Varela, 2001, p. 32). Assim, não é raro encontrar sistemas de informação com alto poder de abstração que restringem a necessidade de ampliar o acesso às informações, implicando a atuação cognoscente dos tomadores de decisão (Pereira e Fonseca, 2009).

No momento em que se alcança um nível de compreensão suficientemente consistente da complexidade sistêmica - tomando-se consciência das limitações do afazer de um engenheiro, quando este atua na função de coordenação - e da ausência de sistemas de informação que possam auxiliá-lo na resolução de problemas em cenários imprevisíveis, instáveis, difíceis e com alto grau de incertezas, a seguinte questão de pesquisa é formulada:

\section{Em que medida os coordenadores devem ampliar os horizontes de avaliação para lidar com situações-problema em cenários complexos?}

Ao coordenador cabe a condução do processo de integração das diferentes atividades desenvolvidas em um dado projeto ou processo de mudança organizacional. A sua atuação requer uma capacidade de aglutinação de conhecimentos que permita estabelecer a relação recíproca ou sucessiva entre partes que compõem o todo. Em função da centralidade que o coordenador exerce em uma rede de conhecimento, Lima (2009) defende que a sua participação constitui-se em um fator habilitador para a aprendizagem organizacional.

Alguns expertos definem o limite de avaliação restringindo o escopo de análise a uma função objetivo, enquanto outros ampliam esse limite para o nível de ecossistema ao qual esteja vinculado à situação-problema. Se os dois extremos não são consensuais, a mera simplificação das partes ou a complexificação do todo não basta para se buscar uma solução de compromisso. Vindo desta última, é preciso produzir sentido para o que se faz, 
quer seja pelos aspectos cognitivos do avaliador, quer seja pelos aspectos sociais que emergem das relações humanas, enquanto relações pedagógicas.

À avaliação pressupõe determinar o valor, o preço, a importância de alguma coisa (Hammond, Keeny e Raiffa, 1998). Para se avaliar uma situação problemática é imprescindível reconhecer a grandeza, a intensidade e a força dos elementos e das relações constituintes do sistema definido em torno do problema (Pereira e Fonseca, 2009).

A ação ou movimento desencadeado pela atuação do coordenador envolve um processo de tomada de decisão recorrente, com horizontes de avaliação peculiares. Empreender um processo decisório envolve um ciclo de vida contendo estágios ou etapas consecutivas que culminam com a concepção de critérios de avaliação para escolha de potenciais alternativas (Gomes, 2007; Lira et al., 2007, Render, Stair e Hanna, 2012; Simon, 1979). No entanto, Kenney (1992) alerta que ao pensar preponderantemente sobre alternativas dadas, como modo de abordar problemas de decisão, pode limitar o interesse de buscar oportunidades de potenciais decisões. A saída, portanto, é pensar sobre a perspectiva de valor ao invés de se pensar em simples alternativas decisórias.

Em um mundo globalizado, competitivo, com inovações tecnológicas ocorrendo incessantemente, o tempo que se leva para tomar uma decisão pode significar a diferença entre estar na vanguarda ou simplesmente fracassar, tornando-se obsoleto nesse cenário complexo (Gomes, Araya e Carignano, 2011). Tomar decisões na presença de múltiplos critérios, dados incompletos, múltiplos agentes de decisão, não é uma tarefa trivial que pode ser resolvida com a simples aplicação de métodos de análise de decisão tradicional.

A complexidade inerente aos sistemas de atividade humana não pode ser meramente simplificada, por princípio. Absorvê-la, portanto, é o caminho a seguir, desde que se tenha uma orientação metodológica para fazê-lo. Ampliar ou reduzir os horizontes de avaliação é uma questão em aberto, cuja resposta poderá ser encontrada na avaliação multifacetada da realidade observada e ulterior construção de um sistema de informação integrado e sistêmico. 


\section{2 - OBJETIVO}

Antes de continuar, é preciso refletir sobre as implicações da definição do pensamento sistêmico, que segundo Morin (2011) é visto como um holograma: o todo está na parte que está no todo, onde tudo se interliga e nada pode ser descartado sem análise minuciosa.

Com a visão sistêmica amplia-se o foco e centra-se nas relações (Vasconcellos, 2013), permitindo captar e lidar com situações de complexidade e incerteza onde não há respostas simples. É uma maneira de aprender o caminho para a ação eficaz (Checkland e Scholes, 1990), olhando para o todo interconectado e interdependente, em vez de partes separadas. É por vezes chamado de holismo prático (Jackson, 2003), para não correr o risco de abarcar a totalidade sistêmica.

Quando um coordenador se depara com situações que se mostram complexas, ou simplesmente confusas, então o pensamento sistêmico pode ser usado para entender a situação sistemicamente. Isso o ajudará a ter uma visão ampliada da realidade, para ver a conectividade entre os elementos da situação, de modo a atingir as ações conjuntamente.

Relacionado à ideia central que serve de propósito ao estudo sob investigação, surge a definição do objetivo geral, vinculando-se à própria significação da tese, qual seja:

\section{Construir um mecanismo de aprendizagem para atuação dos coordenadores com vistas à} prospecção e avaliação de sistemas constituídos em torno de uma situação-problema.

Para Maturana (1997, p. 55) o aspecto central de uma explicação científica é a proposição de um mecanismo, preterindo a aparente centralidade da predição, já que segundo o autor o mecanismo gera não apenas o fenômeno que o pesquisador quer explicar, mas outros fenômenos que também pode observar. Diferentemente dos mecanismos de regulação e controle da cibernética (Beer, 1968), os quais estão orientados à concepção mecanicista, esta é uma proposta de mecanismo de aprendizagem que pretende auxiliar o processo decisório em cenários complexos, onde prevalece a concepção organicista.

Para alcançar o objetivo proposto, etapas intermediárias em âmbito mais restrito estão compreendidas nos seguintes objetivos específicos: 
- levantar abordagens descritivas e interpretativas da realidade para lidar com problemas de desenvolvimento organizacional;

- discutir as faces da complexidade sistêmica à luz do marco teórico presente nas abordagens do pensamento sistêmico e nas Ciências da Complexidade;

- discutir as faces do processo de aprendizagem à luz do marco teórico presente nas abordagens de análise multicritério e multiobjetivo para tomada de decisão em cenários complexos;

- discutir a constituição de sistemas de informação orientados à ontologia e domínios de arquitetura para apoio à decisão;

- identificar as lógicas dominantes para avaliação de cenários de desenvolvimento organizacional;

- empreender pesquisas de campo com orientação metodológica baseada em abordagens de ação comunicativa e intervencionista;

- propor mecanismo de aprendizagem para avaliação de situação-problema com base na visão paradigmática da complexidade sistêmica;

- discutir as implicações do mecanismo em termos pragmáticos, à luz do quadro teórico de referência e dos achados das pesquisas de campo.

\section{1 - DEFININDO AS BASES DO SISTEMA DE INVESTIGAÇÃO DA TESE}

O Programa de Pós-Graduação em Engenharia Elétrica (PPGEE) da Universidade de Brasília (UnB) oferece duas áreas de concentração com dez linhas de pesquisa ${ }^{3}$. Esta produção científica está assentada na área de concentração de telecomunicações e redes de comunicação e, especificamente, centrada nas linhas de pesquisa de tecnologias da informação e de educação em engenharia elétrica, mais precisamente na confluência entre ambas.

Embora tenha como ponto de partida a discussão de temas que remetem à linha de pesquisa, a qual está vinculada a uma área de concentração do PPGEE, este trabalho não está circunscrito apenas em um campo do conhecimento científico. Uma vez que a

${ }^{3}$ PPGEE. Sítio da Internet. (2014). Disponível em: <http://www.ppgee.unb.br/>, acesso em: 25 jul. 2014 às 18 h00min. 
situação-problema sob investigação pode ser enfocada de modo distinto e multienviesado, a depender dos pontos de vista conflitantes e das interpretações difusas dos teóricos, especialistas da matéria e praticantes convictos, ao lidarem com o fenômeno de estudo em situações reais, podendo abarcar conhecimentos multi e interdisciplinares.

Esta pesquisa tem a intenção de contribuir para a comunidade científica por meio de argumentações construídas sobre marcos teóricos consistentes e através da discussão do conhecimento fundamento na prática, que sinalizam para a ampliação da percepção dos tomadores de decisão na resolução de problemas em contextos imprevisíveis, instáveis e complexos, sem, contudo, almejar modelos normativos ou prescritivos. A abrangência do estudo não intenciona ser suficientemente extensa a ponto de esgotar as possibilidades de avaliação dimensional, nem tampouco é uma obra especializada em um único aspecto do processo decisório.

É importante ressaltar que a decisão aqui discutida é parte de um processo sistêmico, paradoxal e contextual, não podendo ser analisada de forma estanque das circunstâncias que a envolve (Pereira e Fonseca, 2009), de modo a propiciar maior grau de distinção ao decisor.

Ciente das dificuldades e dos desafios enfrentados pelos agentes da tomada de decisão quando abordam problemas perversos, é preciso considerar que a decisão pode sinalizar perda, medo ou risco, como também pode desencadear mudança, aprendizado e possibilidade de construção de uma nova realidade, conforme destacam Pereira e Fonseca (2009). Nesse sentido, a tese focaliza os afazeres desse agente na função de coordenação, seja como uma sucessão de decisões rotineiras, criadoras de hábitos e paradigmas, seja como fonte de transformação, mudança e invocação.

Com efeito, esta proposta não pactua com as causas meramente mecanicistas e dissociadas dos contextos político, ambiental, social, tecnológico, econômico e cultural, cujo risco de ser simplista pela abordagem reducionista, acompanha essas construções teóricas. Este trabalho pretende analisar holisticamente a forma como as ideias fundamentais de um sistema de informação podem ser mobilizadas para aprimorar o domínio de aprendizagem sobre o sistema constituído em torno da situação-problema e sua relação com o sistema de atividade humana. 
A preocupação, portanto, não é lidar com sistemas automatizados - aqueles que são concebidos pelo homem. O que é preponderante aqui são as possibilidades de desenvolvimento organizacional, consoante à participação do sistema de atividade humana. Ambos os sistemas, automatizados ou de atividade humana, coexistem em um sistema organizacional maior que define a intencionalidade e a configuração básica de funcionamento.

Diante dessa missão e do caminho a ser trilhado para alcançar os objetivos supracitados, dois importantes aspectos deverão ser considerados: os resultados esperados para o estudo e a orientação metodológica que definirá os meios e os cursos de ação para trilhá-lo.

Para lidar com situações-problema em cenários complexos, espera-se que os coordenadores adotem algum tipo de método de estruturação de problema, já que a realidade não pode ser simplesmente apropriada ou acessada diretamente, mas percebida, sentida e utilizada como palco de mudanças. Nesse sentido, pretende-se contribuir com estudos que permitam dimensionar o problema sob várias perspectivas para compreendêlo, absorvendo a complexidade inerente à situação real ao invés de tentar simplificá-la. Complementarmente, espera-se identificar múltiplos métodos para estruturação do problema no mundo real, que permita modelá-lo segundo os pressupostos do pensamento sistêmico.

As mudanças são desejáveis pelos líderes e pelos gestores em geral quando expostos a novas situações ou para superar um quadro de adversidades existente. Todavia, não é comum observar a viabilidade dessas mudanças frente a questões culturais estabelecidas. Visto que o interesse do estudo é discutir os contextos de autonomia que levem à solução de situações-problema paradoxais, espera-se contribuir com a identificação de métodos de decisão baseados em múltiplos critérios de avaliação que possam lidar com cenários de incertezas e imprevisibilidades.

Ao iniciar os estudos com base nos temas de interesse explicitados no capítulo de introdução, pretende-se viabilizar a pesquisa com métodos e instrumentos adequados para a construção de conhecimento teórico fundamento na prática. Para tanto, busca-se experienciar ações de caráter educativas em sistemas de atividade humanas, exigindo, consequentemente, a proposição de uma orientação metodológica para sua viabilização. 
Com essa contribuição, almeja-se alcançar um mecanismo de aprendizagem para apoio à decisão em cenários complexos.

Uma das importantes contribuições esperadas com a proposta do mecanismo de aprendizagem está em se apresentar como instrumento de viabilização para o alargamento do horizonte informacional estabelecido em torno de uma situação-problema, possibilitando que sejam aprofundados os debates sobre as opções de implementação para sua resolução. Oxalá, este trabalho se apresentar como um marco de referência para o desenvolvimento de pesquisas de campo nas Engenharias.

\section{2 - INICIANDO A DEFINIÇÃO DAS ORIENTAÇÕES METODOLÓGICAS}

Ao longo da história, a filosofia da ciência traz contribuições importantes para apropriação paradigmática do conhecimento. Desde a reformulação da Ciência por Francis Bacon; passando pelo método experimental de Galileu Galilei, que culminou com o início da Ciência Moderna, pelo Método e mecanicismo de René Descartes e de Isaac Newton e pelo critério de demarcação de Ciência de Karl Popper; até a racionalidade científica em Thomas Kuhn, que inaugurou a discussão das quebras de paradigma; vem suscitando o desenvolvimento conceptual e instrumental da Ciência.

Diante de tais inflexões, o primado da Ciência não é mais restrito ao pensamento positivista. Inspirado na concepção do hólon, é possível discutir a Ciência a partir das múltiplas abordagens paradigmáticas, uma vez que a visão de mundo extremada pelo "Método" de Descartes ou pelo "Contra o Método" de Paul Feyerabend não é adequada, sendo, portanto, substituída por uma visão de imbricamento entre as várias manifestações metodológicas, tal como se estabelece nas orientações construtivista, construcionista, estruturalista, funcionalista, participativa e emancipatória, e sistemista (Creswell, 2010; Demo, 2014; Vasconcellos, 2013; Marconi e Lakatos, 2010).

A trajetória de construção da pesquisa reflete o esquema proposto por Martins e Theóphilo (2009), de modo a satisfazer os polos epistemológico, metodológico, teórico, técnico e de avaliação - Figura 2.1.

Ciente do pluralismo científico definido por Demo (2014, p. 50), essa trajetória apresenta postura aberta a orientações contrárias, em termos de discutibilidade. $\mathrm{Na}$ prática, o 
pluralismo esbarra na lógica dominante do poder que não reconhece diferenças, mas desigualdades.

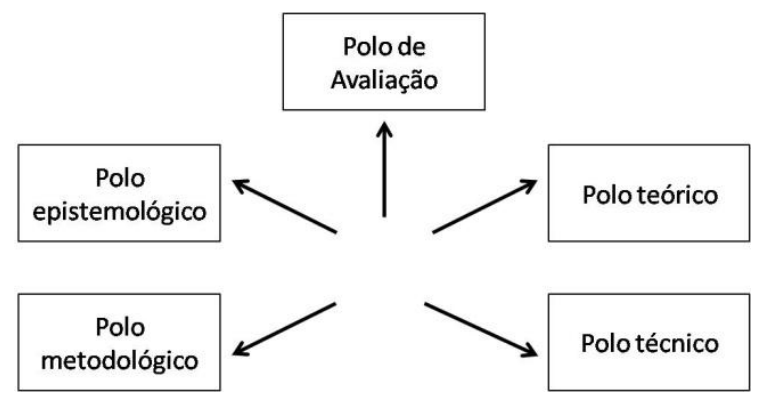

Figura 2.1 - Esquema paradigmático para construção de um trabalho científico

(Martins e Theóphilo, 2009, p. 4)

Uma forma de exercitar o pluralismo da Ciência é buscar no pensamento sistêmico novoparadigmático de Vasconcellos (2013) os pressupostos que servem de alento às diversas formas de manifestação do conhecimento humano, incluindo o científico, uma vez que as perspectivas que essa nova visão nos oferece tem repercussão na nossa forma de viver e atuar no mundo (Maturana e Varela, 2001). Assim sendo, continua a epistemóloga Vasconcellos (2013), é preciso exercitar a capacidade de conviver nas diferenças e nas desigualdades para promoção de relações sociais duradouras, as quais só serão possíveis, desde que haja, segundo Maturana e Varela (2001), a ampliação da aceitação do outro.

Há, portanto, uma (re) conceituação sistêmica determinada pela natureza do problema, necessária para dimensionar o grau de intersubjetividade, da instabilidade dos fatores ambientais e do nível de complexidade aparente (Vasconcellos, 2013).

\section{3 - VIABILIZANDO A PROPOSTA DE PESQUISA}

A viabilização do projeto de pesquisa passa pela definição da estratégia de pesquisa, partindo da definição de uma orientação metodológica capaz de suportar os estágios de desenvolvimento de uma pesquisa sob concepção construtivista, baseada nas ações comunicativas e intervencionistas, e que seja passível de incorporação dos métodos de prospecção e análise sistêmica. 
No caso peculiar deste estudo, três projetos de pesquisa de campo são desenvolvidos com base na abordagem de pesquisa-ação integrada e sistêmica - maiores detalhes na Seção 4.2 - cujas regras e rigor são diferentes daquelas da metodologia tradicional positivista. A observação não é passível, as capacidades de organização e de redefinição das situações dos atores sociais estão no centro das atenções dos pesquisadores, aqui considerados como atores no processo de comunicação, interpretação e delineamento de ações. Por esses motivos, os princípios de cientificidade e objetivação da pesquisa-ação não são idênticos aos da metodologia formulada sob influência positivista (Thiollent, 1997, p. 30).

A estrutura de relação entre pesquisadores e sujeitos da situação investigada nos projetos é do tipo participativa, havendo uma ação por parte dessas pessoas ou grupos implicados no problema sob observação. A atitude dos pesquisadores é pautada pela leitura e elucidação dos vários aspectos das situações desencadeadas em cada projeto, sem imposição unilateral de suas concepções próprias. Destarte, as pesquisas empreendidas sob essa concepção são qualificadas como pesquisa-ação, de acordo com os critérios apontados por Gil (2010) e Thiollent (2011).

A proposta aqui defendida não tem uma vocação limitada à validação de um modelo teórico guiado pela relação de causalidade e explicação de fenômenos reducionistas. Não se trata de uma técnica a ser quotidianamente aplicada para resolver pequenos problemas de caráter produtivo ou gerencial. É uma proposta de pesquisa mais aberta - com características de prospecção sistêmica e práticas desenvolvidas, para tentar clarear uma situação complexa e encaminhar possíveis ações, especialmente em situações insatisfatórias ou de crise, comumente encontradas nos sistemas de atividade humana (Checkland, 1993).

Nesse contexto, o dispositivo de pesquisa-ação é concebido como estrutura de interação pesquisador e ator do sistema organizacional investigado, com procedimento em cinco fases, assim enunciadas por Thiollent (1997, p. 44):

- prospecção para identificar uma situação-problema no sistema organizacional;

- planejamento da ação, considerando as ações alternativas para resolver o problema;

- execução das ações, com seleção de um roteiro de ação; e

- avaliação das consequências da ação. 
Sistema organizacional é aqui empregado como sendo todo e qualquer sistema sociotécnico que organiza e tem a capacidade para se organizar em torno de objetivos, metas e ações intencionais, com forte participação do sistema de atividade humana em nível de direcionamento e formulação de políticas estratégicas.

Por ser um método que favorece a análise interpretativa, a pesquisa-ação atua com foco nas perspectivas dos participantes e dos atores sociais. Seu objetivo é resolver os problemas do cotidiano e melhorar as práticas concretas e imediatas em situações em que o grau de conteúdo humano é elevado, e, por sua vez, expandir as fronteiras do conhecimento científico como a informação é recolhida a partir da análise do comportamento das pessoas em seus contextos reais.

De acordo com Thiollent (1997, p. 14),

\footnotetext{
A pesquisa-ação consiste em acoplar pesquisa e ação em um processo no qual os atores implicados participam, junto com os pesquisadores, para chegarem interativamente a elucidar a realidade em que estão inseridos, identificando problemas coletivos, buscando e experimentando soluções em situação real.
}

Nesse sentido, a pesquisa-ação é uma opção estratégica que possibilita estudar dinamicamente os problemas, decisões, ações, negociações, conflitos e tomadas de consciência que ocorrem indistintamente entre os atores durante o processo de transformação pedagógica das situações presentes em projetos de pesquisa.

A pesquisa-ação é apresentada como alternativa aos métodos experimentais comuns, válidos em laboratórios, mas que são inadequados na pesquisa em organizações reais. Entre as principais características não contempladas na pesquisa convencional de natureza positivista e que ao mesmo tempo levam à escolha da abordagem de pesquisa-ação, destacam-se as seguintes (Thiollent, 1997):

- orientação para o futuro - o processo de pesquisa-ação facilita a criação de alternativas de soluções viáveis voltadas para um futuro desejável pelos interessados;

- colaboração entre pesquisadores e atores do sistema organizacional pesquisado; 
- desenvolvimento de sistema - o dispositivo de pesquisa-ação desenvolve a capacidade do sistema de identificar e resolver situações-problema que o caracteriza;

- geração de teoria fundamentada na ação - a teoria pode ser corroborada ou revisada por meio da avaliação de sua adequação à ação;

- não predeterminação e adaptação situacional - as próprias relações estabelecidas na situação de pesquisa variam e não são totalmente previsíveis.

A pesquisa-ação não trata de hipóteses, mas de temas de interesse de pesquisa, dentro dos quais se aprendem lições, estas se ligam às evidências históricas sobre as situaçõesproblema do mundo real, que leva à ação prática com as pessoas envolvidas no estudo para alcançar resultados culturalmente viáveis e sistematicamente desejáveis (Freyle, Florez e Rincón, 2013).

Há ainda que considerar a natureza intricada, hermética e nebulosa dos fenômenos complexos, tão presentes nos sistemas organizacionais. Porquanto, nesse tipo de cenário, o propósito da aplicação de múltiplos métodos com enfoque sistêmico é poder lidar com a situação-problema, partindo de uma análise ampliada e amplificada dos elementos preponderantes do sistema de interesse para então modelar o problema, respeitando as realidades observadas pelos atores e as circunstâncias contextuais da pesquisa.

Para embasar teoricamente o estudo, um quadro teórico de referência é construído ao longo da tese para confrontar trabalhos seminais e contribuições científicas importantes nos últimos quinze anos acerca dos temas de interesse desta pesquisa, não se restringindo ao capítulo de fundamentação teórica - Capítulo 3.

\section{4 - ESTUDO BIBLIOMÉTRICO}

O propósito deste estudo é identificar contribuições relevantes relacionadas aos temas de interesse da tese nos principais periódicos das Engenharias IV e nos bancos de teses dos Programas de Doutorado em Engenheira Elétrica no Brasil, além de discutir as principais tendências em termos de concepção metodológica.

Os estudos bibliométricos são aplicáveis a qualquer tipo de documento, podendo estar vinculados a processos quantitativos da produção, disseminação e uso da informação, 
havendo relação, também, com os processos e mecanismos avançados de busca on-line e técnicas de recuperação da informação (Maricato e Noronha, 2012).

A avaliação das bibliografias levantadas se baseou em princípios bibliométricos que permitem realizar análises e interpretações teóricas simples e pontuais. Segundo Maricato e Noronha (2012), as limitações dos estudos bibliométricos estão presentes no âmbito teórico e prático. No campo teórico, os maiores problemas estão atrelados à possibilidade de haver interpretações equivocadas dependendo do grau de complexidade das análises pretendidas para o estudo.

O escopo da pesquisa bibliográfica se restringe a artigos publicados nos principais periódicos das Engenharias IV classificados nos estratos Qualis Capes A1, A2, B1 e B2 (Capes, 2014b). Quanto aos temas pesquisados, pretende-se avaliar as produções científicas associadas ao pensamento e prática sistêmica, tomada de decisão em cenários complexos e métodos de estruturação de problema. Para tanto, os argumentos de pesquisa são decompostos em duas consultas, com as seguintes cadeias de literais:

- Consulta 1: "systems thinking” or "complex system” or "systems dynamic" or "systems practice" or "Soft Systems Methodology” or "ssm”

- Consulta 2: "soft operational research" or "soft operation research" or "multiple criteria decision making" or "multiple criteria decision analysis" or "mcdm" or "mcda" or "analytic hierarchy process" or "ahp"

A razão pela qual se define como ponto de corte o estrato qualis B2 é devido ao nível de reputação no meio acadêmico e qualidade esperada das produções científicas publicadas nos periódicos com essa classificação ou superior, e por se tratar de um critério de corte de alguns programas de doutorando, incluindo o PPGEE da Faculdade de Tecnologia da UnB.

No tocante à pesquisa realizada junto aos Programas de Doutorado em Engenharia Elétrica reconhecidos pela Capes (Capes, 2014a), o objetivo é traçar um perfil das teses defendidas. Para tanto, realizou-se uma busca gulosa nos bancos de teses on-line disponibilizados na web por cada um de seus respectivos Programas de Doutorado. Não houve ponto de corte para coleta das teses, cuja sistemática de avaliação fica restrita ao título, resumo e palavraschave de cada obra. 
O levantamento bibliográfico ocorre em duas etapas: no primeiro estudo selecionaram-se os artigos dos periódicos das Engenharias IV para em seguida levantar as teses de doutorado dos programas de engenharia elétrica, ambos no primeiro semestre de $2014^{4}$.

\subsection{1 - Periódicos Científicos das Engenharias IV}

A seleção de artigos no Portal de Periódicos Capes tem como ponto de partida o acesso direto a cada um dos periódicos qualificados nos estratos A1, A2, B1 e B2 das Engenharias IV. Uma análise preliminar sobre a aderência das linhas de pesquisa de cada periódico com os temas de interesse deste estudo permitiu alcançar 149 do total de 1.391 periódicos existentes nos quatro estratos.

O passo seguinte é executar as buscas em cada periódico de acordo com os argumentos de pesquisa mencionados anteriormente, gerando uma grande quantidade de artigos. Desta coleção inicial, eliminaram-se todos os artigos que não se enquadram aos requisitos da pesquisa, seja porque não aborda uma das temáticas de interesse, seja porque não se trata da área de Engenharia Elétrica. Essa triagem inicial reduziu o montante de artigos para 909 itens, os quais estão segmentados por estrato e por ano de publicação na Figura 2.2.

As análises realizadas sobre os artigos selecionados restringem-se aos últimos cinco anos, tendo em vista a grande capilaridade das produções publicadas ao longo do período anterior a 2010 e por se tratar de um estudo de análises de tendências contemporâneas.

Observou-se no período avaliado que há uma tendência de crescimento linear no número de publicações, relativamente aos temas pesquisados, com forte presença nos estratos A1 e A2. Especificamente neste último, há uma grande concentração de produções publicadas em dois periódicos importantes - European Journal of Operational Research e Journal of the Operational Research Society, correspondendo a mais de $80 \%$ de todas as publicações desse estrato.

\footnotetext{
${ }^{4}$ Para ambas as pesquisas, o pesquisador contou com a contribuição de estagiários graduandos e pósgraduandos do Núcleo de Multimídia e Internet da UnB, que passaram por um processo de capacitação para apoiar no levantamento e análise dos artigos de periódico e teses de doutorado.
} 


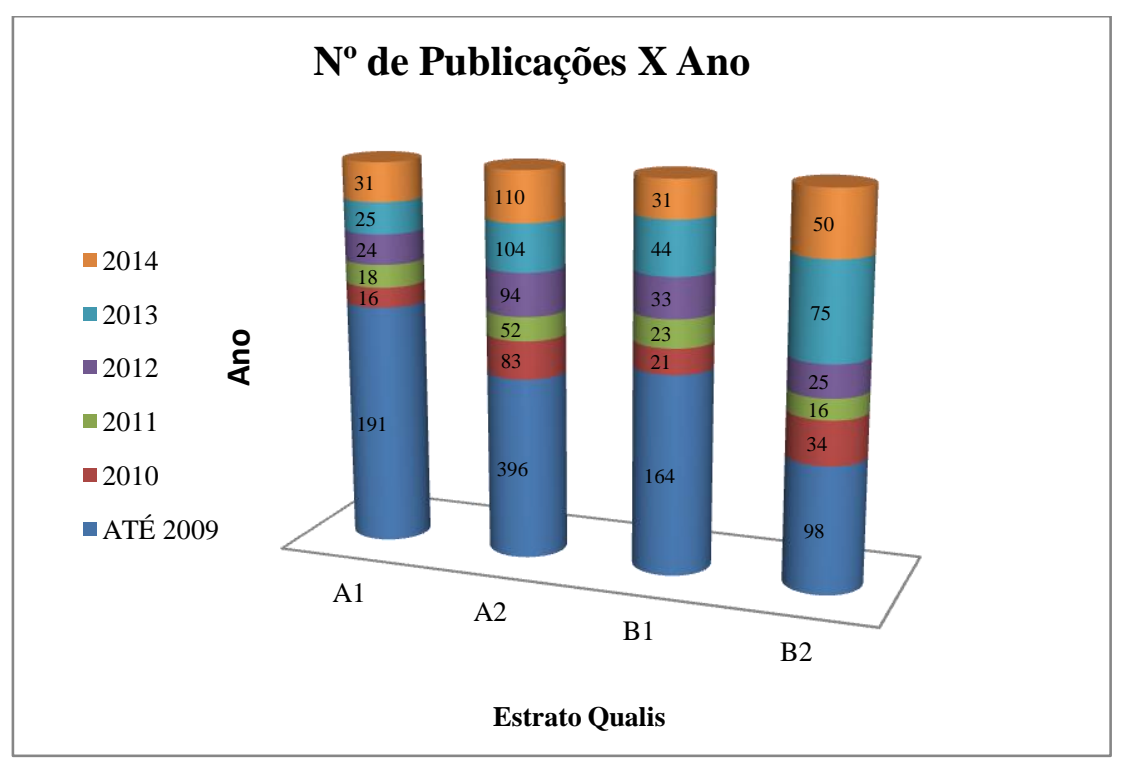

Figura 2.2 - Periódicos das Engenharias IV: publicações

A próxima atividade envolveu a análise dos artigos selecionados para se identificar o tipo de pesquisa predominante e a segmentação em termos de temas de interesse deste estudo, sumarizados nas Figuras 2.3 e 2.4. Há um predomínio de publicações de artigos originais em todos os estratos, alcançado mais de $90 \%$ do total observado no estrato B1. Os artigos de revisão e estudo de caso apresentam participação intermediária, ficando os artigos de atualização com pouca expressividade. Não obstante a pequena quantidade de publicação destes últimos, eles notabilizaram-se por apresentar avaliações críticas que relatam informações atuais sobre os temas de interesse, incluindo a discussão de novas abordagens e métodos, tecnologias e processos, sendo geralmente menos completos que os artigos de revisão.

Quanto aos temas pesquisados, o propósito é verificar a representatividade dos estudos associados ao pensamento e prática sistêmica, pesquisa operacional flexível e decisão multicritério em cenários complexos. De maneira isolada, há uma participação mais acentuada em termos de pensamento e prática sistêmica, enquanto que de forma combinada, desponta a relação mais forte entre abordagens sistêmicas e métodos de pesquisa operacional flexível (termo originário do inglês, Soft Operational Research Methods). Ao combinar os três tópicos, apenas três artigos foram encontrados - vide Figura 2.3.

Dentre as constatações que se destacam na pesquisa dos periódicos, vale ressaltar a forte participação nas autorias e coautorias de pesquisadores expoentes e reconhecidos internacionalmente, que contribuíram fortemente nos anos de 1980 e 1990 com 
publicações de revisão e a partir dos anos 2000 com artigos originais. Além disso, o corpo editorial dos principais periódicos conta com a participação de professores e pesquisadores vinculados às Escolas de Engenharia de Instituições de Ensino Superior de destaque nos Estados Unidos e Europa. À justificação do pensamento holístico, sistêmico e complexo, uma grande quantidade de trabalhos publicados desenvolvem estudos e argumentos teóricos fundamentados na prática. Entre os artigos originais, cerca de $40 \%$ são classificados como pesquisa-ação, dos quais pouco mais de $70 \%$ se orientam pela metodologia de sistemas flexíveis de Peter Checkland. Estes são os autores mais referenciados nos periódicos selecionados: Charles West Churchman, Jay Forrester, John Mingers, Michael C. Jackson, Peter Checkland, Russell L. Ackoff e Stafford Beer.

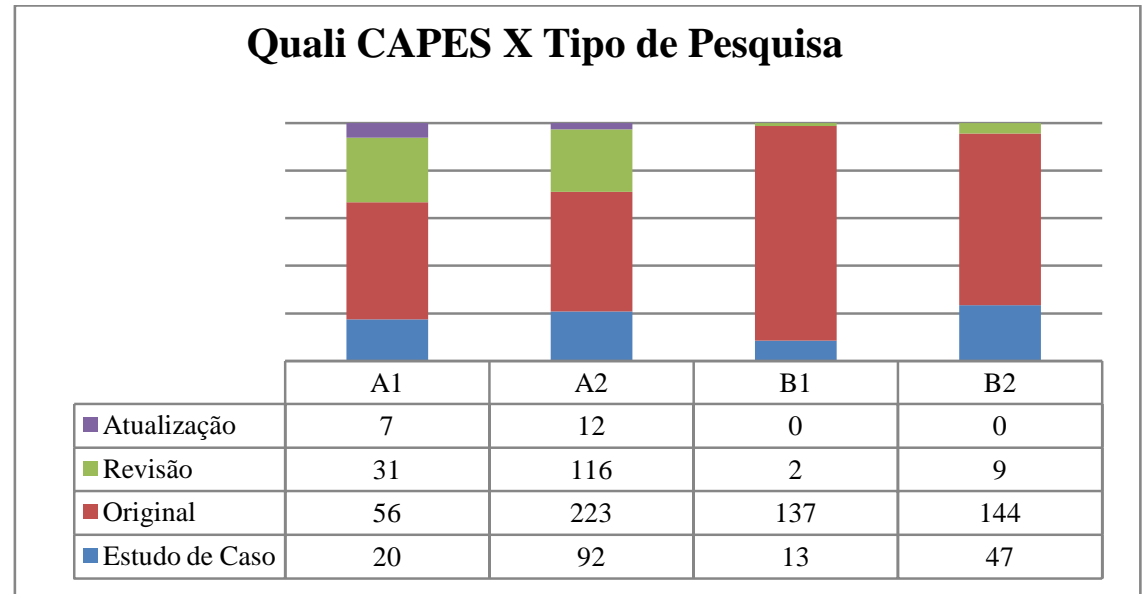

Figura 2.3 - Periódicos das Engenharias IV: tipos de pesquisa

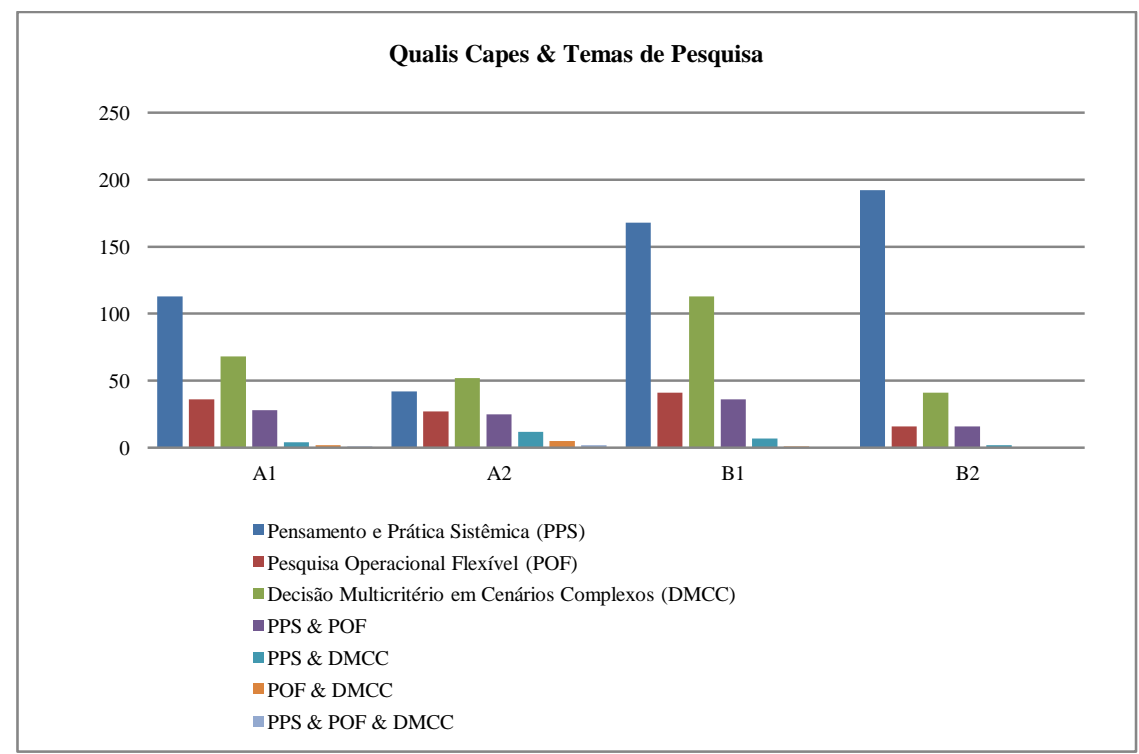

Figura 2.4 - Periódicos das Engenharias IV: temas de pesquisa 


\subsection{2 - Programas de Doutorado da Engenharia Elétrica}

A pesquisa sobre os programas de doutorado em engenharia elétrica reconhecidos pela Capes permitiu conhecer os vinte e sete programas atualmente recomendados, com forte presença na região sudeste do Brasil - Figura 2.5. De forma análoga, do total de 3.313 teses levantadas nos bancos de teses desses programas, pouco mais de $72 \%$ foram defendidas nas instituições localizadas naquela região - Figura 2.6.

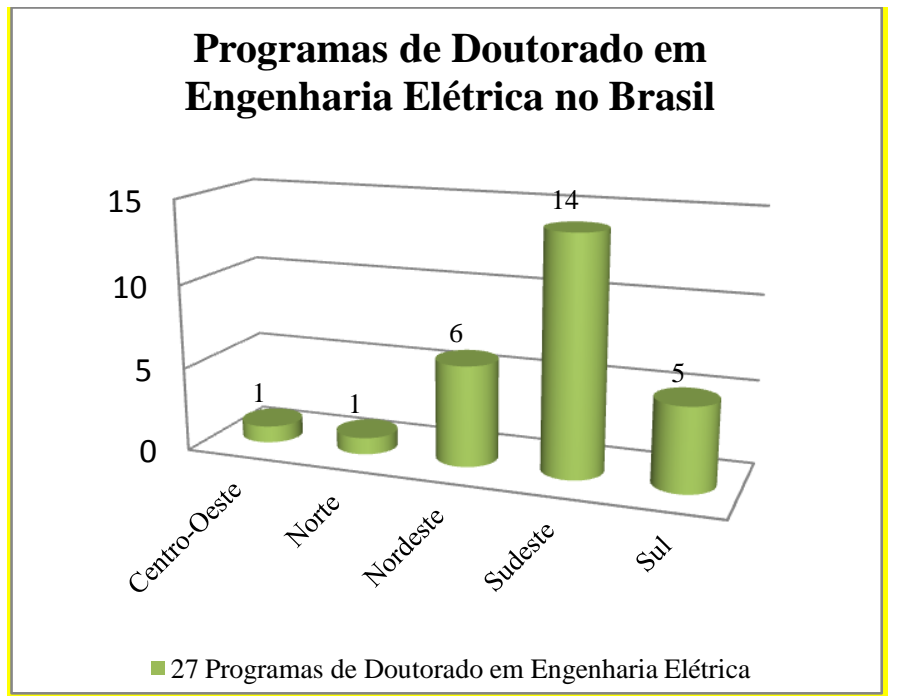

Figura 2.5 - Doutorado em EE no Brasil: programas por região (Capes, 2014)

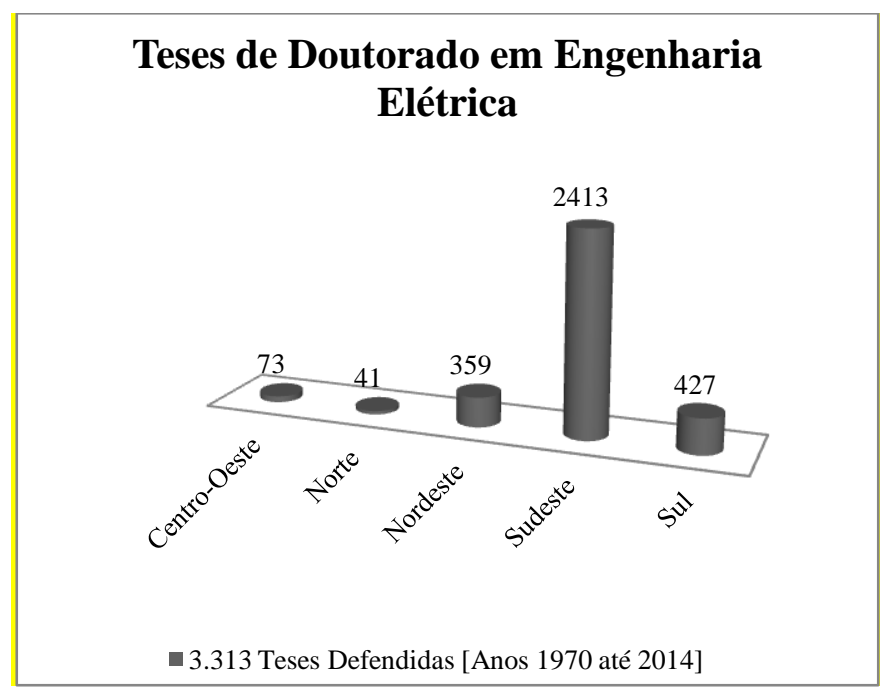

Figura 2.6 - Teses defendidas nos programas de doutorado (Capes, 2014) 
Em relação às áreas de concentração e linhas de pesquisa vinculadas aos Programas de Doutorado em Engenharia Elétrica, após análise de compatibilidade entre as mesmas, obtiveram-se dezoito áreas de concentração e sessenta e duas linhas de pesquisa diferentes.

Uma vez levantadas as teses nos bancos das instituições, o passo seguinte foi analisá-las com o propósito de identificar a representatividade dos temas de interesse da pesquisa, os tipos de pesquisa e a orientação metodológica - Figuras 2.7, 2.8 e 2.9.

Em relação aos temas de interesse, Figura 2.7, o número de estudos centrados na perspectiva de decisão multicritério e sistema de apoio à decisão, é pouco representativo em termos quantitativos, mas são obras recentes que de certo modo sinalizam uma trajetória de interesse dos pesquisadores, principalmente quando justificam o cenário que se apresenta na contemporaneidade das organizações e dos projetos de engenharia. Igualmente, os estudos voltados para o viés de educação e aprendizagem são mais recentes e sinalizam uma possibilidade de crescimento nos próximos anos. Dos trabalhos que lidam com sistemas, apenas dois discutem brevemente o marco teórico de sistemas, atentando-se para a perspectiva paradigmática do pensamento sistêmico.

De um modo geral, as teses estão direcionadas mais fortemente ao núcleo duro da engenharia elétrica, sendo que cerca de $30 \%$ estão preocupadas em desenvolver seus estudos no domínio de sistemas. Mais de $80 \%$ dos trabalhos com vieses que remetem aos temas de interesse desta pesquisa - dentre eles a coordenação, ontologia, arquitetura, cenários complexos (lógica fuzzy e decisão multicritério), sistemas de apoio à decisão, aprendizagem e visão processual e de negócio - foram defendidos em meados da década de 1990 em diante.

Já em relação aos tipos de pesquisa, busca-se evidenciar as seguintes concepções de pesquisa quanto à natureza dos procedimentos adotados: pesquisa experimental, por prototipação, por simulação e estudos de caso. Por definição, há um predomínio dos métodos de pesquisa qualitativa, cerca de $70 \%$ do total, conforme Figura 2.8.

Os procedimentos de prototipação e simulação são empregados de forma significativa, correspondendo a pouco mais da metade das teses, com forte presença nos trabalhos voltados para a área de tecnologia da informação, sistemas de potência e telecomunicações. 
Ainda que corresponda a cerca de $10 \%$ dos estudos realizados, a pesquisa experimental vem mantendo uma média de defesa anual com crescimento linear, muito em função dos recursos tecnológicos empregados, facilitando o cumprimento do protocolo de pesquisa.

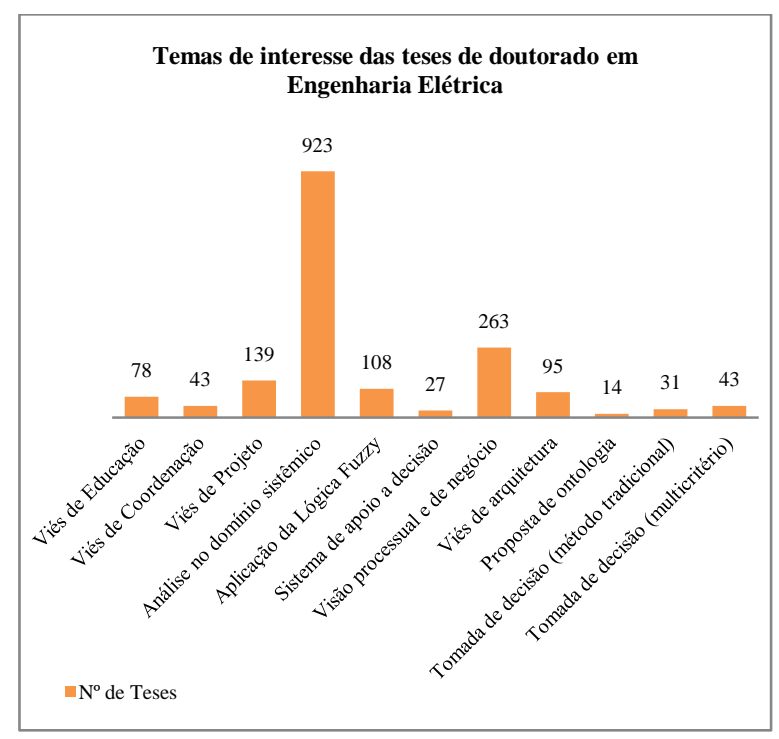

Figura 2.7 - Teses de Doutorado por temas de interesse

A proposta de modelo paradigmático para a prática científica defendida por Martins e Theóphilo (2009) é baseada em uma abordagem quadripolar. Na medida em que o polo epistemológico orienta a direção do referencial teórico, ou seja, implicando as teorias e a formação dos quadros teóricos (Vasconcellos, 2013; Martins e Theóphilo, 2009), é razoável esperar que o pesquisador inclua explicitamente os seus pressupostos epistemológicos para assegurar a sua convicção em termos de prática científica crítica e ética. De igual modo, o referencial teórico, por sua vez, determina as coordenadas do polo metodológico, que influencia o polo técnico. 


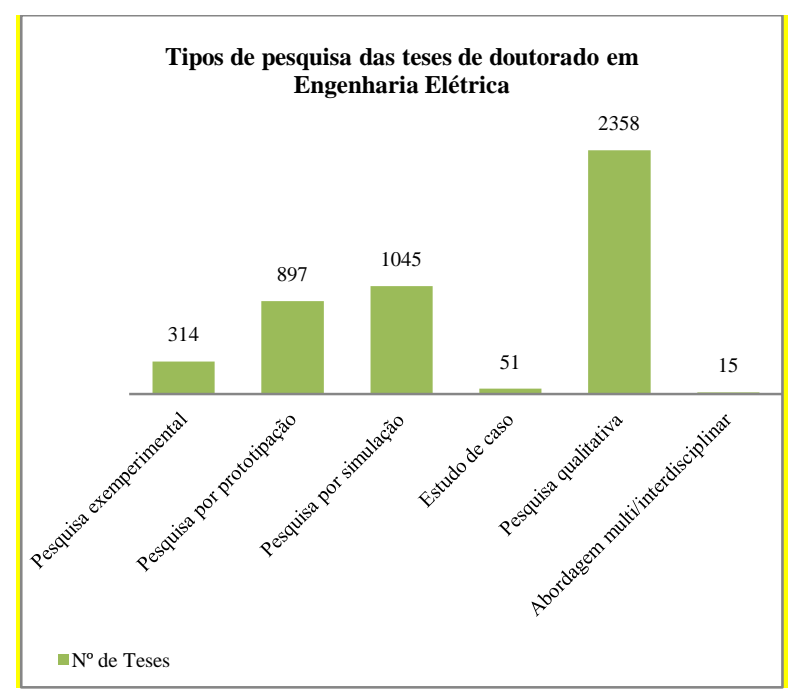

Figura 2.8 - Teses de Doutorado por tipos de pesquisa

Não obstante ao exposto e com o fim de contribuir com o desenvolvimento das pesquisas acadêmicas stricto sensu no campo da engenharia elétrica, os estudos sobre os bancos de teses permitiu descobrir algumas constatações importantes - Figura 2.9. Um percentual expressivo das teses levantadas, pouco menos de $90 \%$ do total, não explicita os pressupostos epistemológicos ou quando o faz não há um indício claro de rigor. Já em relação à concepção metodológica, cerca de $65 \%$ das teses não discutem a abordagem que define a concepção de mundo de seus autores ou realizam parcialmente esclarecendo apenas se se trata de um método de indução ou dedução. Por fim, há uma quantidade razoável de teses avaliadas, no total de 1.380, que não apresentam explicitamente os métodos e/ou os instrumentos de coleta e análise de dados empregados e, quando o fazem, não justificam a razão pela qual o fizeram prejudicando a argumentação e discutibilidade do projeto de pesquisa subjacente.

Considerando que a engenharia elétrica é o ramo da engenharia que trabalha preponderantemente com os estudos e aplicações da eletricidade, eletromagnetismo, eletrônica e telecomunicações. De igual modo, considerando que a engenharia elétrica lida com problemas associados a sistemas de energia elétrica, sistemas eletrônicos e sistemas de comunicações, há uma tendência verificada nos programas de pós-graduação de engenharia elétrica das instituições brasileiras de incorporar grande quantidade de linhas de pesquisa vinculadas às suas respectivas áreas de concentração. 


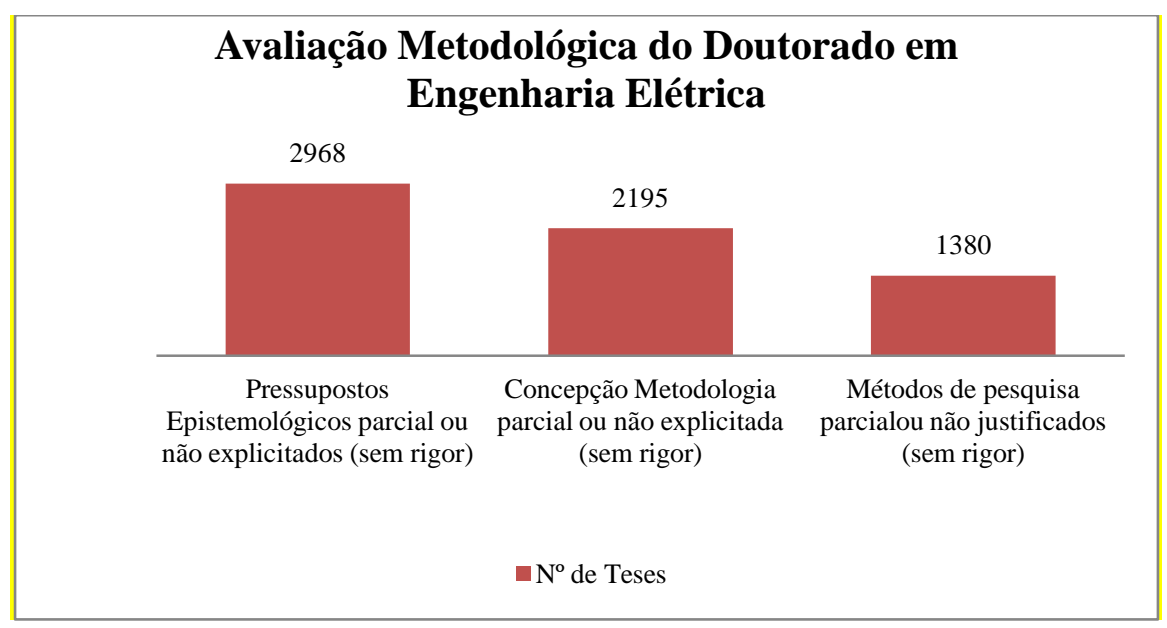

Figura 2.9 - Teses de Doutorado por orientação metodológica

As outras disciplinas das Engenharias e das Ciências em geral estão sofrendo as mesmas mudanças, aumentando-se progressivamente o grau de especialização do conhecimento para lidar com fenômenos complexos (Vasconcellos, 2013; Moraes, 2004; Morin, 2011), cuja emergência se dá pelo próprio processo de descoberta das Ciências e seus desencadeamentos. De acordo com Dagnino e Novaes (2009, p. 101) "tudo se passa como se a realidade pudesse ser fragmentada ou como se os problemas que aparecem na realidade concreta viessem identificados com uma etiqueta que indicasse a disciplina que deveria ser responsável pela sua solução". Maturana e Varela (2001) vão mais além ao dizer que uma disciplina científica não dá conta da complexidade dos fenômenos.

Cabe ressaltar que as dimensões consideradas na avaliação do polo epistemológico incluem a explicitação das problemáticas de pesquisa e a produção do objeto científico, bem como as concepções como as de causalidade, validação e cientificidade (Martins e Theóphilo, 2009). Igualmente, a avaliação do polo metodológico é baseada em critérios que contemplam as dimensões associadas com os diversos modos de tratar a realidade, dentre os quais se destacam as concepções metodológicas (positivista, dialética, fenomenológica, construtivista, sistêmica etc.), e outras mais específicas, como os métodos indutivo, dedutivo, hipotético-dedutivo.

Por fim, a avaliação metodológica é realizada com base nos preceitos e nas proposições argumentativas dos metodologistas, a saber: Creswell (2010), Demo (2014), Gil (2010), Marconi e Lakatos (2010), Martins e Theóphilo (2009). 


\section{5 - ESTRUTURAÇÃO DA TESE}

Tomando como ponto de partida os temas de interesse definidos para esta pesquisa, a sua estruturação é feita com base no esquema visual apresentado nas Figuras 2.10 e 2.11, correspondentes entre si. A Figura 2.10 apresenta o painel do projeto de pesquisa da tese e a Figura 2.11 apresenta a figura-rica da tese.

A tese está dividida em cinco capítulos, além de contar com apêndices e anexos. O primeiro capítulo apresenta o assunto principal e a exposição de motivos que levaram ao desenvolvimento da pesquisa. Sua importância é evidenciada pelas razões sociais, psicológicas e profissionais apontadas, além de relatar o modo de atuação que descreve a lógica de desenvolvimento do trabalho, o delineamento da proposição defendida e a natureza do problema, sua condição inicial, seus limites e as delimitações da investigação.

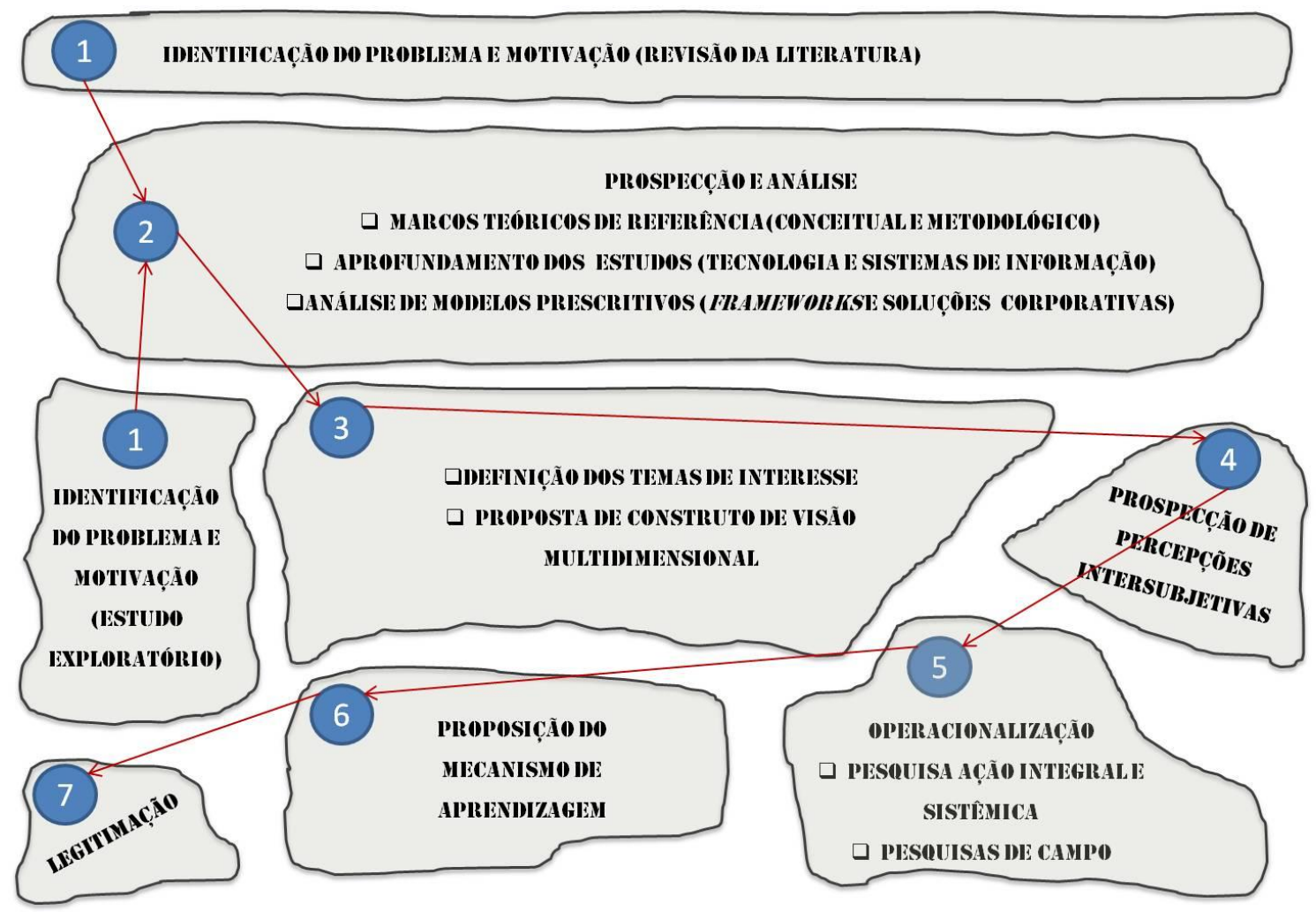

Figura 2.10 - Painel do projeto de pesquisa da tese

(O autor, 2015) 


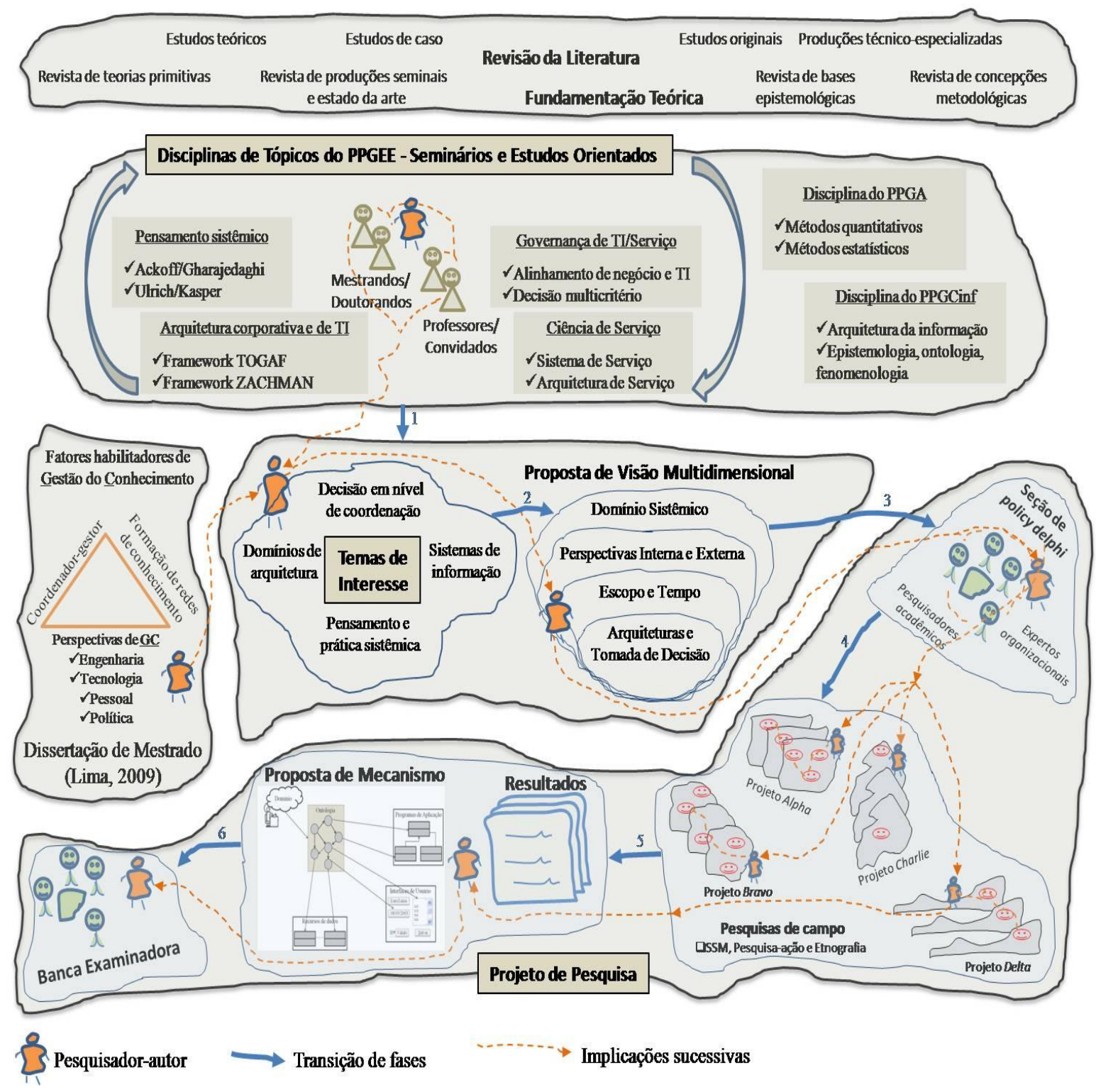

Figura 2.11 - Esquema visual da pesquisa

(O autor, 2015)

O segundo capítulo é uma consequência direta do primeiro, já que apresenta os objetivos da tese, define as bases do sistema de investigação, propõe os pressupostos e as orientações metodológicas e define a viabilização da mudança esperada para a pesquisa, com estudo bibliométrico e a síntese da estruturação da tese.

No terceiro capítulo é feita uma revisão bibliográfica ampla e centrada nos fundamentos conceituais e teóricos sobre complexidade sistêmica, abordagens para tomada de decisão tradicionais e multicriteriais, além de arquiteturas de sistemas de informação. Propõe uma análise dialógica das abordagens que amparam esses tópicos. Ressalta a questão da 
percepção e da interpretação das informações, sistemas e tecnologia da informação. Em cada um dos pontos focais da revisão bibliográfica existe um quadro teórico de referência, abrangente o suficiente para a construção de uma orientação permeada pela situaçãoproblema objeto de estudo desta tese.

Já no quarto capítulo, uma proposta metodológica é desenvolvida com base na concepção e estratégia de pesquisa, incluindo a definição da orientação metodológica a partir da integração dos métodos de pesquisa-ação e abordagem sistêmica, para ao final descrever a operacionalização dos estudos de campo.

O capítulo seguinte trata dos resultados alcançados, organizados sob a orientação metodológica definida no capítulo anterior. Além de descrever os dados coletados e o modo como foram levantados, promove análises descritivas e interpretativas com base na visão sistêmica e na pesquisa-ação, para ao final discutir e avaliar de forma reflexiva a teoria fundamentada na prática.

No capítulo final são feitas as conclusões e recomendações para trabalhos futuros. Inicialmente faz as deduções lógicas baseadas e fundamentadas no texto e decorrentes da pesquisa, que ocorreram sucintamente e justificadas adequadamente nas discussões dos resultados sobre o atendimento dos objetivos propostos, para ao final descrever as limitações da tese e as recomendações e sugestões resultantes da pesquisa.

A seção Apêndice está dividida em duas partes. A primeira contém recursos para melhorar a legibilidade e o entendimento da tese, enfatizando os passos do processo de investigação. Nessa parte, existe um glossário que o leitor poderá utilizar para entender a linguagem da pesquisa, haja vista a existência de termos polissêmicos que são chaves para o desenvolvimento desta pesquisa; e contém o cronograma do projeto da tese. A segunda parte apresenta diagramas e mapas visuais das pesquisas de campo.

Nos Apêndices B, C e D estão disponibilizadas as análises descritivas e interpretativas sobre cada um dos projetos de pesquisa de campo. Por fim, o Apêndice E apresenta as análises sobre o próprio projeto da tese, aplicando a mesma abordagem prevista para aqueles projetos de pesquisa, incluindo a orientação metodológica proposta nesta tese. 


\section{3 - FUNDAMENTOS TEÓRICOS}

De acordo com Gharajedaghi (2011, p. 45), "nós enxergamos o mundo de modo cada vez mais complexo e caótico porque usamos os conceitos inadequados para explicá-lo”. Ainda segundo o autor, há uma tendência das pessoas em subestimar os paradoxos, as contradições e os dilemas que se encerram nos sistemas sociotécnicos.

Abordagens tradicionais que empregam as ideias de sistemas, tais como pesquisa operacional, análise de sistemas e engenharia de sistemas, são adequadas para enfrentar problemas tipicamente bem definidos e estruturados, mas são limitadas quando são empregadas para tratar problemas complexos envolvendo pessoas, com uma variedade de pontos de vista, e muitas vezes antagônicos entre si (Findlay e Straus, 2013; Jackson, 2003).

Este capítulo oferece um quadro teórico baseado na problemática da complexidade nos sistemas de atividade humana, particularmente no processo de aprendizagem e na estruturação de sistemas de informação de apoio à decisão. A fundamentação teórica está dividida em três seções. O objetivo é abordar o marco teórico e a revisão da literatura relativamente aos temas de interesse, incluindo modelos, teorias, práticas e as principais pesquisas relacionadas a:

- complexidade sistêmica,

- processo de aprendizagem, e

- $\quad$ arquitetura de sistemas de informação.

Nesse sentido, a primeira seção trata da natureza da complexidade com enfoque na realidade sistêmica. A seção seguinte explora as facetas do processo de aprendizagem e da tomada de decisão, para lidar com as múltiplas possibilidades em termos de critérios de avaliação e alternativas para tomada de decisão em cenários complexos. Na terceira seção os aspectos concernentes à construção de arquitetura de sistemas de informação são abordados.

\section{1 - FACES DA COMPLEXIDADE SISTÊMICA}

Pensar a complexidade sistêmica envolve um conjunto de pressupostos, teorias, modelos e práticas implicadas tanto no âmbito das Ciências como no âmbito das organizações e 
arranjos sociais. Pensar a complexidade ou pensar sistemicamente é acima de tudo uma visão paradigmática da realidade. Para Snowden e Boone (2007, p.11), “[...] a complexidade é mais uma maneira de pensar sobre o mundo do que uma nova forma de trabalhar com modelos matemáticos. O pressuposto da complexidade é absorver e não simplificar fenômenos da realidade.".

Um dos problemas cruciais que as Ciências enfrentam é a capacidade de lidar com a complexidade, seja porque ela invalida a predição, seja porque a complexidade não é algo pré-existente em um mundo independente do observador (Vasconcellos, 2013; Maturana e Varela, 2001; Morin, 2011). Os modelos conceituais que descrevem o mundo real, as relações e componentes de um sistema de atividades, além do grau de complexidade aparente, são informados pela visão de mundo de quem descreve a situação (Checkland, 1993; Vasconcellos, 2013).

Quando um engenheiro se depara com situações que se mostram complexas, ou simplesmente confusas, então o pensamento sistêmico pode ser usado para entender a situação sistemicamente. Isso o ajudará a ter uma visão ampliada da realidade, para ver a conectividade entre os elementos da situação, de modo a atingir as ações conjuntamente, considerando o sistema de atividade humana atuante.

A tomada de consciência proporcionada pela transversalidade do pensamento complexo, sistêmico, holístico e estratégico nos domínios das Ciências, Figura 3.1, constitui-se em uma questão genérica de interesse desta pesquisa, com cujas implicações poderão ser estudados os sistemas complexos, de atividade humana e sociotécnicos.

Antes mesmo de discutir o marco teórico da complexidade e do pensamento sistêmico, uma importante classificação permite caracterizar o que vem a ser um sistema complexo (Snowden e Boone, 2007):

- $\quad$ trata-se de um grande número de elementos que interagem entre si;

- as interações são não-lineares, e pequenas alterações podem produzir desproporcionalmente grandes consequências;

- o sistema é dinâmico, o todo é maior que a soma de suas partes, e as soluções não podem ser impostas, mas sim, que provenham das circunstâncias; isso é frequentemente referenciado como emergência; 
- o sistema tem uma história, e o passado é integrado com o presente; os elementos evoluem com os outros e com o meio ambiente; e a evolução é irreversível;

- embora um sistema complexo possa, de forma regressiva, parecer estar ordenado e previsível, séries histórias de regressão não levam à previsão, porque as condições externas e os sistemas mudam constantemente; e

- ao contrário de sistemas ordenados (onde o sistema restringe os agentes), ou sistemas caóticos (onde não há restrições), em um sistema complexo os agentes e o sistema se restringem mutuamente, especialmente ao longo do tempo. Isso significa que não podemos prever ou predizer o que vai acontecer.

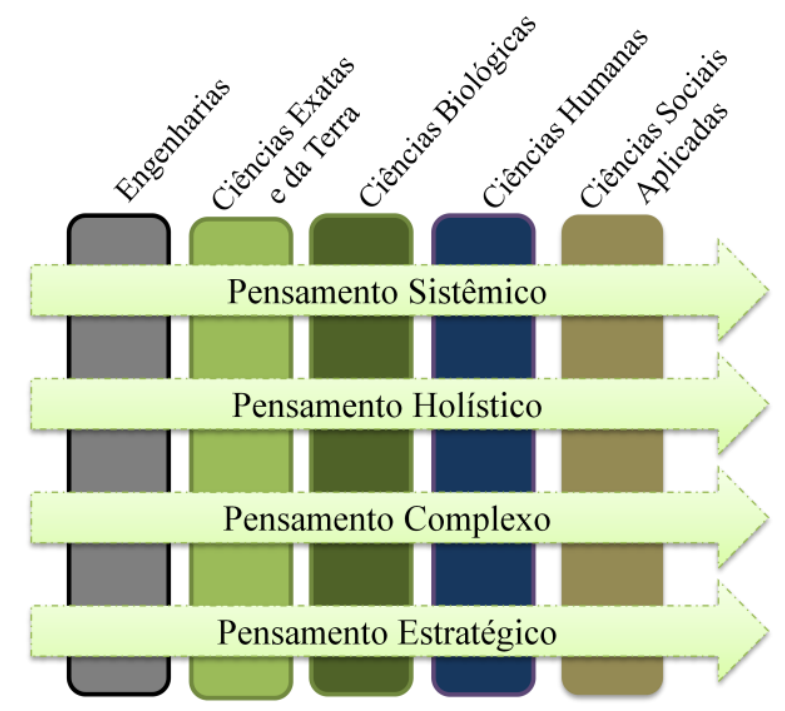

Figura 3.1 - Transversalidade das questões motivacionais da pesquisa (O autor, 2015)

\subsection{1 - Do Pensamento à Teoria e Ciências da Complexidade}

Há um crescente reconhecimento tanto no meio acadêmico como entre os profissionais de engenharia que a engenharia de sistemas complexos de grande escala é inerentemente diferente da engenharia de sistemas tradicional, essencialmente previsível e bem delimitada (Stevens, 2008). Esta, aliás, não está preparada para ciclos de mudanças mais rápidos e o nível de complexidade dos sistemas (Findlay e Straus, 2013).

Karcanias e Hessami (2011) assumem que existe uma importante evolução na análise de sistemas, influenciada principalmente pelo paradigma da engenharia de sistemas tradicional. No entanto, está claro que os resultados alcançados não estão satisfatórios, além do fato de não conseguirem lidar com novos paradigmas, como aqueles encontrados 
nos processos de negócio, sistemas de informação, sistemas biológicos e emergentes e paradigmas de sistemas complexos.

A complexidade decorre do número de estados (níveis) de um sistema, número de enlaces de realimentação e natureza não linear das interações entre os enlaces. As principais características são: estrutura, atrasos e amplificações. A estrutura define, segundo Morin (2011):

- fronteira fechada em torno do sistema;

- enlaces de feedback como estrutura básica dentro da fronteira;

- $\quad$ variáveis de nível e razões de fluxo e metas; e

- condições observadas, condições aparentes, detecção de discrepâncias e ações.

A complexidade pode ser vista em termos objetivos e subjetivos (Jackson, 2003). Na medida em que a complexidade existe na natureza dos sistemas e de seus ambientes, uma vez que eles ficam maiores, mais dinâmicos e entram em contato entre si em um ambiente cada vez mais turbulento - tem-se o viés objetivo. Por outro lado, a complexidade subjetiva surge porque há uma diversidade muito grande de pontos de vista, filosofias e visões de mundo das pessoas.

Os princípios das relações do sistema complexo dizem respeito à interação circular em que o todo é explicado pelas partes e as partes em função do todo, a interação circular entre a unidade e diversidade, em que as unidades complexas são constituídas a partir da diversidade e a diversidade é resultante da unidade (Allen, 2001).

Não obstante a existência de várias teorias da complexidade, ainda não se estabeleceu uma "Teoria Geral da Complexidade" (Borgatti Neto, 2008). Karcanias e Hessami (2011) admitem que ainda existam muitos desafios na compreensão, caracterização e garantia dos sistemas complexos, especialmente os que envolvem um grande corpo integrado de hardware, software, regras e agentes humanos.

Conforme enfatizado pelo renomado cientista John Von Neumann em seu estudo sobre autômatos auto-replicáveis, a concepção de complexidade é um pré-requisito para a compreensão da aprendizagem e dos processos evolutivos. Além disso, a complexidade é uma propriedade de sistemas que é largamente independente de seus conteúdos 
específicos. Ter essa compreensão, portanto, parece ser um pré-requisito para o desenvolvimento de uma teoria geral dos sistemas. O estudo da complexidade também parece ter importância prática considerável para uma variedade de fins, tais como projetos de sistema real, avaliação tecnológica, estabelecimento de padrões, no caso da interação homem-máquina (Allen, 2001).

Em se tratando de sistemas complexos, Juarrero (2010) assume com bases nos experimentos realizados, que aqueles apresentam um enraizamento contextual profundo que dificulta aos pesquisadores compreendê-lo. Isso porque a retroalimentação e as interações de incorporação de novos domínios podem se espalhar casualmente, como restrições contextuais, ampliando, assim, o domínio do sistema em questão e propagando imprevistos incontrolavelmente.

A conectividade entre as partes de um sistema complexo tem crescido de forma significativa, impulsionando a imprevisibilidade e a incerteza. Reconhece-se que a relação entre as partes em sistemas complexos é não linear. Estes são sensíveis às condições iniciais (Jackson, 2013).

Findlay e Straus (2013, p. 10) destacam três leis fundamentais aplicáveis aos sistemas complexos:

- variedade de requisitos (Lei de Ashby): qualquer sistema de controle deve ter um número igual ou maior de estados do que o sistema a ser controlado, ou seja, a complexidade só pode ser tratada por complexidade igual ou maior;

- modelo robusto do sistema (Teorema de Conant): ninguém pode efetivamente influenciar um sistema até que este o tenha sido entendido por completo, seu escopo, as conexões e suas interdependências, incluindo um mapa de todos os stakeholders, e os estágios de desenvolvimento sociotecnológico; e

- escala: situações altamente complexas podem ser solucionadas com maior grau de liberdade em escala local para que a inovação e a capacidade de adaptação sejam maximizadas.

Ao assumir os princípios de auto-organização e adaptabilidade, os sistemas complexos passam a ser considerados como sistemas adaptativos complexos. Segundo Juarrero (2010), os sistemas adaptativos complexos mostram não só os efeitos não lineares, mas 
também o que muitas vezes é conhecido como propagação causal, uma forma de causalidade diferente daquela observada em termos de eficiência, que é mais comumente entendida.

Os sistemas adaptativos complexos aprendem e evoluem, e usualmente interagem com outros sistemas adaptativos complexos. Eles sobrevivem porque aprendem ou evoluem de uma forma adaptativa: computam informação de forma a extrair regularidades, transformando estas regularidades em esquemas que são continuamente mudados à luz da experiência (Coelho, 2001).

Uma variação do sistema adaptativo complexo pesquisado por Juarrero (2010) são os sistemas dinâmicos complexos que incorporam as condições iniciais em que foram criadas, sua origem e trajetória, restringindo o seu futuro desenvolvimento e evolução. Tendo em vista que a sensibilidade apurada para as condições iniciais é uma das marcas dos sistemas adaptativos complexos, os processos dinâmicos também são essencialmente históricos, pois sua estrutura interna reflete a sua história. É aquilo que Maturana e Varela (2001) classificam como acoplamento estrutural, pelas características das restrições funcionais.

Havendo um acoplamento estrutural entre indivíduos, que implica em uma mediação coordenada, ao observar um grupo de trabalho pode-se descrever uma conduta de coordenação recíproca entre seus atores, gerando a necessidade de uma nova instância de coordenação para se coordenar as múltiplas interações construídas (Vasconcellos, 2013). Este, aliás, é um dos requisitos para se constituir sistemas adaptativos complexos.

Todo sistema adaptativo complexo é único. Cada qual emerge a partir de uma história específica e interage com um ambiente que, enquanto possa parecer similar, nunca é exatamente o mesmo para outro sistema (Coelho, 2001). A conectividade e interação necessárias para os sistemas complexos se auto-organizarem, e o que lhes proporciona a sua contextualidade e eficácia causal, são mais bem compreendidas em termos de restrições sensíveis ao contexto. Com isso, as relações de retroalimentação com o meio ambiente recalibram a dinâmica interna dos sistemas complexos por meio dos sinais de entrada (Juarrero, 2010). 
Alternativamente, Findlay e Straus (2013, p. 10) desenvolveram uma abordagem para lidar com os sistemas humanos, considerando as características de sistemas adaptativos complexos, incluindo as seguintes propriedades principais:

- não linearidade: os cérebros, os mercados, as ecologias, o clima e as organizações, todos se comportam de maneira não lineares;

- emergência: novos padrões de atividade surgem com o resultado das interações entre as partes;

- regras simples de interação: regras simples de interação entre agentes ou participantes de um sistema podem levar a padrões complexos de atividade ou comportamento;

- realimentação: processo através do qual os fluxos de informação a levam de um parte do sistema para outro e influenciam sua evolução ao longo do tempo; e

- auto-organização: por meio de interações locais, novos padrões de organização em nível global emergem, o que, por sua vez, influencia o padrão das interações locais.

\subsubsection{1 - Abordagens Complexas para o Desenvolvimento Organizacional}

Projetos de larga escala em energia, infraestrutura ou defesa são um fator central da economia globalizada. São caracterizados por múltiplos elementos inter-relacionados, múltiplos stakeholders, escopo global e longos horizontes temporais (Jackson, 2013), exigindo a assimilação da complexidade sistêmica. É mais útil considerar projetos complexos e de organizações que operam em ambientes que mudam rapidamente e utilizar abordagem de sistemas adaptativos complexos (Findlay e Straus, 2013).

Diferentes modos de compreensão da gestão de stakeholders, incluindo partes internas e externas, partem da perspectiva de sistemas complexos, onde simples soluções falham porque não são holísticas ou criativas o suficiente (Jackson, 2013).

A partir das contribuições da Teoria Geral de Sistemas, as Ciências da Complexidade encontram campo para se desenvolverem, assumindo novos preceitos paradigmáticos, superando as premissas do pensamento mecanicista e incluindo o princípio da emergência, para se estabelecerem como quadro de referências para estudos e modelos de sistemas de informação e de gestão (Borgatti Neto, 2008). É por meio da evolução das Ciências da Complexidade que algumas abordagens sistêmicas na gestão puderam se viabilizar. 
Por meio de um estudo de revisão amplo sobre teorias e Ciências da Complexidade, a tese de Borgatti Neto (2008) é uma fonte inspiradora para discutir a complexidade enquanto teoria e enquanto Ciência, além de tratar apropriadamente da complexidade sistêmica.

Pereira e Fonseca (2009) argumentam que, quanto maior a complexidade do sistema, maior é a possibilidade de desordem, e, portanto, maior é o perigo da crise. Paradoxalmente, é também maior a capacidade do sistema para vencer suas dificuldades e tirar proveito delas para o seu desenvolvimento. Portanto, pensar sistemicamente é um meio adequado ao gerenciamento da complexidade (Jackson, 2003).

Pensar o desenvolvimento organizacional requer uma abordagem fundamentada nos princípios da complexidade sistêmica. Na prática, vários são os construtos, arquétipos, frameworks e abordagens baseadas na noção geral de sistemas, que não é uma atividade nova, conforme pode ser observado no trabalho de Borgatti Neto (2008).

Segundo Karcanias e Hessami (2011), o paradigma de sistemas de sistemas oferece atributos arquitetônicos e operacionais que apresentam condições apropriadas para lidar com problemas em larga escala e com características globais. A multidimensionalidade é um dos princípios da complexidade sistêmica mais apropriado na definição de construtos ou abordagens organizacionais (Gharajedaghi, 2011). Nesta revisão da literatura, quatro propostas com essas características serão discutidas a seguir:

- Arquétipo Cynefin (Snowden e Boone, 2007);

- Construto Conceptagon (Boardman et al., 2009);

- Framework de Arquitetura de negócio (Gharajedaghi, 2011);

- Framework Profiler (Stevens, 2008).

O Cynefin é um arquétipo sistêmico para decisões em múltiplos contextos baseado em quatro quadrantes: simples, complicado, complexo e caótico. No contexto simples predomina a estabilidade com clara relação entre causa e efeito, o decisor reconhece o que é conhecido, é passível ao domínio das melhores práticas. Já o contexto complicado pode conter múltiplas respostas corretas, com clara relação entre causa e efeito, mas nem todos podem percebê-la. É o domínio dos especialistas, onde se reconhece o desconhecido. 
No contexto complicado o decisor não dispõe de conhecimento técnico suficiente para analisar a situação-problema. Se ao recorrer aos especialistas a avaliação for bem-sucedida, é possível suscitar a adoção de boas práticas da academia ou da indústria (Snowden e Boone, 2007). Segundo Demo (2014, p. 48), A posição do especialista ganhou notoriedade modernamente devido à complexificação crescente de nossa sociedade.

No contexto complexo, o decisor desconhece o desconhecido, respostas corretas não podem ser descobertas, prevalecendo o domínio da emergência. Por fim, o contexto caótico, que apresenta domínio de resposta rápida, já que a busca por respostas certa é inútil, e as relações entre causa e efeito são impossíveis de determinar porque elas mudam constantemente e não há padrões gerenciáveis - apenas turbulência. Este é o reino dos desconhecidos (Snowden e Boone, 2007).

O Conceptagon é um construto fundamentado no paradigma de sistema de sistemas (termo originário do inglês, Systems of Systems-SoS). Seu objetivo é formar uma base para o debate inteligente e colaboração efetiva entre os sistemas sociais humanos de todas as esferas da vida, e proporciona uma visão holística de toda a missão assegurando que qualquer que seja as partes específicas - os especialistas contemplam - de modo que o próprio todo seja coerente, eficiente e adequado para a finalidade (Boardman et al., 2009).

O Conceptagon fornece uma ferramenta específica para se alcançar uma visão multidimensional, podendo ser aplicado a uma variada gama de situações. Como não existem métodos prescritivos para usar o Conceptagon, especialistas de domínio desfrutam a liberdade de pensar em novas maneiras sobre o sistema de interesse, escolher sua própria navegação no conjunto de triplos que se torna óbvia e intuitiva para fazê-lo. São estes os triplos existentes no Conceptagon: 1) comunicação, comando e controle; 2) emergência, hierarquia e capacidade receptiva, 3 ) transformação, entrada e saída; 4) função, estrutura e processo; 5) fronteira, interior e exterior; 6) harmonia, variedade e parcimônia; e 7) relacionamento, todo e parte (Boardman et al., 2009).

A proposta de plataforma de negócio de Gharajedaghi $(2011$; 2004) é baseada na visão multidimensional para criar um único sistema indagador sobre contexto e stakeholders, função, processo e estrutura. A Figura 3.1 ilustra o processo de desenvolvimento baseado em múltiplas iterações da espiral de aprendizagem. 


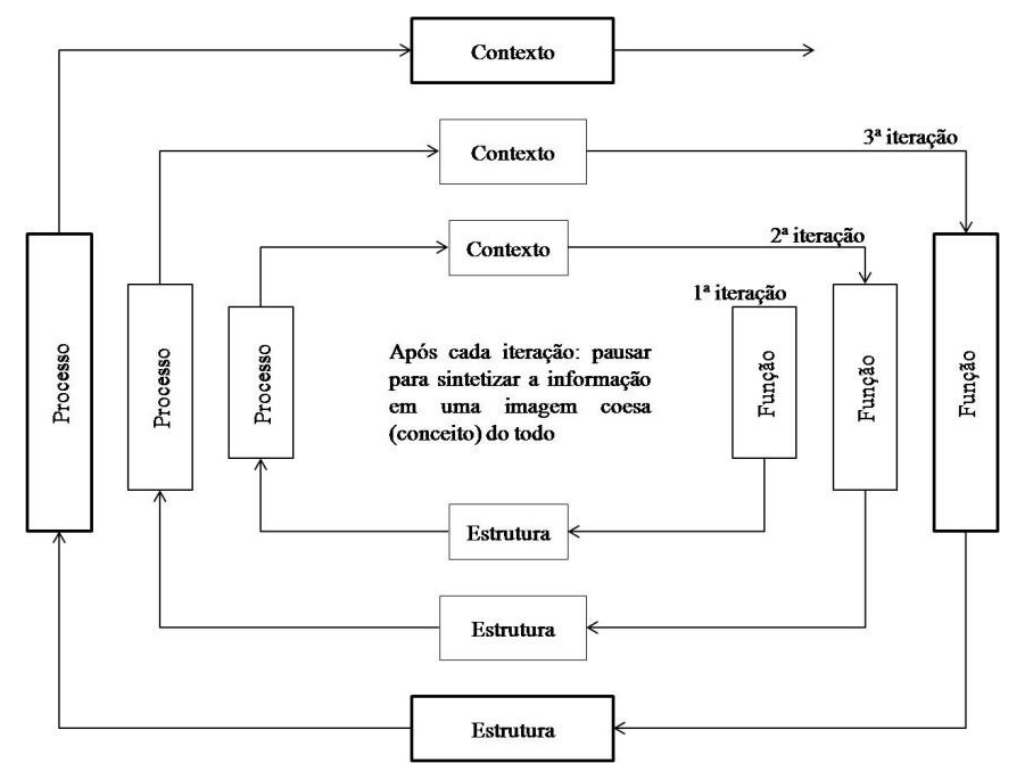

Figura 3.2 - Processo de investigação iterativo para compreender a complexidade

(Gharajedaghi, 2004, p. 6)

A noção de definir o contexto do problema ao longo de múltiplas dimensões fornece a base intelectual para o framework Profiler (Stevens, 2008). O conceito de combinar técnicas de resolução de problemas a um determinado contexto de problemas é subjacente aos esforços para compreender quais os processos e técnicas de engenharia de sistemas tradicionais ainda se aplicam ao mundo de problemas de larga escala, aos sistemas de alta complexidade e para iniciar o processo de definição de novos problemas, onde essas questões estão presentes.

O framework Profiler consiste na definição de quatro quadrantes, contendo os seguintes contextos de avaliação multidimensional: contexto de sistema, contexto das partes interessadas, contexto estratégico e contexto de implementação. No contexto de sistema a preocupação está voltada para os resultados desejados e o comportamento do sistema. Em relação ao contexto das partes interessadas, o objetivo é avaliar o relacionamento e o envolvimento com os públicos de interesse. O contexto estratégico aborda o ambiente de missão e o escopo de esforço, enquanto que o contexto de implementação está interessado em avaliar o ambiente de aquisição e a escala de esforço. A descrição completa do framework encontra-se disponível em Stevens (2008). 


\subsection{2 - Do Pensamento à Teoria e Prática Sistêmica}

Depois de meio século de evolução, ainda persiste a pergunta sobre o que é o pensamento e a prática sistêmica? A essência do pensamento e da prática sistêmica é a forma de perceber o mundo de uma maneira particular, porque esse olhar sobre as coisas afeta a maneira como se aproxima das situações ou mesmo para realizar tarefas específicas. Nesta seção abordaremos os problemas de definição de um sistema, partindo do reconhecimento de alguns dos principais conceitos utilizados na teoria de sistemas, até alcançar as múltiplas vertentes de pensamento e práticas sistêmicas.

O pensamento e a prática sistêmica são empregados para compreender a complexidade e gerir mudanças, segundo os princípios holísticos. Um coordenador pode pensar em qualquer coisa de forma holística, mas quando aplica o pensamento holístico de sistemas, descobre que algumas ideias e metodologias são particularmente úteis; essas ideias e metodologias constituem o pensamento sistêmico (Jackson, 2013).

O trabalho pioneiro do biólogo austríaco Karl Ludwig Von Bertalanffy e de seus sucessores mais proeminentes como Charles West Churchman, Russell Lincoln Ackoff, Peter Checkland, Jay Wright Forrester, Werner Ulrich, Edgar Morin, Humberto R. Maturana e Michael Christopher Jackson contribuíram para a cristalização de princípios e pressupostos básicos para a formulação de bases teórico-conceituais para o estudo de sistemas e para criar condições de aplicações na realidade empírica.

Partindo das produções científicas de Von Bertalanffy no período de 1950 a 1970, que culminaram com a Teoria Geral de Sistemas (TGS) (Bertalanffy, 1969), desencadearam-se várias interpretações sobre as aplicações sistêmicas, ondas de desenvolvimento e ramificações teóricas (Boardman et al., 2009). O objetivo da TGS é investigar as características gerais dos sistemas, bem como, subsidiar conceitualmente o desenvolvimento de modelos aplicáveis a mais de uma disciplina (Bertalanffy, 1969).

Para Morin (2011) a formulação de uma teoria geral de sistemas limita as abordagens específicas de cada assunto e propõe um novo paradigma de macro conceito que envolve três aspectos: i) sistema como manifestação emergente da unidade complexa; ii) sistema como relações entre partes ou variáveis qualitativamente distintas, que mantém interações, 
e não somente ações simples entre si; e iii) sistema como configuração das interações que constitui a organização sistêmica.

Há uma tendência recente de se abordar a teoria de sistemas a partir das relações entre as partes ou subsistemas para melhor compreender a sua organização e estrutura. As contribuições de pesquisadores renomados como Werner Ulrich e Michael Christopher Jackson, permitiram trazer o foco da teoria de sistemas para as interações e a relações entre as partes a fim de compreender a organização, o funcionamento e os resultados de uma entidade. Essa perspectiva, segundo Mele et al. (2010), implica um diálogo aberto entre holismo e reducionismo.

Os sistemas podem ser encontrados na natureza, na Ciência, na sociedade, no contexto econômico, de modo artificial e como sistemas de informação. Fazendo referência ao trabalho de Von Bertalanffy, ao retratar uma das abordagens desenvolvidas pela TGS, Mele et al. (2010) assumem que a teoria de sistema aberto aborda as relações entre as entidades e o ambiente em que estão envolvidos. Este enfoque reflete sobre a capacidade das organizações para se adaptarem às mudanças nas condições ambientes.

Uma das importantes ramificações da teoria de sistemas são os estudos sobre sistema de sistemas (SoS) (Boardman et al., 2009). Apesar disso, Karcanias e Hessami (2011) advertem que o termo SoS tem sido associado a problemas de natureza complexa, por diferentes comunidades, sem nenhum esforço especial para dar-lhe uma definição precisa e vinculá-lo aos conceitos de metodologias rigorosas e ferramentas da teoria de sistemas.

A palavra 'sistema' vem do verbo grego synhistanai, que significa 'estar juntos', cuja raiz etimológica é a mesma da palavra 'epistemologia'. Assim, um sistema é um todo percebido, cujos elementos ou partes estão interligadas (Ison, 2008). Sistema é um conjunto de elementos inter-relacionados, onde cada elemento é conectado, direta ou indiretamente, a todos os outros elementos do sistema. Por consequência, qualquer subconjunto de elementos está relacionado a algum outro subconjunto (Ackoff, 1971).

O pensamento sistêmico tomou o lugar da TGS como mecanismo de suporte fundamental para a prática de sistemas em diversas áreas de atuação. É formado por um corpo de conhecimento tanto de princípios e pragmatismos, que serve aos profissionais de sistemas, 
independentemente do domínio, na realização de análise, síntese e investigação dentro de sistemas de interesse identificados (Boardman et al., 2009).

O pensamento sistêmico surge com a ideia de que tudo está interligado, e cabe a nós respeitar essa condição e as percepções que derivam dele. Ainda que leve mais tempo e que possa parecer mais complicado, o pensamento sistêmico pode levar a melhores soluções de médio e longo prazos (Jackson, 2003).

Neste estudo, o pensamento sistêmico é adotado com a noção de paradigma (Vasconcellos, 2013). É uma forma de conceber o mundo na qual as coisas são vistas de forma holística e interligadas. De acordo com Kasper (2000), uma das dificuldades para aplicação das ideias sistêmicas é a ausência de trabalhos que articulem as concepções sistêmicas, apontando aspectos convergentes e divergentes nas abordagens já desenvolvidas.

Dilemas e paradoxos da sociedade contemporânea não podem ser resolvidos adequadamente com as abordagens tipicamente tradicionais. Pereira e Fonseca (2009) lembram que não se pode negar a contribuição trazida pelo modelo cartesiano. Ele foi e continua sendo válido como o método que propiciou o desenvolvimento da Ciência e da tecnologia até o ponto em que elas se encontram. Mas, quando é tomado como o único parâmetro para a tomada de decisões, contribui para acirrar os paradoxos da sociedade contemporânea.

Paradoxo é uma situação com alternativas múltiplas e consequências opostas (Boardman et al., 2009; Pereira e Fonseca, 2009). Se os paradoxos não podem ser resolvidos, também não podem ser ignorados, porque não há como eliminar a complexidade. Com isso, decidir por meio dos paradoxos implica a capacidade de perceber o global e atuar sobre as pequenas coisas que estão ao nosso alcance, aceitando a nossa impotência diante do que não tem solução (Pereira e Fonseca, 2009).

A amplitude do pensamento sistêmico encerra o universo complexo, englobando o todo e as partes. Segundo Capra (1996), o conteúdo do termo sistema passou a significar um todo cujas propriedades advêm da organização das relações entre as partes que o constituem. Destarte, a definição de pensamento sistêmico é visto como a compreensão de um fenômeno dentro de um contexto, estabelecendo-se a totalidade das interações envolvidas, 
formando redes de interações, em oposição à busca das relações causais simples entre partes isoladas.

A concepção sistêmica sobre a qual repousam as ambições das novas áreas de conhecimento interdisciplinares, como a biologia sintética e a computação quântica, parte do princípio de que uma perturbação em uma rede de interações não admite a priori quais serão as reações do sistema. É por isso que o engenheiro não é um especialista que realiza um projeto complexo que ele tem em mente reunindo os meios técnicos adequados, mas um explorador dos possíveis. É alguém que introduz uma perturbação em um sistema, sem saber o que resultará daí, mas com a esperança de que ela terá, entre suas consequências, um efeito que se aproxime de um resultado desejável - de modo que o principal é saber para quem esse resultado é desejável (Larrère, 2012).

O pensar sistêmico está presente nas mais diversas disciplinas do conhecimento como uma importante referência teórica, mas que nem sempre é discutido apropriadamente. Refere-se à compreensão de um fenômeno dentro do contexto de um todo maior (Ison, 2008). Na sua obra clássica $^{5}$, Senge (2013, p. 39) explora o pensamento sistêmico enquanto disciplina, segundo o qual:

O pensamento sistêmico é um quadro de referência conceitual, um conjunto de conhecimentos e ferramentas desenvolvido ao longo dos últimos cinquenta anos para esclarecer os padrões como um todo e ajudar-nos a ver como modificá-los efetivamente.

Um coordenador que deseja ser sistêmico, segundo a avaliação de Ison (2008), deve ser alguém que presta atenção especial às interconexões. Do ponto de vista sistêmico, vemos o indivíduo sempre inserido e partícipe de sistemas ou subsistemas como o sistema familiar, o sistema profissional e o sistema social entre tantos outros possíveis e existentes. A essência do pensamento sistêmico, portanto, é visualizar o mundo de uma forma ampliada entendendo suas relações (Vasconcellos, 2013).

\footnotetext{
5 'A Quinta Disciplina - a arte e a prática da organização que aprende', já na sua vigésima nona edição.
} 
Para Ulrich (1987) a essência do pensamento sistêmico leva em consideração questões que envolvem diversos fatores ou variáveis a partir de padrões organizados de interações. Isso implica as concepções teóricas e princípios que procuram explicar entidades, fenômenos e situações, cujo entendimento não pode ser compreendido em sua totalidade pelo pensamento analítico.

O modelo sistêmico é um esquema conceitual, que permite analisar de maneira ampla e direta os objetivos, a estrutura, o funcionamento e as inter-relações dos organismos complexos. Ele permite a análise dos sistemas sociais não apenas pelos seus componentes ou pela sua dinâmica interna, mas também pela identificação e possibilidade de intervenção no comportamento dos atores que dele participam e influenciam o alcance de seus resultados (Pereira e Fonseca, 2009).

Para assentar sua proposta de plataforma para gerenciar a complexidade e o caos, Gharajedaghi (2011) enumera os seguintes princípios sistêmicos: capacidade receptiva, senso de propósito, multidimensionalidade, propriedade emergente e comportamento contraditório.

A multidimensionalidade é, provavelmente, um dos princípios mais poderosos do pensamento sistêmico. É a capacidade de ver relações complementares em tendências opostas e criar conjuntos viáveis com partes inviáveis (Gharajedaghi, 2011; Morin, 2011).

A teoria sistêmica é um importante instrumento de avaliação de temas de interesse que abarcam a atividade humana dentro de sistemas sociais, onde existem múltiplos fatores que influenciam seu funcionamento (Checkland, 1993; Vasconcellos, 2013).

Recorrendo ao trabalho do neurobiólogo Humberto Maturana sobre a Teoria da Autopoiese, que revela questões essenciais sobre a vida e o funcionamento dos seres vivos, Vasconcellos (2013) assevera que se trata de uma contribuição para a vertente organicista da Ciência dos Sistemas (a visão sistêmica dos seres vivos), iniciada anteriormente pelo também biólogo, o austríaco Von Bertalanffy, com a TGS. Coincidentemente, da outra vertente que Vasconcellos distingue na Ciência dos Sistemas, a vertente mecanicista (a visão sistêmica das máquinas), iniciada com a Teoria Cibernética, do matemático americano Norbert Wiener, também advém importante contribuição para a Ciência passar a 
pensar cientificamente a epistemologia com a contribuição do ciberneticista austríaco, Von Foerster, com a Cibernética da Cibernética.

Para Gharajedaghi (2011) a organização deve ser vista a partir da pluralidade de estrutura, função e processo, correspondendo ao cerne da teoria de sistemas de desenvolvimento. A pluralidade simplesmente afirma que sistemas podem ter estruturas múltiplas e funções múltiplas e serem governadas por vários processos.

Os fundamentos do pensamento sistêmico se confundem com a própria estrutura das organizações produtivas, mecanizadas, sociais e ecológicas. Ackoff (1979) associa as mudanças na sociedade industrial à segunda guerra mundial. São estas as principais alterações observadas:

- fim da era das máquinas e início da era dos sistemas;

- era das máquinas - tudo se refere analogamente às máquinas, inclusive o homem; o pensamento analítico trata a natureza das coisas e situações a partir dos seus elementos básicos;

- era dos sistemas - visão sociológica e interdependência dos sistemas complexos. O pensamento sistêmico visa contemplar a complexidade organizada como redes dinâmicas de interações, baseado no conceito de sistemas.

A abordagem analítica consiste em se apoiar nos preceitos do pensamento cartesiano para investigar um conteúdo em qualquer campo de conhecimento. Isto posto, as principais características do pensamento analítico estão associadas com análise, reducionismo, determinismo e mecanicismo (Ackoff, 1979). Do mesmo modo, o autor elenca as principais consequências desse tipo de pensamento, quais sejam: foco nos elementos ou partes, exclusão do ambiente, concepção da realidade e a natureza do conhecimento e métodos do pensamento analítico.

Das contribuições teóricas dos biólogos organicistas nasceram as primeiras noções, que, aprimoradas, estão na origem do pensamento sistêmico. Estas noções estão assim sumarizadas por Capra (1996):

- o conceito de organização como um padrão ou "configuração de relações ordenadas"; 
- o conteúdo do termo 'sistema' que passou a significar um 'todo', cujas propriedades provém da organização das relações entre as partes que o constituem;

- a definição de 'pensamento sistêmico' como “a compreensão de um fenômeno dentro de um contexto" (ibid., p. 39), estabelecendo-se a totalidade das interações envolvidas, em oposição à busca das relações causais simples entre partes isoladas;

- a expressão 'complexidade organizada' como a denominação para caracterizar a existência de diversos tipos e vários níveis de complexidade que podem ser descritos ou capturados pelo conceito de sistema;

- a noção de hierarquia como designação para a tendência dos sistemas vivos de estruturar-se em múltiplos níveis: células, tecidos, órgãos, organismos, sociedade e ecossistema; e

- a expressão 'propriedades emergentes' como designação das características propriedades, qualidades e comportamento - pelas quais são identificados os fenômenos complexos organizados, descritos pelo conceito de sistema.

O importante trabalho de revisão de Kasper (2000) permitiu definir o pensamento sistêmico, apoiado nas contribuições da literatura específica, consistindo em:

- uma nova estrutura de pensamento para lidar com a complexidade;

- a busca do desenvolvimento de uma epistemologia para descrever a realidade e para elucidar alguns de seus problemas;

- um processo de pensamento que vê algo como parte de um sistema maior e em termos do papel que cumpre no mesmo, invertendo a lógica que caracteriza o pensamento analítico;

- pensar em termos de contexto e em termos de padrões de interações dentro de padrões maiores de interações; e

- mudar o foco das partes para os processos, onde estruturas são concebidas como estabilizações temporárias de relações entre partes e processos.

Uma das contribuições mais importantes para a análise dos sistemas foi concebida por Arthur Koestler, por meio do conceito de hólon, como uma forma de contraposição aos extremos do reducionismo proposto pela metodologia científica cartesiana e aos exageros do holismo, que pretende a hegemonia do todo sobre as partes, em todas as circunstâncias (Gharajedaghi, 2011; Pereira e Fonseca, 2009). 
Os hólons apresentam três características específicas, visíveis em qualquer tipo de sistema (Pereira e Fonseca, 2009):

- hierarquia - todo sistema tem uma finalidade e está organizado hierarquicamente em relação à sua função e ao controle de seus processos internos.

- códigos fixos - regras que sustentam a identidade do sistema e organizam a sua estrutura em profundidade e extensão, contendo os limites do sistema, aquilo que não pode ser mudado, que constitui o seu núcleo essencial.

- estratégias flexíveis - dinâmica e flexibilização do sistema, bem como as estratégias que ele usa para sobreviver.

\title{
3.1.3 - Abordagens Sistêmicas Aplicadas às Organizações
}

\begin{abstract}
Há um interesse enorme de governos e empresas, dos serviços de saúde, do setor de energia, de infraestrutura, das indústrias de defesa e da educação, entre outros, na abordagem de sistemas. [...] Nesta era da interconectividade, a utilização do conceito de sistemas está se tornando mais popular. (Jackson, 2013, p. 25).
\end{abstract}

Não existe uma única forma de pensamento sistêmico. De fato, há modelos e metodologias de desenvolvimento que, de acordo com Checkland (1993), podem ser mapeados em: i) desenvolvimento teórico puro, citando como exemplo a Teoria Geral de Sistemas, e ii) desenvolvimento teórico a partir da aplicação a problemas do mundo real, exemplificando a engenharia de sistemas, a metodologia de sistemas flexíveis, o modelo de viabilidade de sistemas e a heurística sistêmica crítica.

O desenvolvimento organizacional é operacionalizado na forma de projetos e processos de mudança. Projetos de larga escala exigem importantes intervenções, as quais são precedidas por análises decisórias que devem identificar os problemas mais cruciais dentro da situação-problema para aquele momento (Jackson, 2013). Os gerentes de projetos precisam atualmente de uma liderança mais sofisticada, governança e abordagens para gestão das partes interessadas para ajudá-los a entender a complexidade e fornecer orientações práticas para o pensamento e ação (Findlay e Straus, 2013).

No caso da tecnologia, a realidade social é bastante complexa. Muitas tecnologias diferentes são implantadas em diferentes contextos sociais por razões muito diferentes, muitas vezes com efeitos completamente opostos para o sistema organizacional (Liker, 
Haddad e Karlin, 1999). Abordagens como a heurística sistêmica crítica e o pensamento sistêmico crítico, são apropriadas para esse tipo de avaliação (Jackson, 2003).

As práticas e aplicações do pensamento sistêmico em outras áreas do conhecimento são decorrentes da forma como o movimento sistêmico se desenvolveu, conforme pode ser observado na Figura 3.3. Pensadores de sistemas respondem com abordagens como a dinâmica de sistemas e cibernética organizacional para enfrentar a complexidade; metodologia de sistemas flexíveis e planejamento interativo para lidar com a subjetividade; e heurística sistêmica crítica para ajudar os mais desfavorecidos em situações que envolvam conflitos (Jackson, 2003).

\begin{tabular}{|l|l|l|}
\hline \multicolumn{2}{|l|}{ Movimento sistêmico } \\
\hline & \multicolumn{2}{l|}{ Estudo das ideias sistêmicas em si } \\
\hline & & $\begin{array}{l}\text { Desenvolvimento teórico das ideias sistêmicas } \\
\text { problemas do mundo real }\end{array}$ \\
\hline & $\begin{array}{l}\text { Trabalho com sistemas hard (concretos) } \\
\text { Ajuda à tomada de decisão } \\
\text { Trabalho em sistemas soft (conceituais) }\end{array}$ \\
\hline & \multicolumn{2}{|l|}{\begin{tabular}{l} 
Aplicação do pensamento em outras disciplinas \\
\hline
\end{tabular}}
\end{tabular}

Figura 3.3 - Forma do movimento sistêmico

(Checkland, 1993)

Ao abordar a Ciência de Sistemas, Flood e Carlson (1988) propuseram um modelo dinâmico para visualizar o processo de desenvolvimento do pensamento sistêmico, por meio de ciclos evolutivos, constantes na Figura 3.4.

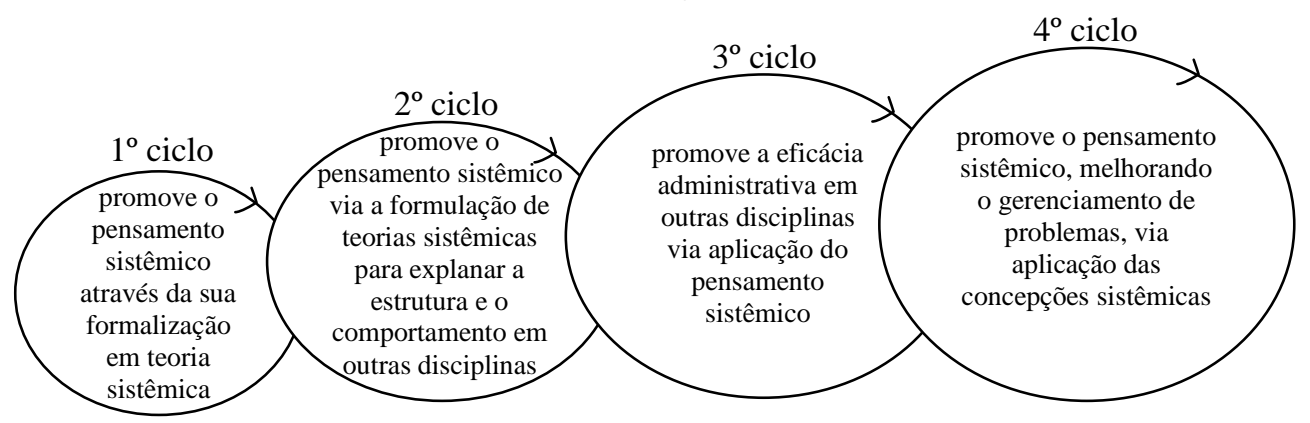

Figura 3.4 - Ciclos do processo de desenvolvimento do pensamento sistêmico (Flood e Carlson, 1988) 
O modo de investigação em um sistema organizacional depende de duas dimensões de análise: a natureza da organização e a natureza da investigação. Gharajedaghi (2011) ilustra sua proposta de orientação, atentando-se para os métodos que devem ser incorporados, dependendo da combinação entre as duas dimensões - Figura 3.4.

No contexto organizacional, o pensamento sistêmico, ao fornecer os conceitos para entender a importância do gerenciamento das interconexões, permite romper as barreiras funcionais e visões compartimentadas. Oferece assim uma moldura conceitual para visualizar como cada decisão no negócio afeta a empresa como um todo (Kasper, 2000).

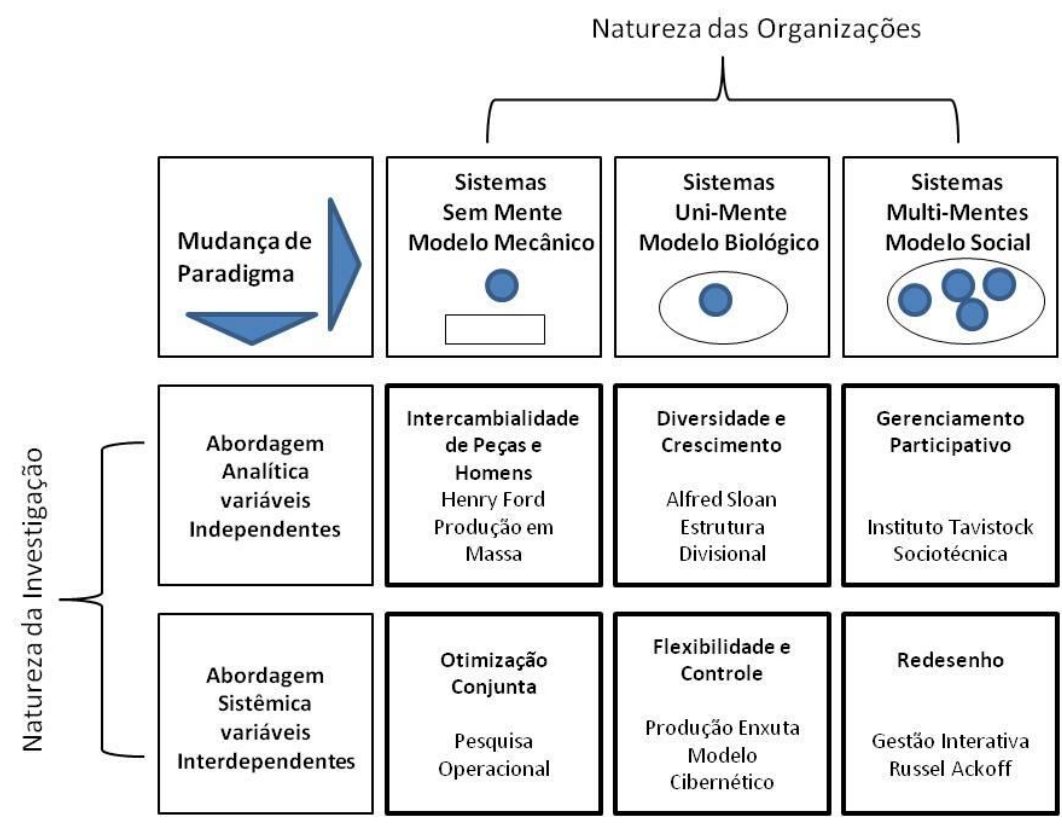

Figura 3.5 - Abordagens de investigação nos sistemas organizacionais

(Gharajedaghi, 2011)

Para examinar as organizações como sistema, alguns pressupostos são reconhecidos e assumidos por parte da literatura específica:

- obter visão holística dos processos (Jackson, 2003; Rummler e Brache, 1994);

- compreender relação todo-parte (Ackoff e Gharajedaghi, 1996; Boardman et al., 2006);

- crítica de fronteira, interior e exterior (Boardman et al., 2006; Ulrich, 1987);

- dinâmica de sistemas - agir localmente sem se esquecer do global (Capra, 1996; Senge e Sterman, 1992; Sterman, 2000). 
As estruturas organizacionais são representadas pelas partes componentes, ao mesmo tempo em que formam um todo organizado. A ênfase nas partes tem sido chamada de mecanicista, reducionista ou atomística (Gharajedaghi, 2011; Capra, 1996). A ênfase no todo, de holística, organicista ou ecológica (Capra, 1996). Com o advento da Revolução Industrial, aquilo que era concebido sistemicamente era visto como uma perspectiva holística e a partir do século XX esta maneira de pensar passou a ser conhecida como "pensamento sistêmico" (ibid., p. 33).

O conceito de sistemas no contexto organizacional denota que a organização é um grande sistema aberto e dinâmico que interage plenamente com outros sistemas externos e com seus subsistemas (Molinaro e Ramos, 2011). Sistemas como grandes projetos internacionais de energia ou grandes processos de mudança social existem em ambientes cada vez mais dinâmicos e turbulentos, onde se planeja com antecedência, tanto quanto puder, mas deve manter-se consciente de que os planos vão mudar (Jackson, 2013).

A dinâmica de sistemas foi desenvolvida originalmente pelo engenheiro Jay W. Forrester, com o objetivo inicial de auxiliar a administração de sistemas industriais complexos. É sustentada pelas áreas de engenharia de controle (servomecanismos), cibernética e decisão em organizações humanas.

Comportamento dinâmico em sistemas complexos decorre de estruturas causais constituídas de múltiplos laços de realimentação negativos e positivos, que se realizam via fluxos de recursos e informações (Sterman, 2000).

Se a visão estrutural e funcional não é suficiente, o pensamento sistêmico também é explorado em termos da visão processual e da dinâmica relacional. A dinâmica dos sistemas organizacionais é objeto de estudo e análise de uma corrente de pesquisadores e teóricos de grande prestígio nesse campo do conhecimento, liderados por Jay Wright Forrester, John D. Sterman e Peter Senge. De acordo com Senge (2013, p. 9), Jay W. Forrester é um dos principais responsáveis pela introdução do pensamento sistêmico como disciplina gerencial e de liderança.

O objetivo do pensamento sistêmico e da modelagem de dinâmica de sistemas é melhorar a compreensão dos diferentes modos de relacionamento entre o desempenho de uma 
organização com sua estrutura interna e políticas operacionais que atendam clientes, concorrentes e fornecedores, para então, usar esse conhecimento para conceber políticas de alta alavancagem para alcançar o sucesso (Sterman, 2000).

Os sistemas organizacionais apresentam uma dinâmica própria, dependendo fundamentalmente da atuação humana que pode estar condicionada pelo status de turbulências, incertezas, complexidades e/ou imprevisibilidades que, em última análise, moldarão o comportamento organizacional. De acordo com os argumentos apresentados por Senge (2013) e Sterman (2000), nesse contexto a dinâmica de sistemas é uma perspectiva e um conjunto de ferramentas conceituais que nos permitem compreender a estrutura e a dinâmica dos sistemas organizacionais.

Um recurso amplamente empregado nas concepções sistêmicas críticas são as metáforas no contexto organizacional. Elas têm sido utilizadas para descrever a natureza do funcionamento das organizações e das ações dos administradores (Kasper, 2000). Aliada a uma linguagem visual, permite explicitar com mais entusiasmo a perspectiva sistêmica da situação-problema (Checkland, 1993).

As perspectivas de desenvolvimento organizacional sob o enfoque sistêmico podem ser alcançadas a partir de diferentes pontos de vista sobre a sua organização ou estrutura. A estrutura organizacional de um sistema pode ser descrita por meio de uma arquitetura, que em última análise oferece uma visão dos componentes e de suas relações no sistema. Gharajedaghi (2011) propõe uma arquitetura de negócio que descreve as partes envolvidas externa e internamente sob uma visão multidimensional - Figura 3.5.

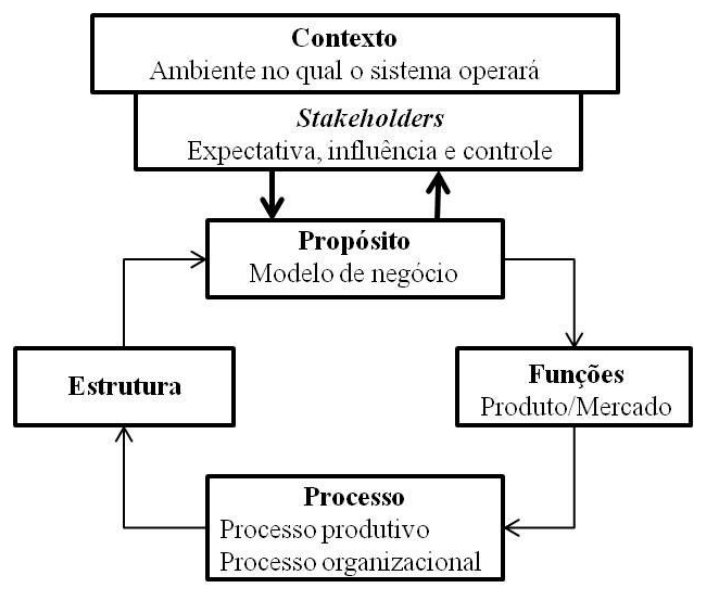

Figura 3.6 - Arquitetura do sistema de negócio

(Gharajedaghi, 2011) 
O desenvolvimento organizacional e de sistemas de informação são mais bem compreendidos com a presença de arquiteturas (Gharajedaghi, 2011; Zachman, 1987). Dentre as várias possibilidades de arquitetura para os sistemas organizacionais, estas são reconhecidas por aqueles autores: arquitetura do sistema de produção, arquitetura do sistema de gestão, arquitetura tecnológica, arquitetura funcional e arquitetura de serviços.

As arquiteturas de serviço são uma das possíveis perspectivas de sistemas (Mele et al., 2010). Nessa perspectiva, advertem Stanicek et al. (2010), o sistema deve ser reconhecido pelo alto grau de complexidade e dinamismo. Para capturar toda a complexidade e dinâmica em um único modelo que seja ao mesmo tempo compreensível e útil, torna-se uma tarefa árdua e que requer um trabalho intenso. Desse modo, continuam Stanicek et al. (2010), a atividade de modelagem de sistemas de serviço deve se concentrar nas relações ao invés dos próprios objetos, tendo em vista a capacidade de construir objetos compostos de forma diferente em vários contextos.

\subsubsection{1 - Estruturação de Problemas na Perspectiva Sistêmica}

Quando Kant (2005, p. 70) se questiona sobre a possibilidade de vivermos em uma época esclarecida, ele próprio responde que vivemos em uma época de esclarecimento. $\mathrm{O}$ homem, em maior ou menor grau, ainda se ressente da insegurança que o torna incapaz de entender autonomamente uma dada situação. Ainda segundo Kant (ibid., p. 65), para se ter esclarecimento não basta ter um profundo conhecimento sobre um assunto, mas combinar isso com a conquista da autonomia, que permitirá sobrepujar a falta de decisão e coragem de servir-se de si mesmo sem a direção de outrem.

Ainda que estejamos nessa era de esclarecimento, o fato é que muito pouco se discute sobre as estruturas de um problema. Para conceituar um problema, Ackoff (1987, p. 11) lança mão de cinco tipos de componentes:

- $\quad$ aqueles que estão diante do problema - os tomadores de decisão;

- aqueles aspectos da situação-problema que o tomador de decisão pode controlar: as variáveis controladas;

- aqueles aspectos da situação-problema que o tomador de decisão não pode controlar, mas que, juntos com as variáveis controladas, pode afetar o resultado de sua escolha: as variáveis não controladas; 
- restrições internas ou externas sobre os possíveis valores que as variáveis controladas e não controladas poderão assumir; e

- os possíveis resultados produzidos conjuntamente pelas escolhas feitas pelo tomador de decisão e as variáveis não controladas.

É no domínio do problema onde se pode observar as relações sociais e as manifestações culturais. Para Morin (2004) o conhecimento baseado nas práticas sociais e culturais dos grupos envolvidos, gerado a partir da interlocução entre pesquisadores e atores da situação observada e que se revela como sendo de grande utilidade para desencadear mudanças ou melhorias de diversos tipos, em particular, no mundo da decisão.

Uma situação-problema pode ser avaliada sob diversos aspectos. Para Morgan (1982) a análise das várias metodologias de resolução de problemas deve mostrar que as mesmas não competem pelas mesmas situações ou problema, podendo assumir duas dimensões:

- $\quad$ simples (mecânico) x sistêmico (complexo); e

- processo de tomada de decisão - relações unitárias, quando existir concordância sobre um conjunto de metas; e pluralista, se os objetivos são distintos ou conflitantes; a este último, foi acrescentado o contexto coercitivo.

O princípio metodológico do núcleo da crítica sistêmica de Ulrich (1987) pode assumir duas formas - prática reflexiva e prática emancipatória. O propósito é lidar com situaçõesproblema de natureza diversa. Da mesma forma, a qualidade argumentativa de uma reflexão ou discussão se reflete nos julgamentos de fronteira.

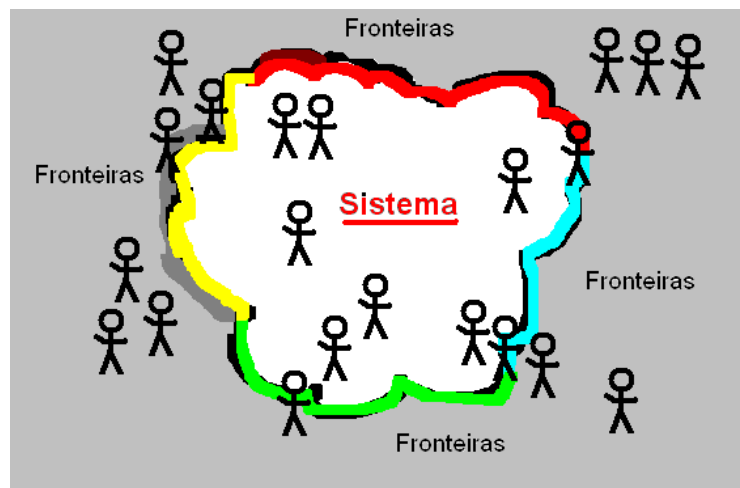

Figura 3.7 - Crítica de fronteiras

(Ulrich, 1987) 
A mesma observação se aplica à influência do poder e outros meios não argumentativos de justaposição de uma reclamação: se aqueles que estiverem no controle de uma situação, deliberadamente suprimirem ou ignorarem alguns aspectos de uma situação-problema em questão, eles estarão tratando de algo diferente daquilo que atualmente é pretendido. Está assentado na definição da tipificação dos atores que estão no ambiente interno e externo ao sistema de referência, o tipo de influência e relação de poder existente e de que forma impacta o alcance dos propósitos do sistema (Garrossini, 2010; Ulrich, 1987). O princípio metodológico do núcleo da crítica sistêmica está representado na Figura 3.6.

\subsubsection{2 - Métodos de Estruturação de Problemas}

Os Métodos de Estruturação de Problema (MEP, termo originário do inglês Problem Structuring Methods-PSM) são abordagens interativas e participativas para ajudar grupos diversos a atenuar uma situação complexa e problemática de interesse comum. Normalmente o elemento mais difícil da situação é enquadrar as questões que constituem o problema (Mingers e Rosenhead, 2004).

Os MEP estão orientados ao contexto real da situação-problema, utilizando os sistemas e o pensamento sistêmico para formar um framework abstrato para investigação, em vez de uma estrutura para criação de soluções. As descrições dos sistemas são utilizadas para entender a situação atual e descrever um futuro desejado para subsidiar a análise de decisão (Von Winterfeld e Fasolo, 2009).

Os problemas mal estruturados, ou não estruturados, são caracterizados por Mingers e Rosenhead (2004) por apresentar os seguintes aspectos: múltiplos atores envolvidos e/ou afetados, múltiplas perspectivas de avaliação, incomensurabilidade e/ou interesses conflitantes das partes envolvidas, altamente intangíveis e por haver incertezas chaves.

As abordagens de estruturação de problema visam tirar proveito da diversidade para compreender diferentes perspectivas de situações problemáticas (Jackson, 2013). Acrescenta-se ao fato de que, mediante intervenções diretas na organização é possível reconhecer que as premissas e modelos mentais dos participantes são uma obstrução importante para a mudança e que esses pontos de vista diferentes não podem ser 
descartados, mas devem fazer parte da abordagem de intervenção (Checkland e Scholes, 1998; White, 2009).

Para Vasconcellos (2013), esse cenário é descrito na forma de um sistema linguístico, onde as relações entre as pessoas possibilitam construir, conjuntamente, significados para a situação que estão vivendo. Porquanto, diversos domínios linguísticos são distinguidos no estágio prospectivo de uma intervenção para que nas atividades de análise e avaliação holística possam definir um único sistema linguístico em torno da situação-problema.

Os MEP são resultantes da evolução da Ciência da Gestão e das abordagens da pesquisa operacional flexível (Mingers e Rosenhead, 2004; Munro e Mingers, 2002; White, 2009). Para Ackoff e Sasieni (1968) a pesquisa operacional é uma área do conhecimento interessada na aplicação do método científico, envolvendo equipes multidisciplinares, para lidar com problemas concernentes ao controle de sistemas organizados, buscando soluções que melhor interessam à determinada organização.

A abordagem pioneira de pesquisa operacional, doravante denominada de Pesquisa Operacional (PO) Tradicional (termo originário do inglês, Hard $\mathrm{OR}$ ), é reconhecida pela incessante busca de caminhos que levem à solução ótima de problemas reais (Ackoff, 1971). É baseada nos métodos estatísticos ou probabilísticos, muitas das vezes fundamentados em uma função objetivo. Por outro lado, as abordagens de PO Flexível (termo originário do inglês, Soft OR) não pretendem buscar a solução ótima, mas, sobretudo, encaminhar as ações de pesquisa com vistas a soluções harmoniosas e/ou robustas (Mingers, 2011).

Pesquisa Operacional é originária do vocábulo Operations Research da Escola Americana e apropriado pela Escola Europeia como Operational Research. De acordo com a SOBRAPO (2014), a pesquisa operacional é uma Ciência Aplicada, voltada para a resolução de problemas reais. Aplica conceitos e métodos de diversos campos da Ciência na concepção, planejamento ou operação de sistemas. É adota para avaliar linhas de ação alternativas e encontrar soluções que melhor servem aos objetivos dos indivíduos ou organizações, tendo como foco as tomadas de decisão. 
Em alguns países, em que prevaleceu a preocupação com os fundamentos teóricos, a PO se desenvolveu sob o nome de Ciência da Gestão (termo originário do inglês, Management Science) ou Ciência da Decisão (termo originário do inglês, Decisions Science) e em outros, em que predominou a ênfase nas aplicações, com o nome de Engenharia Industrial ou Engenharia de Produção (SOBRAPO, 2014).

Seguiram-se então grandes desenvolvimentos técnicos e metodológicos que hoje, com o apoio de meios computacionais de crescente capacidade e disseminação, nos permitem trabalhar enormes volumes de dados sobre as atividades, não apenas das empresas, mas, também de instituições do setor público dentro e fora da área econômica (ibid.).

Existem grandes desafios para a pesquisa operacional superar na realidade complexa que se apresenta nos tempos atuais. Em particular, terá que focar as conexões entre teorias e práticas para melhor apoiar as atividades humanas na tomada de decisão (Bernroider e Schmollerl, 2013).

Face ao seu caráter transdisciplinar que vem recebendo na contemporaneidade, a PO é formada por um corpo de conhecimento científico de causalidade circular com suas contribuições estendendo-se por praticamente todos os domínios da atividade humana, da engenharia à medicina, passando pela economia e a gestão empresarial (Ackoff e Gharajedaghi, 1996). Seagriff e Lord (2009) defendem que a PO flexível deve tornar-se mais transparente e uma abordagem transdisciplinar é necessária com métodos que podem reunir psicologia social, psicologia, matemática, gestão estratégica, lógica e Ciência da Computação.

$\mathrm{Na}$ atual conjuntura, o grande desafio é compreender a estruturação de problemas, os quais estão cada vez mais complexos e perversos, onde a maioria das intervenções do sistema de atividade humana no contexto organizacional pode acontecer ocasionalmente, sendo, portanto, difíceis de avaliar utilizando-se os métodos tradicionais (White, 2009).

O que diferencia a abordagem de PO Tradicional da PO Flexível é objeto de estudo de grupos de pesquisa e escolas de pensamento que realizam longas discussões sobre a definição dessas duas noções. Tais discussões podem parecer impróprias, mas, no fundo, revelam divergências entre escolas de pensamento, tipos de objetivos, práticas de pesquisa 
e formas de aplicação. Existem também diferenças em função dos países ou das disciplinas envolvidas. Todavia, essas divergências parecem superáveis, mediante maior atenção aos pressupostos epistemológicos e à metodologia das propostas (Mingers, 2011).

Não obstante os avanços alcançados, a pesquisa operacional começou a ser questionada nos anos de 1960 e 1970 por parte de alguns de seus próprios teóricos. Contrária à PO clássica, na qual se usam os métodos quantitativos - modelagem matemática e simulação, a PO flexível recorre aos métodos qualitativos das Ciências Sociais: entrevistas, trabalho de grupos com pesquisadores e usuários (Thiollent, 2011; White, 2009). Tudo vai depender das circunstâncias contextuais do problema ou da situação-problema em avaliação. Por exemplo, crises em nível nacional ou mundial não são adequadamente abordadas por métodos da esperança matemática ou por modelos lineares. Este tipo de cenário é multivariado e apresenta multiatributos ou multiobjetivos, sinalizando o emprego de métodos típicos da PO flexível (Von Winterfeld e Fasolo, 2009).

Clutterbuck (2001) repercute a relação entre PO tradicional e PO flexível por meio da tipificação das situações-problema, aqui representada por uma pirâmide - Figura 3.6, onde na parte superior encontram-se as instâncias políticas e estratégicas, com apropriação dos métodos de estruturação de problema, e nas questões mais tático-operacionais - como efetividade e produtividade - a PO tradicional é mais comumente empregada. Nessa mesma perspectiva, Kreher (1995) faz a distinção das duas vertentes, distinguindo parâmetros de avaliação suscetíveis a ambas - Quadro 3.1.

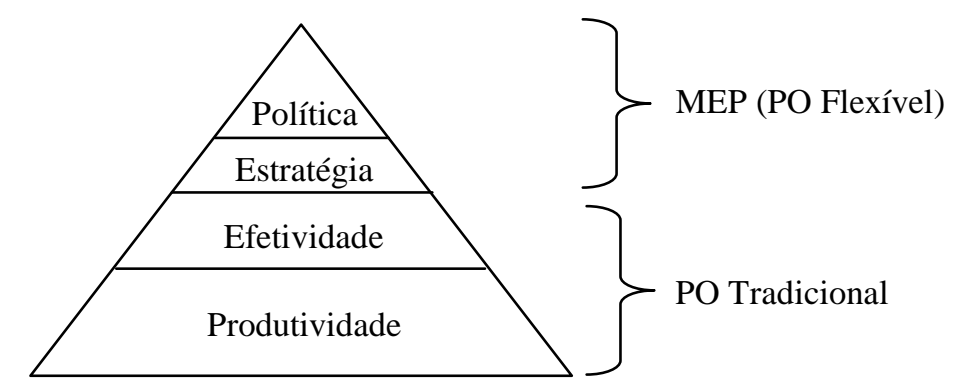

Figura 3.8 - Tipos de problemas e escolas de pesquisa operacional

(Clutterbuck, 2001, modificado)

Cada abordagem de estruturação de problema apresenta características distintivas que a credencia para o emprego em situações específicas (Mingers e Rosenhead, 2004). Dentre aquelas disponíveis na literatura, estas são as mais referenciadas pelos pesquisadores e com 
experimentação na prática (Jackson, 2003; Mingers, 2011; Mingers e Blocklesby, 1997; Munro e Mingers, 2002):

- $\quad$ Soft Systems Methodology (SSM);

- Strategic Option Development and Analysis (SODA);

- Strategic Assumption Surfacing and Testing (SAST);

- Inquiring Systems;

- $\quad$ Total Systems Intervention (TSI);

- $\quad$ Critical Systems Heuristic (CSH);

- $\quad$ Strategic Choice Approach (SCA);

- Interactive Planning; e

- Viable Systems Model (VSM).

Quadro 3.1 - Distinção das abordagens de PO tradicional e flexível

(Kreher, 1995, modificado)

\begin{tabular}{|l|l|}
\hline \multicolumn{1}{|c|}{ Abordagem PO tradicional } & \multicolumn{1}{c|}{ Abordagem PO Flexível (MSP) } \\
\hline Bem definido e estruturado & Mal definido e não estruturado \\
\hline Problema & Situação-problema (problema e seu contexto) \\
\hline Objetivo & Problemático (intersubjetivo) \\
\hline Maximização (otimização) & Aprendizagem (dar sentido) \\
\hline Projeto de gerenciamento & Projeto de investigação \\
\hline Engenharia de um sistema & Sistema como dispositivo epistemológico \\
\hline Quadro estável (determinístico) & Quadro perverso (instável) \\
\hline
\end{tabular}

\subsubsection{3 - Metodologia de Sistemas Flexíveis}

A metodologia de sistemas flexíveis (SSM) foi proposta por Peter Checkland no ano de 1981 na Universidade de Lancaster, cujo propósito principal é tratar problemas tipificados como flexíveis (soft), mal definidos e com necessidade de um detalhamento maior. É, portanto, uma metodologia de aprendizagem (systems methodology) capaz de descobrir aspectos relevantes de uma situação-problema, orquestrar conflitos e promover o consenso (Checkland, 1993; Jackson, 2003; Martinelli et al., 2012).

A partir da análise sistêmica feita com a SSM, é possível identificar a situação-problema e detalhá-la, bem como, orientar as intervenções para reduzi-las, com o propósito de formular modelos adequados para o redesenho do sistema, para buscar soluções viáveis (Jackson, 2003; Martinelli et al., 2012; Munro e Mingers, 2002). A SSM e outras 
abordagens flexíveis utilizam sistemas de pensamento para garantir que as situaçõesproblema sejam totalmente exploradas e resolvidas. Essas abordagens são adequadas para os problemas pluralistas (Checkland, 1993).

No plano de aplicação organizacional e gerencial, a SSM está mais voltada para a compreensão interna e a cultura do sistema de atividade humana do que propriamente das práticas de controle (Jackson, 1993). Além disso, fornece um guia para o desenvolvimento de pesquisas em ambientes do mundo real, onde os fatores sociais, culturais e políticos influenciam o desempenho dos negócios (Freyle, Florez e Rincón, 2013).

Em seu conjunto, os sete estágios da SSM (Figura 4.3) representam um sistema de aprendizagem, que descobre os aspectos cruciais de uma situação em que pelo menos um dos participantes considera problemática (Martinelli, 2006). Para Seagriff e Lord (2009) a SSM não oferece uma resposta, mas uma ferramenta para aprender sobre a situaçãoproblema, realizando projeções de forma adequada para atuação futura.

A SSM tem suas raízes na engenharia de sistemas, sendo considerada a grande precursora para a aplicação das Ciências da Complexidade no "[...] cenário de maior desafio de todos os sistemas - sistemas de atividades humanas" (Boardman et al., 2009).

\subsubsection{4 - Concepções Sistêmicas Críticas}

O pensamento sistêmico crítico e as metodologias associadas foram desenvolvidos justamente para permitir a análise dos problemas sociais complexos e as possibilidades de intervenção para resolver tais problemas (Jackson, 2003).

Em meio ao crescente aumento das situações-problema, em quantidade e em complexidade, a SSM não consegue contemplar todas as possibilidades de intervenção possíveis. Seus próprios críticos sugerem que ela não considera o processo de intervenção, e em particular, como as diferenças de poder entre os indivíduos e os grupos sociais podem impactar a eficácia das intervenções (Mingers, 1997). O pensamento crítico de sistemas, no entanto, que fornece uma fotografia maior, permite pensar e amadurecer como uma disciplina, mostrando de que forma a variedade de metodologias agora disponíveis podem ser utilizadas em conjunto de forma coerente para promover o sucesso da intervenção em situações sociais complexas e problemáticas (Jackson, 2013). 
A heurística crítica para o planejamento social de Ulrich (1987) é uma abordagem metodológica para lidar com situações problemáticas nos contornos de um sistema. Segundo o autor, a palavra heurística vem do grego, procurar, descobrir, "arte do descobrimento". Por consequência, a abordagem crítica ou pensamento crítico é um requisito exigido, pois não há um caminho simples e direto para lidar com conceitos e ideias críticas - relações de poder coercitivas, informação distorcida, que potencializam e ampliam as aplicações do pensamento sistêmico.

Nesse ramo da teoria de sistema, o pensamento sistêmico visa abordar todas as definições do problema, propostas de solução, onde as avaliações dos resultados dependem de julgamentos do todo. O juízo de fronteira determina quais observações empíricas e considerações de valor são relevantes ou não ao sistema, de acordo com as reivindicações - afirmações ou sugestões que agregam relevância (sentido) e validade no processo de formação de opinião, resolução de problema, tomada de decisão, ação ou resolução de conflito. Para tanto, faz-se necessário avaliar o mérito da questão que seja relevante e aceitável àqueles preocupados com as consequências no mundo real.

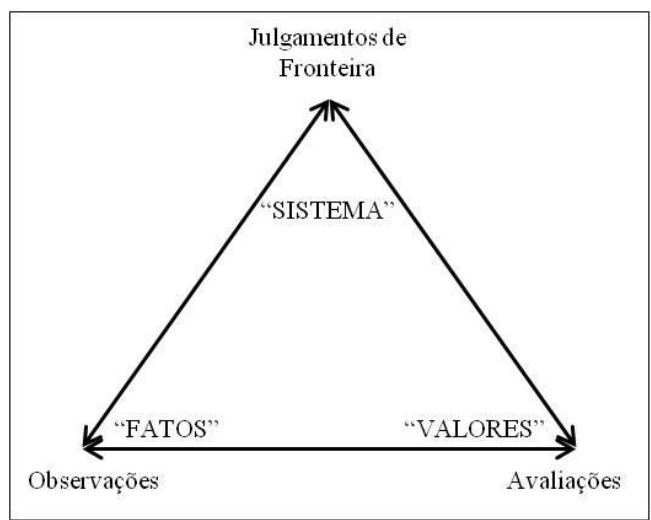

Figura 3.9 - O triângulo eterno de julgamentos de fronteira, fatos e valores (Ulrich, 1987)

A relação triádica observada na Figura 3.9, reforça a proposta de Ulrich (1987) de atitude reflexiva para observar os fatos, avaliar de acordo com os valores e realizar os julgamentos de fronteira sobre o sistema de referência.

O processo sistemático proposto por Ulrich (1987), para a crítica de fronteira, inclui os seguintes aspectos:

- identificação das fontes de reivindicação; 
- exame dos juízos de fronteira com relação às implicações éticas e práticas;

- identificação das opções para a determinação do sistema de referência;

- busca da compreensão mútua entre os stakeholders; e

- quando alguma parte coloca seu próprio julgamento de fronteira de forma não crítica, seja porque estão muitos seguros, seja por pura imposição, é necessário desafiá-los por meio da crítica de fronteira emancipatória.

As abordagens sistêmicas críticas incorporam fundamentos teóricos críticos que buscam compreender situações que envolvem desigualdades, interesses distintos, conflitos e contradições. Tal fato se deve a busca da ampliação do conhecimento e de possibilidades de intervenção em organizações sociais (Garrossini, 2010).

A Heurística Sistêmica Crítica (termo originário do inglês, Critical Systems HeuristicCSH), concebida por Ulrich (1987), é um sistema de análise que nos permite compreender as relações entre os atores envolvidos, abrindo as fronteiras para que se busque o entendimento das relações entre atores (Garrossini, 2010). Os atores são considerados parte ativa de um determinado contexto e poderão alterar sua percepção em razão das condições materiais, acesso à informação e conhecimentos.

De acordo com (Ulrich, 1987), os passos almejados para aplicar a CSH, são:

a. identificar as fontes de seletividade (o que faz parte do sistema);

b. examinar os julgamentos de fronteira e suas implicações práticas e éticas (determinar o sistema);

c. encontrar alternativas para o sistema de referência (à luz de novas opções);

d. procurar compreensão mútua entre os envolvidos, sobre os sistemas de referência; e

e. questionar as demandas por meio do uso irrestrito da crítica de fronteira.

A Heurística Sistêmica Crítica prevê que o sistema deve ser visto de duas formas: o modo "como é" (fonte de seletividade empírica) e o modo "como deve ser" (fonte de seletividade normativa). As doze categorias críticas da heurística estão dispostas no Quadro 2.A Anexo A.

Ulrich (1987) propõe uma mudança de perspectiva na determinação das fronteiras de um sistema baseado em dois critérios: 
- todos os aspectos não compreendidos devem ser considerados parte do sistema até que sua importância tenha sido elucidada e;

- a investigação das questões de delimitação não deve ser restrita ao 'é' mas precisa sempre incluir o 'deve ser'.

Uma proposta de intervenção sistêmica total (termo originário do inglês, Total Systems Intervention-TSI) foi concebida por Jackson (1991), para lidar com sistemas críticos. A implementação da TSI é constituída de três fases (Jackson, 1991, p. 276): criatividade utilização das metáforas sistêmicas, escolha - definição da metodologia sistêmica de intervenção, e implementação - ação intervencionista com base na abordagem metodológica escolhida.

O principal propósito da TSI é tornar propícia a investigação sistêmica por meio de métodos sistêmicos de intervenção, especialmente quando se trata de cenários altamente complexos (Mingers, 1997).

\subsubsection{5 - Modelo de Viabilidade de Sistemas}

O Modelo de Viabilidade de Sistemas (termo originário do inglês, Viable Systems ModelVSM), desenvolvido pelo pesquisador e consultor britânico Stafford Beer, é talvez o mais conhecido exemplo de um modelo que lida com a resiliência e de como tornar as organizações viáveis. Ele encoraja a abordagem holística e integrada para as organizações, provendo grande clareza de pensamento (Jackson, 2013).

Dentre as abordagens de desenvolvimento da Teoria Geral de Sistemas, Mele et al. (2010) destacam que o modelo de sistema viável concentra-se em ferramentas conceituais para a compreensão da organização dos sistemas, a fim de alcançar os seguintes propósitos: i) gestão da mudança; ii) entendimento da organização como um todo integrado; e iii) avaliação das funções essenciais de implementação, coordenação, controle, inteligência e política. Para caracterizar o sistema de interesse no modelo de viabilidade de sistemas, Espejo et al. (1996, p. 49) propõem uma ferramenta para identificação dos seguintes aspectos TASCOI ${ }^{6}$ :

\footnotetext{
${ }^{6}$ TASCOI - Transformations, Actors, Suplliers, Customers, Owners e Interveners (ESPEJO et al. (1996, p.
} 49). 
- Transformações: identificar os insumos que serão transformados em quais resultados.

- Atores: identificar quem cumpre as atividades necessárias para a transformação.

- Fornecedores: identificar quais são, ou seriam, os fornecedores dos insumos necessários.

- Clientes: identificar quais são, ou seriam, os clientes imediatos para os produtos da transformação.

- Proprietários: identificar quem tem a capacidade de ter a perspectiva geral dessas transformações.

- Interventores: identificar quem define, ou definiria, o contexto (ambiente) para a transformação.

O VSM é fundamentado nos pressupostos da cibernética, particularmente com o propósito de tornar o sistema e seus subsistemas comunicáveis e controláveis. O movimento da Cibernética, liderado por Norbert Wiener, originalmente pretendia estudar os autocontroles encontrados em sistemas estáveis, sejam eles mecânicos, elétricos ou biológicos (Espejo et al.,1996; Jackson, 2003).

Segundo Vasconcellos (2013), na terceira geração da cibernética, é possível estudar os sistemas a partir da grande variedade de influências externas e internas que impendem com que sejam abordados analiticamente o problema, cuja variedade de um sistema é definida como sendo o número de estados possíveis que o mesmo pode exibir em função do propósito pelo qual é examinado. Portanto, o sistema passa a ser tratado como caixa preta, onde a complexidade do sistema é relativa ao observador. Tal comportamento é retratado por Espejo et al. (1996) e por Rizzoli e Schlindwein (2012), como parte da Lei da Variedade Requerida de Ashby (1970).

O modelo VSM possibilita entender a viabilidade da organização do ponto de vista sistêmico. Parte do pressuposto de que um sistema só pode ser considerado viável se for capaz de responder a mudanças ambientais, previstas ou imprevistas, capaz de ter uma existência independente e que lhe permita autonomia. Esse modelo aplica a cibernética a qualquer tipo de organização e se baseia em leis de viabilidade, segundo as quais uma organização só pode ser considerada viável se possuir cinco subsistemas com inter- 
relações específicas (Espejo et al.,1996; Jackson, 2003; Rizzoli e Schlindwein, 2012). A Figura 3.10 apresenta uma perspectiva visual do VSM com seus subsistemas.

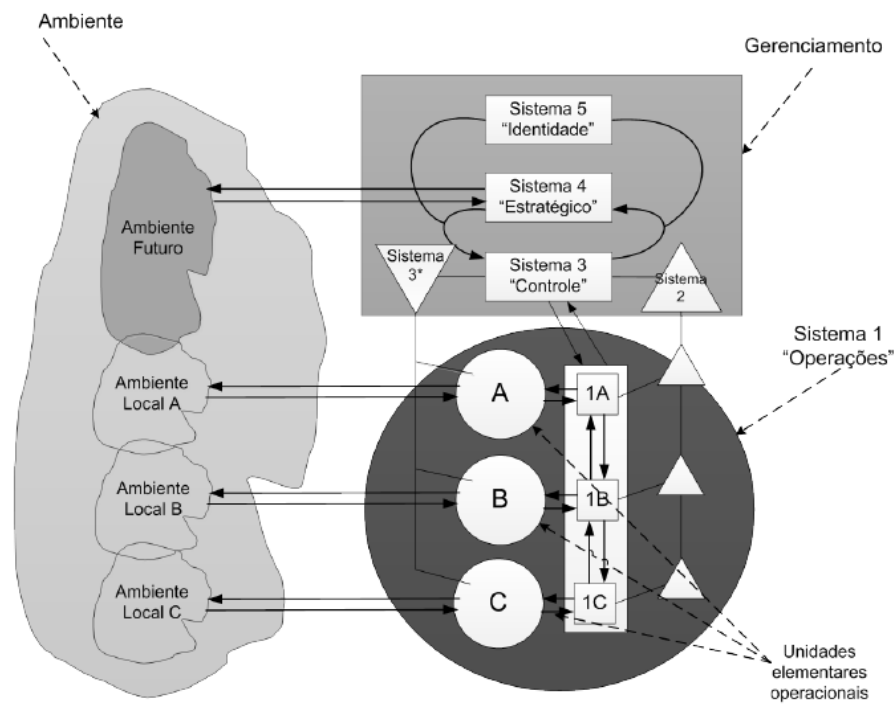

Figura 3.10 - Visão Geral do VSM

(Rizzoli e Schlindwein, 2012)

\subsubsection{6 - Abordagens Multimetodológicas}

A metodologia é um conjunto estruturado de orientações ou atividades para ajudar as pessoas na realização de uma pesquisa ou intervenção (Mingers e White, 2010). Dificilmente se encontrará uma única metodologia que possa atacar e lidar com todos os aspectos da complexidade. O desafio é conseguir uma metodologia que permita combinar metodologias capazes de reunir o conhecimento que poder ser útil na criação de soluções que funcionem. Trabalhar com uma variedade de metodologias de sistemas ao mesmo tempo é teoricamente adequado, mas, objetivamente, bastante difícil de gerir na prática (Jackson, 2013; 2003).

Existe um movimento importante dentro da pesquisa operacional em direção ao emprego concomitante de paradigmas e metodologias da PO tradicional e da PO flexível (Jackson, 2003; Munro e Mingers, 2002). O emprego de uma abordagem multimetodológica, resultado da combinação de métodos e técnicas com enfoque sistêmico, é visto como um foco importante para que o futuro das pesquisas operacionais flexíveis e da estruturação de problemas se desenvolva de forma robusta (Jackson, 2003; Seagriff e Lord, 2009). 
Com o surgimento de métodos e práticas sistêmicas flexíveis, várias possibilidades de aplicação dessas abordagens têm sido experienciadas (Jackson, 2003). A partir de uma extensa revisão bibliográfica, Howick e Ackerman (2011) argumentam que a combinação de métodos com enfoque sistêmico vem ganhando interesse na estruturação de problemas há mais de duas décadas. Contudo, pouco se tem produzido sobre a combinação de métodos na prática.

Ainda que exista uma farta publicação de casos empregando múltiplas abordagens sistêmicas, Howick e Ackerman (2011) advertem, com base no seu estudo, que há uma grande diversidade de combinação de métodos. Todavia, perceberam a falta de critérios bem definidos ou um paradigma sobre como e porque utilizar diferentes métodos na pesquisa operacional.

Embora existam diversos métodos disponíveis sob enfoque sistêmico, poucas são as pesquisas empíricas que de fato mostram como eles podem ser combinados e colocados em prática. Ainda assim, a abordagem multimetodológica é facilitadora no sentido de estruturar rapidamente problemas, analisar alternativas de projetos de processos e especificar a implementação de soluções de sistemas (Small e Wainwright, 2014).

Adicionalmente, Mingers e Blocklesby (1997, p. 492) apresentam quatro argumentos em favor da abordagem multimetodológica: (i) que as situações-problema do mundo real são inevitavelmente complexas e multidimensionais, (ii) uma intervenção não é geralmente um evento simples e discreto, mas um processo que acontece tipicamente por meio de estágios, (iii) uma análise mais aprofundada dos aspectos filosóficos e teóricos da abordagem multimetodológica é oportuna uma vez que muitas pessoas já estão combinando metodologias na prática, e (iv) argumentos de uma perspectiva pós-moderna também suporta o pluralismo na metodologia.

Jackson (2003) propõe três fases na seleção de uma abordagem multimetodológica: (i) criatividade - exploração inicial da situação; (ii) escolha - a seleção de uma ou várias metodologias específicas; e (iii) implementação - colocar as metodologias em prática. De acordo com Jackson (2013) e Mingers e White (2010), compreender os pontos fortes e fracos dos diferentes métodos que compõem cada metodologia é um passo importante, pois 
é a necessidade de refletir sobre os interesses que estão sendo desenvolvidos nas intervenções e estar preparado para usá-las de forma conjunta.

As múltiplas abordagens sistêmicas propiciam a adoção de uma diversidade de metodologias, que se diferenciam tanto em complexidade quanto em conteúdo. Dentre essas metodologias. Martinelli e Ventura (2006) destacam: pesquisa-ação, metodologia cibernética, sistemas indagadores, planejamento interativo, SAST (Strategic Assumption Surfacing and Testing), desenvolvimento e análise de opções estratégicas, heurística crítica para o pensamento social, CSH, Administração Evolutiva, SSM e VSM.

O resultado da pesquisa de Small e Wainwright (2014) mostra que através do uso da pesquisa-ação e do desenvolvimento de uma abordagem multimetodológica contextualizada, as partes interessadas dentro da organização podem participar no projeto de novos sistemas e mais rapidamente adotar tecnologias para abordar os problemas operacionais colocados pelas partes interessadas de forma mais sistêmica e inovadora.

A essência de uma abordagem multimetodológica é a associação das partes das metodologias participantes, combinadas por justaposição ou por aglutinação. Mingers e Blocklesby (1997) propõem um framework que combina as partes decompostas da SSM de Peter Checkland, com o CSH de Werner Ulrich e o VSM de Stafford Beer, além de outras ferramentas computacionais - CASE e COPE - vide Figura 3.11.

Georgiou (2012) propõe uma abordagem multimetodológica baseada na combinação do mapa SODA e a SSM. Um mapa SODA pode enriquecer a SSM, oferecendo um recurso metodológico para a estruturação de um grande número de transformações. O mapa ajuda a identificar as relações entre as transformações do sistema, suas hierarquias e prioridades, epicentros de problemas e pontos de partida para a intervenção - que servem para informar a maneira com que tais intervenções podem ser realizadas (Georgiou, 2012). 


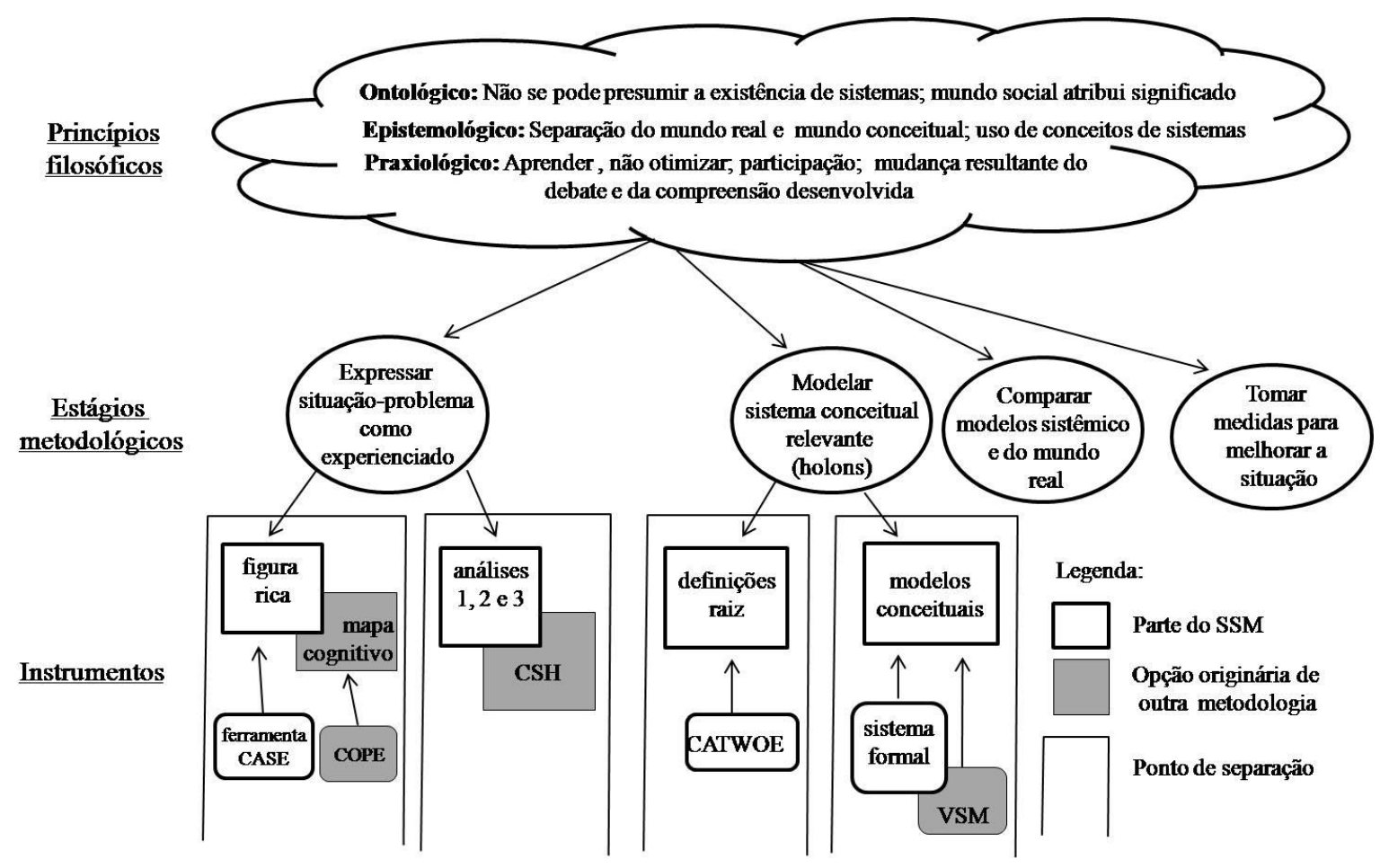

Figura 3.11 - Abordagem multimetodológica: SSM, CSH e VSM

(Mingers e Blocklesby, 1997)

Alguns exemplos de aplicação de abordagens multimetodológicas podem ser encontrados em Mingers e Rosenhead (2004). Dentre os casos descritos, um deles destaca o desenvolvimento de uma estratégia de TI para uma cadeia de supermercado - com adoção, de forma combinada, dos métodos SODA, SSM e SCA. Os autores apresentam também uma lista contendo dezenas de trabalhos, resgatados da literatura, com diversas experiências de aplicação de abordagens multimetodológicas (ibid., p. 541). Em mais de 80\% das aplicações divulgadas, a metodologia SSM é adotada.

\section{2 - FACES DO PROCESSO DE APRENDIZAGEM}

Esta seção cobre os seguintes tópicos:

- mecanismo de aprendizagem organizacional

- processo de tomada de decisão

- implicações da aprendizagem organizacional no processo de tomada de decisão

- apoio à decisão em cenários complexos 
O enfoque centrado na aprendizagem remonta importantes contribuições do pensador russo Lev Semenovitch Vygotsky, do epistemólogo suíço William Fritz Piaget, do antropólogo e filósofo Edgar Morin, e do educador brasileiro Paulo Freire. Cada um fundou uma escola de pensamento sobre o processo de desenvolvimento da aprendizagem com peculiaridades e singularidades que as tornam distintas e por vezes antagônicas, mas de igual importância para fundamentar o conhecimento e a epistemologia do saber. Uma das importantes características que elas têm em comum envolve a condicionante apreciativa que antecedente e sucede uma ação ou mudança da percepção humana sobre a realidade.

A aprendizagem em contextos organizacionais tornou-se um tema que vem recebendo atenção de pesquisadores, acadêmicos e consultores nas três últimas décadas. Para IsidroFilho e Guimarães (2008) e Senge (2013), isso se deu em virtude da complexidade e instabilidade do ambiente em que as organizações estão inseridas, cuja demanda por novas competências para uma melhor resposta às pressões do meio justifica-se em função da necessidade de alcance e manutenção da vantagem competitiva.

A aprendizagem e o conhecimento são considerados por Gerritsen et al. (2013) como temas centrais para a gestão e governança de questões sociais complexas de um sistema organizacional.

O desenvolvimento da aprendizagem pode acontecer em diferentes níveis de acoplamento. Shrivastava (1983) defende a ação participativa dos níveis individual, social e organizacional, para a formação do sistema de aprendizagem organizacional. As comunidades de prática são outro nível que se junta aos anteriores para ampliar o escopo de atuação desse sistema (Lima, 2009; Wenger, 2000).

\subsection{1 - Mecanismo de Aprendizagem Organizacional}

Mecanismos de aprendizagem são arranjos e procedimentos utilizados por organizações para coletar, analisar, armazenar, disseminar e utilizar informações e conhecimentos necessários ao seu desempenho e de seus membros (Popper e Lipshitz, 2000). Para tanto, López, Peón e Ordás (2005) asseveram que tais mecanismos tenham que proceder a aquisição, distribuição e interpretação do conhecimento e registro da memória organizacional para suportar o processo de aprendizagem. 
Lipshitz, Popper e Friedman (2002) defendem que os estudos relacionados com mecanismos de aprendizagem em organizações são importantes para que a aprendizagem seja disseminada na organização como um todo. Igualmente, Bui e Baruch (2010) argumentam que as instituições são encorajadas a adotar uma perspectiva sistêmica para desenvolver estratégias e rotinas para alavancar a aprendizagem organizacional.

O desenconhecimento da dinâmica do sistema organizacional, com freqüência, impede que as políticas corporativas sejam adequadamente implementadas, desencadeando situações que, ao resolver problemas importantes, falham, pioram o problema, ou criam novos problemas (Sterman, 2000). Diante de tal situação, a função de coordenação constitui-se em um fator habilitador para a aprendizagem organizacional (Lima, 2009).

A formação das redes sociais pressupõe a existência de uma organização e de uma estrutura tipicamente de natureza sistêmica (Maturana e Varela, 2001), que são a fundação para a fruição do conhecimento e da aprendizagem individual e organizacional. Senge (2013, p.27) assevera que as organizações estão criando mais redes, o que enfraquece as hierarquias tradicionais da administração e potencialmente abre novos espaços para o aprendizado, a inovação e a adaptação constante.

Ainda que os mecanismos de aprendizagem em organizações sejam necessários, não são suficientes para que ocorra aprendizagem em ambiente organizacional (Lipshitz, Popper e Friedman, 2002). Para que o processo de aprendizagem seja efetivo, além dos aspectos associados a cada dimensão de aprendizagem organizacional, há outros fatores que poderão influenciar o seu desenvolvimento.

Para desenvolver a aprendizagem organizacional, Senge (2013) propõe um mecanismo baseado em cinco disciplinas, para contemplar a configuração e a dinâmica organizacional. São estas as disciplinas: domínio pessoal, modelo mental, aprendizagem em equipe, visão compartilhada e pensamento sistêmico.

Partindo das bases conceituais que norteiam as cinco disciplinas de Peter Senge (Senge, 2013), Bui e Baruch (2010) propõem um mecanismo baseado na definição de fatores antecedentes, consequentes e moderadores, para a alavancagem da aprendizagem 
organizacional no contexto educacional. O Quadro 3.2 apresenta tais fatores e as respectivas vinculações com o modelo das cinco disciplinas de Senge (2013).

Quadro 3.2 - Fatores de alavancagem de aprendizagem organizacional

(Bui e Baruch, 2010)

\begin{tabular}{|c|c|}
\hline Fatores & Disciplinas do modelo de Senge (2013) \\
\hline \multicolumn{2}{|r|}{ Antecedentes } \\
\hline valores pessoais & domínio pessoal e visão compartilhada \\
\hline Motivação & domínio pessoal e visão compartilhada \\
\hline aprendizagem individual & domínio pessoal \\
\hline visão pessoal & domínio pessoal e visão compartilhada \\
\hline desenvolvimento e treinamento & domínio pessoal e aprendizagem em equipe \\
\hline comprometimento organizacional & modelo mental \\
\hline comprometimento da equipe & aprendizagem em equipe \\
\hline Liderança & $\begin{array}{l}\text { modelo mental, aprendizagem em equipe, visão compartilhada e } \\
\text { pensamento sistêmico }\end{array}$ \\
\hline cultura organizacional & $\begin{array}{l}\text { modelo mental e aprendizagem em equipe, visão compartilhada e } \\
\text { pensamento sistêmico }\end{array}$ \\
\hline estabelecimento de metas & aprendizagem em equipe \\
\hline Competência & pensamento sistêmico \\
\hline \multicolumn{2}{|r|}{ Consequentes (Resultados) } \\
\hline desempenho individual e sucesso & domínio pessoal e visão compartilhada \\
\hline auto-eficácia & domínio pessoal \\
\hline equilíbrio trabalho-vida pessoal & domínio pessoal \\
\hline compartilhamento de conhecimento & modelo mental e aprendizagem em equipe \\
\hline desempenho da equipe & modelo mental e aprendizagem em equipe \\
\hline sucesso organizacional & visão compartilhada e pensamento sistêmico \\
\hline \multicolumn{2}{|r|}{ Moderadores } \\
\hline políticas de recursos humanos & domínio pessoal e pensamento sistêmico \\
\hline tamanho - espaço ocupado & visão compartilhada \\
\hline setor público ou privado & domínio pessoal e aprendizagem em equipe \\
\hline sistemas de comunicação & modelo mental, aprendizagem em equipe e visão compartilhada \\
\hline ambiente de aprendizagem & modelo mental e aprendizagem em equipe \\
\hline
\end{tabular}

As perspectivas sistêmicas da aprendizagem social implicam o modo de desenvolvimento dos níveis individual, de comunidades de prática e organizacional. Deste último nível é esperado que se desenvolvesse uma aprendizagem tal que permita participar de sistemas de aprendizagem mais amplos até alcançar o nível de ecossistema de aprendizagem (Wenger, 2000).

A aprendizagem organizacional é um fator crítico para a formulação de estratégias e mudanças organizacionais mais amplas. Para aumentar a capacidade de aprendizagem da organização, deve-se estimular o aumento da participação na tomada de decisão e melhorar a comunicação entre os decisores (Shrivastava, 1983). 


\subsection{2 - Processo de Tomada de Decisão}

A tomada de decisão é o momento de definição consciente ou de sublimação. Inclui o ato da decisão, seus aspectos antecedentes e consequentes. Há inúmeras abordagens empregadas para modelar o processo decisório. Desde Peter Simon, anos sessenta em diante, diferentes métodos foram propostos com o intuito de promover análises de decisão hard e soft para se buscar soluções "ótimas" ou "subótimas" e "robustas", respectivamente.

O processo decisório é parte de um sistema de relações que congrega elementos de natureza objetiva e elementos de natureza subjetiva. Desse modo, se por um lado a objetividade é requerida, especialmente quando se trata de ações programadas (Simon, 1979), por outro, a atividade humana, sustentada na noção de valor, é um elemento característico da subjetividade do decisor (Pereira, Lobler e Simonetto, 2010, p. 268).

A falta de acesso à informação em tempo hábil é considerada um pesadelo para os tomadores de decisão. No entanto, o problema do decisor contemporâneo não é obter, mas interpretar a informação, transformando dados comuns em informações úteis por meio de um sistema de aprendizagem confiável (Pereira e Fonseca, 2009, p. 27).

De acordo com os preceitos do paradigma tradicional de análise, a teoria de decisão é o estudo dos paradigmas subjacentes à tomada de decisão e seus fundamentos analíticos. É uma abordagem analítica e sistemática para o estudo de tomada de decisão que permite enfrentar problemas (Render, Stair e Hanna, 2012).

Os modelos de decisão propostos desde as contribuições pioneiras de Herbert Simon (Simon, 1972) até a contemporaneidade, baseiam-se na estruturação de um processo decisório subjacente e na necessidade de buscar uma melhor compreensão do real comportamento humano no processo de tomada de decisão e na resolução de problemas dentro das organizações.

Nesse contexto, as informações têm um papel fundamental, possibilitando tornar mais rápida a percepção das mudanças, facilitando a tomada de decisão e alavancando um reposicionamento dos negócios com maior rapidez e agilidade de resposta às novas necessidades. 
Um importante desafio para o tomador de decisão é conservar a natureza intrínseca de um problema para que ele consiga buscar uma solução consistente. Russell L. Ackoff destaca que ao lidar com uma situação problemática, um tomador de decisão deve desenvolver um conceito, seja por meio de uma representação ou de um modelo, de modo que consiga resolver o problema tal como é concebido (Ackoff, 1987).

A decisão compreende três fases principais: i) descobrir as ocasiões em que deve ser tomada, ii) identificar os possíveis cursos de ação, e iii) decidir-se entre um deles. Os executivos empregam grande parte do tempo estudando o ambiente econômico, técnico, político e social, procurando identificar condições novas que exijam novas ações. A maior parte do tempo é gasta com a identificação e a prospecção dos possíveis cursos de ação, restando uma pequena fração do tempo decidindo entre medidas alternativas, já tomadas para solucionar problemas já identificados e analisados em suas consequiências (Simon, 1972).

Bernroider e Schmoller (2012) alertam que existe grande carência de pesquisa sobre a compreensão de métodos postos em prática e a ação dos fatores de promoção e propagação que levam a uma maior satisfação na tomada de decisão.

\subsection{3 - Apoio à Decisão em Cenários Complexos}

A tomada de decisão está intimamente vinculada com o processo de mudanças. Pereira e Fonseca (2009) destacam que o sentimento de ameaça pela mudança dificulta a adoção de novas ideias, especialmente quando se trata de mudanças transformativas, enigmáticas e paradigmáticas. Os autores entendem que é preciso desafiar o sistema conceitual prevalente para não correr o risco de torná-lo fator de resistência às mudanças e mais restrito será o seu contexto na tomada de decisão.

A abordagem analítica de tomada de decisão procura modelar o processo decisório sob diferentes estágios ou etapas de análise (Gomes, 2007; Lira et al., 2007; Render, Stair e Hanna, 2012; Simon, 1979; Shimizu, 2010). Quando Render, Stair e Hanna (2012) asseveram que a análise quantitativa é a abordagem científica para tomada de decisão gerencial, significa que a preocupação está centrada nos testes de hipóteses e nos modelos de análise de decisão reducionistas. 
Em contrapartida, o modelo sistêmico organiza e clareia as percepções, possibilitando análises mais consistentes das alternativas, escolhas mais adequadas e avaliações mais objetivas das consequências (Pereira e Fonseca, 2009). Ainda que se constitua em um fenômeno estritamente individual, a decisão humana é complexa porque seus efeitos se estendem por todos os sistemas sociais envolvidos. Os critérios de escolha para tomada de decisão nesse cenário devem ser compartilhados, transdisciplinarmente, pelos decisores para propiciar a reflexão plural dos princípios norteadores da investigação em curso.

Diante de cenários complexos, os métodos oriundos da pesquisa operacional e esperança matemática - baseada nos métodos estatísticos, heurísticas e arquétipos diversos - não conseguem se desvencilhar das armadilhas das condicionantes multivariadas e multifacetadas dos contextos de análise sempre presentes em um sistema organizacional (Gomes, 2007; Von Winterfeldt e Fasolo, 2009). Isso ocorre principalmente no âmbito das decisões estratégicas e táticas do meio corporativo e devido à existência de cenários complexos ou caóticos fortemente caracterizados pelas incertezas do ambiente e pela tempestividade inerente aos elementos condutores do negócio (Shimizu, 2010).

Um dos fatores menos evidentes, que torna difícil a decisão nas ações humanas, é a complexidade do mundo moderno. Vivendo no meio dessa complexidade, estamos mais condicionados a ela, mas nossos embaraços começam quando as circunstâncias geram decisões cujas consequências consideramos importantes. Assim, para resolver problemas complexos, o número de soluções possíveis é tal que uma simples declaração de preferência é inadequada (Kaufmann, 1968).

Simon (1979) sustenta que o processo de tomada de decisão em uma organização é complexo devido à dinâmica de sistema que o caracteriza. Os problemas de decisão são considerados complexos quando compreendem vários elementos ou aspectos distintos, cujas múltiplas formas possuem relações de interdependências, dificultando sua clareza e entendimento. Para esclarecer o momento de apropriação de procedimentos de análise, Holloway (1979) representa o cenário típico para avaliação de problemas de decisão complexos, conforme Figura 3.12. 
O processo de tomada de decisão em cenários complexos parte do pressuposto de que se deve absorver a complexidade e não eliminá-la (Gharajedaghi, 2011; Snowden, 1999), uma vez observados os princípios de auto-organização e variabilidade sistêmica.

Enquanto a pesquisa operacional continua a desenvolver e propagar metodologias de tomada de decisão, a compreensão e consequente aceitação de metodologias na avaliação do ambiente complexo de tecnologia da informação, por meio da sua utilização na prática de negócios, permanece em um ritmo muito lento (Bernroider e Schmoller, 2012).

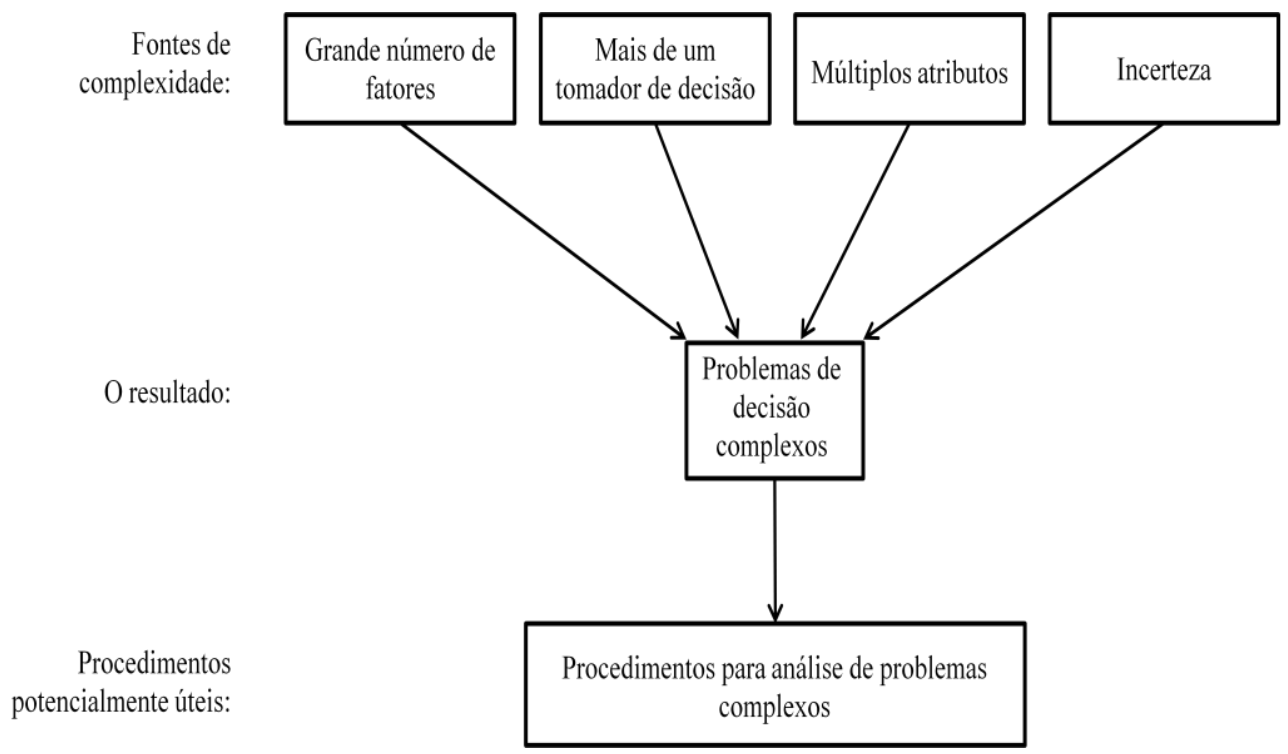

Figura 3.12 - Modelo de avaliação de problemas de decisão complexas

(Holloway, 1979)

Partindo de uma abordagem sistêmica, e considerando a natureza complexa das organizações sociotécnicas, o processo decisório é repleto de nuances e carregado de elementos idiossincráticos. Para Pereira e Fonseca (2009, p. 45) o processo decisório é sistêmico e integrado, envolvendo todo o nosso ser - em suas dimensões lógica, biológica e psicológica. Modificar uma posição exige esforço.

A terceirização dos serviços de TI é um fenômeno inerentemente complexo por envolver questões sistêmicas e orgânicas. Para compreender a natureza do problema de terceirização que emerge de uma instituição pública, por exemplo, Silva, Lima e Molinaro (2013) elencam múltiplos critérios que devem ser observados para se ter uma dimensão de análise mais adequada. 
Inspirado no trabalho de Capra (1982), Pereira e Fonseca (2009) relacionam os critérios para a tomada de decisão nos cenários da contemporaneidade, marcados pela turbulência, alto grau de incertezas e exposição a riscos desconhecidos:

- transitar da visão mecanicista do mundo, contemplada pelo reducionismo da metodologia científica cartesiana, para uma visão ecológica e sistêmica de todos os fenômenos (Capra, 1982; Vasconcellos, 2013; Maturana e Varela, 2001; Moraes, 2004);

- $\quad$ superar a visão do corpo humano como uma máquina (Ashby, 1970; Beer, 1984; Espejo et al., 1996; Morgan, 1982), para uma concepção integrada do ser humano;

- passar de um sistema de valores baseado na dominação e na luta competitiva para sobreviver, para outro sistema de valores baseado em parceria, colaboração e reconhecimento da interdependência (Capra, 1982).

Com base nos trabalhos pioneiros de Thomas Saat, por meio do método AHP, uma nova abordagem para análise de decisão corporativa emerge com o propósito de tratar cenários que envolvam múltiplos critérios de avaliação e múltiplas alternativas. Com isso, os métodos de análise multicritério de decisão permitem avançar as fronteiras do contexto decisório para além dos modelos de análise lineares e reducionistas (Gomes, Araya e Carignano, 2011).

$\mathrm{Na}$ realidade das empresas, o processo de tomada de decisão é usualmente complexo. As decisões tomadas pelo negócio e pela TI devem ser orientadas pelos resultados desejados pela organização, de modo a contemplar as expectativas de seus stakeholders (Gomes, 2007). O responsável pela tomada de decisão em uma empresa necessita de um tipo de informação relacionado diretamente com o nível da tomada de decisão gerencial e a dimensão estrutural das situações decisórias existentes (O'Brien e Marakas, 2007). As situações decisórias podem estar inseridas em cenários complexos, tornando a análise multicriterial, nem sempre compreendidos estruturalmente.

\section{3 - ARQUITETURA DE SISTEMAS DE INFORMAÇÃO}

Esta seção cobre os seguintes tópicos:

- informação, tecnologia e sistemas de informação

- modelagem de sistemas de informação 
- ontologias para sistemas de informação

- $\quad$ sistemas de apoio à decisão

\subsection{1 - Informação, Sistemas de Informação e Linguagem}

Ao homem cabe a distinção das propriedades de um sistema por meio da informação. Em função desta, o homem atribui sentido e forma às partes integrantes e interagentes de um sistema. De acordo com Pereira e Fonseca (2009, p. 37), a informação é um instrumento de redução da incerteza. Paradoxalmente, o excesso de informações pode gerar mais incertezas, já que os seres humanos têm um limite biopsicocultural para processá-las (Maturana e Varela, 2001; Pereira e Fonseca, 2009).

Entende-se sistema de informação como um conjunto de informações sistematicamente estruturado, servindo a propósitos bem definidos (Lima-Marques e Lacerda, 2006). Operacionalmente, O'Brien e Marakas (2007) definem SI como sendo uma combinação de pessoas, hardware, software, redes de comunicação, recursos de dados e políticas e procedimentos que armazenam, restauram, transformam e disseminam informações em uma organização.

A disponibilidade de informação no mundo contemporâneo cria um desafio importante: a integração, a monitoração e a segurança das informações como forma de preservar ou desenvolver pessoas, negócios e recursos (Pereira e Fonseca, 2009, p. 27). Às tecnologias da informação cabe o provimento de suporte para a execução dessas atividades.

Em tese os sistemas de informação poderiam ser concebidos sem contar com a TI, mas na prática são fundamentados e altamente dependentes de tecnologias de informação e comunicação (Checkland e Holwell, 1998). Molinaro e Ramos (2011, p.50) vão além e entendem que a relação entre os Sistemas de Informação (SI) e a TI pode acontecer de duas formas: do ponto de vista dos SI, a TI passa a ser o suporte que promove o funcionamento dos SI; enquanto que sob o ponto de vista da TI, os SI são um componente que faz parte da TI. Para efeito desta pesquisa, adotar-se-á o primeiro ponto de vista, corroborando com o entendimento de Checkland e Holwell (1998) e McDonald (2005) sobre o papel preponderante do SI na interação da TI com os sistemas de atividades humanas. 
A complexidade objetiva dos negócios na atual conjuntura, tanto em termos da relação dinâmica que mantém com os ambientes externo e interno, como também pela dinamicidade e pela mutabilidade que os caracterizam individualmente, contrapõe-se à realidade global dos negócios, tipicamente indelével em termos de inovação e flexibilidade proporcionadas pela atuação da TI. Nesse contexto, Chan e Reich (2007) lembram que a natureza complexa do alinhamento de negócio e TI espelha a complexidade crescente das organizações em geral.

Para que esse alinhamento estratégico de negócio e TI seja efetivo, Affeldt e Vanti (2009) e Henderson e Venkatraman (1993) defendem que os resultados devem refletir o modo sistêmico de atuação organizacional, em que a TI influencia e é influenciada pelo negócio por meio dos sistemas de informação.

Porquanto, o alinhamento de TI é melhor descrito não como um fenômeno unidimensional, mas como um superconjunto de múltiplos alinhamentos componentes simultâneos que reúnem a estrutura da organização, a estratégia, o trabalho e a cultura em múltiplos (TI, unidade de negócios e corporativo) níveis, com todas as suas demandas inerentes (Affeldt e Vanti, 2009; Chan e Reich, 2007).

Para McDonald (2005), sistemas de informação é uma disciplina ativa, intervencionista que mobiliza informação e conhecimento para que as pessoas possam efetivamente tomar ações inteligentes e bem conhecidas em seu ambiente organizacional e social. Ao mesmo tempo em que está preocupada com a compreensão e formalização das áreas de atividade humana, também procura desenvolver sistemas baseados em TI, os quais intervêm responsavelmente naquelas áreas para o benefício de todas as partes interessadas.

Os três papéis fundamentais que um SI pode exercer em uma empresa dizem respeito ao suporte de seus processos e operações de negócios, suporte da tomada de decisão pelos seus empregados e gerentes e suporte das suas estratégias para vantagem competitiva (O'Brien e Marakas, 2007).

A informação é resultado da estrutura perceptiva do sujeito aliada ao contexto, sendo conceitual, instrumental, pactual e simbólica, além de condicionar as formas de relacionamento existentes no mundo atual. Já a comunicação, é um processo em via dupla, 
que decorre dos relacionamentos interpessoais ou da existência de redes de informação interativas. A informação só tem sentido se for conectada a outras. A informação é percebida, a comunicação é vivenciada. Há uma predominância da comunicação humana relacional do que propriamente verbal (Pereira e Fonseca, 2009).

Ainda segundo os autores (ibid.), se uma mensagem contém informação, diz-se que ela apresenta novidade. De outra forma, ao trazer apenas coisas conhecidas, é chamada de redundância. Quando a quantidade de informação é muito maior que a de redundância, ocorre o "caos perceptivo". Invertendo-se as proporções da relação, obtém-se o "tédio perceptivo absoluto".

Se por um lado as principais características da era da informação são a quantidade e a disponibilidade das informações, por outro as necessidades das pessoas em relação à informação mudam constantemente porque a percepção é individual e contingente. Além disso, a incapacidade para lidar com o excesso ou a falta de informação conduz ao mesmo sintoma crítico: a ansiedade. A ansiedade pela informação é um dos males do mundo moderno (Pereira e Fonseca, 2009, p.26).

De forma complementar, O'Brien e Marakas (2007) destacam as dimensões que asseguram a qualidade da informação, a saber: tempo, conteúdo e forma. Segundo os autores, os SI devem ser criados para produzir uma variedade de informações para atender às necessidades, que mudam constantemente, dos responsáveis pelas decisões de toda a organização.

A linguagem é o instrumento de comunicação que se manifesta verbal ou não verbalmente. $\mathrm{Na}$ sua forma verbal, pode assumir duas dimensões: denotativa e conotativa. De acordo com Pereira e Fonseca (2009, p. 36), lidar com o sentido denotativo é mais fácil porque envolve menos implicações emocionais. Independentemente da forma assumida, problemas emergem na linguagem (Maturana e Varela, 2001).

Linguagem é o que nos expressa, assim como aquilo que falamos. Nossos neurônios, genes e gestos, premissas compartilhadas e hábitos pessoais exprimem diariamente, enquanto falamos, muitas linguagens (Bringhurst, 2006). 
Toda reflexão, inclusive a que se faz sobre os fundamentos do conhecer humano, ocorre necessariamente na linguagem, que é nossa maneira particular de ser humanos e estar no fazer humano. Por isso, a linguagem é também nosso ponto de partida, nosso instrumento cognitivo e nosso problema (Maturana e Varela, 2001, p. 32). A linguagem poderia ser compreendida como, dialeticamente, produto e produtora da capacidade humana de construir significados (Correia, 2009).

Ao inserir a informação no contexto da linguagem, Pereira e Fonseca (2009) advertem que é difícil estabilizar a percepção quando há informações excessivas, desencadeando efeitos colaterais ao coordenador. Correia (2009) destaca que na filosofia da linguagem, ao se tentar demonstrar a importância do significado, chama a atenção para o fato de que em nossas interações construímos e compartilhamos coisas que vão além do formato aparente.

A apreensão da informação é uma função cognitiva superior, que se processa no âmbito da linguagem. Sempre que quisermos apreender mais informações do contexto em que estamos inseridos, teremos que ampliar as nossas habilidades perceptivas, porque o nosso modo de viver atual nos induz a um estreitamento perceptivo e a uma visão de mundo restrita e fragmentada (Pereira e Fonseca, 2009, p.26).

Pode-se afirmar, nesse sentido, que existe concordância sobre a participação fundamental da linguagem na cognição humana, sendo inclusive o seu diferencial. Entretanto, pode-se afirmar também a sua insuficiência para explicar toda a complexidade do processo de construção de significados (Correia, 2009).

Entre o observador, a linguagem e a sociedade se estabelece uma conexão não trivial, ou seja, uma relação triádica fechada, em que não de pode determinar quem foi primeiro, quem foi último e em que se necessita dos três para se ter cada um dos três (Von Foerster 1991).

$\mathrm{Na}$ tentativa de explicar a relação entre a linguagem e a construção de significados, Correia (2009, p. 253) argumenta que a linguagem seria a ponta de um "iceberg cognitivo espetacular", observado na comparação entre a brevidade da forma linguística e a riqueza da construção de significados correspondente, mas não explicaria, por si, o processo. 
Maturana e Varela (2001) explicam que o significado é uma reflexão do observador e não um elemento na linguagem ou no funcionamento da linguagem.

\title{
3.3.2 - Modelagem de Sistemas de Informação
}

O processamento das informações por um SI pressupõe sua codificação para posterior tratamento. Reduzir a informação a código e tratá-la adequadamente envolve muitos aspectos circunstanciais e contextuais. De acordo com Montenegro e Barros (1988, apud Pereira e Fonseca, 2009, p. 40),

\begin{abstract}
A maior parte das informações é processada ciclicamente e sofre diversas formas de tratamento (algumas inconscientes). De modo geral, guarda ligações muito tênues com seu momento de gênese. Se este ciclo não for visualizado ou compreendido o uso da informação fica contaminado pelas percepções, valores, condicionamentos, intenções e manipulações do decisor. (grifo nosso)
\end{abstract}

A constituição de um sistema de informação inicia pela sua modelagem. No entanto, só é possível constituir um sistema se conseguir distingui-lo (Vasconcellos, 2013).

A forma com que um SI é praticado pode ser observada na Figura 3.13, notadamente no ciclo iterativo constituído pela modelagem de sistemas, construção de sistemas e sistema de atividade humana (Mcdonald, 2005).

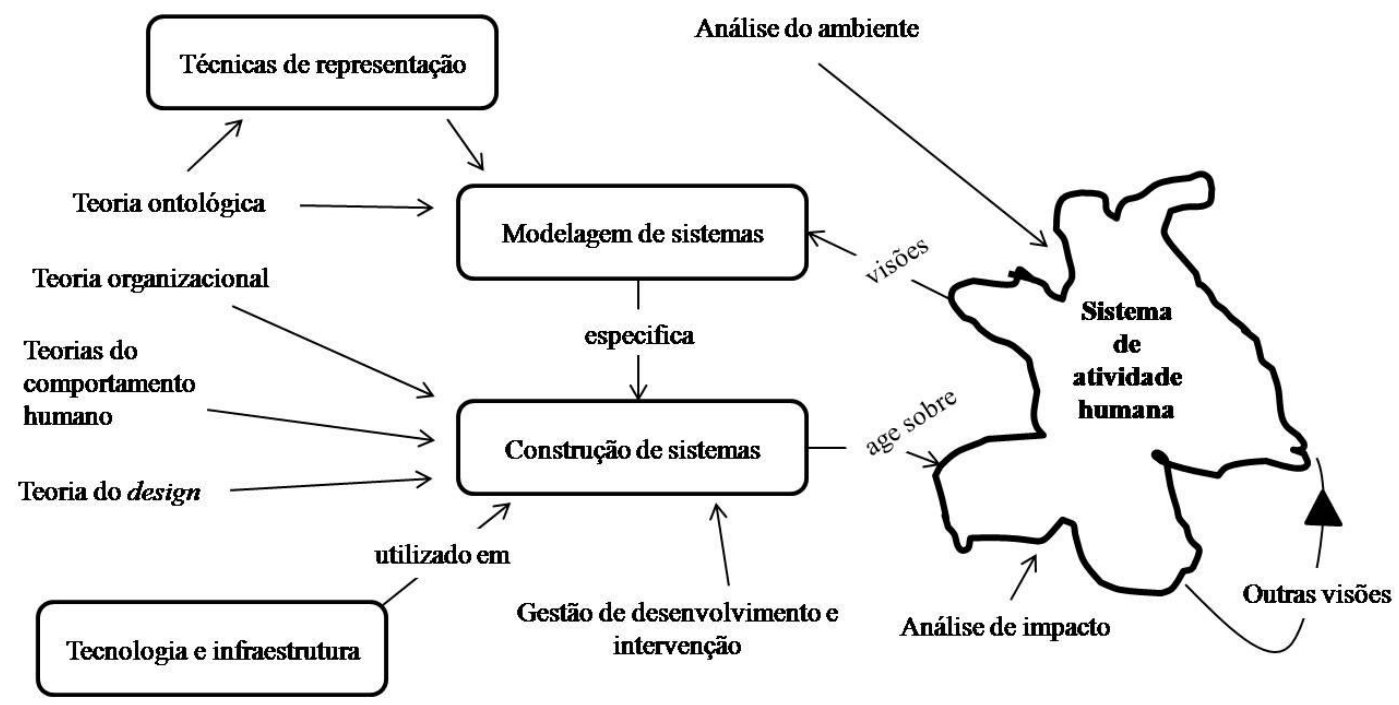

Figura 3.13 - Modelo genérico de atividade de um SI

(McDonald, 2005) 
Os componentes nas bordas da Figura 3.13 mostram algumas das teorias genéricas, ferramentas e técnicas utilizadas no processo de trabalho de um SI. As teorias e entendimentos de ontologia, comportamento organizacional, ética, e assim por diante, influenciam a prática de SI. A tecnologia da informação e infraestrutura são uma força motriz no processo de um SI, gerando um efeito específico sobre técnicas de representação e as possibilidades de especificação de sistemas (Mcdonald, 2005).

Na medida em que se desenvolve o SI, as contribuições do sistema de atividade humana são propiciadas pelo processo de aprendizagem sócio-cognitivo (Checkland e Scholes, 1998).

Um sistema de atividade humana pode ser analisado em diferentes níveis de granularidade, partido do nível pessoal, mais refinado, até ao nível social. A pesquisa em nível interpessoal envolve questões de motivação, personalidade, conhecimento e habilidade que o pesquisador individual traz para o seu trabalho. No nível social, a atividade humana consiste nas redes pessoais, os comportamentos públicos, normas e cultura que são exibidos por grupos de trabalho e colaboradores. Já em nível organizacional, os sistemas de atividade humana diz respeito aos processos, prestação de contas e estruturas de poder nas organizações. Por fim, o nível social aborda questões gerais sobre quem financia, e quem se beneficia de um sistema de atividade humana (Mcdonald, 2005).

Em qualquer campo de desenvolvimento vinculado com as mudanças de tecnologia, existe um relacionamento entre a descoberta e a exploração de possibilidades técnicas (prática) e o desenvolvimento do pensamento que atribui sentido aos acontecimentos (teoria). Com isso, o desenvolvimento de novas possibilidades tecnológicas tem sido muito mais rápido do que o desenvolvimento do pensamento sobre o sistema de informação, levando a desequilíbrio e confusão (Checkland e Scholes, 1998).

Nesse sentido, os autores propuseram um esquema de relacionamento tecnologia-práticateoria para a modelagem de um SI - vide Figura 3.14 - em qualquer campo onde a tecnologia é condutora do desenvolvimento, onde as mudanças são introduzidas na prática para depois serem apropriadas pela teoria. 
Quando uma nova teoria científica pode ser aplicada a certo campo da tecnologia, os homens são tão envolvidos quanto os objetos, o que muito frequentemente significa reavaliar a posição e o futuro das pessoas (Kaufmann, 1968). O progresso tecnológico, portanto, tem sempre tido repercussões importantes no sistema de atividade humana.

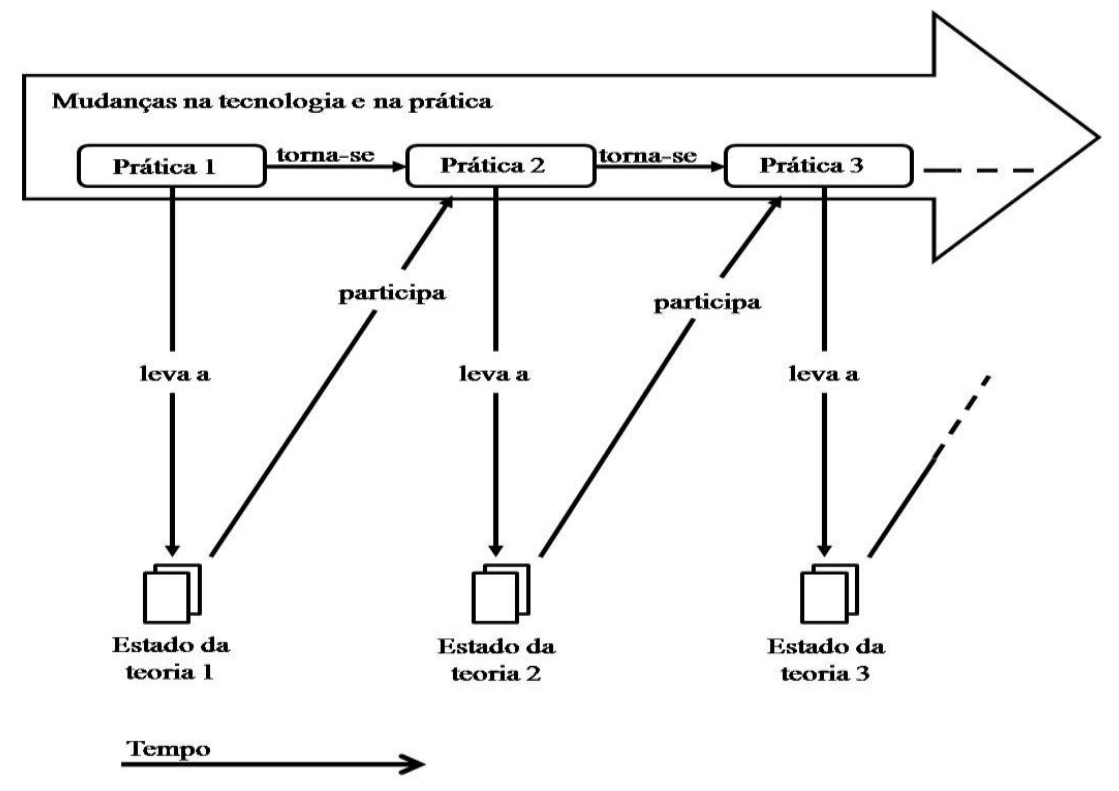

Figura 3.14 - Relação de forças da tecnologia, prática e teoria no SI

(Checkland e Holwell, 1998, p. 56)

Na prática os sistemas de informação estão sendo desenvolvidos para apoiar a tomada de decisão, quer seja como sistemas especialistas, quer seja como sistemas de apoio à decisão (Olson, 2001, p. 246). Para a tomada de decisão, os SI podem auxiliar ou apoiar a análise de problemas, contribuir par a visualização de assuntos complexos e criar novos produtos (Molinaro e Ramos, 2011).

Courtney (2001, p. 17) defende que as organizações e seus sistemas de apoio à decisão devem compreender os procedimentos que podem lidar com situações problemáticas perversas, de alta complexidade e interconectadas, que vão além da orientação técnica dos sistemas de apoio à decisão de outrora, cujas exigências eram menores e o escopo de atuação reduzido. 


\subsection{3 - Ontologias para Sistemas de Informação}

O desenvolvimento de sistemas de informação prescinde de uma abordagem ontológica, desde que se tenha clara e evidente os conceitos, suas relações e as formas de representálos. Na prática, a natureza das situações problemáticas e a complexidade do sistema determinado pelo problema, ou sistema de interesse, pressupõe uma ontologia, a qual orientará o desenvolvimento de sistemas. Dietz (2010) estuda o papel da ontologia no desenvolvimento de sistemas, em especial, os sistemas corporativos e de seus sistemas de informação de suporte.

O primeiro passo da atividade de modelagem conceitual de sistemas de informação é a transformação do mundo real percebido em um modelo do mundo que pretende representar (Soares e Fonseca, 2009). Há dois aspectos essenciais a considerar nessa modelagem: a organização e a estrutura.

O que é a organização de algo? Trata-se daquelas relações que tem de existir, ou têm de ocorrer, para que esse algo seja. Para que se julgue um objeto como sendo uma cadeira, é necessário que reconheça que certas relações acontecem entre as partes que se chama de pés, espaldar, assento, de tal maneira que é possível sentar nela (Maturana e Varela, 2001, p. 50).

Ontologia significa especificar explicitamente a formação de um conceito ou ideia de algo. Assim, a representação do mundo real, de um sistema ou de um ser qualquer pode ser feita por uma ontologia, que em última análise, poderá organizá-lo em conceitos explícitos. Soares e Fonseca (2009) deduzem a partir de uma proposição lógica que, se os sistemas de informação são modelos de sistemas do mundo real, então as descrições do mundo serão compatíveis com o nível de satisfatoriedade das ontologias construídas.

É simples apontar para uma determinada organização ao indicar os objetos que formam uma classe. Mas pode ser complexo e difícil descrever com exatidão e de modo explícito as relações que constituem tal organização (Maturana e Varela, 2001, p. 50).

Já a estrutura é a maneira como as partes de um todo estão dispostas entre si. É a estrutura de algo, unidade ou objeto, que determina como ela interage com o meio e que mundo configura (ibid, p. 99). 
A Ontologia contribui para a definição de um acordo semântico, ou vocabulário controlado, para superar circunstâncias idiossincráticas, as quais moldam a maneira de ver, sentir, reagir peculiar de cada pessoa. Para determinar o que se percebe e o que se faz, Maturana e Varela (2001) explicam que o modo de viver e as conversações que guiam esse viver são preponderantes. Ainda assim, Pereira e Fonseca (2009, p. 15) argumentam que a percepção é um processo muito complexo, sujeito a inúmeras variáveis. Mais que uma característica biológica, a percepção é um fenômeno cultural. Pessoas de diferentes culturas leem o mundo de maneira diferente porque percebem de maneira diversa, porque percebem a realidade de modo desigual.

Soares (2009) refere-se à construção do domínio de ontologia como um artefato para representar o conhecimento de um determinado universo de discurso para seu uso em modelagem de sistemas de informação, conforme destacado na Figura 3.15.

A proposta de desenvolvimento da ontologia corporativa de Dietz (2010) representa um ponto de partida para compreender o espaço organizacional de uma empresa e subsequentemente para analisá-lo, (re) projetá-lo ou (re) estruturá-lo.

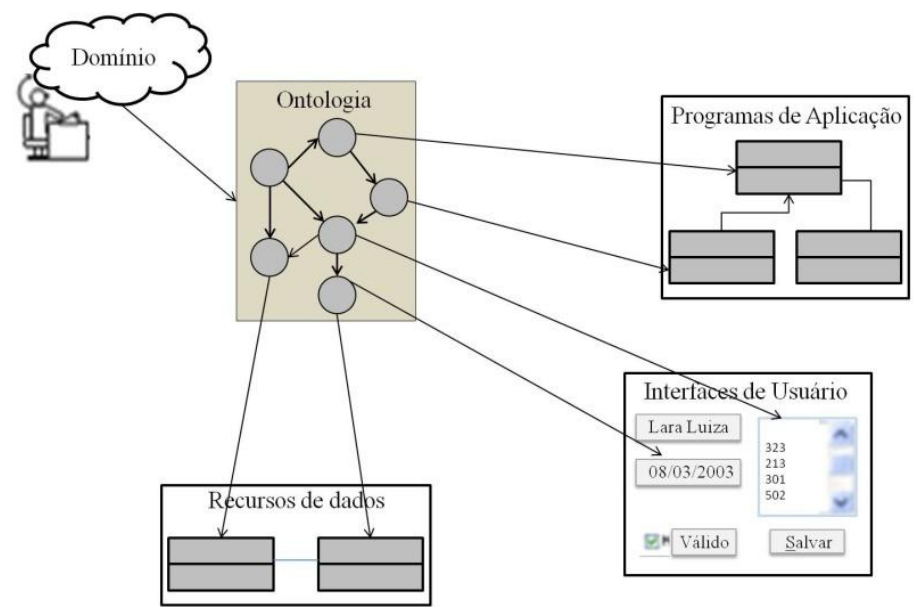

Figura 3.15 - Ontologia em destaque na concepção de um SI

(Soares, 2009, p. 21)

\subsection{4 - Arquitetura de Sistemas de Informação}

Enquanto a organização de um sistema é descrita por meio de uma ontologia, a sua estrutura é representada por meio de uma arquitetura (Dietz, 2010). Para gerenciar a 
complexidade de qualquer grande organização ou sistema, é necessária uma abordagem arquitetônica (Jonkers et al., 2004).

De acordo com o padrão IEEE $1471^{7}$, “Arquitetura é a estrutura fundamental de um sistema, incluindo seus componentes, suas relações entre si e com o meio ambiente, bem como o princípio norteador da sua concepção e evolução".

Já em relação à arquitetura de sistemas de informação, Vasconcelos, Sousa e Tribolet (2003) a definem como sendo a representação da estrutura de componentes de um SI, suas relações, princípios e diretrizes, com o objetivo principal de apoiar o negócio. O uso de arquiteturas é exigido quando se pretende construir um sistema de informação de grande porte, complexo, que abranja toda a empresa.

A arquitetura de um sistema de informação é concebida a partir de modelos que caracterizam suas propriedades e as diferentes etapas do ciclo de vida. Deve, portanto, retratar a gênese, a transformação, a consolidação e a comunicação da informação (LimaMarques e Lacerda, 2006).

Uma arquitetura de sistemas de informação geralmente distingue três aspectos, definidos na forma de subarquiteturas (Vasconcelos, Sousa e Tribolet, 2003; Zachman, 1987):

- arquitetura de dados: representa os principais tipos de dados que suportam os negócios;

- arquitetura de aplicação: define os aplicativos necessários para a gestão de dados e suporte aos negócios; e

- arquitetura tecnológica: representa as principais tecnologias utilizadas na implementação de aplicativos e as infraestruturas que fornecem um ambiente para a implantação.

O framework $\mathrm{TOGAF}^{8}{ }^{8}$ descreve a arquitetura corporativa por meio de um domínio com quatro arquiteturas, como segue:

\footnotetext{
${ }^{7}$ Padrão IEEE 1471 (IEEE Computer Society, 2000) - Conceptual Framework for Architectural Description
} 
- arquitetura de negócio: descreve quais os processos de negócio necessários para cumprir seus objetivos;

- arquitetura de aplicação: descreve como os aplicativos específicos são projetos e como interagem;

- arquitetura de dados: descreve como os armazenamentos de dados são estruturados e acessados; e

- arquitetura técnica: descreve as infraestruturas de hardware e software que suportam os aplicativos e suas interações.

A arquitetura corporativa aborda problemas relacionados aos sistemas organizacionais, contendo duas questões centrais (Zachman, 1987):

- complexidade do sistema: as organizações estão gastando cada vez mais para construir sistemas de TI; e

- alinhamento ineficiente do negócio: as organizações consideram cada vez mais difícil manter os sistemas de TI, sempre mais caros, alinhados às necessidades do negócio.

De acordo com as especificações do TOGAF®, as arquiteturas de aplicação e de dados compreendem uma arquitetura mais ampla - a arquitetura de sistemas de informação (Molinaro e Ramos, 2011). O domínio de arquiteturas foi concebido para enfrentar alguns problemas evidenciados pelo mercado nos últimos tempos, como segue: (i) sistemas de TI tornam-se incrivelmente complexos, com manutenção cada vez mais cara; (ii) informações de missão crítica inconsistentes, desatualizadas e/ou totalmente equivocadas; e (iii) cultura da desconfiança entre os lados social, comercial e tecnológico da organização.

Preocupado com o valor e a agilidade do negócio, Zachman (1987) propôs um framework de arquitetura de SI. Para tanto, a condição assumida é que a abordagem seja holística, considerando, explicitamente, todas as questões importantes de todas as perspectivas também importantes.

\footnotetext{
${ }^{8}$ The Open Group Architecture Framework (TOGAF) - Framework de Arquitetura Corporativa. Open Group Standard. <<Disponível em: http://www.opengroup.org/togaf/>>, acesso em <<10 de outubro de 2014>>.
} 
A arquitetura de SI de Zachman (1987) é uma estrutura lógica de classificação e apresentação dos modelos de um sistema organizacional relevantes para a respectiva gestão, bem como para o desenvolvimento dos seus produtos ou serviços. Nela, a representação da organização é desagregada por perspectivas e por dimensões - Figura 3.16. Cada perspectiva fornece uma visão da organização adequada a um determinado nível, nomeadamente o da visão, o da gestão, o da arquitetura, o da engenharia, o da implementação, o da subcontratação e, por fim, o do colaborador que é a realidade da organização em funcionamento.

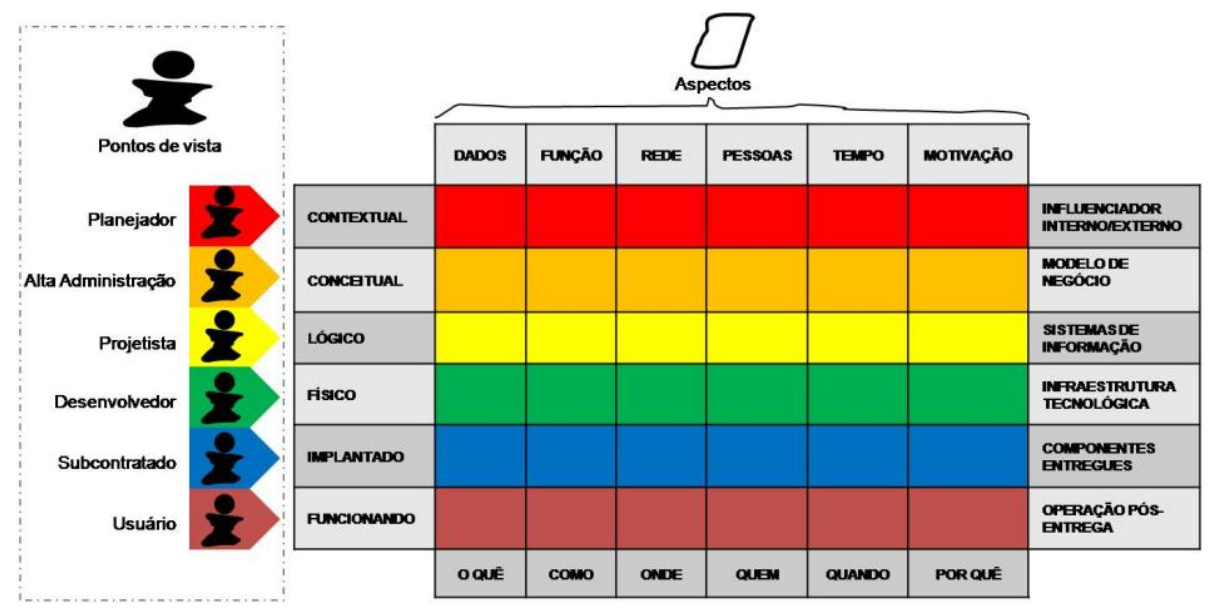

Figura 3.16 - Visão geral do framework de arquitetura corporativa de SI (Zachman, 1987, modificado) 


\section{4 - METODOLOGIA}

[...] podemos enfrentar o nosso tempo presente: o presente, ainda que custoso, pode ser vivido e aceito, se levar a uma meta e se pudermos estar seguros desta meta, se esta meta for tão grande que justifique a canseira do caminho (Bento $\mathrm{XVI}^{9}, 2013$, grifo do autor).

A falta de preocupação metodológica leva à condição de incapacidade profunda (Demo, 2014). Isso porque ao mesmo tempo que visa conhecer caminhos do processo científico, a metodologia também problematiza criticamente, no sentido de indagar os limites da Ciência, seja com referência à capacidade de conhecer, seja com referência à capacidade de intervir na realidade.

A metodologia é um dos polos paradigmáticos para a construção de um trabalho científico (Martins e Theóphilo, 2009, p. 4), cujo significado está atrelado ao estudo dos caminhos do processo científico e dos instrumentos usados para se fazer Ciência (Demo, 2014, p. 11).

O termo metodologia refere-se às análises relacionais e às suposições filosóficas que subjazem um estudo em particular. Para orientar as escolhas dos métodos usados para responder as questões de pesquisa é necessário descrever as suposições epistemológicas e ontológicas primeiramente (Moraes e Valente, 2008). Em termos práticos, a metodologia é um conjunto estruturado de orientações ou de atividades para ajudar as pessoas na realização de pesquisa ou intervenção (Mingers e Blocklesby, 1997).

Corbin e Strauss (2008, p.10) defendem que a metodologia é uma forma de pensar sobre a realidade social e de estudá-la, evidenciando os aspectos preponderantes das atividades humanas no contexto organizacional e permitindo esclarecer e ampliar a discussão sobre a práxis e a ação na prática para produzir novos conhecimentos.

A metodologia distingue-se dos métodos e técnicas, por considerar que estas últimas centram no trato da realidade empírica, enquanto para a primeira existe a intenção da discussão problematizante, a começar pela repulsa em aceitar que a realidade social se

\footnotetext{
${ }^{9}$ Enc. Spe salvi, 1. Papa Bento XVI. Migrações: peregrinação de fé e de esperança.
} 
reduza à face empírica (Demo, 2014). Nem por isso, a metodologia existe para se lançar apelo desesperado contra a ideologia, a autoridade, a infiltração estranha, mas para armar estratagemas conscientes de seu controle.

Segundo Thiollent (2002, p. 24), o objetivo da metodologia consiste em analisar as características dos vários métodos disponíveis, avaliar suas capacidades, potencialidades, limitações ou distorções e criticar os pressupostos ou as implicações de sua utilização.

Uma metodologia é um conjunto estruturado de diretrizes ou atividades para ajudar as pessoas na realização de pesquisa ou intervenção. Geralmente, a metodologia irá se desenvolver, de forma implícita ou explícita, dentro de um paradigma particular e vai incorporar os pressupostos filosóficos e princípios do paradigma (Demo, 2014).

Ao longo deste capítulo serão abordadas as questões preponderantes para o posicionamento metodológico da tese, ao mesmo tempo em que desenvolve as bases para a construção de uma orientação metodológica que guiará o processo de implementação do mecanismo de discussão e avaliação a ser discutido no próximo capítulo.

\section{1 - CONCEPÇÃO METODOLÓGICA}

Ainda há muita influência do método cartesiano de Descartes na produção do conhecimento científico. Muitas de suas regras são aplicadas, a exemplo da própria estruturação de um trabalho científico, bem como, na metodologia e mesmo nos objetivos específicos a serem alcançados para se obter o objetivo geral. Contudo, na contemporaneidade, são várias as referências metodológicas que temos. O que indica que hoje não há um método universal, como René Descartes propunha, mas, inúmeros a depender do objeto de estudo, assim, todos os objetos podem ser conhecidos, sejam eles de cunho qualitativo ou quantitativo (Becker, 2012), indutivo ou dedutivo, reducionista ou holístico.

Recentemente, alguns desenvolvimentos da própria Ciência, na microfísica, na termodinâmica, na física quântica, na cibernética, na biologia, levaram os cientistas a repensar seus pressupostos. Viram não um mundo estável, mas um mundo instável, em processo de tornar-se. (Vasconcellos, 2013). Superar, ir além da mera discussão sobre a distinção de conhecimento científico e outras formas de conhecimento - filosófico, 
religioso e senso comum (Demo, 2014; Vasconcellos, 2013) - para viabilizar o desenvolvimento de novas tecnologias, como as biotecnologias, as nanotecnologias, a biologia sintética e a computação quântica (Larrére, 2012).

Ao assumir que a Ciência não é o método, mas a realidade que não é evidente, nem coincidem completamente a ideia que temos da realidade e a própria realidade, Demo (2014) defende que somente em teoria se pode dizer que a Ciência é a interpretação verdadeira da realidade, porque na prática realiza apenas visão historicamente possível. Se por um lado o conceito de Ciência e seu critério de demarcação são reconhecidamente tão discutíveis, por outro ainda não há consenso sobre os dualismos de pesquisa qualitativa e quantitativa, subjetividade e objetividade, indução e dedução e holismo e reducionismo (Silvino, 2007, p. 278).

O pioneirismo sobre a discussão da quebra de paradigma na Ciência, o modelo de avanço científico se deve ao filósofo Thomas Kuhn. Os questionamentos a respeito do paradigma tradicional da Ciência começaram a surgir, no próprio domínio linguístico da Ciência, no início do século XX, com contribuições dos físicos Max Plank, Einstein, Niels Bohr, Boltzman, Heisenberg. Mais recentemente, sobretudo nas três ultimas décadas do século $\mathrm{XX}$, acrescentaram-se as contribuições de diversos outros cientistas, dentre os quais distingue o químico russo Ilya Prigogine, o físico e ciberneticista austríaco Heinz Von Foerster, o biofísico francês Henri Atlan, os biólogos chilenos Humberto Maturana e Francisco Varela (Aun, Vasconcellos e Coelho, 2012).

Há certa resignação por parte das Ciências quanto à discutibilidade dos paradigmas científicos. A epistemóloga Maria José Esteves de Vasconcellos argumenta que as Ciências aplicadas não incluem metodologia da pesquisa e produção do conhecimento científico, porque o paradigma fica implícito. Nas Ciências Básicas e Exatas, o paradigma de ciência já é incorporado a seu modelo de pesquisa e elaboração teórica, enquanto que as ciências básicas sociais costumam recusar o paradigma de ciência, considerado inaplicável a seu objeto de estudo (Vasconcellos, 2013).

A epistemologia exerce um papel de questionamento crítico dos fundamentos e princípios das diversas Ciências (Martins e Theóphilo, 2009), apesar de não ser demonstrável cientificamente por se tratar de uma concepção de mundo, um paradigma que orienta o 
modelo mental de uma pessoa ou comunidade (VASCONCELLOS, 2013), para compreender o processo de conhecimento subjacente, de modo a oportunizar o aprender a aprender.

Se nossa visão de mundo é constitutiva da consciência e determinada pela consciência diante dos fenômenos, podemos inferir que a relação entre o mundo empírico com o mundo racional é o mundo do fenômeno compreendendo por fenômeno tudo que aparece, que se manifesta ou se revela. Para Hegel tudo está no fenômeno, as coisas só existem para a consciência na medida em que se manifestam (Carneiro, 2006).

Para Vasconcellos (2013) assumir o paradigma epistemológico é uma condição necessária para a implicação de novas teorias. No entanto, Pereira e Fonseca (2009, p. 43) advertem que a difusão e aceitação de novas ideias constituem um processo complexo. Assim, diante de uma inovação com enormes implicações existenciais, como um novo modelo paradigmático de concepção de mundo, o tempo de adoção pode ser alongado, como por exemplo, o sistema heliocêntrico no lugar do geocêntrico.

A Ciência busca explicações para fenômenos naturais ou artificiais, sociais ou culturais, políticos ou históricos, psicológicos ou antropológicos. Com base nos experimentos científicos realizados por mais de vinte anos, Maturana e Varela (2001, p. 34) defendem que uma explicação é sempre uma proposição que reformula ou recria as observações de um fenômeno, em um sistema de conceitos aceitáveis para um grupo de pessoas que compartilham um critério de validação. Para os autores (ibid.), estas quatro condições devem ser satisfeitas na proposição de uma explicação científica: (i) descrição do fenômeno; (ii) proposição de um sistema conceitual capaz de gerar o fenômeno a explicar de modo aceitável; (iii) dedução, a partir do item (i), de outros fenômenos não explicitamente considerados em sua proposição; e (iv) observação desses outros fenômenos.

A maior parte dos cientistas ainda não fez a grande descoberta científica: a Ciência não é totalmente científica. A cientificidade é a parte emersa de um iceberg de não cientificidade, formada pelos pressupostos ou postulados. Por exemplo, o postulado do determinismo universal e o princípio da causalidade são indemonstráveis (Morin, 2011). 
Ao discutir sobre as dimensões do afazer científico, Vasconcellos (2013), reforça o aspecto nocional que deve estar presente na lide do pesquisador, em termos de epistemologia, teoria e prática - vide Figura 4.1. A dimensão epistemológica, também conhecida como paradigma ou pensamento, define o conjunto dos pressupostos e crenças de uma comunidade científica - compartilhados interdisciplinarmente; a dimensão teórica provê um conjunto de princípios explicativos para se estudar um fenômeno de interesse; e a dimensão prática busca refletir a ação do profissional e do cientista sobre esse mesmo fenômeno.

Mingers e Blocklesby (1997) defendem que a distinção entre paradigmas deve se basear em três dimensões filosóficas: ontologia, epistemologia e praxiologia. A ontologia diz respeito aos tipos de entidades que se pressupõem existirem e a natureza de sua existência; a epistemologia centra nas possibilidades e limitações do nosso conhecimento do mundo; e a praxiologia se ocupa em como devemos agir de modo esclarecido e reflexivo. Esta última dimensão é de particular importância para esta pesquisa, pois está principalmente preocupada com a estratégia de intervenção e ação.

Não é por acaso que se resgatam os pressupostos epistemológicos. Em termos práticos, Martins e Theóphilo (2009), destacam que os pesquisadores enfrentam problemas passíveis de serem solucionados com o subsídio das considerações epistemológicas.

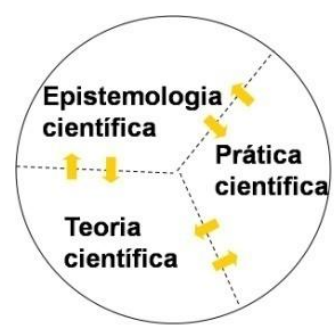

Figura 4.1 - Dimensões epistemológica, teórica e prática

(Vasconcellos, 2013)

Concepções metodológicas nas Engenharias são apropriadas, geralmente, pelos modelos teóricos sob a concepção positivista, cujo ideal de cientificidade e objetividade é visto como busca de imparcialidade para retratar as visões de todos os atores da situação. Há também um esforço na busca de consenso entre pesquisadores para evitar os excessos de subjetividade. Os princípios de explicação são assumidos no processo de argumentação (ou 
deliberação) para que os pesquisadores e os demais participantes cheguem a aceitar como resultados as informações que se revelam mais adequadas tanto do ponto de vista teórico como do prático (Thiollent, 1997, p. 30).

Devido a essa concepção paradigmática, que implica tanto na distinção e formação dos corpos de conhecimento que doutrinam cada disciplina científica, como na teorização de novos conhecimentos, ditos especializados, evidencia-se uma forte corrente de legitimação das abordagens do positivismo clássico de Comte e do neopositivismo contemporâneo do Círculo de Viena nos campos das Ciências Exatas, das engenharias e das demais Ciências. Tais movimentos teimam em ignorar e não aceitar as demais manifestações epistemológicas e ontológicas, as quais estão assentadas na filosofia da ciência - tais como a fenomenologia, o pragmatismo, o construtivismo e mais recentemente o sistemismo como se não houvesse critérios de cientificidade, senão aqueles validados pelos positivistas, em um verdadeiro processo de desqualificação da visão de mundo que todo e qualquer pesquisador deveria defender.

Embora se reconheça a importante contribuição da concepção positivista para o avanço da Ciência nos últimos quatro séculos, a impossibilidade de suportar a complexidade dos fenômenos, a intersubjetividade dos pesquisadores e atores do cenário sob investigação e a instabilidade decorrente de mudanças ambientais, implicam no surgimento de novas concepções paradigmáticas para o desenvolvimento da ciência sustentada em outros pressupostos epistemológicos. Uma lacuna observada por Thiollent (1997, p. 44) nas pesquisas de orientação positivista é a falta de mecanismos adequados para tratar problemas em termos práticos, implicando, por exemplo, de acordo com Freyle, Florez e Rincón (2013), na inadequada concepção de tecnologia da informação para implementar os sistemas de gestão de conhecimento.

Nesse contexto, a busca de objetividade na pesquisa consiste em limitar a parcialidade ao retratar os vários pontos de vista, sem omissão de nenhum deles (Demo, 2014; Thiollent, 2011). Os líderes devem aceitar que os subordinados não sejam apenas subordinados, mas colaboradores e atores sociais com visão e interesses próprios. Do mesmo modo, os colaboradores devem conhecer a visão dos líderes e chefes da organização. Não faz sentido procurar a opinião ou a representação média. A visão panorâmica é muito mais interessante 
que qualquer indicador sintético e é mais útil para planejar reformas ou quaisquer mudanças na organização (Thiollent, 1997, p. 31).

Para não ser confundido com qualquer outro tipo de conhecimento gerado pelo homem, o conhecimento científico é pautado pelos critérios de cientificidade. Os critérios de cientificidade, aqui apropriados, são decorrentes das posições assumidas por Demo (2014), Vasconcellos (2013) e Morin (2011), segundo os quais se devem tentar cercar a complexidade do fenômeno científico, sem poder esgotá-lo, até por uma razão lógica inerente. Com isso, Demo (2014, p.20) reconhece os seguintes critérios internos, próprios da ciência:

- coerência significa sua propriedade lógica;

- consistência significa a capacidade de resistir a argumentações contrárias;

- originalidade significa produção não tautológica;

- objetivação significa a tentativa, nunca completa, de descobrir a realidade assim como ela é mais do que como gostaríamos que fosse.

Já em relação aos critérios externos, que representa a vontade da comunidade científica em determinada época e lugar, serão adotados aqueles previstos para o cenário de complexidade sistêmica, assim enunciados por Vasconcellos (2013): instabilidade, complexidade e intersubjetividade.

O paradigma da instabilidade trabalha com a mudança e admite que não a controla. Ao reconhecer a instabilidade dos sistemas, foca nos vínculos afetivo-sociais, na mobilização dos recursos da rede e na criação de contextos de autonomia. Enquanto isso, o contexto da intersubjetividade reconhece parte do sistema e atua na perspectiva da coconstrução, adotando o caminho da "objetividade entre parênteses" de Maturana e Varela (2001), mantendo o foco nas conversações sobre diferentes versões e narrativas, coconstrução de planos e soluções viáveis, experiência de autoria e envolvimento com as mudanças (Vasconcellos, 2013). Já o paradigma da complexidade contextualiza o fenômeno e focaliza as interações recursivas, permitindo ver sistemas de sistemas, com foco nas relações, além de suportar o trabalho com sistema amplo, constituído em torno do problema. 
Adicionalmente, o paradigma da intersubjetividade estabelece a condição de construção de conhecimento do mundo, por meio do pensamento relacional, com a inclusão do observador, da auto-referência, e da significação da experiência na conversação e coconstrução (Vasconcellos, 2013).

Enquanto observadores, não se pode assegurar que estamos em condições de conhecer o necessário sobre o funcionamento de certo sistema que nos capacite a fazer previsões sobre ele. Nossa limitação decorre da incapacidade de observação (Maturana e Varela, 2001, p. 137). Se ao observar coletamos informações sobre o sistema e se atualmente a quantidade e a disponibilidade de informação crescem em uma progressão exponencial (Pereira e Fonseca, 2009, p. 37), a capacidade de processamento condicionará o poder de observação.

Há outro critério de cientificidade que não é interno nem externo por definição, pois está na fronteira de ambos, qual seja a discutibilidade, entendido como característica formal e política, ao mesmo tempo (Demo, 2014, p. 26). Ainda segundo o metodologista Pedro Demo, somente pode ser científico, o que for discutível. Isso traz duas implicações.

Do lado formal, significa:

- deve ser formalmente inteligível, lógico, bem sistematizado, competente em termos instrumentais;

- não deve levar à confusão, à indeterminação, mas à explicação, que permita aumentar o nível de compreensão da realidade; e

- dever ser criativo e disciplinadamente voltado para a realidade.

Do lado político, significa:

- não se colhem resultados definitivos, a não ser nas ilusões totalitárias;

- não há como separar teoria e prática; e

- o estudo dos problemas tem a ver com suas soluções.

Em síntese, Vasconcellos (2013) faz uma distinção importante sobre os pressupostos científicos na Ciência tradicional e na Ciência contemporânea. Por um lado, a Ciência tradicional preconiza a epistemologia filosófica - para fins de filosofia da ciência - e a epistemologia para a Ciência - para atuar cientificamente. Por outro, a Ciência 
contemporânea preconiza a epistemologia científica - para fins de ciência da ciência (Maturana e Varela, 2001) - e a epistemologia para a vida - para ver e agir no mundo.

Logo, a epistemologia aqui discutida visa representar uma fatia da pesquisa, de importância significativa na busca de um maior conhecimento sobre os objetos investigados. Destarte, para tratar a realidade social concebida como sistema, o método de captação empregado é o sistêmico (Demo, 2014, p. 17). De igual modo, para evidenciar as relações dialógicas dos atores contextualizados caberá o método dialético.

A menos que se pense com um novo marco de referência teórico, a probabilidade de se ver desanimado pelas dificuldades que encontra em investigar fenômenos complexos, geralmente impedem o pesquisador de fazer as coisas mais evidentes (Speck e Attneave, 1973). De acordo com Vasconcellos (2013), esse novo pesquisador deve fazer a ultrapassagem de alguns pressupostos tradicionais, tais como:

- o pressuposto da simplicidade do microscópico, assumindo o pressuposto da complexidade do mundo;

- o pressuposto da estabilidade do mundo, assumindo o pressuposto da instabilidade do mundo; e

- o pressuposto da objetividade, assumindo o pressuposto da intersubjetividade na construção do conhecimento.

\section{2 - ESTRATÉGIA DE PESQUISA}

A estratégia de pesquisa visa ao planejamento e estruturação da pesquisa em sua dimensão mais ampla, compreendendo tanto a orientação metodológica quanto à definição dos meios e recursos para análise e coleta de informações, dados e evidências (Martins e Theóphilo, 2009).

De acordo com a tipologia reconhecida por Demo (2014, p. 13), existem quatro gêneros delineáveis de pesquisa:

- metodológica, dedicada a indagar por instrumentos, caminhos, por modos de fazer Ciência, produzir técnicas de tratamento da realidade;

- teórica, dedicada a formular quadros de referência, a estudar teorias;

- empírica, dedicada a codificar a face mensurável da realidade social; e 
- prática, voltada para intervir na realidade social, conhecida por pesquisa participante, avaliação qualitativa, pesquisa-ação etc.

De certo modo, o trabalho aqui apresentado remete aos quatro gêneros, porque pretende combinar o ciclo de desenvolvimento de teoria-prática-teoria de Checkland e Holwell (1998) - ilustrado na Figura 3.12 (Seção 3.3.2) - especialmente orientada pela pesquisaação integrada (Morin, 2004; Thiollent, 2002, 1997), que prevê a intervenção na realidade dos sistemas organizacionais por meio de atividades de campo (empíricas), segundo o que preconiza a orientação metodológica e seu modelo de ciclo de vida com as atividades e recursos a serem empregados (Checkland e Holwell, 1998).

Com o intuito de promover o suporte empírico condizente com o modelo teórico da tese, levantaram-se métodos e ferramentas compatíveis com o fenômeno de pesquisa. Gil (2010) adverte que a investigação empírica é subsidiada pelos métodos e ferramentas disponíveis na literatura, coerentes com o objeto de pesquisa, o problema e os temas de interesse levantados.

\title{
4.2.1 - Pesquisa-Ação
}

De acordo com Thiollent (2002, p. 14)

\begin{abstract}
A pesquisa-ação é um tipo de pesquisa social com base empírica que é concebida e realizada em estreita associação com uma ação ou com a resolução de um problema coletivo e no qual os pesquisadores e os participantes representativos da situação ou do problema estão envolvidos de modo cooperativo ou participativo. (grifo nosso)
\end{abstract}

A pesquisa-ação é um tipo de investigação participante que tem como característica peculiar o propósito de ação planejada sobre os problemas detectados (Martins e Theóphilo, 2009, p. 72). Segundo Morin (2004), a pesquisa-ação designa em geral um método utilizado com vistas a uma ação estratégica e requerendo a participação dos atores.

Já há uma longa tradição de pesquisa-ação nas organizações em escala internacional, tanto públicas como privadas. No mundo anglo-saxônico, por exemplo, a pesquisa-ação é usada como meio de pesquisa social aplicada compatível com os objetivos do desenvolvimento organizacional e da sociotécnica (Thiollent, 1997). Vindo destas últimas, há uma contribuição relevante em termos de pesquisa-ação, sobretudo como mecanismo de 
retroalimentação dos resultados da investigação para os usuários ou a organização-cliente (ibid.).

Um dos objetivos destacados na perspectiva do desenvolvimento organizacional consiste em identificar e solucionar situações-problema internas à organização por meio de implicação das pessoas que vivem e nelas trabalham. Busca-se motivação pelo fato de que as pessoas são levadas a discutir coletivamente problemas e propostas com o auxílio de participantes externos, como consultores, apoiadores ou ativadores (Thiollent, 1997, p. 40).

A pesquisa-ação é participativa por essência. Diferentemente da perspectiva positivista, preocupada em grande medida com os resultados experimentais, a pesquisa-ação focaliza o processo, as relações sociais, culturais e educacionais. O espírito de criação está no centro da pesquisa-ação sem que nunca se saiba o que vai acontecer no final das contas (Morin, 2004, p. 24).

Para ser qualificada de pesquisa-ação, a investigação deve realizar efetivamente uma ação por parte das pessoas ou grupos implicados no problema sob investigação, cuja participação dos pesquisadores não deve chegar a substituir a atividade própria dos grupos e suas iniciativas (Thiollent, 2002).

A estratégia de pesquisa baseada na pesquisa-ação é geralmente operacionalizada por meio de três fases interdependentes (Martinelli et al., 2012), a saber: diagnóstico, ação e reflexão. Apesar disso, Thiollent (1997, p. 15) argumenta que, dependendo da situação social ou do quadro organizacional em que se aplicam, os procedimentos e a ordenação das etapas da pesquisa-ação podem variar.

Para Gil (2010) a modalidade de coleta de dados baseada na pesquisa-ação é uma forma de interação entre o pesquisador e as pessoas envolvidas nas situações investigadas. Para o autor, a pesquisa-ação supõe alguma forma de ação, que pode ser de caráter social, educativo ou pedagógico, técnico ou outro. Thiollent (2002, p. 15) as classifica como sendo de caráter reivindicatório, prático ou técnico.

Para escolher uma abordagem de pesquisa-ação que seja ao mesmo tempo integral e sistêmica, é preciso observar os seguintes aspectos (Morin, 2004): 
- trata-se de uma pesquisa participativa em todas as etapas do processo,

- conhecimento da natureza da situação problemática,

- descoberta da necessidade de participação e a natureza dos problemas,

- emprego de linguagem comum e lúdica, e

- realizada sob o estabelecimento de um contrato aberto.

A concepção do Professor André Morin oferece um quadro de reflexão sobre a metodologia de pesquisa-ação e vários instrumentos de observação, registro, interpretação e redação coletiva, para organizar os projetos com possibilidades de adaptação em amplo leque de possibilidades - maiores detalhes podem ser obtidos nos capítulos 2, 3 e 4 da obra (Morin, 2004).

Quadro 4.1 - Quadro-resumo entre Ciência positivista e pesquisa-ação (Susman e Evered, 1978 apud Thiollent, 1997)

\begin{tabular}{|c|c|c|}
\hline Pontos de comparação & Ciência Positivista & Pesquisa-ação \\
\hline Posição valorativa & $\begin{array}{l}\text { Os métodos são neutros em } \\
\text { termos de valores }\end{array}$ & $\begin{array}{l}\text { Os métodos desenvolvem sistemas } \\
\text { sociais e liberam o potencial } \\
\text { humano }\end{array}$ \\
\hline Perspectiva temporal & Observação do presente & $\begin{array}{l}\text { Observação do presente, mais } \\
\text { interpretação do presente com base } \\
\text { no conhecimento do passado, } \\
\text { conceituação dos futuros mais } \\
\text { desejáveis }\end{array}$ \\
\hline $\begin{array}{l}\text { Relacionamento com as } \\
\text { unidades }\end{array}$ & $\begin{array}{l}\text { Pesquisador espectador. Os } \\
\text { membros do sistema- cliente são } \\
\text { objetos de estudo }\end{array}$ & $\begin{array}{l}\text { Os membros do sistema-cliente são } \\
\text { sujeitos auto-reflexivos com os } \\
\text { quais existe colaboração }\end{array}$ \\
\hline $\begin{array}{l}\text { Tratamento das unidades } \\
\text { estudadas }\end{array}$ & $\begin{array}{l}\text { Os casos são interessantes } \\
\text { somente se forem } \\
\text { representativos da população }\end{array}$ & $\begin{array}{l}\text { Os casos podem ser fontes } \\
\text { suficientes de conhecimento }\end{array}$ \\
\hline $\begin{array}{l}\text { Linguagem para descrever as } \\
\text { unidades }\end{array}$ & Denotativa, observacional & Conotativa, metafórica \\
\hline $\begin{array}{l}\text { Base para assumir a existência } \\
\text { das unidades }\end{array}$ & $\begin{array}{l}\text { Existem independentemente dos } \\
\text { seres humanos }\end{array}$ & $\begin{array}{l}\text { São artefatos humanos para } \\
\text { propósitos também humanos }\end{array}$ \\
\hline Objetivos epistemológicos & $\begin{array}{l}\text { Predição de eventos com base } \\
\text { em proposições ordenadas } \\
\text { hierarquicamente }\end{array}$ & $\begin{array}{l}\text { Desenvolvimento de roteiros para } \\
\text { definir ações de desejados retornos }\end{array}$ \\
\hline $\begin{array}{l}\text { Estratégia de crescimento do } \\
\text { conhecimento }\end{array}$ & Indução e dedução & $\begin{array}{l}\text { Conjecturas, criação de dispositivos } \\
\text { para atender e modelar o } \\
\text { comportamento }\end{array}$ \\
\hline Critério de confirmação & $\begin{array}{l}\text { Consistência lógica, predição e } \\
\text { controle }\end{array}$ & $\begin{array}{l}\text { Avaliação da eficácia das ações em } \\
\text { produzir as consequências desejadas }\end{array}$ \\
\hline Base para generalização & $\begin{array}{l}\text { Ampla, universal e livre do } \\
\text { contexto }\end{array}$ & $\begin{array}{l}\text { Estreita, situacional e limitada pelo } \\
\text { contexto }\end{array}$ \\
\hline
\end{tabular}


A efetividade de um projeto de pesquisa-ação consistiria na discussão das implicações dos resultados para o desempenho dos clientes, a ampliação de seus conhecimentos e a aplicação nas ações (Thiollent, 1997, p. 39).

Para melhor distinguir métodos tradicionais da Ciência positivista e da pesquisa-ação, Thiollent (1997, p. 45) recorre aos estudos de Susman e Evered para realçar os pontos de destaque que orientam ambos os métodos - vide Quadro 4.1.

\subsubsection{1 - Modos de Conceber a Articulação da Pesquisa com a Ação}

As contribuições dos estudos de André Morin (Morin, 2004), Michel Thiollent (Thiollent, 2002; 1997) e Peter Checkland (Checkland, 1993; Checkland e Holwell, 1998; Checkland e Scholes, 1990) e outras referências aqui consideradas, foi possível delinear o modo de articulação da pesquisa-ação a partir das possibilidades levantas e das discussões críticas e construtivas.

Além do quadro de análise sociotécnico, é possível relacionar a pesquisa-ação com o planejamento participativo. A pesquisa-ação pode permitir a captação de fenômenos interativos entre as pessoas e os grupos que participam do projeto e desencadeia em propostas de mudança coletivamente cogitadas e negociadas, com pressupostos colaborativos, o que chega a ser condição favorável a uma efetiva realização dos projetos (Thiollent, 1997, p. 47).

A articulação da pesquisa e da ação é o tema central da metodologia de pesquisa-ação, a qual comporta três aspectos simultâneos, segundo avalia Desroche (1990 apud Thiollent, 1997, p. 37): i) pesquisa sobre os atores sociais, suas ações, transações, interações - seu objetivo é a explicação; ii) pesquisa para dotar de uma prática racional as práticas espontâneas - seu objetivo é a aplicação; e iii) pesquisa por ação ou pela ação, assumida tanto em tempo de concepção como em tempo de execução e acompanhamento - seu objetivo é a implicação.

Embora o projeto de pesquisa-ação não tenha uma forma totalmente predefinida (Checkland e Holwell, 1998; Thiollent, 1997), considera-se que existem, no mínimo, quatro grandes fases, a saber, (Thiollent, 2002, 1997): 
- fase exploratória, na qual os pesquisadores e alguns membros do sistema organizacional na situação investigada começam a detectar os problemas, os atores, as capacidades de ação e os tipos de ação possível;

- fase de pesquisa aprofundada, na qual a situação é pesquisada por meio de diversos tipos de instrumentos de coleta de dados que são discutidos e progressivamente interpretados pelos grupos que participam;

- fase de ação que consiste, com base nas investigações em curso, em difundir os resultados, definir objetivos alcançáveis por meio de ações concretas, apresentar propostas que poderão ser negociadas entre as partes interessadas; e

- fase de avaliação tem por objetivos: observar, redirecionar o que realmente acontece e resgatar o conhecimento produzido no decorrer do processo.

A experiência presume inicialmente a sequenciação das fases, mas, na prática, pode existir entre as três últimas um tipo de alternância ou mesmo de simultaneidade da pesquisa e da ação (Morin, 2004; Thiollent, 1997).

\subsection{2 - Estudos Etnográficos}

A etnografia, também conhecida como etnologia, é por definição o método utilizado pela antropologia na coleta de informações, dados e evidências. Baseia-se no contato intersubjetivo entre o antropólogo e o seu objeto, seja este um grupo social ou uma tribo ou qualquer outra manifestação étnica, sob o qual o recorte analítico seja feito (Magnani, 2009).

A etnografia é uma estratégia qualitativa em que o pesquisador estuda um grupo cultural no seu próprio ambiente durante um período de tempo suficiente para coletar principalmente dados de observação e entrevistas (Creswell, 2010).

A pesquisa etnográfica refere-se à descrição de um sistema de significados culturais de um determinado grupo, cuja característica fundamental é a procura de fontes múltiplas de objetos de informação, dados e evidência, para com isso obter diferentes perspectivas sobre a situação pesquisada, e coleta desses objetos por meio da observação participante (Martins e Theóphilo, 2009, p. 75). 
Na etnografia a investigação se inicia com uma ideia global ou temática do trabalho, de modo a compreender o sistema de significados próprio do pesquisador (Marconi e Lakatos, 2010, p.94). Com isso, a aplicação do estudo etnográfico pode se orientar pelas etapas do processo investigativo propostas por Wilcox (1993, apud Marconi e Lakatos, 2010, p. 94):

- acender, manter e desenvolver uma relação com os atores geradores de dados;

- empregar uma variedade de técnicas para coletar o maior número de dados, com o intuito de aumentar a validez e a confiabilidade do estudo;

- permanecer no campo o tempo suficiente para assegurar uma interpretação correta dos fatos observados e discriminar o que é regular e/ou irregular;

- utilizar teorias e conhecimentos para guiar e informar as próprias informações do que viu ou ouviu, redefinir o tema e depurar o processo do estudo.

A intenção da pesquisa etnográfica é obter um quadro holístico do tema em estudo, com ênfase na retratação das experiências cotidianas dos indivíduos por meio da observação e de entrevistas realizadas com eles e com outras pessoas relevantes no sistema de interesse (Creswell, 2010).

\subsubsection{1 - Pesquisa-Ação-Etnográfica}

Combinar pesquisa-ação com estudo etnográfico é uma prática adotada por pesquisadores e grupos de pesquisa que tencionam desenvolver projetos em cenários onde os grupos sociais e étnicos devem ser observados e cuidadosamente emancipados pela ação interventora, sem que isso afete ou contagie negativamente sua estrutura cognoscente.

Neves (2006, p. 15) assume que o passo adiante da pesquisa-ação, o trabalho com a demanda reprimida levanta no grupo e a consequente ação comunicativa, é associado a uma ética emancipatória, propondo-se a desenvolver a reflexão dos participantes, atores e sujeitos do seu contexto histórico, político e social. É do entendimento, a partir da dimensão dialógica da linguagem, que é possível a reconstrução do conhecimento entre as pessoas envolvidas no processo de investigação, e seu engajamento na transformação de seu contexto sociocultural.

Utilizada em projetos de sistemas de informação, a abordagem de pesquisa-açãoetnográfica traz muitos benefícios para a atividade de elicitação e análise de requisitos. A 
coleta de dados etnográfica requer, em geral, uma forte integração da equipe do projeto com os pesquisadores. Estes poderão analisar esses dados coletados por triangulação de diferentes fontes de dados para subsidiar o projeto de sistemas de informação (Hartmann, Fischer e Haymaker, 2009).

A justificativa para se trabalhar com a pesquisa-ação-etnográfica, segundo Hartmann, Fischer e Haymaker (2009), é a necessidade de coletar dados de diferentes fontes, tais como observações passivas, observação participante, entrevistas e outros documentos, como atas de reuniões ou relatórios que podem apoiar as suas observações. Os autores propõem um ciclo de pesquisa-ação-etnográfica para viabilização do desenvolvimento de um sistema de informação, conforme ilustrado na Figura 4.2.

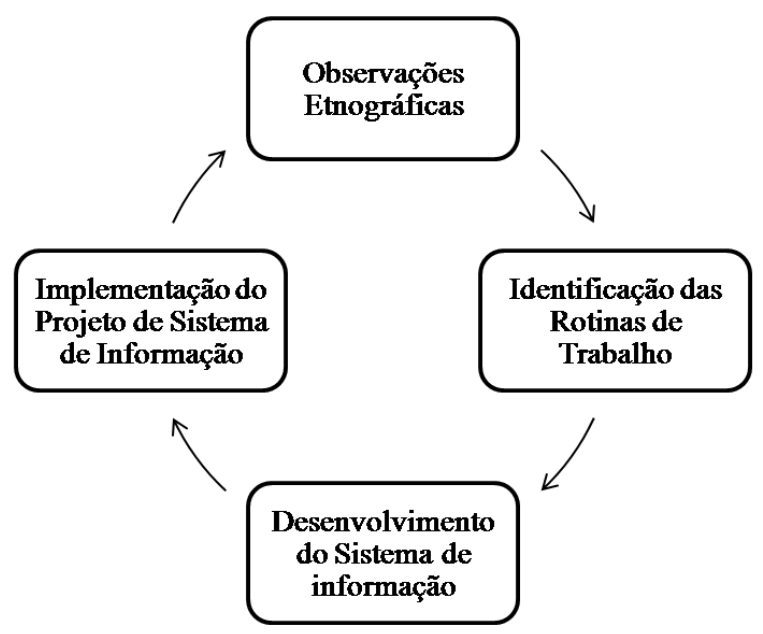

Figura 4.2 - Ciclo de pesquisa-ação-etnográfica para os sistemas de informação

(Hartmann, Fischer e Haymaker, 2009, p. 60)

\subsection{4 - Orientação Metodológica Fundamentada na Abordagem Integrada e Sistêmica}

Metodologicamente, a captação de informação individual por meio de questionários e entrevistas estruturadas, com construção de indicadores de satisfação/insatisfação ou de escalas de atitudes de tipo Likert, e de técnicas de amostragem gera um problema de observabilidade em nível grupal e, mais ainda, em nível de sistema organizacional, pois as entidades coletivas não se formam apenas por adição de elementos individuais (Thiollent, 1997, p. 39).

Além de possuírem propriedades emergentes, as características dos grandes temas de interesse de uma comunidade ou nação podem levar, por exemplo, a um plebiscito. Isso 
não se reproduz nas categorias de problemas aditivos, como no caso das políticas públicas ou dos impactos das mudanças organizacionais (ibid.), que ao final obstaculizam a discutibilidade tão necessária para a argumentação em nível de análise, interpretação e implicação dos resultados da pesquisa (Demo, 2014).

Em princípio, a emergência do pensamento sistêmico como uma resposta para alguns problemas na Ciência (Checkland, 1993; Vasconcellos, 2013; Moraes, 2004), permite lidar com situações problemáticas mal estruturadas e para as quais não se têm (ou não se deveria ter) respostas triviais.

Quando se trata de aplicar o método científico aos sistemas de atividade humana e aos fenômenos sociais, dificilmente haverá invariabilidade que se mantenha independente de tempo e lugar, como os aspectos sociais, culturais e políticos do comportamento humano, que diferem de uma pessoa para outra, e singular para o mesmo indivíduo em momentos diferentes. É por isso que a investigação experimental de teste de hipóteses torna-se inaplicável em cenários de pesquisa altamente dependentes das atividades humanas (Freyle, Florez e Rincón, 2013).

A estratégia da pesquisa em desenvolvimento está sustentada na abordagem integrada e sistêmica, cuja exploração da situação-problema inclui não só descobrir elementos que remetem às suas características instrumentais, mas também estudar seus aspectos sociais e políticos (Checkland e Holwell, 1998; Demo, 2014; Thiollent, 1997). Isso é muito importante, visto que as mudanças são indiscutivelmente desejáveis, mas ao mesmo tempo devem ser culturalmente viáveis, não sendo, portanto, resultado unicamente da lógica instrumental (Checkland e Holwell, 1998, p. 161; Demo, 2014).

A complexidade do real nos ensina que uma só ferramenta não basta para abordar, compreender e mudar alguma coisa (Morin, 2004, p. 114). A adoção de múltiplas metodologias favorece a investigação da situação-problema (Jackson, 2003), de modo a integrar as potencialidades de cada uma. Nesta pesquisa, adotamos três abordagens principais, em face da complementaridade existente entre elas para a elucidação da situação-problema de pesquisa. São elas: metodologia de sistemas flexíveis, pesquisa-ação integral e sistêmica e estudo etnográfico. 
A prática baseada no pensamento sistêmico é justificada pela possibilidade de alcançar a visão conjuntural e panorâmica do sistema determinado pelo problema. Espera-se, portanto, que a análise sistêmica permita diagnosticar o concurso de circunstâncias e o conjunto de elementos que constituem uma solução, ou um problema, presente. Portanto, o modelo de investigação será baseado na aplicação combinada das seguintes abordagens:

1. Pesquisa metodológica - especificamente a metodologia ecossistêmica de Moraes (2004) e a metodologia de redes sociais sistêmicas de Aun, Vasconcellos e Coelho (2012).

2. Métodos de estruturação de problema - especificamente a SSM de Peter Checkland (Checkland e Scholes, 1990), Planejamento Interativo de Russell Ackoff (Ackoff, 1979), Sistemas Indagadores de Charles West Churchman (Churchman, 1971), Crítica de Fronteira de Werner Ulrich (Ulrich, 1987).

3. Pesquisa social e organizacional - especificamente a pesquisa-ação de André Morin (Morin, 2004), Peter Checkland (Checkland e Holwell, 1998; Checkland, 1993) e Michel Thiollent (Thiollent, 2002; 1997) e o estudo etnográfico de Magnani (2009).

A metodologia SSM - descrita na Seção 3.1.3.3 - é especificamente concebida para contextos onde há visões altamente divergentes do que deveria ser feito e como deverá ser feito. A SSM posiciona os pesquisadores e praticantes no contexto do projeto ou do processo de mudança, auxiliando-os a direcionar suas energias por meio da criação de estratégias esclarecedoras (Jackson, 2003). A Figura 4.3 ilustra os sete estágios ou etapas que compõem a SSM (Checkland e Scholes, 1990).

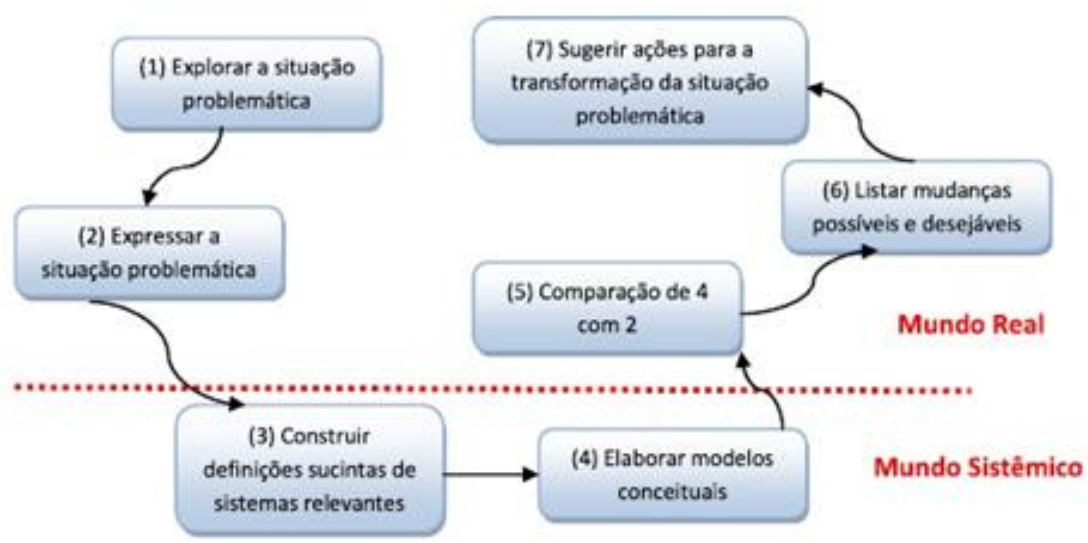

Figura 4.3 - Etapas da SSM

(Chekland e Scholes, 1990, modificado) 
Os pesquisadores e praticantes da SSM iniciam com uma situação-problema do mundo real que eles pretendem melhorar. Após obter uma compreensão rica daquela situaçãoproblema, inicia-se a descrição dos aspectos mais importantes do sistema definido em torno da situação-problema, para depois confrontar as duas perspectivas para buscar as mudanças que sejam desejáveis e ao mesmo tempo realizáveis.

A evolução natural e sistêmica de uma coletivamente depende essencialmente dos mecanismos de aprendizagem implementados, que possam refletir em última análise as práticas e as ações desenvolvidas no sistema de atividade humana (Checkland e Holwell, 1998; Senge, 2013). Diante dos desafios apresentados na realidade complexa de tais sistemas, Checkland e Holwell (1998) propõem uma abordagem estruturada para operacionalizar a pesquisa-ação fundamentada no sistema de aprendizagem - Figura 4.4.

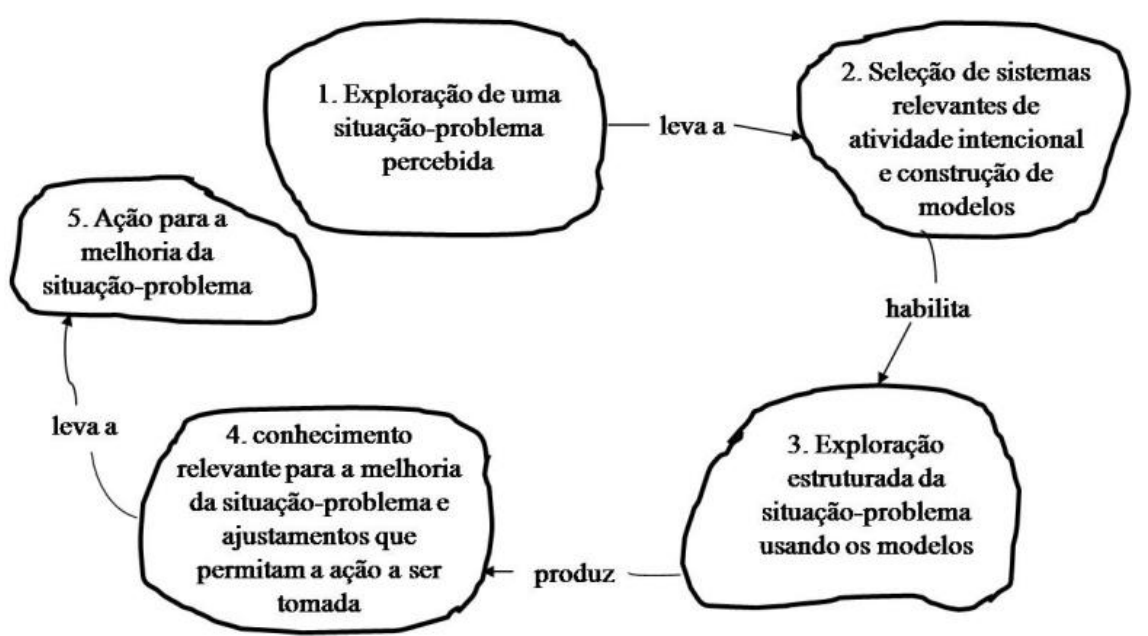

Figura 4.4 - Estrutura formalizada da SSM para o sistema de aprendizagem (Chekland e Holwell, 1998, p. 160).

A SSM é uma metodologia de pesquisa-ação que utiliza conceitos de sistemas como um meio de aprendizagem e compreensão quando houver uma situação na qual alguns possam vê-la como problemática (Checkland e Scholes, 1990). Particularmente, a fase três da Figura 4.3 pode ser conduzida de várias maneiras, e para fins diferentes. Pela experienciação de Chekland e Holwell (1998), uma forma rica e produtiva de utilizar a abordagem é fazer com que as pessoas envolvidas conduzam seus próprios estudos em oficinas abertas e outras formas de interação, se necessário. 
A abordagem sistêmica que orienta o modo de operacionalização desta pesquisa apropriase de pressupostos da teoria da informação, da cibernética e de sua utilidade nas estruturas organizacionais. A proposta de instrumentação é ampla e diversificada, sendo capaz de dirimir conflitos, oposições, contestações e situações mal definidas, tal como definido em Demo (2014, p. 203), sobretudo com o propósito de buscar estudar a dinâmica, as fronteiras e as relações que se encerram no horizonte do sistema de interesse.

Ao retomar a perspectiva de aprendizagem, e com o propósito de tornar a pesquisa viável sob a acepção sistêmica, Checkland e Holwell (1998) propõem um modelo para a pesquisa-ação se desenrolar segundo o ciclo de percepção e atribuição de sentido às percepções - vide Figura 4.5. Para tanto, a coordenação das ações previstas nesse ciclo deve ser satisfeita, tendo em vista que todos os seres vivos podem, em suas interações, coordenar suas ações (Vasconcellos, 2013).

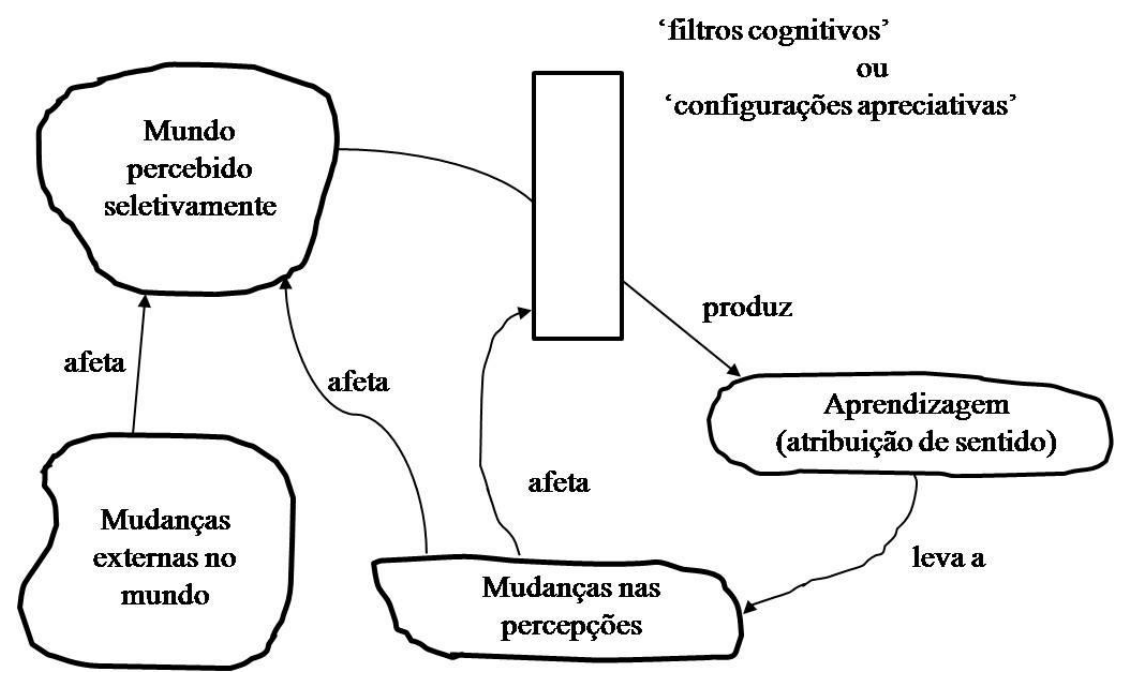

Figura 4.5 - Ciclo da pesquisa-ação: percepção e atribuição de sentido

(Checkland e Holwell, 1998, p. 189)

A realidade percebida pelo observador, a partir dos estímulos gerados pelas mudanças externas no mundo, desencadeia uma tomada de consciência sensitiva que será modulada pelos filtros cognitivos do indivíduo. Neste momento, produz-se o aprendizado com a criação ou reforço de ideias que gerarão mudanças nas percepções, afetando o modelo mental do observador, que repercutirá no desenvolvimento de um novo ciclo. 
As iterações do ciclo de pesquisa-ação aumentam as chances de ampliar o poder de assimilação do pesquisador. Checkland (1993) assevera que a SSM não é só um meio de aprendizagem sobre determinada situação-problema, é também um aprendizado sobre ela mesma, pois o processo cíclico de seus estágios - vide Seção 3.1.3.3 - não só proporciona o surgimento de outras ideias sobre a situação corrente, como promove o desenvolvimento de outras ideias sobre o sistema. As melhorias e as mudanças envolvem alterações nos procedimentos e também promovem mudanças na percepção de situações específicas pelos envolvidos.

Thiollent (2002) defende que no contexto dos sistemas de informação, o papel da pesquisaação consiste em facilitar a aprendizagem. Nesse contexto, a pesquisa-ação consiste em identificar os problemas e desenvolver um programa de ação a ser acompanhado e avaliado.

O princípio da investigação iterativa, aquela na qual se busca repetir os mesmos passos da pesquisa de campo a cada novo ciclo de aprendizagem, assume que não existe uma verdade fundamental (Gharajedaghi, 2004). Que antes disso, é preciso esclarecer as realidades que serão assumidas inicialmente, a fim de ser aprendida; a verdade não se encontra na partida, mas no ponto final de uma investigação. Iterações sucessivas traz uma maior compreensão e aproxima-se mais da natureza do todo. Nesse sentido, Morin (2004) destaca que a pesquisa-ação, participativa ou integral e sistêmica, é iterativa, repleta de ciclos de reajuste para uma reflexão e uma ação mais esclarecidas.

Uma pesquisa-ação bem conduzida alcança suficiente rigor científico quando retrata bem a realidade do sistema organizacional e equaciona seus problemas sem parcialidade ou complacência relacionada com os interesses vigentes (Thiollent, 1997).

Sob enfoque dos métodos de estruturação de problema, a pesquisa-ação ocupa um lugar de destaque e aparece como método explicitamente adotado na relação entre pesquisadores, atores e membros da organização investigada (Thiollent, 1997, p. 139). A proposta adotada, segundo Thiollent (ibid.), é herança da tradição lewiniana, que amadureceu nas 
práticas conhecidas como Desenvolvimento Organizacional e Sociotécnica no Instituto Tavistock $^{10}$.

Há que se considerar, portanto, que a pesquisa-ação integral e sistêmica é diferente de outras pesquisas qualitativas que não são participativas em todas as etapas do processo (Morin, 2004, p. 114). Assim sendo, André Morin assevera que a escolha da abordagem de pesquisa-ação integral e sistêmica deve contemplar os seguintes aspectos:

- conhecer a natureza da problemática: no caso da pesquisa aplicada, a problemática se torna mais complexa, podendo envolver a participação de engenheiros na pesquisa de desenvolvimento, e contanto que haja criação coletiva ou redação coletiva;

- descobrir a necessidade de participação e a natureza dos problemas: em todas as situações em que é preciso implicar mais de uma pessoa, há fundamentalmente uma necessidade de participação; uma mudança, por exemplo, poderia consistir em rever as estruturas de funcionamento para que facilitem a cooperação entre os atores;

- garantir a finalidade de mudança e dos modos de participação: o conhecimento dos objetivos do grupo querendo solucionar um problema permite ao pesquisador de fora, convidado por sua experiência em pesquisa-ação, de descobrir até que ponto o grupo pretende engajar-se no processo de participação;

- dar-se uma linguagem comum: pode parecer simplista, mas as pessoas que se lançam na aventura de uma pesquisa-ação integral e sistêmica devem se dar, no início, uma linguagem comum, embora isso seja frequentemente esquecido; e

- realizar um contrato aberto: entendimento que visa definir a participação de todos no estudo do problema para encontrar soluções e realizar as ações decididas.

${ }^{10}$ O Instituto Tavistock de Relações Humanas (termo originário do inglês, Tavistock Institute of Human Relations-TIHR) aplica as ciências sociais às questões e problemas contemporâneos. Foi criado como uma organização sem fins lucrativos e de caráter filantrópica em 1947. O TIHR está envolvido com a avaliação e pesquisa-ação, desenvolvimento e mudança organizacional, aconselhamento executivo e desenvolvimento profissional, tudo em serviço de apoio à mudança sustentável e aprendizagem contínua. O Instituto tem uma história de trabalho com organizações e setores que exigem um olhar mais amplo para as questões sistêmicas, objetivando alcançar mudanças com maior eficácia. Disponível em: < http://www.tavinstitute.org/>, acesso em: 28 mar. 2014. 
Para determinar o plano de pesquisa, Morin (2014, p.120) discorre sobre o modelo apropriado para lidar com situações-problema complexas. Ele admite que o modelo dinâmico seja aquele que melhor representa as idiossincrasias das pessoas e grupos que participam da pesquisa-ação. Por meio de uma espiral, ele representa tal modelo, destacando que a base é mais larga quando a complexidade do contexto é percebida desde o início na definição do problema devido à utilização da abordagem sistêmica, global e holística. A percepção do problema se tornará cada vez mais clara e a precisão das interações fará perceber significações desconhecidas.

Paradoxalmente, é a partir de questionamentos mais abrangentes que se caminhará, porque se compreende melhor, descobrem-se trilhas, tarefas mais precisas a serem cumpridas e surgem novas significações graças às interações dos atores; o círculo se estreita cada vez mais e o problema se torna mais preciso. Cada curva pode representar uma etapa do conjunto, e várias curvas são necessárias para realizar uma pesquisa-ação sistêmica.

Em outra perspectiva, Morin (2004, p. 123) adverte que a espiral pode se desenvolver de forma invertida. Em certos contextos, quando a situação é simples no início, isso pode significar que, talvez, o problema seja muito agudo e não favoreça um intercâmbio sistêmico. Estamos mais perto de uma pesquisa-ação integrada. Todavia, à medida que se tente solucionar o problema, as ações e as reflexões revelarão a complexidade das componentes que ficavam implícitas ou ocultadas quando apareceram as dificuldades. Aos poucos, obter-se-á uma visão mais global e, até, holística e a pesquisa-ação integral se tornará sistêmica. Um problema, que parecia simples, revelar-se-á mais difícil de resolver por causa de confusões e de inter-relações descobertas no processo. A realidade aparece mais intrigante, complexa e opaca.

Diante do exposto e com vistas à construção do plano de pesquisa integrado e sistêmico, desenvolver-se-á nas próximas três seções a orientação metodológica, contendo os estágios, os instrumentos de análise e coleta de informações, dados e evidências. Não obstante o propósito da orientação metodológica, esta não é uma metodologia. É, essencialmente, uma atitude reflexiva. E não é autocontida - deve ser usada em conjunto com outras técnicas de abordagem de problemas de pesquisa científica. 


\subsubsection{1 - Metodologia para Resolução de Problemas Complexos.}

Para descobrir as motivações que levam à caracterização de um problema de pesquisa e sua contextura, esta orientação metodológica preceitua uma postura de objetivação e discutibilidade, ao invés de se buscar critérios de objetividade e relações de causa e efeito. O metodologista Pedro Demo adverte que a busca da objetividade é uma grande utopia da Ciência, uma vez que, do ponto de vista formal, pretende conhecer a realidade assim como ela é, no retrato mais perfeito, na explicação mais analítica possível (Demo, 2014) característico da concepção positivista.

Os próprios estudiosos e cientistas dos métodos tradicionais da econometria reconhecem e admitem a limitação de tais abordagens quando lidam com situações de baixa previsibilidade e alto grau de incertezas. Para esses casos, Wooldridge (2011) aponta a adoção de medidas de contorno, quando eventualmente os valores de uma ou mais variáveis não podem ser obtidos de modo realista, gerando a necessidade de observar estatísticas relevantes e derivadas de outras variáveis que se aproximem daquelas.

O princípio da multidimensionalidade de Gharajedaghi (2011), combinado com a perspectiva de aprendizagem do sistema de informação de Checkland e Holwell (1998) Figuras 4.3 e 4.4 - com a abordagem antropopedagógica de Morin (2004) e as bases conceptuais da metodologia de Aun, Vasconcellos e Coelho (2012), desencadearam a formação da orientação metodológica.

Trata-se, portanto, de uma proposta de orientação metodológica que tenciona o desenvolvimento das atividades de prospecção, coleta de dados, análises descritiva e interpretativa, além da discussão e avaliação reflexiva - assim retratado na Figura 4.6. Ao fazer um recorte da organização para distinguir o aspecto social do aspecto tecnológico, é preciso apreender sistemicamente as relações entre ambos para fundamentar a abordagem sociotécnica (Thiollent, 1997, p. 14).

Para melhor retratar a complexidade sistêmica, as ações comunicativas e de intervenção pedagógica na realidade, a orientação metodológica contempla os preceitos das abordagens multimetodológicas, apropriando-se de métodos de estruturação de problema e de diferentes concepções paradigmáticas. 
A Ciência de algum modo se propõe a transformar conceitos abstratos em realidades concretas ou objetos. $\mathrm{Na}$ atual conjuntura, ela alimenta os pesquisadores com as vicissitudes de caráter paradigmático, metodológico e humano sem precedentes na história, tornando o empreendimento da pesquisa mais desafiador. Creswell (2010) destaca que o pluralismo metodológico presente em pesquisa atualmente - cujas discussões incorporam ideias filosóficas alternativas, modos de investigação e numerosos procedimentos - provê ao pesquisador uma diversidade de opções estratégicas para melhor conduzir projetos de pesquisa mais sofisticados.

Os problemas complexos surgem por causa da interdependência e das inter-relações entre as partes. Se não observar as inter-relações, poderá sentir falta dos aspectos mais importantes que dão origem ao comportamento do sistema e, portanto, à complexidade do sistema (Jackson, 2013; 2003).

A transição entre os estágios de desenvolvimento da pesquisa decorre das relações percebidas e assumidas pelo pesquisador, em meio às atividades de coordenação que acontecem no processo de orientação metodológica. A forma de coordenação, segundo avalia Vasconcellos (2013), faz emergir o sistema transformador das próprias relações.

Cada estágio possui um conjunto específico de atividades de pesquisa a desenvolver, com o propósito de orientar as ações comunicativas e ações intervencionistas que precedem a reflexão avaliativa da pesquisa de campo. Para efeito desta tese, a orientação metodológica está estruturada com base no método de pesquisa-ação-participante integral e sistêmica, de André Morin (Morin, 2004), além de estar instrumentalizada com as abordagens do pensamento sistêmico para coleta e análises descritiva e interpretativa. A seguir, serão descritas as atividades e os instrumentos apropriados por esta orientação metodológica vide Quadro 4.2.

\section{Estágio 0 - Visão multidimensional}

Tomando como ponto de partida os temas de interesse desta pesquisa, repassou-se o marco teórico e conceitual - faces da complexidade sistêmica, faces da tomada de decisão e arquiteturas de sistema de informação - para estabelecer os parâmetros que implicarão a 
construção da visão multidimensional. A visão orientada pelas múltiplas dimensões corresponde ao estágio preliminar (estágio zero), o qual visa:

i) propor as perspectivas de avaliação para o sistema definido em torno da situação-problema de interesse, e

ii) preparar a estratégia de pesquisa integrada e sistêmica.

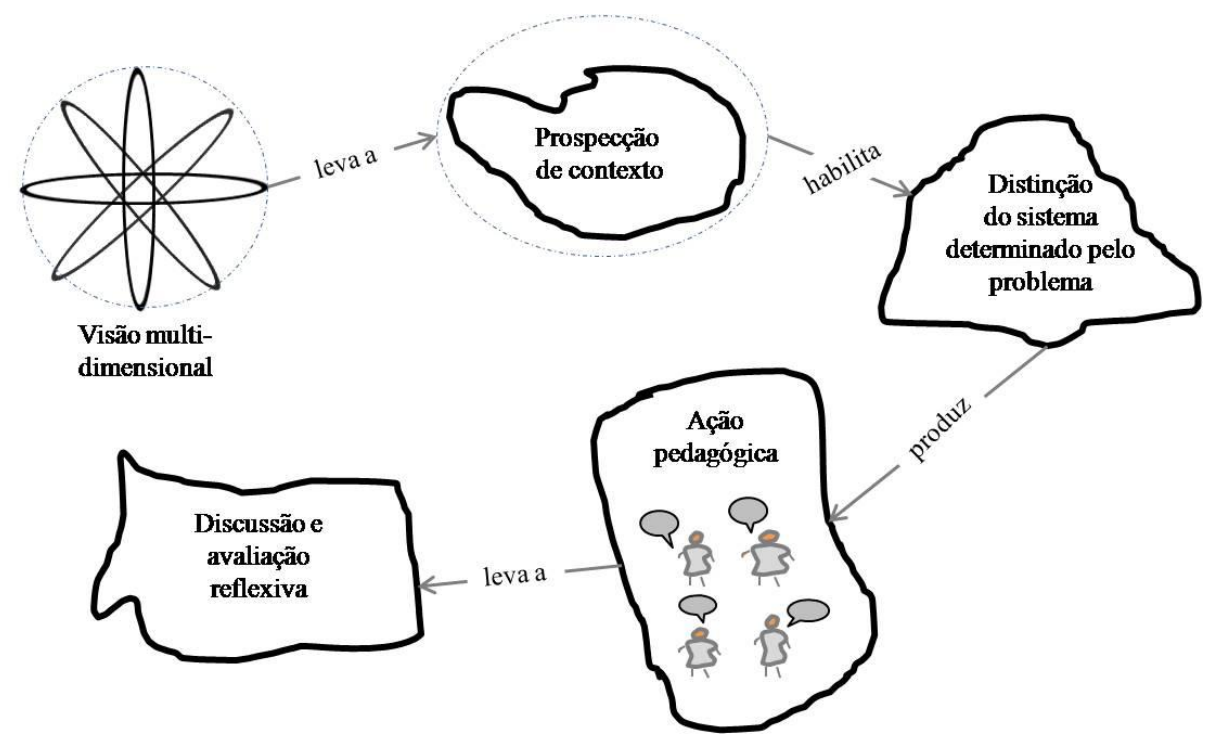

Figura 4.6 - Orientação metodológica da pesquisa integrada e sistêmica

(O autor, 2015)

\section{Estágio 1 - Prospecção de contexto}

Estudar as possibilidades de prospecção e as circunstâncias contextuais que emergem das realidades observadas sob a ótica de cada dimensão de avaliação, contribui para a exploração das situações e dos problemas descobertos. As realidades se constroem em conversações, em espaço de intersubjetividade (Vasconcellos, 2013). Cada dimensão permitirá ter acesso a uma fatia da realidade. Isto posto, a prospecção de contexto terá como principais atividades:

i) prospecção dos contextos da realidade observada (Vasconcellos, 2013; Morin, 2004; Thiollent, 1997),

ii) identificação do sistema construído em torno do problema e do sistema de resolução de problema (Checkland, 1993), e

iii) levantamento das principais necessidades dos pesquisadores e atores da pesquisa (Morin, 2004). Neste estágio se desenvolverá a primeira etapa da metodologia SSM de Peter Checkland. 


\section{Estágio 2 - Distinção do Sistema Determinado pelo Problema}

Neste estágio é feita a distinção do Sistema Determinado pelo Problema (SDP), que consiste na distinção de um sistema constituído em torno da situação-problema. Esteves de Vasconcelos (2013) argumenta que é das interações e conversações que emerge a situaçãoproblema, onde o observador distingue a situação como problemática, ou seja, o observador compartilha sua distinção. De sorte que a situação-problema é construção na conversação, construção social da realidade (ibid.). Este estágio envolve a introdução da situação-problema junto com a identificação das pessoas, da cultura e das normas, por meio de entrevistas e discussões, observações, brainstorming e figuras ricas (Checkland, 1993).

De forma análoga ao SDP, Ulrich (1987) define o sistema de referência como sendo o conjunto de considerações de fatos e de valores importantes a serem incorporados à sua organização. Para Ackoff (1979), corresponde ao sistema relevante, que compreende os elementos indispensáveis para a sua existência.

As figuras ricas são representações altamente contextuais de desenhos animados, como os atores, questões, problemas, processos, relações e conflitos de uma situação, que fornecem uma ideia do clima da situação (Checkland e Scholes, 1990). No Estágio 2 se desenvolverá a segunda etapa da metodologia SSM. Imagens ricas capturam a essência de uma situação e ajudam a identificar temas relevantes e garantir um entendimento comum das diferentes perspectivas. As atividades a cumprir neste estágio incluem:

i) compreensão da finalidade do projeto a empreender (Morin, 2004), e

ii) realização de pesquisa acurada da situação por meio de diversos tipos de instrumentos de coleta de dados que serão discutidos e progressivamente interpretados (Morin, 2004; Thiollent, 1997).

\section{Estágio 3 - Ação pedagógica}

Uma vez consciente das dimensões do SDP, é quando se envidam os esforços para a viabilização da ação pedagógica. Partindo dos pressupostos do método antropopedagógico de André Morin, o modelo de intervenção faz um resgate antropológico para em seguida 
definir os parâmetros que serão adotados no processo da ação orientativa. As demais etapas da metodologia SSM, etapa três até etapa sete, serão desenvolvidas neste estágio.

São estas as atividades propostas para o Estágio três:

i) difusão dos resultados e definição dos objetivos alcançáveis por meio de ações concretas (Morin, 2004; Thiollent, 1997), e

ii) apresentação de propostas que poderão ser negociadas entre as partes interessadas (Checkland, 1993; Vasconcellos, 2013; Morin, 2004).

\section{Estágio 4 - Discussão e Avaliação Reflexiva}

Nesta fase, é quando ocorre a discussão e avaliação reflexiva sobre a ação na prática e a prática na teoria. As atividades a desenvolver, com base na metodologia de Morin (2004), são as seguintes:

i) observar e redirecionar o que realmente acontece (Checkland e Holwell, 1998; Morin, 2004);

ii) resgatar o conhecimento produzido no decorrer do processo (Checkland, 1993; Morin, 2004; Thiollent, 2002), e

iii) construir objetos de conhecimento teóricos implicados pela prática.

Em síntese, Morin (2004) destaca que o ciclo de aprendizagem do modelo espontâneo, dinâmico e significativo consiste em uma ação seguida de uma reflexão.

A orientação metodológica é destinada ao desenvolvimento de pesquisa-ação-participante integrada com a metodologia de sistemas flexíveis. Segundo Morin (2004), a pesquisa com fins educacionais ou pedagógicos em uma situação real não construída é demasiado complexa para aceitar como verdade um conjunto de instrumentos experimentais, com o que se esqueceria do amalgama das interações humanas. Mesmo quando é preciso decompor, em parte, o objeto, é necessário fazê-lo com a vontade de unir e de estudar as relações e a finalidade dos componentes. $\mathrm{O}$ momento no qual o pesquisador deve refletir sobre a ação na prática.

Em suma, a aplicação da orientação metodológica segue os pressupostos da metodologia de Aun, Vasconcellos e Coelho (2012). Inicia com a identificação de uma situação- 
problema, envolvendo dois aspectos fundamentais, a forma de constituição do sistema definido em torno da situação-problema e a forma de coordenação das interações e dos encontros conversacionais promovidos. O mapa contendo as atividades e os principais instrumentos de coleta e análise vinculados a cada estágio do plano de pesquisa está delineado no Quadro 4.2.

Quadro 4.2 - Mapa de atividades e recursos da orientação metodológica

(O autor, 2015)

\begin{tabular}{|c|c|c|c|}
\hline ESTÁGIO & ATIVIDADE & REFERÊNCIAS & INSTRUMENTOS \\
\hline \multirow[t]{2}{*}{$\begin{array}{l}\text { ESTÁGIO 0: } \\
\text { Visão multi- } \\
\text { dimensional }\end{array}$} & $\begin{array}{l}\text { Propor dimensões de avaliação para o } \\
\text { sistema definido em torno da situação- } \\
\text { problema. }\end{array}$ & $\begin{array}{l}\text { Ackoff (1979), } \\
\text { Gharajedaghi (2011) }\end{array}$ & \multirow{13}{*}{$\begin{array}{l}\quad \underline{\text { Instrumentos de coleta }} \\
\text { - Observação participante } \\
\text { - Estudo etnográfico } \\
\text { - Pesquisa documental } \\
\text { - Análise de conteúdo } \\
\text { - Análise do discurso } \\
\text { - Entrevista semi-estruturada } \\
\text { - Entrevista não estruturada } \\
\text { (espontânea) } \\
\text { Instrumentos de análise descritiva } \\
\text { - Roteiro para iniciar os estudos } \\
\text { de sistemas } \\
\text { - Aspectos da análise de fronteira } \\
\text { de Ulrich } \\
\text { - Prospecção da tipologia de rede } \\
\text { - Matriz de atribuição de } \\
\text { responsabilidades RACI } \\
\text { - Diagnóstico da capacidade de } \\
\text { atuação do sistema } \\
\text { - Categorias avaliativas da análise } \\
\text { de fronteira } \\
\text { - Matriz de relacionamento dos } \\
\text { atores } \\
\quad \text { Instrumentos de análise } \\
\text { interpretativa } \\
\text { - Seção Policy Delphi (Turoff, } \\
\text { 1975; 1970) } \\
\text { - Análise de Redes Sociais (Van } \\
\text { Wardeen, 1992) } \\
\text { - Análise de viabilidade de } \\
\text { sistema (Beer, 1968) } \\
\text { - Organização do sistema } \\
\text { - Estruturação do sistema }\end{array}$} \\
\hline & $\begin{array}{l}\text { Preparar estratégia de pesquisa } \\
\text { integrada e sistêmica }\end{array}$ & \multirow{2}{*}{$\begin{array}{l}\text { Chekland e Holwell } \\
\text { (1998); Jackson (2003); } \\
\text { Morin (2004); Thiollent } \\
(2002 ; 1997)\end{array}$} & \\
\hline \multirow{4}{*}{$\begin{array}{l}\text { ESTÁGIO 1: } \\
\text { prospecção de } \\
\text { contexto }\end{array}$} & $\begin{array}{l}\text { Explorar situação-problema de } \\
\text { interesse. }\end{array}$ & & \\
\hline & $\begin{array}{l}\text { Identificar o sistema construído em } \\
\text { torno do problema e o sistema de } \\
\text { resolução de problema. }\end{array}$ & $\begin{array}{l}\text { Chekland e Holwell } \\
\text { (1998), Morin (2004), } \\
\text { Ulrich (1987) }\end{array}$ & \\
\hline & $\begin{array}{l}\text { Identificar claramente as principais } \\
\text { necessidades dos pesquisadores e atores } \\
\text { da pesquisa. }\end{array}$ & Morin (2004) & \\
\hline & $\begin{array}{l}\text { Detectar os problemas, os atores, as } \\
\text { capacidades de ação e os tipos de ação } \\
\text { possíveis. }\end{array}$ & $\begin{array}{l}\text { Chekland e Holwell } \\
\text { (1998), Ulrich (1987) }\end{array}$ & \\
\hline \multirow{2}{*}{$\begin{array}{l}\text { ESTÁGIO 2: } \\
\text { distinção do } \\
\text { sistema } \\
\text { determinado } \\
\text { pelo } \\
\text { problema }\end{array}$} & $\begin{array}{l}\text { Compreender bem a finalidade do } \\
\text { projeto a empreender. }\end{array}$ & $\begin{array}{l}\text { Chekland e Holwell } \\
\text { (1998), Morin (2004), } \\
\text { Thiollent }(2002 ; 1997)\end{array}$ & \\
\hline & $\begin{array}{l}\text { Proceder a pesquisa acurada da situação } \\
\text { por meio de diversos tipos de } \\
\text { instrumentos de coleta de dados que são } \\
\text { discutidos e progressivamente } \\
\text { interpretados. }\end{array}$ & $\begin{array}{l}\text { Morin (2004), Thiollent } \\
\text { (1997) }\end{array}$ & \\
\hline \multirow{2}{*}{$\begin{array}{l}\text { ESTÁGIO 3: } \\
\text { ação } \\
\text { pedagógica }\end{array}$} & $\begin{array}{l}\text { Difundir os resultados e definir } \\
\text { objetivos alcançáveis por meio de ações } \\
\text { concretas. }\end{array}$ & \multirow{2}{*}{$\begin{array}{l}\text { Chekland e Holwell } \\
\text { (1998), Morin (2004), } \\
\text { Ulrich (1987) }\end{array}$} & \\
\hline & $\begin{array}{l}\text { Apresentar propostas que poderão ser } \\
\text { negociadas entre as partes interessadas. }\end{array}$ & & \\
\hline \multirow{3}{*}{$\begin{array}{l}\text { ESTÁGIO 4: } \\
\text { discussão e } \\
\text { avaliação } \\
\text { reflexiva }\end{array}$} & $\begin{array}{l}\text { Observar e redirecionar o que realmente } \\
\text { acontece. }\end{array}$ & \multirow{3}{*}{$\begin{array}{l}\text { Checkland (1993), } \\
\text { Chekland e Holwell } \\
\text { (1998), Gharajedaghi } \\
\text { (2011), Morin (2004) }\end{array}$} & \\
\hline & $\begin{array}{l}\text { Resgatar o conhecimento produzido no } \\
\text { decorrer do processo. }\end{array}$ & & \\
\hline & $\begin{array}{l}\text { Construir objetos de conhecimento } \\
\text { teóricos implicados pela prática. }\end{array}$ & & \\
\hline
\end{tabular}

\subsubsection{2 - Instrumentos de Análise Descritiva}

No geral, ao longo do processo de construção de um trabalho científico, o pesquisador, dependendo da natureza das informações, dados e das evidências levantadas, poderá empreender uma análise qualitativa e quantitativa (Gil, 2010; Marconi e Lakatos, 2010; Martins e Theóphilo, 2009), ou mesmo uma análise mista - qualitativa e quantitativa 
integradas (Creswell, 2010; Martins e Theóphilo, 2009). Vindo destes últimos, ao assumir uma estratégia de pesquisa de natureza qualitativa, uma das seguintes abordagens poderá ser empregada individual ou de forma combinada: pesquisa-ação, teoria fundamentada, estudo etnográfico e/ou estudo de caso.

Diferentemente dos métodos quantitativos que buscam dar um tratamento instrumental e exaustivo com vistas a alcançar uma grandeza matemática que poderá ser explicada posteriormente pelas técnicas estatísticas ou probabilísticas, neste estudo a análise dos dados consiste no desenvolvimento de técnicas associadas à abordagem integrada e sistêmica, combinando os instrumentos da metodologia de sistemas flexíveis, da pesquisaação e do estudo etnográfico, os quais são de caráter meramente qualitativo - o interesse é voltado à descrição da natureza e da organização e estrutura dos objetos e suas interrelações, sob os pontos de vista intersubjetivos dos atores e pesquisadores.

Morin (2004) avalia que a análise dos dados deve ser vista como uma técnica que contribui para a viabilização da pesquisa, possibilitando a interpretação dos dados levantados e as posteriores implicações práticas que poderão advir. Para lidar com volume grande de dados, característica inerente à abordagem adotada, o pesquisador deve se perguntar como analisá-los para conseguir redigir um relatório, respeitando o objeto da pesquisa e adquirindo a credibilidade de uma contribuição em conhecimento prático.

Partindo dos pressupostos assumidos para a definição deste plano de pesquisa, os instrumentos foram definidos com o intuito de contemplar o nível de abrangência e especificidade das abordagens metodológicas, quais sejam:

- Roteiro para iniciar os estudos de sistemas

- Aspectos da análise de fronteira

- Dimensões da tipologia de rede

- Matriz de atribuição de responsabilidades RACI

- Diagnóstico da capacidade de atuação do sistema

- Categorias avaliativas da análise de fronteira

- Matriz de relacionamento dos atores 


\section{Roteiro para iniciar estudos de sistemas}

Para iniciar os estudos de sistemas, o roteiro proposto por Peter Checkland (Checkland, 1993, p. 294) será adotado com o propósito de descrever a situação de estudo para a qual o responsável pela demanda ou pelo projeto tenha encomendado para análise, incluindo a descrição do sistema de resolução de problemas e o sistema definido em torno da situaçãoproblema alvo.

\section{Aspectos da análise de fronteira}

A análise de sistema proposta por Werner Ulrich (Ulrich, 1987), conforme descrito na Seção 3.1.3.5 - Concepções Críticas de Sistemas permite compreender as relações entre os atores envolvidos, abrindo as fronteiras para que se busque o entendimento das relações entre atores, que consiste na descrição dos aspectos condicionantes de propósito, poder, conhecimento e legitimação das partes envolvidas e afetadas pelo sistema de referência.

\section{Dimensões da tipologia de rede}

Para ser capaz de trabalhar com redes sociais, é preciso ter uma visão sistêmica novoparadigmática, sustentada nos pressupostos da epistemologia sistêmica, do paradigma ecológico e do pensamento ecossistêmico (Vasconcellos, 2013). Moraes e Torre (2006) argumentam que nos tempos atuais a realidade é constituída de objetos inter-relacionados, de redes de conexões dinâmicas caracterizadoras dos mais diferentes processos.

As dimensões, aqui consideradas, envolverão as perspectivas tipológicas de rede de Van Waarden (1992), conforme segue:

i) temporalidade - em termos de comunicação em rede em tempo real, permitindo conexões de tempos sociais distintos;

ii) espacialidade - com a qual se relaciona a criação de territorialidade de novo tipo, virtuais e presenciais, e a conexão entre ambas; e

iii) sociabilidade - que define as novas formas de relações sociais, em intensidade, abrangência, intencionalidade e, em especial, seu significado e alcance em um novo tipo de esfera de atuação. 


\section{Matriz de atribuição de responsabilidades $\mathrm{RACI}$}

A ferramenta utilizada para a identificação de papéis e responsabilidades das partes interessadas na resolução da situação-problema será a matriz de atribuição de responsabilidades $\mathrm{RACI}^{11}$. RACI é o acrônimo em inglês para: Responsible, Accountable, Consulted e Informed. Responsible (Executor): pessoa ou função responsável por executar a atividade; Accountable (Responsável): pessoa que, em última instância, se responsabiliza pela atividade que está sendo executada; Consulted (Consultado) - pessoas consultadas cuja contribuição é usada para completar a atividade; Informed (Informado): pessoas que serão informadas sobre o status da atividade.

\section{Diagnóstico da capacidade de atuação do sistema}

Para realizar a prospecção do sistema com vistas a dimensionar a sua capacidade de atuação, utilizar-se-á o instrumento construído a partir das contribuições de Peter Morgan (Morgan, 2005). A ferramenta consiste na descrição de:

i) perspectivas - que corresponde aos tópicos de interesse;

ii) dificuldades encontradas - que tratam das limitações, deficiências e restrições;

iii) políticas e planos - que inclui as práticas e procedimentos; e

iv) resposta à pergunta - que deve ser feito minimamente para trazer o impacto desejado para cada perspectiva relevante?

\section{Categorias avaliativas da análise de fronteira}

O interesse em levantar as percepções dos atores internos e externos ao sistema definido em torno do problema motivou buscar as categorias avaliativas da análise de fronteira de Werner Ulrich (Ulrich, 1987, p. 279). Como resultado, por meio desta análise será possível identificar as motivações das partes envolvidas para a resolução da situação-problema.

11 Ferramenta empregada originalmente pelo framework de governança Cobit (IT Governance Institute. (2012). Control Objectives for Information and Related Technology, 5th Edition. Rolling Meadows, IL: IT Governance Institute. 


\section{Matriz de relacionamento dos atores}

Para subsidiar a análise de redes sociais, uma matriz de relacionamento dos atores será construída para refletir a força das relações entre os atores. A análise de redes sociais é a ferramenta que permite compreender e avaliar fenômenos em determinado contexto da rede, sendo empregada em diversas áreas das Ciências Sociais, cujo foco está nas relações entre os atores sociais, que podem ser indivíduos, organizações, governos e etc. (Garrossini, 2010).

\subsubsection{3 - Instrumentos de Análise Interpretativa}

Para desenvolver a análise interpretativa, os seguintes instrumentos serão empregados:

- Seção policy delphi,

- Análise de redes sociais,

- Análise de viabilidade de sistema,

- Organização do sistema, e

- Estruturação do sistema.

\section{Seção policy delphi}

O método delphi foi concebido pioneiramente para prever eventos futuros da empresa RAND Corporation, em 1950. Tal designação inspirou-se no antigo oráculo de Delfos Grécia, dedicado a Apolo. A técnica empregada foi chamada de método Delphi. Seus precursores foram Dalkey \& Helmer, que apresentaram seus fundamentos teóricos (Turoff, 1970).

O método delphi consiste no uso de pesquisas e feedback de opinião controlada para coletar informações, mantendo-se o anonimato dos participantes e o uso de votação para reduzir a necessidade de longas discussões e debates diretos (Turoff, 1975).

Diferentemente do método delphi tradicional, o policy delphi não pretende obter consenso entre os participantes. No fundo, buscará oportunizar a todos os participantes partilharem suas opiniões sobre o assunto em questão, gerando uma infinidade de pontos de vista e possíveis alternativas de solução (Turoff, 1975; 1970). Com isso, o policy delphi serve para 
evitar o problema de estrangulamento do método delphi clássico, proporcionando uma análise mais aprofundada das questões divergentes, ao invés de buscar consenso.

\section{Análise de redes sociais}

Para ser capaz de usar os métodos de rede, usar o pensamento de rede e trabalhar efetivamente com os vínculos que constituem as redes sociais, é necessário um quadro de referência da teoria sistêmica (Aun, Vasconcellos e Coelho, 2012) - maiores detalhes na Seção 3.1.4. A Análise de Redes Sociais (ARS) começa a partir da matriz de relacionamentos. Os atributos a serem utilizados na ARS serão densidade, centralidade, centralização, intermediação e proximidade.

A densidade corresponde ao grau de intensidade de conectividade em uma rede, enquanto que a centralidade se refere à quantidade de atores aos quais um determinado ator está diretamente ligado. No tocante ao atributo de centralização, evidenciam-se os atores que possuem um papel de destaque na rede, relativamente à proximidade que estiver do total de possibilidades de conexão, e por fim a intermediação diz respeito à possibilidade que um ator possui de controlar os processos de comunicação em uma rede.

\section{Análise de viabilidade de sistema}

A análise de viabilidade de sistema especifica cinco sistemas teóricos que devem existir em um sistema organizacional, quais sejam: operações, coordenação, controle, inteligência, e políticas. Tais sistemas atuam conjuntamente com a estrutura de controle e relações comunicacionais apropriadas. Apesar de ter sido desenvolvido com a intenção prescritiva, ele também pode ser usado como parte de uma análise sobre os problemas do desenho organizacional e seu redesenho (Mingers e Rosenhead, 2004). O modelo de viabilidade de sistemas é discutido na Seção 3.1.3.6.

\section{Organização do sistema}

A análise interpretativa que culminará com a definição da organização do sistema definido em torno da situação-problema, de modo a refletir as nuanças da visão multidimensional, ocorrerá por meio da construção da ontologia desse sistema. Neste estudo, a ontologia será 
empregada para descrever as relações entre as propriedades, classes e instâncias que compreendem a organização daquele sistema associado à situação-problema. $\mathrm{O}$ quadro teórico que trata dessa abordagem ontológica encontra-se na Seção 3.3.4.

\section{Estruturação do sistema}

A estruturação do sistema é parte do instrumento de análise interpretativa destinada à instanciação dos domínios de arquitetura de referência, os quais contribuirão para a constituição do sistema de resolução do problema - maiores detalhes na Seção 3.5.3. Na avaliação de Gharajedaghi (2011), o desenho organizacional é precedido por uma construção arquitetônica que define o modo como as diferentes partes de um todo estão dispostas.

\subsubsection{4 - Instrumentos de Coleta e Registro de Dados}

Ainda que as técnicas de coleta de dados estejam sendo desenvolvidas concomitamente com outras etapas da pesquisa, esta seção discute aquelas que subsidiarão as análises e posterior discussão deste estudo.

Dentre as possibilidades de uso de instrumentos que se ajustam às necessidades de pesquisa, estas são as opções escolhidas:

- observação participante

- estudo etnográfico

- pesquisa documental

- $\quad$ análise de conteúdo

- análise do discurso

- entrevistas espontâneas e programadas

- diário de bordo.

\section{Observação participante}

A abordagem integrada e sistêmica exige do pesquisador um modo de participação que valorize o engajamento pessoal, abertura à atividade humana, sem relação de dependência, onde o diálogo deve prevalecer nas relações de cooperação ou de colaboração. De acordo com Aun, Vasconcellos e Coelho (2012) e Martins e Theóphilo (2009), a observação 
participante é uma técnica na qual o pesquisador-observador torna-se parte integrante de uma estrutura social, e na relação face a face com os sujeitos da pesquisa para realizar a coleta de dados. Trata-se, portanto, de se alocar o investigador no contexto físico a ser estudado, e de criar condições para a coleta de informações, dados e evidências por meio dos sentidos e percepções do pesquisador.

Toda pesquisa-ação possui um caráter participativo, pelo fato de promover ampla interação entre pesquisadores e membros representativos da situação investigada. Nela existe vontade de ação planejada sobre os problemas detectados na fase investigativa (Thiollent, 1997). A significância de um trabalho dessa natureza é evidenciada pela riqueza, profundidade e singularidade das descrições obtidas (Martins e Theóphilo, 2009).

\section{Estudo etnográfico}

O estudo etnográfico se desenvolverá desde que o projeto de pesquisa reúna as condições mínimas de acessibilidade aos grupos sociais e étnicos associados ao contexto de análise. A opção etnográfica se deve à necessidade de trazer respostas a problemas específicos sobre como ir a campo de forma a produzir resultados válidos. Por meio da descrição densa proporcionada pela etnografia é possível alcançar a produção de sentidos nos grupos sociais, que as redes sociais têm como um dos objetos principais (Lima, Alves e Molinaro, 2014).

\section{Pesquisa documental}

Apesar de ser confundida com a pesquisa bibliográfica, a pesquisa documental busca levantar material que ainda não tenha sido editado, como relatórios, propostas, estudos, avaliações, correspondências etc. Martins e Theóphilo (2009) asseveram que as pesquisas documentais são frequentes nos estudos orientados por estratégias participativas, como estudo de caso e pesquisa-ação.

\section{Análise de conteúdo}

A aplicação da pesquisa documental envolve geralmente a análise de conteúdo, a qual busca a essência de um texto nos detalhes das informações, dados e evidências disponíveis. 
O interesse não se restringe à descrição dos conteúdos, mas no desejo de inferir sobre o todo da comunicação, buscando entendimentos sobre os elementos condicionantes e determinantes por trás das mensagens, bem como seus efeitos e consequências (ibid., p. 99).

\section{Análise do discurso}

A análise do discurso parte do pressuposto de que em todo discurso há um sentido oculto que pode ser captado, o qual, sem uma técnica apropriada, permanece inacessível. Logo, o foco de interesse é a construção de procedimentos capazes de transportar o olhar aparente a compreensões menos óbvias, mais profundas por meio da desconstrução do literal, do imediato (ibid, p. 100).

\section{Entrevistas espontâneas e programadas}

Com as entrevistas se pretende coletar informações, dados e evidências para fins de entendimento e compreensão do significado que entrevistados atribuem a questões e situações, em contextos que não foram estruturados anteriormente, com base nas suposições e conjecturas do pesquisador. Comumente desenvolvida nos estudos etnográficos, a entrevista espontânea ajuda na descoberta de indícios revelados com naturalidade em situações do cotidiano.

\section{Diário de bordo}

Ao desempenhar o papel de descobridor, durante o processo de coleta e levantamento de dados, informações e evidências de campo, um instrumento útil e revelador pode ser usado, principalmente nos estudos etnográficos e de participação coletiva. De acordo com Morin (2004), o diário de bordo cumpre esse papel, além de ser uma ferramenta convivial que permite ao pesquisador, ao ator, registrar suas observações diárias, suas reflexões e todos os acontecimentos importantes relacionados com as ações empreendidas.

Independentemente do método de análise e de coleta a serem adotados na pesquisa de campo, quer seja individualmente ou de forma combinada, é no momento da implementação que o pesquisador deve ficar atento às mudanças no cenário de 
investigação. Embora a implementação seja crítica para a estratégia de pesquisa ser bem sucedida, fazer com que a estratégia funcione é um enorme desafio. Uma série de fatores, incluindo questões políticas e culturais, resistência à mudança e inércia, é apontada por Hrebiniak (2005) como influenciadores que atuarão sobre a estratégia. A próxima seção descreve o cenário de pesquisa e os procedimentos operacionais para a implementação desta estratégia.

\section{3 - OPERACIONALIZAÇÃO DA PESQUISA DE CAMPO}

Uma vez superada a fase de planejamento inicial do projeto de pesquisa, culminando com a definição da orientação metodológica e dos cursos de ação para empreender a pesquisa em curso, a sua viabilização dependerá desta fase de preparo da pesquisa de campo, a qual se orienta pela satisfatoriedade dos critérios da abordagem de pesquisa integrada e sistêmica e a viabilização da escolha da unidade de investigação, além de reunir os meios e recursos necessários para desenvolvê-la.

Para executar os passos e procedimentos previstos no plano de pesquisa, especial atenção é dada às condições contextuais e circunstâncias dos cenários de pesquisa que poderão sugerir novos cursos de ação, a depender da dinâmica inerente ao contexto de análise e suas mudanças inerentes.

A pesquisa-ação permite aos atores que construam teorias e estratégias que emergem do campo e que, em seguida, são validadas, confrontadas, desafiadas dentro do campo e acarretam mudanças desejáveis para resolver ou questionar melhor uma situação problemática (Morin, 2004, p. 57).

Imbuído do desafio de experienciar na prática situações com problemas associados ao desenvolvimento organizacional, de modo que as suposições assumidas neste estudo pudessem ser instigadas por meio da pesquisa-ação-participante, o ponto de partida seria a definição do projeto de pesquisa de campo.

Diante da possibilidade de desenvolver um estudo sobre o sistema energético brasileiro, ainda na fase de prospecção e planejamento inicial, descartou-se dar prosseguimento à investigação, tendo em vista a impossibilidade de reunir condições favoráveis para 
viabilização do projeto de pesquisa-ação-participante. Conforme atesta Thiollent (2002), o mundo corporativo brasileiro ainda não assimilou os benefícios que esse tipo de pesquisa pode trazer para o desenvolvimento organizacional, tendo como principal justificativa a falta de mecanismos internos capazes de suportar investigações com essas características. Uma nova tentativa foi pensada, a propósito dos sistemas de telecomunicações, mas a peculiaridade do setor em termos de concorrência comercial recairia no mesmo caso anterior.

Adiante, três possibilidades de projeto de pesquisa de campo se apresentaram viáveis, face à natureza dos projetos e da condição de acessibilidade e participação. No primeiro caso, o projeto envolvia uma perspectiva de desenvolvimento organizacional, voltada para a modelagem de processos, com duração de dez meses. Nos demais casos, tratavam-se de dois projetos de pesquisa, desenvolvimento e inovação, fruto de cooperação institucional. O segundo projeto é de 18 meses e o terceiro de 12 meses.

Com base nas definições de Morin (2004) e Thiollent (1997), a configuração da pesquisaação-participante adotada neste trabalho está tipificada, face à natureza dos projetos de pesquisa escolhidos, da seguinte forma:

- quanto ao aspecto: é uma pesquisa por ação e pela ação - a implicação é devida à efetividade ou reciprocidade do relacionamento entre pesquisadores e atores e a clareza dos posicionamentos de cada parte no plano ético;

- quanto ao tipo de participação do pesquisador: aplicada - conforme contexto dos projetos de pesquisa; e

- quanto à dimensão: participação cooperativa - devido ao tipo de pactuação dos Órgãos participantes dos projetos de pesquisa.

A sistemática de desenvolvimento da pesquisa de campo nos projetos três projetos levará em consideração a orientação metodológica (mais detalhes na Seção 4.2.4.1) e as questões de cunho cultural e social predominantes em cada caso. Nesse sentido, Morin (2004) argumenta que, para melhor compreender o processo de mudança, é importante dar destaque às decisões do grupo, observar o grau de implicação dos sujeitos, a expressão de suas motivações, as normas de iniciação à mudança e, evidentemente, a personalidade do facilitador e sua aptidão a tornar eficaz a intervenção. 
Por se tratar de um estudo feito sob circunstâncias contextuais em resposta às realidades vividas encontradas no ambiente de campo, os estudos se desenrolam durante um período de tempo relativamente prolongado - incluindo as unidades de análise e as partes envolvidas a serem pesquisadas, cujos projetos foram concebidos de acordo com as necessidades de cada viés de interesse. A lógica da investigação é, portanto, elaborar ou expandir objetos de conhecimento teóricos fundamentados na prática da ação.

\subsection{1 - Projeto de Desenvolvimento Organizacional - Projeto Alpha}

O projeto de pesquisa de campo, denominado Projeto Alpha, é resultado de um projeto de desenvolvimento organizacional em um Órgão da Administração Direta do Governo Federal, doravante denominado Órgão de Operação Aérea, cuja participação deste pesquisador estava vinculada ao grupo de trabalho responsável pela coordenação das atividades de projeto.

O Órgão de Operação Aérea atua na execução do planejamento, do preparo, do emprego, do controle e da fiscalização das operações de uma Força Militar, neste ato denominada de Força-Mãe. O Órgão de Operação Aérea detém os mais relevantes meios aéreos, sendo o responsável, ainda, por comandar as ações de pronta-resposta, em situações de conflito ou de emergência, antes da ativação da estrutura de defesa.

Igualmente, o Órgão de Operação Aérea é o "braço operacional" da Força-Mãe, responsável pelo preparo e emprego da força operacional. Compreende cerca de $55 \%$ do efetivo da Força-Mãe e mais de cem Organizacionais Militares (OM) Apoiadas.

\subsection{2 - Projeto de PD\&I - Projeto Bravo}

O projeto de pesquisa de campo, denominado Projeto Bravo, é resultado de um projeto de cooperação técnica para desenvolvimento de Pesquisa, Desenvolvimento e Inovação (PD\&I), pleiteado por um Órgão de Tecnologia da Informação vinculado à Administração Pública Federal, doravante denominado Órgão de TI, em parceria com um Núcleo de Multimídia e Internet (NMI) da Universidade de Brasília, cuja participação deste pesquisador estava vinculada ao NMI - responsável pela coordenação técnica do projeto. 
O projeto de PD\&I é voltado para os processos e projetos de gestão e governança de tecnologia da informação do Órgão de TI.

\subsection{3 - Projeto de PD\&I - Projeto Charlie}

O projeto de pesquisa de campo, denominado Projeto Charlie, é resultado de um projeto de cooperação técnica para desenvolvimento de PD\&I, pleiteado por um Órgão de Fomento à Cultura vinculado à Administração Pública Federal, doravante denominado Órgão de Cultura, em parceria com o NMI/UnB, cuja participação deste pesquisador estava vinculada ao NMI - responsável pela coordenação técnica do projeto.

O projeto de PD\&I é voltado para os processos e projetos de suporte técnico-metodológico à implantação de uma rede de escritórios de articulação da economia criativa, aqui denominados de Escritórios de Articulação (Lima, Alves e Molinaro, 2014).

Os pontos de presença dos escritórios de articulação situam-se em treze Estados brasileiros. A implantação desses espaços, por sua fez, é proveniente de convênio pactuado entre aqueles Estados (convenentes) e um Órgão de Cultura. 


\section{5 - RESULTADOS E DISCUSSÃO}

Este capítulo apresenta os resultados das pesquisas empreendidas, as análises dos dados, informações e evidências levantadas, bem como a discussão pormenorizada da proposta de mecanismo teórico fundamentado na prática da ação. A estrutura do capítulo reflete a orientação metodológica da pesquisa-ação integrada e sistêmica - maiores detalhes na Seção 4.2.4.

\section{1 - APLICAÇÃO DOS INSTRUMENTOS DE COLETA E ANÁLISE DE DADOS}

A implementação dos projetos de pesquisa de campo ocorreram em tempos e espaços distintos e com níveis de complexidade assimétricos entre si. Em comum o fato de terem sido orientados pelos mesmos pressupostos metodológicos, com algumas variações em termos de instrumentos de coleta e análise de dados, dependendo da pertinência e da conveniência encontrada no contexto do projeto e nas circunstâncias ambientais. O Quadro 5.1 relaciona os instrumentos aplicados em cada um dos três projetos, além daqueles desenvolvidos no próprio projeto de pesquisa da tese.

Para buscar um aprofundamento intensivo e contextualizado da investigação, Morin (2004) defende o uso combinado de diferentes fontes e instrumentos de coleta de dados e informações, característico da abordagem qualitativa, de modo a assegurar a representatividade que é um aspecto característico da abordagem quantitativa.

Dentre os estudos realizados, somente o projeto charlie implementou o estudo etnográfico. A natureza do projeto, a maior disponibilidade de tempo para realizar o plano de estudo etnográfico e a participação de pesquisadores multidisciplinares, favoreceram o empreendimento da pesquisa. As mesmas condições e recursos não foram encontrados nos demais projetos. O guia de tópicos do estudo etnográfico encontra-se no Quadro D.8 Apêndice D. 
Quadro 5.1 - Aplicação dos instrumentos de coleta nas pesquisas de campo

(O autor, 2015)

\begin{tabular}{|c|c|c|c|c|}
\hline Projeto & Fontes/ Recursos & $\begin{array}{l}\text { Métodos de } \\
\text { coleta e análise } \\
\text { de dados }\end{array}$ & $\begin{array}{c}\text { Frequência / } \\
\text { Duração média }\end{array}$ & Registro \\
\hline \multirow{3}{*}{ Alpha } & $\begin{array}{l}\text { Workshop: } \\
\text { - Executivos, diretores e gerentes } \\
\text { das áreas de negócio, } \\
\text { - Analistas de processo }\end{array}$ & $\begin{array}{l}\text { - observação } \\
\text { participante }\end{array}$ & 5 seções / 30min & $\begin{array}{l}\text { - Diário de campo, } \\
\text { - Cópia do material de } \\
\text { apoio }\end{array}$ \\
\hline & $\begin{array}{l}\text { Seminário (Ação planejada): } \\
\text { - Diretores e gerentes das áreas } \\
\text { de negócio, } \\
\text { - Analistas de processo }\end{array}$ & $\begin{array}{l}\text { - observação } \\
\text { participante } \\
\text { - análise do } \\
\text { discurso }\end{array}$ & $\begin{array}{l}10 \text { seções / } \\
1 \mathrm{~h} 30 \mathrm{~min}\end{array}$ & $\begin{array}{l}\text { - Diário de campo, } \\
\text { - Roteiro de } \\
\text { intervenção } \\
\text { pedagógica }\end{array}$ \\
\hline & $\begin{array}{l}\text { Biblioteca digital: } \\
\text { - Legislação, } \\
\text { - Planos institucionais e setoriais }\end{array}$ & $\begin{array}{l}\text { - análise de } \\
\text { conteúdo }\end{array}$ & - & $\begin{array}{l}\text { - Cópia dos } \\
\text { documentos } \\
\text { selecionados }\end{array}$ \\
\hline \multirow{4}{*}{ Bravo } & $\begin{array}{l}\text { Seminário: } \\
\text { - Coordenadores e Analistas de } \\
\text { TI, } \\
\text { - Pesquisadores }\end{array}$ & $\begin{array}{l}\text { - entrevista } \\
\text { semi-estruturada } \\
\text { - análise do } \\
\text { discurso } \\
\end{array}$ & $\begin{array}{l}24 \text { seções / } \\
\text { 30min }\end{array}$ & - Diário de campo \\
\hline & $\begin{array}{l}\text { Entrevista: } \\
\text { - Coordenadores e Analistas de } \\
\text { TI, } \\
\text { - Pesquisadores }\end{array}$ & $\begin{array}{l}\text { - entrevista } \\
\text { semi-estruturada } \\
\text { - observação } \\
\text { participante } \\
\end{array}$ & $\begin{array}{l}21 \text { seções / } \\
1 \text { h30min }\end{array}$ & $\begin{array}{l}\text { - Formulário (respostas } \\
\text { anotadas pelos } \\
\text { pesquisadores), } \\
\text { - Gravação em áudio } \\
\end{array}$ \\
\hline & $\begin{array}{l}\text { Ação planejada: } \\
\text { - Coordenadores e Analistas de } \\
\text { TI, } \\
\text { - Coordenadores das áreas de } \\
\text { negócio, } \\
\text { - Pesquisadores }\end{array}$ & $\begin{array}{l}\text { - observação } \\
\text { participante }\end{array}$ & $\begin{array}{l}3 \text { seções / } \\
2 \text { h00min }\end{array}$ & $\begin{array}{l}\text { - Diário de campo, } \\
\text { - Gravação em áudio }\end{array}$ \\
\hline & $\begin{array}{l}\text { Repositórios: } \\
\text { - Normas e legislação, } \\
\text { - Planos institucionais e setoriais }\end{array}$ & $\begin{array}{l}\text { - análise de } \\
\text { conteúdo }\end{array}$ & - & $\begin{array}{l}\text { - Cópia dos } \\
\text { documentos } \\
\text { selecionados }\end{array}$ \\
\hline \multirow{6}{*}{ Charlie } & \multirow{3}{*}{ Estudo etnográfico: } & $\begin{array}{l}\text { - observação } \\
\text { participante }\end{array}$ & $\begin{array}{l}4 \text { visitações / } \\
3 \text { dias }\end{array}$ & $\begin{array}{l}\text { - Diário de campo, } \\
\text { - Gravação em áudio, } \\
\text { - Fotografia }\end{array}$ \\
\hline & & $\begin{array}{l}\text { - entrevista } \\
\text { semi-estruturada } \\
\text { - análise do } \\
\text { discurso } \\
\end{array}$ & $\begin{array}{l}8 \text { seções / } \\
1 \mathrm{~h} 30 \mathrm{~min}\end{array}$ & $\begin{array}{l}\text { - Diário de campo, } \\
\text { - Gravação em áudio }\end{array}$ \\
\hline & & $\begin{array}{l}\text { - entrevista } \\
\text { semi-estruturada }\end{array}$ & $\begin{array}{l}8 \text { seções / } \\
1 \mathrm{~h} 30 \mathrm{~min}\end{array}$ & $\begin{array}{l}\text { - Diário de campo, } \\
\text { - Gravação em áudio }\end{array}$ \\
\hline & $\frac{\text { Ação reflexiva: }}{\text { - Pesquisadores }}$ & $\begin{array}{l}\text { - entrevista } \\
\text { semi-estruturada }\end{array}$ & $\begin{array}{l}10 \text { seções / } \\
1 \mathrm{~h} 30 \mathrm{~min}\end{array}$ & $\begin{array}{l}\text { - Formulário } \\
\text { (questionário auto- } \\
\text { preenchido) }\end{array}$ \\
\hline & $\begin{array}{l}\text { Seminário (Ação planejada): } \\
\text { - Coordenadores técnicos e } \\
\text { pessoal de apoio da área de } \\
\text { negócio, } \\
\text { - Agentes de cultura e gestores } \\
\text { públicos eventuais }\end{array}$ & $\begin{array}{l}\text { - observação } \\
\text { participante }\end{array}$ & $\begin{array}{l}4 \text { seções / } \\
\text { 3h00min }\end{array}$ & $\begin{array}{l}\text { - Diário de campo, } \\
\text { - Roteiro de } \\
\text { intervenção } \\
\text { pedagógica }\end{array}$ \\
\hline & $\begin{array}{l}\text { Repositórios: } \\
\text { - Normas e legislação, } \\
\text { - Planos institucionais e setoriais }\end{array}$ & $\begin{array}{l}\text { - análise de } \\
\text { conteúdo }\end{array}$ & - & $\begin{array}{l}\text { - Cópia dos } \\
\text { documentos } \\
\text { selecionados }\end{array}$ \\
\hline
\end{tabular}


Por se tratar de uma abordagem multimetodológica, a aplicação dos instrumentos de análise permitiu explorar aspectos ou perspectivas complementares do pensamento sistêmico, obtendo os achados das pesquisas de campo. Ao longo das próximas seções serão apresentados os resultados das análises realizadas sobre o Projeto Alpha. Similarmente, os demais Projetos, Bravo e Charlie, passaram pelas mesmas análises, o que levou à decisão de não incluí-las no corpo da tese. Consequentemente, as análises previstas e realizadas que não estiverem explicitadas neste capítulo, estão disponibilizadas nos seguintes apêndices:

- Apêndice B - Projeto Alpha;

- Apêndice C - Projeto Bravo;

- Apêndice D - Projeto Charlie.

\section{2 - ESTÁGIO 0 - VISÃO MULTIDIMENSIONAL}

Para executar os quatro estágios subsequentes, a orientação metodológica pressupõe a existência deste estágio preliminar. Um construto de visão multidimensional é proposto para orientar a aplicação dos instrumentos de coleta e análise de dados, informações e evidências.

\subsection{1 - Gênese do Construto de Visão Multidimensional}

A confluência dos temas de interesse que deram origem a este projeto de pesquisa e a assimilação dos estudos sobre o pensamento complexo de Edgar Morin (Morin, 2011), o princípio sistêmico de multidimensionalidade de Jamshid Gharajedaghi (Gharajedaghi, 2011) e Michael Christopher Jackson (Jackson, 2003) e o pensamento ecossistêmico de Maria Cândida Moraes (Moraes, 2004), além de outras referências importantes que lidam com o pressuposto da multidimensionalidade, contribuíram para a idealização de uma proposta de construto baseado na visão multifacetada da realidade.

A complexidade é multidimensional e, portanto, requer abordagens diferentes para resolver os seus diferentes aspectos (Jackson, 2003). O construto é constituído de múltiplas dimensões distintamente concebidas para ampliar os horizontes de avaliação de situaçõesproblema que emergem dos contextos de negócio e de TI, com vistas à apreensão da complexidade inerente a cada um deles. São estas as dimensões do construto:

- domínio sistêmico, 
- perspectiva interna e externa,

- escopo e tempo,

- $\quad$ arquiteturas e tomada de decisão.

$\mathrm{Na}$ acepção da palavra ${ }^{12}$, o vocábulo "dimensão" denota sentido em que se mede a extensão para avaliar, podendo também significar medida ou tamanho. Na matemática, por exemplo, a dimensão de um espaço é o número de parâmetros necessários para identificar um ponto desse espaço. Já em outra fonte ${ }^{13}$, o vocábulo “dimensão” refere-se a um aspecto de uma situação, ou problema, e que o vocábulo "dimensional” tem um número específico de dimensões.

Para lidar com a complexidade em sistemas de atividade humana, um dos recursos mais poderosos é a capacidade de pensar o sistema sob várias perspectivas ou por meio de múltiplas dimensões de avaliação. Seja como um dos fundamentos do pensamento complexo (Morin, 2011), seja como um dos princípios de sistemas socioculturais (Gharajedaghi, 2011; Moraes, 2004), a multidimensionalidade define tanto as características essenciais e o comportamento de um sistema amorfo - antes de sua distinção - como o modo de observar, aprender, conhecer e compreender os aspectos multifacetados do sistema - depois de sua distinção.

A dimensão de sistemas considerada no construto remete a autores clássicos, como Ludwig Von Bertalanffy, Edgar Morin, Humberto Maturana e West Churchman, encarando a questão da complexidade sistêmica. Para Morin (2011), a dimensão de sistemas permite integrar melhor a mudança na complexidade do real.

Por mais que a lógica cartesiana seja um instrumento valioso para se raciocinar utilizando linguagem simbólica, possibilitando a construção de silogismos e estruturas argumentativas sobre elementos da realidade formalmente estabelecidos e coerentemente

${ }^{12}$ Dicionário Aurélio. Disponível em: <Dicionário Aurélio - versão completa para Smartphone>, Acesso em: 05 Fev. 2014.

${ }^{13}$ Dicionário Oxford. (1995). Oxford Advanced Learner's Dictionary, Oxford University Press, Nova Iorque, E.U.A. 
representados, quando se trata de um sistema social humano, que depende fundamentalmente da condição humana de ser e de se estabelecer individual e coletivamente, não é razoável ou suficiente esperar que qualquer tipo de associação entre conceitos impliquem deduções lógicas, sem que antes se compreenda o nível de interdependência entre eles.

A interdependência entre as tendências opostas é caracterizada por um relacionamento do tipo 'e' no lugar de um 'ou'. Ainda assim, muitas são as culturas que alimentam a falácia de assumir o tratamento de tendências opostas como uma dualidade em um jogo de soma zero. Tudo parece vir em um par de opostos: coletividade / individualidade; segurança / liberdade; modernidade / tradição, ordem / complexidade; arte / ciência e assim por diante. São moldados de tal maneira que um ganho para um está invariavelmente associado com uma perda para o outro. Se X é verdade, então não-X não pode ser verdade. Isso representa um relacionamento do tipo 'ou' (Gharajedaghi, 2004; Morin, 2011). Portanto, o princípio da multidimensionalidade assume que pode haver relacionamentos de perda/perda e ganha/ganha, bem como ganhos/perdas, da mesma forma que nega a falácia de que se $\mathrm{X}$ é bom, mais X é ainda melhor (Gharajedaghi, 2004).

Para reforçar o aspecto nocional de sistema, Moraes e Torre (2006, p. 155) esclarecem que pensar de maneira complexa é não fragmentar a realidade, nem dividir o que é relacional, mas compreender a multidimensionalidade dos processos, tanto no que se refere ao indivíduo como à sociedade. De igual modo, Morin (2011) assevera que ao admitir o pensamento complexo, não se pode isolar os objetos uns dos outros. Logo, a complexidade pressupõe a integração e o caráter multidimensional de qualquer realidade.

O paradigma cartesiano define a lógica do raciocínio analítico, focalizando as partes em detrimento do todo. Em um sistema organizacional, por exemplo, ora se evidencia o aspecto funcional, ora o processual, ora o estrutural. Para Gharajedaghi (2011) esse tipo de reflexão pressupõe que a compreensão da estrutura é suficiente para entender um sistema, ou que a função no pensamento sintético é a chave para ver o todo, ou mesmo que a lógica comportamental, por outro lado, fixa no processo, para responder a questão 'como', com a intenção de definir o todo. Cada lógica dominante tem sido adotada como conceito central de um sistema indagador diferente, produzindo uma quantidade enorme de informação e conhecimento. 
Com o intuito de reunir em um único sistema indagador os aspectos supracitados, de modo que se possa tratar o caos e a complexidade, Gharajedaghi (2011) propõe uma plataforma para concepção de arquitetura de negócio com enfoque sistêmico. A plataforma consiste na definição de conceitos e objetos de conhecimento que sintetizam as informações obtidas em iterações sucessivas de avaliação dos fatores externos à organização - para compreender o contexto, os interesses dos stakeholders e o modelo de negócio que define o propósito do sistema - e dos fatores internos, que compreendem as lógicas dominantes por função, processo e estrutura.

A atual conjuntura econômica, social e política no mundo sofrem os efeitos dos avanços tecnológicos experimentados nos últimos tempos. Não é diferente para os negócios, cujas incertezas do ambiente inviabilizam aqueles que estão presos a uma única forma de capturar e entregar valor para o mercado. Gharajedaghi (2011) ressalta que em vez disso, o sucesso depende de uma capacidade de autorenovação para criar espontaneamente funções, processos e estruturas que respondem a um cenário de negócios flutuante.

Para fundamentar seu modelo de alinhamento estratégico de negócio e TI, Henderson e Venkatraman (1993) distinguiram três dimensões necessárias:

i) alinhamento dos domínios internos e externos de TI;

ii) integração dos domínios de negócio e TI; e

iii) definição da lógica do alinhamento estratégico.

Esse modelo serviu como base para Brodbeck (2001) sustentar sua proposta de mecanismo de alinhamento de negócio e TI, tendo como principal novidade a incorporação da dimensão tempo que habilita a avaliação da dinâmica do sistema organizacional para assegurar o alinhamento estratégico.

A compreensão da complexidade sistêmica pode envolver a dimensão temporal, seja para lidar com o presente, passado e futuro, seja para regressar ou repercutir algo em curto, médio e longo prazo. Maturana e Varela (2001, p. 138) argumentam que o passado com referência de interações já ocorridas e o futuro como referência a interações a ocorrer, são dimensões valiosas para que, como observadores, nos comuniquemos mutuamente. 
Há que se considerar também que toda organização está inserida em diversos contextos, dependendo das condições ambientais e das circunstâncias as quais é submetida. Ao propor um arquétipo para tomada de decisão, Snowden e Boone (2007) classificam os problemas enfrentados pelos coordenadores em quatro dimensões, definidas de acordo com a natureza da relação de causa e efeito, quando esta existir: simples, complicado, complexo e caótico. Os três primeiros contextos exigem o exame das circunstâncias situacionais para depois agir de modo apropriado com a situação-problema. Enquanto que o contexto caótico é evidenciado quando não está claro o enquadramento em nenhum dos contextos anteriores, não sendo possível estabelecer qualquer tipo de relação de causalidade.

O contexto inovador tão comum nas organizações contemporâneas exige horizontes de tempo muito curtos para as organizações se ajustarem, agravado por um contexto de baixa previsibilidade que tipicamente assolam empresas fortemente orientadas ao conhecimento e aprendizagem organizacional (Johnson, Scholes e Whittington, 2007). Nenhum problema ou solução é válido sem a presença do contexto, pois este estabelece a natureza das relações que encerram aqueles (Gharajedaghi, 2011, p.31; Ison, 2008).

Na busca de um construto de governança de TI, Simonsson e Ekstedt (2005) confrontaram parte da literatura específica com práticas de governança de TI para definir um modelo para tomada de decisão centrada em três dimensões: domínio, escopo e tomada de decisão. O domínio contempla as unidades dimensionais vinculadas à política, processos, pessoas e tecnologias. O escopo compreende os cursos de ação tático e estratégico, tradicionalmente considerados como instâncias de direcionamento e desenvolvimento organizacionais (Johnson, Scholes e Whittington, 2007; Mintzberg, 2000). Por fim, a dimensão tomada de decisão está dividida nas unidades de compreensão, decisão e monitoramento.

Com efeito, o tomador de decisão é passível de receber informações de diversas fontes, sob os mais diversos formatos e sem uma tessitura adequada. Se não bastasse, a maneira de observar, de julgar e de agir de um decisor, depende de fatores motivacionais que nem sempre estão presentes diante de certas circunstâncias contextuais. Snowden e Boone (2007) asseveram que nem todos os líderes conseguem alcançar os resultados desejados quando se deparam com situações que exigem uma série de decisões e respostas em cenários com múltiplas dimensões de avaliação. 
Para esse fim, Lankhorst et al. (2005) mencionam que é preciso buscar a definição de uma nova dimensão de arquiteturas para expressar de forma mais clara possível as necessidades e os desejos dos tomadores de decisão. Isso vale tanto para seu próprio entendimento como para a comunicação com outros stakeholders, bem como para os desenvolvedores de sistemas, usuários finais e gestores em geral.

Pelo fato de não existir, até o momento, uma linguagem padrão para descrever arquiteturas corporativas de uma forma precisa, a ponto de conectar os domínios linguísticos existentes, a heterogeneidade dos métodos e técnicas utilizadas para documentar as arquiteturas, torna muito difícil determinar como os diferentes domínios estão interligados (Lankhorst et al., 2005).

\subsection{2 - Aplicação da Seção de Policy Delphi}

Ainda que a proposta do construto de visão multidimensional sinalizasse para perspectivas tópicas da realidade sistêmica, servindo de parâmetro para as pesquisas de campo ulteriores, era preciso assegurar o princípio de discutibilidade e de objetivação para mitigar a possibilidade de solipsismo. Segundo Demo (2014), observar tais princípios não só cumpre com o caráter de cientificidade da pesquisa, como possibilita a agregação de novos valores a uma proposta que supostamente já teria uma forma acabada, mas que poderá sofrer mudanças provenientes da discussão e do devir.

A negação do solipsismo é uma das importantes implicações da biologia do conhecer de Maturana e Varela (2001), muito bem retratado no trabalho de Vasconcellos (2013). O solipsismo é uma condição indesejável em qualquer produção científica, já que se trata de uma construção baseada unicamente na visão individual e estanque do pesquisador. Uma maneira de superar essa condição é contar com as contribuições de outras pessoas em situações de discussão em grupo ou separadamente, de maneira que elas possam partilhar as suas observações, críticas, sugestões e refutações sobre o objeto de conhecimento construído.

Os achados da pesquisa possibilitaram a distinção de múltiplas dimensões, que suportam os parâmetros de avaliação em cenários de complexidade sistêmica. A Figura 5.1 oferece uma perspectiva visual dos estudos e das pesquisas que implicaram a proposta de visão 
multidimensional. Partindo da pesquisa exploratória, que culminou com os fatores habilitadores de gestão do conhecimento, e mediante a realização de seminários e estudos orientados, que permitiu expandir os horizontes de avaliação sobre a complexidade sistêmica, foi possível definir os temas de interesse da pesquisa, que em última análise foram responsáveis pela proposta de visão multidimensional.

A partir desse entendimento e com o intuito de tornar mais robusta a proposta de visão multidimensional, diversas discussões foram desenvolvidas no âmbito das disciplinas acadêmicas de Tópicos do PPGEE da Faculdade de Tecnologia da UnB, na forma de seminários internos. Além disso, a seção de discussão em grupo foi desenvolvida por meio da técnica de policy delphi, com a participação de pesquisadores e peritos da área de negócio e de TI, atuando como coordenadores ou analistas em Órgãos estratégicos da Administração Pública Federal Brasileira.

O desenvolvimento da seção de policy delphi exigiu o atendimento a critérios de viabilização, para tornar as discussões mais produtivas e participativas (Turoff, 1975). Com isso, a seção foi realizada de acordo com uma configuração adequada ao número de participantes. A técnica foi aplicada no segundo semestre de 2012, contando com dez participantes, dos quais três eram professores-pesquisadores, quatro eram especialistas de TI e três atuavam como coordenadores da área de negócio de Órgãos Públicos Federais, instalados na cidade de Brasília. O espaço físico utilizado foi o Laboratório Núcleo de Multimídia e Internet da Universidade de Brasília, com duração aproximada de 3h00min.

A seção de discussão no formato policy delphi foi conduzida por um dos pesquisadores, desempenhando o papel de facilitador. Iniciou-se com uma breve exposição sobre a proposta de visão multidimensional, com os respectivos parâmetros de avaliação, seguida de discussões abertas dos especialistas e pesquisadores presentes. $\mathrm{O}$ suporte de um roteiro com indagações sobre as dimensões, vide Quadro A.2 (Apêndice A), ajudou a dinamizar melhor as conversações, sem ter o propósito de limitar os eixos de discussão dos participantes.

Em relação à dimensão sistêmica, todos concordaram que ela deveria fazer parte da proposta. No entanto, houve uma importante discussão sobre a pertinência de seus 
parâmetros de avaliação, tendo em vista a complexidade inerente à modelagem do contexto real, para não correr o risco de encerrar a análise na totalidade do sistema de interesse.

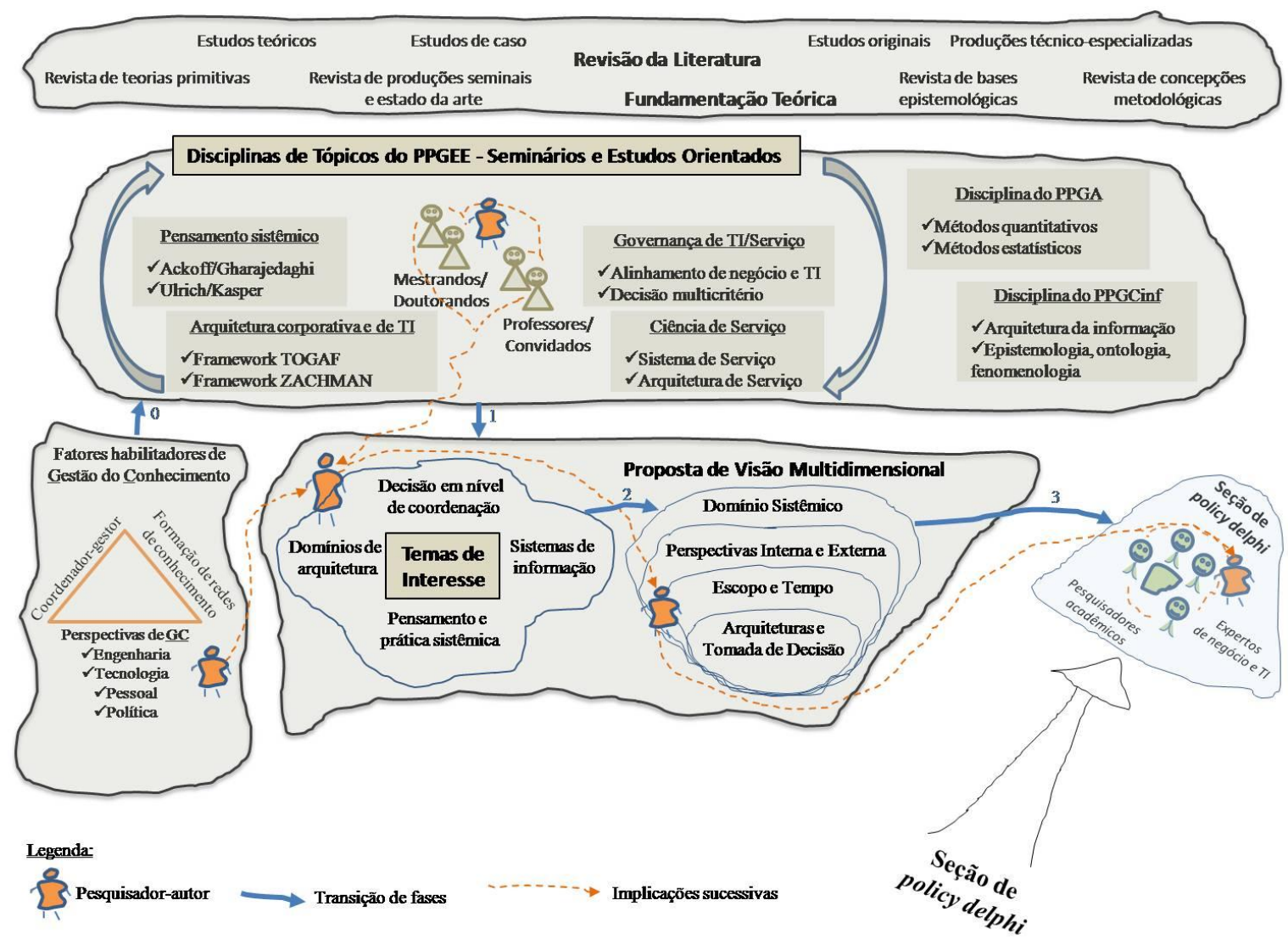

Figura 5.1 - Visão Multidimensional e Seção de Policy Delphi

(O autor, 2015)

No passo seguinte, ao abordar as perspectivas interna e externa da organização, a grande maioria dos especialistas se manifestaram favoravelmente à inclusão dessa dimensão, reforçando as suposições iniciais da pesquisa. Subsequentemente, houve um entendimento geral de que o domínio sistêmico contribuiria para a compreensão das perspectivas interna e externa.

Ao discutirem a dimensão escopo e tempo, os especialistas de negócio levantaram a possibilidade de incluir um parâmetro de avaliação em termos político, somando-se aos já existentes - estratégico e tático. No entanto, após esclarecimentos sobre a definição da dimensão escopo, enquanto curso de ação, favoreceu o entendimento geral, eliminando com isso o aspecto político. 
A dimensão tomada de decisão sofreu críticas quanto à possibilidade de agregar uma grande quantidade de informações na fase de compreensão, dificultando à análise decisória. No entanto, não houve objeção quanto aos aspectos considerados para avaliação.

Por fim, o domínio de arquiteturas foi discutido, tendo em vista a relevância dessa dimensão para o processo de comunicação do tomador de decisão. Além dos parâmetros de avaliação, baseados nas arquiteturas técnica, de negócio e de informação, os especialistas propuseram a inclusão de uma arquitetura social para melhor descrever a estrutura de pessoal, e a cultura organizacional.

Com isso, a discussão aberta entre os especialistas de negócio e de TI, juntamente com os pesquisadores, acerca da proposta dos parâmetros de avaliação para composição da visão multidimensional, propiciou o fortalecimento das suposições iniciais do framework, e trouxe contribuições novas que permitiu a sua reconfiguração. Com isso, sua configuração final contempla as dimensões e os parâmetros de aprendizagem dispostos no Quadro 5.2.

\section{3 - ESTÁGIO 1 - PROSPECÇÃO DE CONTEXTO}

Ao confrontar os estudos precedentes que levaram ao construto de visão multidimensional e as contribuições decorrentes da participação dos pesquisadores e especialistas na discussão promovida na seção de Policy Delphi, distinguimos uma melhor formatação do construto - Quadro 5.2, mantendo-se as dimensões propostas originalmente, porém incluindo ou ajustando os aspectos de aprendizagem associados a cada dimensão.

Neste Estágio 0, conforme previsto na orientação metodológica, o propósito é analisar os dados, informações e evidências coletadas em cada um dos três projetos de pesquisa de campo, para iniciar a estruturação do problema e identificar as partes constituintes dos sistemas relevantes a cada projeto de pesquisa de campo.

Os instrumentos de análise empregados neste estágio foram os seguintes:

- Definição da situação e do problema - Etapa 1 da SSM

- Roteiro para iniciar os estudos de sistemas

- Situação-problema expressa - Etapa 2 da SSM

- Mapeamento cognitivo (SODA) 
Quadro 5.2 - Construto com múltiplas dimensões e parâmetros de aprendizagem

(O autor, 2015)

\begin{tabular}{|l|ll|}
\hline \multicolumn{1}{|c|}{ DIMENSÃO } & \multicolumn{2}{|c|}{ PARÂMETROS DE APRENDIZAGEM } \\
\hline \multirow{2}{*}{ domínio sistêmico } & 1. & Reconhecimento da situação-problema real. \\
\cline { 2 - 3 } & 2. & Reconhecimento do sistema definido em torno da situação-problema. \\
\hline \multirow{2}{*}{$\begin{array}{l}\text { perspectiva interna } \\
\text { e externa }\end{array}$} & 3. & Influenciadores externos: contexto, stakeholders e modelo de negócio \\
\cline { 2 - 3 } escopo e tempo & 4. & Influenciadores internos: função, processos e estrutura \\
\hline \multirow{2}{*}{$\begin{array}{l}\text { arquiteturas e } \\
\text { tomada de decisão }\end{array}$} & 6. & Cursos de ação: estratégico e tático \\
\cline { 2 - 3 } & 6. & Horizontes temporais. \\
\hline
\end{tabular}

A Etapa um da metodologia SSM visa descrever sucintamente a situação-problema e o contexto no qual o projeto se insere. Por meio do roteiro de estudo de sistemas (Checkland, 1993), foram descritivos os elementos do sistema construído em torno da situaçãoproblema e do sistema de resolução do problema. Na Etapa dois da SSM foi construída uma figura rica representativa do sistema construído em torno da situação-problema. Já o mapeamento cognitivo é um instrumento de análise racional da situação-problema, por meio do qual construímos um mapa cognitivo, para estruturação do problema.

Os três projetos de pesquisa de campo foram analisados por meio desses instrumentos. A próxima seção apresenta os resultados das análises do Projeto Alpha. As análises dos demais projetos, Projeto Bravo e Projeto Charlie, estão disponíveis nos Apêndices C e D, respectivamente.

\subsection{1 - Prospecção de Contexto - Projeto Alpha}

\section{Definição da situação e do problema (Etapa um da SSM)}

Para apropriar-se de forma mais adequada da diversidade encontrada em um determinado cenário de pesquisa, propiciando a coleta de opiniões diferentes de partes interessadas, por meio de uma representação mais próxima possível do mundo real e do pensamento sistêmico, Peter Checkland propôs a SSM como uma metodologia flexível e bastante simples para lidar com situações-problema complexas (Jackson, 2003). 
Trata-se de um projeto de desenvolvimento organizacional implementado por um Órgão de Operação Aérea com o objetivo de modelar os processos de negócio daquela organização. O projeto durou 10 meses, com término em agosto de 2013. Um grupo de trabalho foi nomeado para desenvolver as atividades de projeto, contendo analistas de TI, dentre os quais se encontravam este pesquisador.

O Órgão de Operação Aérea apresenta uma estrutura funcional rigidamente hierarquizada, com organograma bem estruturado. Todos os setores da organização dispõem de uma norma padrão de funcionamento, baseada exclusivamente nas suas funções precípuas, definindo claramente os papéis e responsabilidades do setor e de cada colaborador. Para além dos dispositivos de regulamentação interna, que incluem outras normas, diretrizes, regimentos e códigos de conduta, o Órgão dispõe de um corpo de conhecimento doutrinário vasto e de grande utilidade para orientação e preparo de seus líderes e liderados.

No entanto, a baixa competência em mapeamento de processos e a falta de cultura de processos e projetos, dificultam a condução das atividades de gestão e governança, além de gerar ineficiência por conta de retrabalho, sobreposição de tarefas e má distribuição das atividades. O predomínio da lógica orientada a funções explica parte das dificuldades encontradas. Embora haja resistência por parte das diretorias e gerências, a alta administração entende que o mapeamento de processos pode contribuir para a tomada de decisão em nível de direcionamento, além de melhorar os indicadores de desempenho organizacionais. Diante desse cenário, e tendo como principal patrocinador o Presidente do Órgão, o projeto de modelagem de processos foi iniciado com o propósito de mapear e modelar os processos de negócio.

\section{Roteiro para iniciar os estudos de sistemas}

O modelo de um sistema de atividade humana contém um conjunto de atividades conectadas entre si. A linguagem básica utilizada para construção do modelo é, portanto, assentada nos verbos enunciados pelo analista. O modelo conterá o número mínimo de verbos necessários para o sistema ser nomeado e descrito sucintamente pelas definiçõesraiz (Checkland, 1993, p. 286). O Quadro 5.3 apresenta os resultados da análise que permitiu evidenciar importantes desígnios sobre a constituição da situação-problema 
concernente ao Projeto Alpha. Esta análise ajuda no esclarecimento de questões-chave que envolve a participação dos principais interessados na resolução do problema.

\section{Quadro 5.3 - Roteiro para iniciar os estudos de sistemas: Projeto Alpha}

\section{(Checkland 1993, p. 294, modificado)}

\begin{tabular}{|c|c|}
\hline \multicolumn{2}{|r|}{ Considerar o cliente } \\
\hline 1. Quem é o cliente? & $\begin{array}{l}\text { Presidência da República. Autoridades públicas federais brasileiras. } \\
\text { Instituições de ensino e autoridades do sistema de defesa aéreo brasileiro. } \\
\text { Sociedade. }\end{array}$ \\
\hline 2. Quais são suas aspirações? & $\begin{array}{l}\text { Acesso aos meios aeroespaciais para realizar ações de preparo, defesa e/ou } \\
\text { transporte. }\end{array}$ \\
\hline \multicolumn{2}{|c|}{ Considerar o sistema constituído em torno do problema } \\
\hline $\begin{array}{l}\text { 3. Quem são os detentores do papel de conhecedor } \\
\text { do problema? }\end{array}$ & $\begin{array}{l}\text { Chefias de Divisão e Chefiais Setoriais. } \\
\text { Supervisores e encarregados setoriais. }\end{array}$ \\
\hline $\begin{array}{l}\text { 4. Quem são os detentores do papel de tomador de } \\
\text { decisão? }\end{array}$ & $\begin{array}{l}\text { Alta Administração do Órgão. } \\
\text { Chefias de Divisão e Chefiais Setoriais. }\end{array}$ \\
\hline $\begin{array}{l}\text { 5. A versão consensuada dos tomadores de decisão } \\
\text { sobre a natureza do problema, é: }\end{array}$ & Estrutura de governança de processos insatisfatória. \\
\hline $\begin{array}{l}\text { 6. As razões consensuadas dos tomadores de decisão } \\
\text { para considerar "o problema" como o problema, } \\
\text { são: }\end{array}$ & $\begin{array}{l}\text { Ausência de mecanismos de medição de desempenho. } \\
\text { Desconhecimento da estrutura de processos de negócio e de trabalho dos } \\
\text { setores da organização. } \\
\text { Baixa capacidade de inovação. } \\
\text { Alta Administração e Chefias de Divisão com sobrecarga de trabalho. } \\
\text { Dificuldade em dimensionar capacidades técnicas e de competências da } \\
\text { organização. }\end{array}$ \\
\hline $\begin{array}{l}\text { 7. As expectativas consensuadas dos tomadores de } \\
\text { decisão sobre o sistema de resolução de } \\
\text { problemas, são: }\end{array}$ & $\begin{array}{l}\text { Reorganizar processos e atividades de negócio. } \\
\text { Estruturar um sistema de governança de processos de negócio (em termos } \\
\text { de estrutura, funcionamento e políticas). } \\
\text { Atualizar procedimentos operacionais internos contemplando as atividades } \\
\text { de negócio mapeadas. }\end{array}$ \\
\hline $\begin{array}{l}\text { 8. A resposta para o item 6. sugere a seguir as que } \\
\text { são altamente avaliadas pelos tomadores de } \\
\text { decisão. }\end{array}$ & $\begin{array}{l}\text { Ausência de mecanismos de medição de desempenho. } \\
\text { Alta Administração e Chefias de Divisão com sobrecarga de trabalho. } \\
\text { Dificuldade em dimensionar capacidades técnicas e de competências da } \\
\text { organização. }\end{array}$ \\
\hline $\begin{array}{l}\text { 9. A versão consensuada dos conhecedores do } \\
\text { problema sobre a natureza do problema, é: }\end{array}$ & $\begin{array}{l}\text { Dinâmica interna das áreas funcionais do Órgão de modo assíncrono, sem } \\
\text { mecanismos de ligação dos processos transversais. }\end{array}$ \\
\hline $\begin{array}{l}\text { 10. As razões dos conhecedores do problema para } \\
\text { considerar "o problema" como o problema, são: }\end{array}$ & $\begin{array}{l}\text { Organização com foco em desenvolvimento e entrega. } \\
\text { Alto índice de retrabalho nas Divisões e áreas funcionais do Órgão. } \\
\text { Gerências funcionais com dificuldade de comunicação intersetorial. } \\
\text { Ausência de catálogo e acordos de níveis de serviço. } \\
\text { Baixo nível de competências em termos de gestão de processos e projetos. } \\
\text { Inexistência de um plano de comunicação interno satisfatório. } \\
\text { Necessidade de capacitação e aplicação de tecnologias de gestão. }\end{array}$ \\
\hline $\begin{array}{l}\text { 11. As expectativas consensuadas dos conhecedores } \\
\text { do problema sobre o sistema de resolução de } \\
\text { problemas, são: }\end{array}$ & $\begin{array}{l}\text { Reposicionar a Instituição para atuar sumariamente como direcionadora, } \\
\text { estabelecendo mecanismos de planejamento, gestão e controles para as OM } \\
\text { apoiadas. } \\
\text { Revisar competências essenciais das Divisões e áreas funcionais do Órgão. } \\
\text { Desenvolver plano de capacitação em gestão orientada a processos. } \\
\text { Criar setor de gerência de processos e projetos do Órgão. }\end{array}$ \\
\hline $\begin{array}{l}\text { 12. A resposta para o item 10. sugere a seguir os que } \\
\text { são altamente avaliados pelos conhecedores do } \\
\text { problema. }\end{array}$ & $\begin{array}{l}\text { Organização com foco em desenvolvimento e entrega. } \\
\text { Alto índice de retrabalho nas Divisões e áreas funcionais do Órgão. } \\
\text { Baixo nível de competências em termos de gestão de processos e projetos. }\end{array}$ \\
\hline $\begin{array}{l}\text { 13. Alguns nomes possíveis para o sistema que } \\
\text { contém o problema, são: }\end{array}$ & $\begin{array}{l}\text { Sistema de direcionamento estratégico. } \\
\text { Sistema de gestão de preparo e emprego. } \\
\text { Sistema de governança de processos de negócio. }\end{array}$ \\
\hline \multirow[t]{2}{*}{$\begin{array}{l}\text { 14. Ao descrever inicialmente o sistema determinado } \\
\text { pelo problema, os seguintes elementos parecem } \\
\text { propensos a serem relevantes: }\end{array}$} & $\begin{array}{l}\text { Substantivos - processo, sistema, arquitetura, projeto, missão, competência, } \\
\text { capacidade, logística, subsistência, infraestrutura, tecnologia, hierarquia, } \\
\text { disciplina, doutrina. }\end{array}$ \\
\hline & Verbos - planejar, direcionar, medir, reposicionar, sistematizar, comunicar, \\
\hline
\end{tabular}




\begin{tabular}{|c|c|}
\hline & $\begin{array}{l}\text { reconhecer, mapear, reunir, controlar, habilitar, facilitar, coordenar, } \\
\text { comandar, obedecer. }\end{array}$ \\
\hline $\begin{array}{l}\text { 15. Restrições ambientais sobre o sistema } \\
\text { determinado pelo problema, são: }\end{array}$ & $\begin{array}{l}\text { Inexistência de estrutura de governança de processos. Código de conduta } \\
\text { baseado nos princípios de hierarquia e disciplina. Relações institucionais } \\
\text { com os demais Órgãos da Força-Mãe assimétricas. }\end{array}$ \\
\hline \multicolumn{2}{|c|}{ Considerar o sistema de resolução de problema } \\
\hline $\begin{array}{l}\text { 16. Os detentores do papel de solucionadores do } \\
\text { problema são: }\end{array}$ & Especialistas do negócio e analistas de processos. \\
\hline $\begin{array}{l}\text { 17. As outras pessoas (papéis) no sistema de } \\
\text { resolução de problema são: }\end{array}$ & Especialistas-técnicos. \\
\hline \multicolumn{2}{|c|}{$\begin{array}{l}\text { 18. Os recursos do sistema de resolução do problema são: } \\
\text { a. Pessoas (papéis) - supervisores e encarregados setoriais, instituições de cooperação e consultoria em tecnologias de gestão e } \\
\text { governança. } \\
\text { b. Recursos físicos - salas de reunião para treinamentos, workshops e planejamento interativo, sala de comando e controle, } \\
\text { infraestrutura de apoio do gabinete. } \\
\text { c. Capacidades distintivas - sistema de inteligência, base de conhecimento técnico altamente especializado, plataforma } \\
\text { operacional. } \\
\text { d. Financeiro - orçamento e financeiro definidos pela União e Força-Mãe e executados pelo próprio Órgão; } \\
\text { e. Horizonte temporal - objetivos estratégicos de longo prazo contidos nos planos setoriais, revisados anualmente para orientar } \\
\text { os planos operativos do Órgão e suas OM apoiadas. }\end{array}$} \\
\hline $\begin{array}{l}\text { 19. Restrições ambientais prováveis ou conhecidas } \\
\text { sobre o sistema de resolução de problema são: }\end{array}$ & $\begin{array}{l}\text { - } \quad \text { Assimetria com Órgãos congêneres e Órgãos apoiados, sistema de } \\
\text { normatização e doutrinamento corrente. }\end{array}$ \\
\hline $\begin{array}{l}\text { 20. Os solucionadores do problema saberão quando o } \\
\text { problema poderá ser solucionado: }\end{array}$ & Ao término do atual ciclo gestor do Órgão. \\
\hline
\end{tabular}

\section{Situação-problema expressa (Etapa 2 da SSM)}

É por meio da figura rica que se pode expressar visualmente a situação real e o entorno do problema ou questão de interesse. A Figura 5.2 idealiza um quadro panorâmico que remete a atuação do Órgão de Operação Aérea tanto em nível de preparação e planejamento como em nível de emprego e operação. Para se preparar é preciso doutrinar e aparelhar, enquanto que para se empregar os meios aéreos é preciso ter comando e controle. Há uma estrutura organizacional reconhecidamente clara, o mesmo não se pode dizer dos processos essenciais de viabilização do atendimento às autoridades e entidades externas que demandam apoio aéreo.

\section{Mapeamento cognitivo (SODA)}

Há uma tendência crescente em combinar os elementos das principais abordagens de estruturação de problema tanto por parte dos pesquisadores como em relação aos profissionais sistêmicos. Por exemplo, o uso de figuras ricas visa entender a situaçãoproblema em um primeiro estágio, para depois se apropriar de métodos típicos como o SODA, incluindo mapeamento cognitivo e análise de decisão (SEAGRIFF E LORD, 2009). 
Esta aplicação analítica do mapeamento SODA, no coração da SSM, sugere que a ligação multimetodológica entre as duas metodologias constitua um conjunto metodológico maior que deve ser considerado sempre que uma ou outra metodologia esteja sendo utilizada. Pois, mesmo que uma situação problemática seja abordada inicialmente por meio de SODA, as construções resultantes das múltiplas interligações podem exigir sua operacionalização (GEORGIOU, 2012).

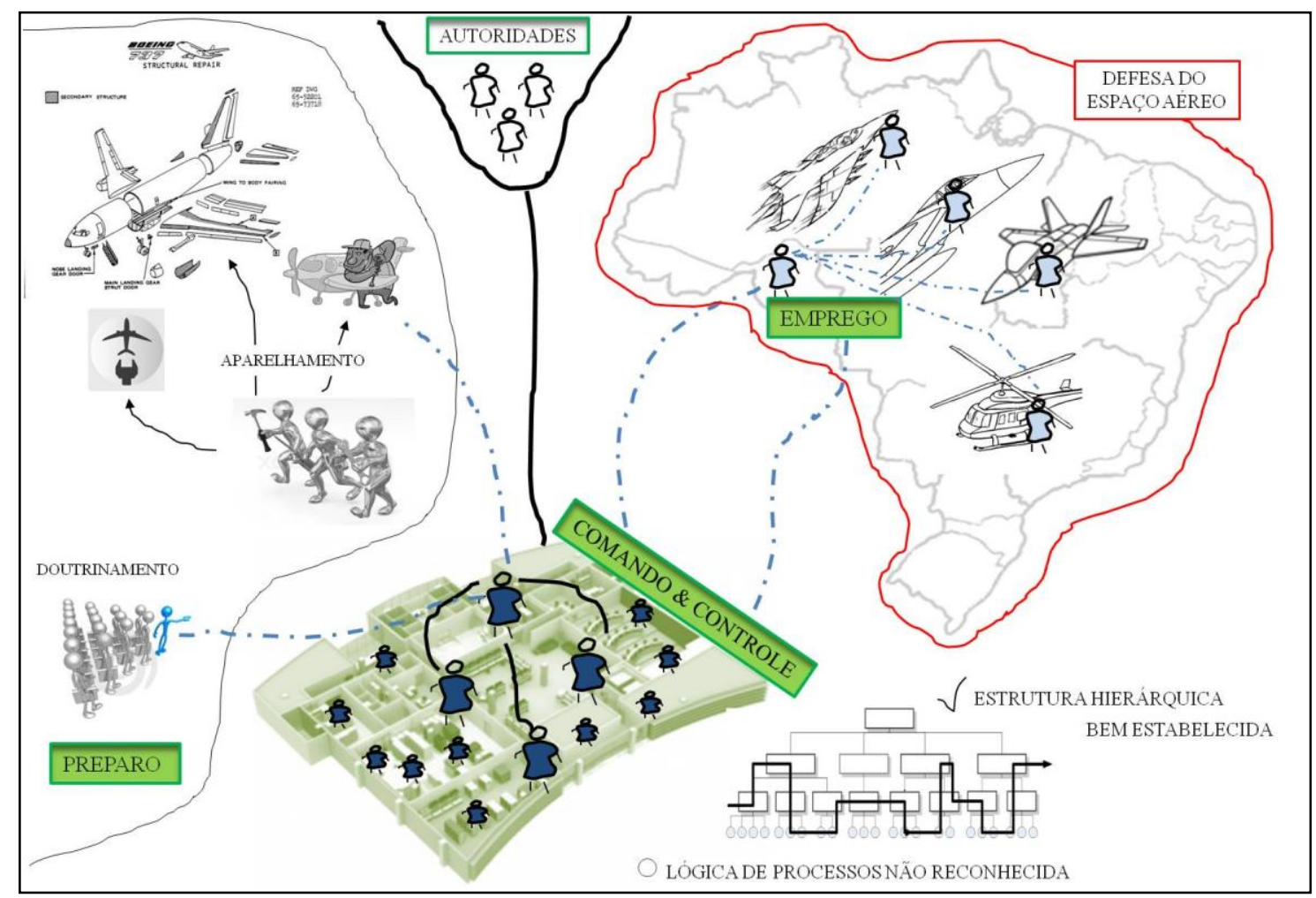

Figura 5.2 - Figura rica: Projeto Alpha

(O autor, 2015)

SODA é uma abordagem que emprega o mapeamento cognitivo para realizar a análise e desenvolvimento de opções estratégicas. Partindo dos principais objetivos pretendidos para o Projeto Alpha, os recursos e meios potenciais que contribuem para o alcance dos objetivos e as ações ativadoras que iniciam as respectivas frentes estratégicas, foram identificados e dispostos segundo as relações tributárias que cada um teria em relação às opções estratégicas, conforme pode ser visto na Figura 5.3. 


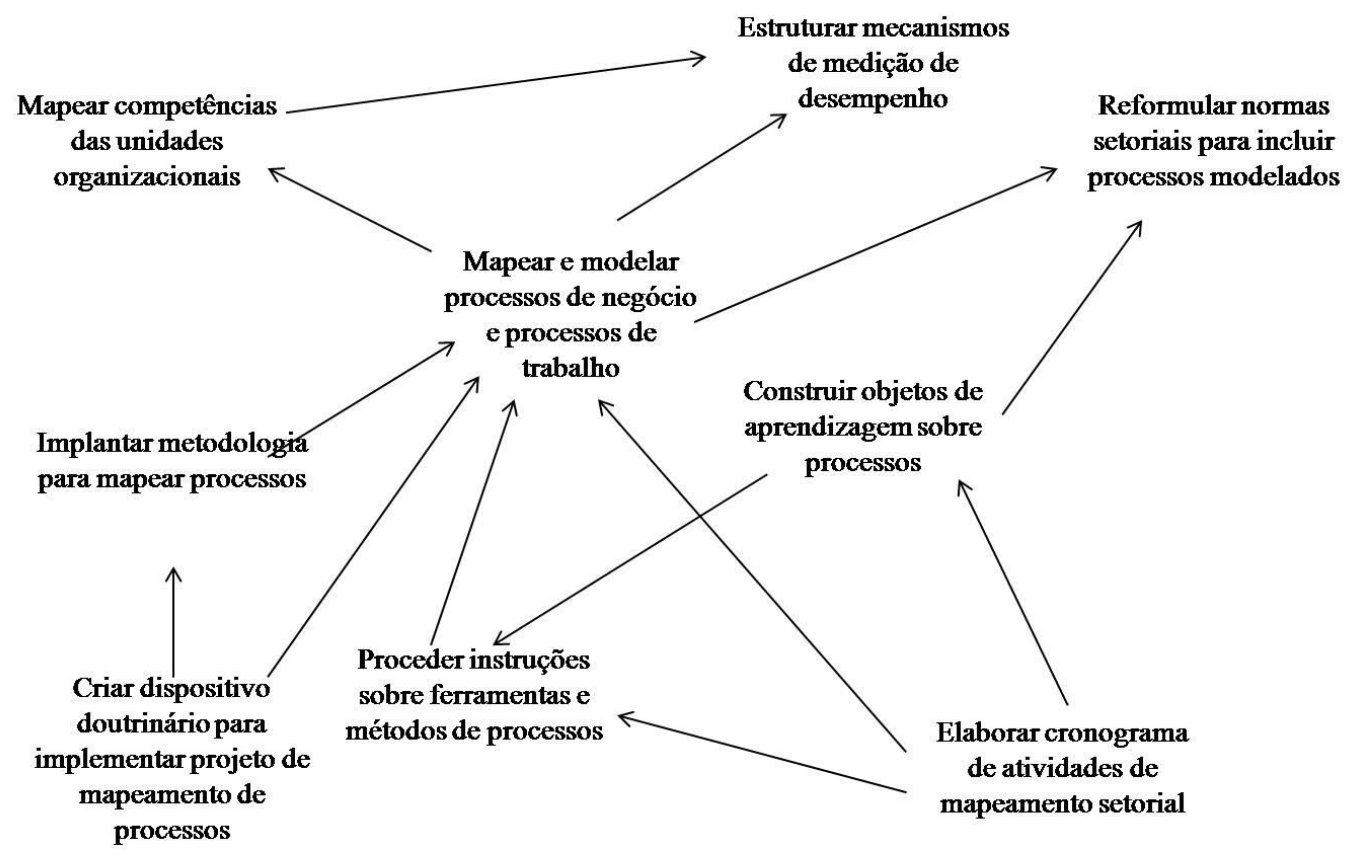

Figura 5.3 - Mapa Cognitivo: Projeto Alpha

(O autor, 2015)

\section{4 - ESTÁGIO 2 - DISTINÇÃO DO SDP}

O propósito deste estágio é avançar na compreensão da situação-problema por meio de análises que permitam distinguir o sistema determinado pelo problema.

Os resultados das análises estão sintetizados nos seguintes instrumentos:

- definição raiz dos sistemas relevantes CATWOE (Etapa 3 da SSM),

- mapeamento conceitual (Etapa 4 da SSM),

- aspectos da análise de fronteira,

- dimensões da tipologia de rede,

- matriz de atribuição de responsabilidades RACI,

- prospecção da capacidade de atuação do sistema de TI,

- categorias avaliativas da análise de fronteira, e

- matriz de relacionamento dos atores.

\subsection{1 - Distinção do SDP - Projeto Alpha}

Os resultados das análises empreendidas no Estágio 1 do Projeto Alpha, permitiram esclarecer a magnitude e a extensão do problema, uma vez que os atores da pesquisa 
puderam se manifestar sobre a situação, com os seus respectivos pontos de vista. As condicionantes do ambiente, as questões institucionais e o formato de participação dos atores da pesquisa e das demais partes envolvidas no projeto, foram importantes para entender o que cada um demandava ou ofertava, o seu papel e os seus interesses e as principais expectativas.

\section{Definições essenciais do sistema relevante (Etapa 3 da SSM)}

Trata-se de um instrumento de análise proposto por Checkland e Scholes (1990) que visa sintetizar as definições essenciais para modelar o sistema determinado pela situaçãoproblema. Para elaborar a análise, as seguintes questões avaliativas foram consideradas (ibid.):

- Quais as diferentes perspectivas de compreensão da situação-problema?

- Considerando cada perspectiva, o que poderia ser feito, para quem, o quê, com quais pressupostos e em que tipo de ambiente?

Complementarmente ao mapeamento cognitivo, se usam na metodologia SSM várias técnicas particulares, como, por exemplo, o CATWOE que consiste em coletar e ordenar a informação sobre a situação investigada a ser transformada, de acordo com a sequência estabelecida e levando em conta as implicações de todos os atores envolvidos (Thiollent, 1997). De forma a enriquecer a técnica CATWOE, foi emprega a técnica TASCOI, proposta por Espejo et al. (1996, p. 49), para caracterizar o sistema de interesse. Ambas as abordagens estão descritas de forma integrada no Quadro 5.4.

\section{Mapeamento conceitual (Etapa 4 da SSM)}

Uma vez definidas as questões essenciais para descrever o sistema relevante, a modelagem conceitual permite refletir sobre sua composição e estrutura de conceitos, conforme ilustrado na Figura 5.4. O objetivo é alcançar um emparelhamento das definições essenciais (o que é o sistema) e o modelo conceitual (o que o sistema faz), de forma a torná-los coerentes entre si (Checkland, 1993, p. 290). 
Quadro 5.4 - Definições-chave do sistema relevante: Projeto Alpha

(Checkland e Scholes, 1990, p. 35, modificado)

\begin{tabular}{|c|c|c|}
\hline Definições & Abordagens & Definições \\
\hline Visão de mundo & CATWOE & $\begin{array}{l}\text { Aperfeiçoamento contínuo do sistema de inteligência de preparo e } \\
\text { emprego dos meios aeroespaciais. }\end{array}$ \\
\hline Atores & $\begin{array}{l}\text { CATWOE, } \\
\text { TASCOI }\end{array}$ & $\begin{array}{l}\text { Alta administração da Instituição. Diretores e gerentes de nível } \\
\text { médio. Encarregados e supervisores setoriais. Analistas de processos. }\end{array}$ \\
\hline Fornecedores & TASCOI & $\begin{array}{l}\text { Empresas de prestação de serviço especializado e de apoio. } \\
\text { Empresas fornecedoras de equipamentos e itens de subsistência e } \\
\text { logística. }\end{array}$ \\
\hline Clientes & $\begin{array}{l}\text { CATWOE, } \\
\text { TASCOI }\end{array}$ & $\begin{array}{l}\text { Presidência da República. Autoridades públicas federais brasileiras. } \\
\text { Instituições de ensino e comando do sistema de defesa aéreo } \\
\text { brasileiro. Sociedade. }\end{array}$ \\
\hline Proprietários & $\begin{array}{l}\text { CATWOE, } \\
\text { TASCOI }\end{array}$ & O Estado e a sociedade brasileira. \\
\hline Interventores & TASCOI & $\begin{array}{l}\text { O Estado, por meio do sistema jurídico e dos princípios } \\
\text { constitucionais dirigidos à Administração Pública Federal. }\end{array}$ \\
\hline $\begin{array}{l}\text { Restrições } \\
\text { ambientais }\end{array}$ & CATWOE & $\begin{array}{l}\text { Inexistência de estrutura de governança de processos. Código de } \\
\text { conduta baseado nos princípios de hierarquia e disciplina. Relações } \\
\text { institucionais assíncronas. }\end{array}$ \\
\hline
\end{tabular}

\section{Legenda:}

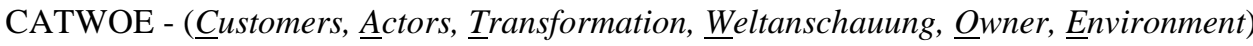

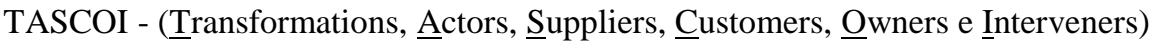

\section{Aspectos da análise de fronteira}

Ulrich (1987) propõe um instrumento de análise de fronteira do sistema de referência para poder realizar o diagnóstico da heurística sistêmica crítica. É o sistema de referência que determina quais observações (fatos) e avaliações (valores) são considerados relevantes quando avaliamos os méritos e deficiências de uma proposição (Garrossini, 2010).

A aplicação deste instrumento é destinada a abrir possibilidades de se pensar a partir de pontos de vista múltiplos do contexto do sistema de operação do Órgão de Operação Aérea - Projeto Bravo, onde o problema não se limita a suas fronteiras e onde as possibilidades de resolução ultrapassam as tradicionais formas de compreensão da realidade analisada. 


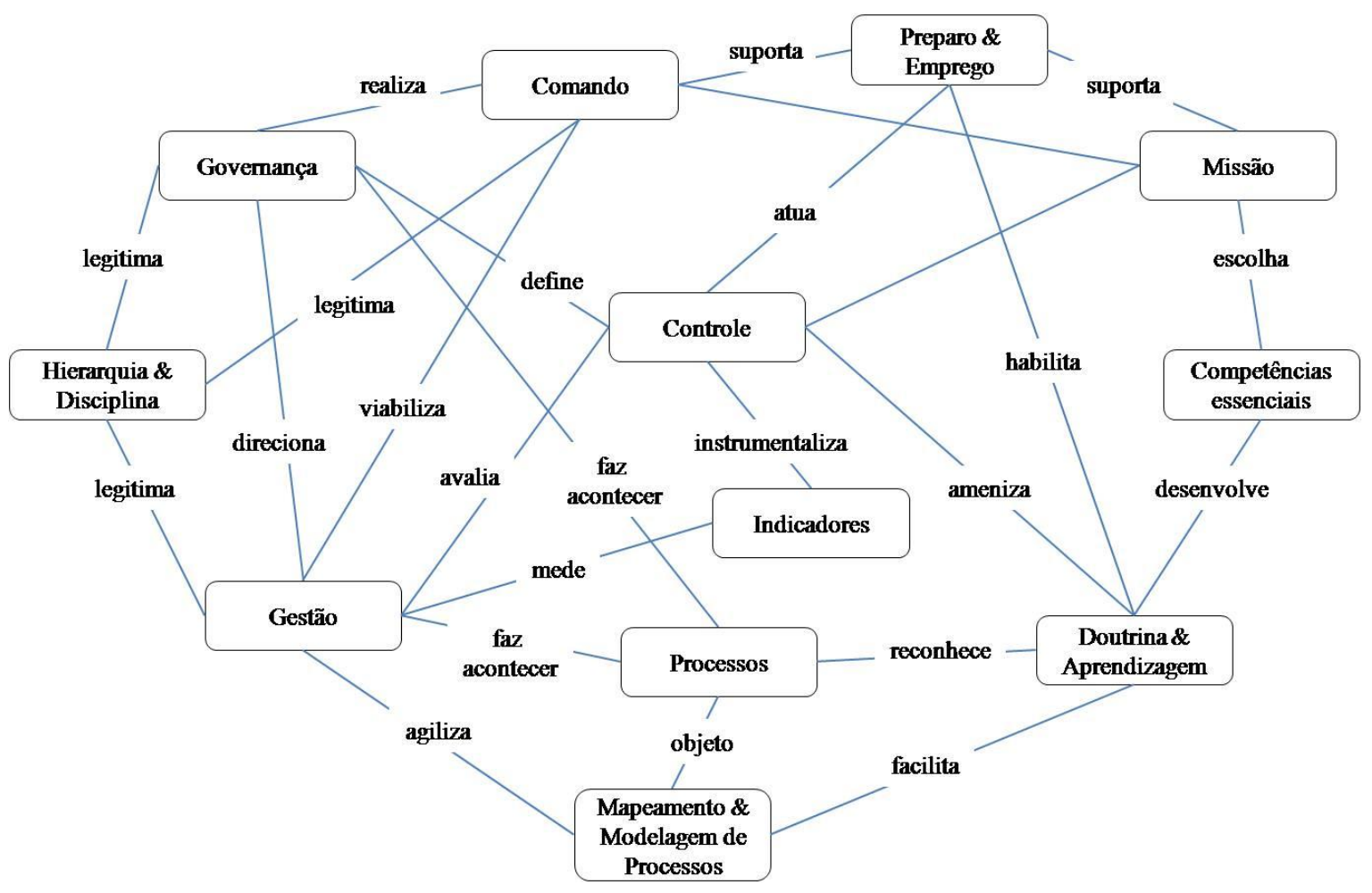

Figura 5.4 - Mapa Conceitual - Projeto Alpha

(O autor, 2015)

O mapeamento de um sistema e seu desenho pode ser efetuado a partir de diversas técnicas. Optou-se aqui por utilizar o mapa de relacionamento para construir as relações possíveis entre os atores. O mapa tem como propósito descrever os relacionamentos entre os atores do processo a ser descrito. Além disso, fornece uma visão sobre as entradas e saídas por onde fluem as "funções" de cada ator, permitindo que encontremos as "lacunas", ou, no caso deste trabalho, as falhas no processo de comunicação entre os atores. A descrição dos aspectos da análise de fronteira está disponível no Apêndice B Quadro B.1.

\section{Atributos da Análise de Redes Sociais (ARS)}

A ARS proposta para este estágio não foi conduzida no projeto alpha. Por se tratar de uma estrutura institucionalizada e funcionalmente verticalizada, cujas relações entre os atores e os poderes estabelecidos são condicionadas pela posição na hierarquia e a legitimação de poder claramente definida, a aplicação dos atributos de ARS apenas confirmariam a configuração formal existente. 
Não obstante a ARS não ter sido desenvolvida para este Projeto, os seguintes instrumentos de análise foram executados para uma melhor compreensão das relações e das questões comportamentais envolvendo os atores:

- Dimensões da tipologia de rede - Apêndice B - Quadro B.2

- Matriz de atribuição de responsabilidades RACI - Apêndice B - Quadro B.3

- Prospecção da capacidade de atuação do sistema de TI - Apêndice B - Quadro B.4

- Categorias avaliativas da análise de fronteira - Apêndice B - Quadro B.5

- Matriz de relacionamento dos atores - Apêndice B - Tabela B.1

\section{5 - ESTÁGIO 3 - AÇÃo PEDAGógICA}

Neste estágio se busca equalizar as mudanças desejadas e a viabilização do modelo sistêmico frente ao mundo real, para então negociar e desenvolver as intervenções de melhoria no âmbito do sistema de atividade humana vinculado a cada projeto.

Instrumentos de análise empregados neste estágio:

- Estágio 5 da SSM - Comparar modelo conceitual com a realidade,

- Etapa 6 da SSM - Mudanças possíveis e desejadas,

- Modelo de viabilidade de sistemas de Stafford Beer,

- Descrição do modo de intervenção,

- Estágio 7 da SSM - Ações para melhoria da situação-problema.

\subsection{1 - Ação Pedagógica - Projeto Alpha}

As análises realizadas nos três estágios anteriores proporcionaram um conjunto de informações e vestígios que permitiram as seguintes constatações:

- baixa cultura de processos e projetos;

- estrutura rigidamente hierárquica, com pouca fluidez em termos de processos de negócio;

- normas de procedimentos operacionais centradas em funções;

- inexistência de arquitetura corporativa de tecnologia da informação; e

- número insatisfatório de especialistas de TI. 


\section{Comparar modelo conceitual com a realidade (Estágio 5 da SSM)}

Para Checkland e Scholes (1990) este é um ponto de inflexão, já que presume o retorno ao mundo real e ao modelo sistêmico para realizar uma análise confrontativa. Os quatro modos de fazê-la estão relacionadas adiante:

i) discussões não estruturadas,

ii) questionamento estruturado do modelo usando uma abordagem matricial,

iii) cenário ou modelagem dinâmica, $\mathrm{e}$

iv) tentativa de modelar o mundo real usando a mesma estrutura que o modelo conceptual (de sistemas).

\section{Mudanças possíveis e desejadas (Etapa 6 da SSM)}

Fruto da comparação anterior, o Quadro 5.5 apresenta as mudanças que serviram de parâmetro para o modo de intervenção.

Após avaliação conjunta dos atores da pesquisa com o grupo de trabalho do projeto e pesquisadores, para viabilidade das mudanças propostas, as três primeiras mudanças foram as únicas consideradas factíveis para aquele momento, dadas as condições de análise anteriores e a capacidade de atuação sob a perspectiva sistêmica.

Quadro 5.5 - Mudanças desejáveis e factíveis: Projeto Alpha

(O autor, 2015)

\begin{tabular}{|c|c|c|}
\hline MUDANÇAS & DESEJÁVEIS & FACTÍVEIS \\
\hline Implementação de oficinas de ativação para as chefias setoriais. & $\operatorname{Sim}$ & Sim \\
\hline Implantação de metodologia de mapeamento de processos de negócios. & Sim & Sim \\
\hline Mapeamento e modelagem de processos de negócio e de trabalho. & Sim & Sim \\
\hline Definir mecanismos de medição de desempenho. & Sim & Não \\
\hline $\begin{array}{l}\text { Propor estrutura de processos de negócio e de trabalho dos setores da } \\
\text { organização. }\end{array}$ & Sim & Não \\
\hline Definir mecanismos de inovação de processos. & Sim & Não \\
\hline Mapear competências essenciais dos setores da organização. & Sim & \\
\hline Dimensionar capacidades técnicas de atuação operacional da organização. & Sim & Não \\
\hline Definir plano de comunicação intersetorial. & Sim & Não \\
\hline Estruturar escritório de gestão de processos e projetos. & Não & Não \\
\hline Capacitar e aplicar tecnologias de gestão. & Não & Não \\
\hline
\end{tabular}




\section{Modelo de viabilidade de sistemas}

Por meio da avaliação feita com base no modelo de sistema viável, apresentado na Figura 5.5, o sistema relevante para resolução do problema passou por análise considerando seus principais subsistemas, a saber: política, inteligência, controle, monitoramento, coordenação e unidades operacionais. Dentre estes, apenas o sistema de coordenação não é formalmente estabelecido, apesar de ser exercido de forma cumulativa pelas três principais diretorias do Órgão de Operação Aérea.

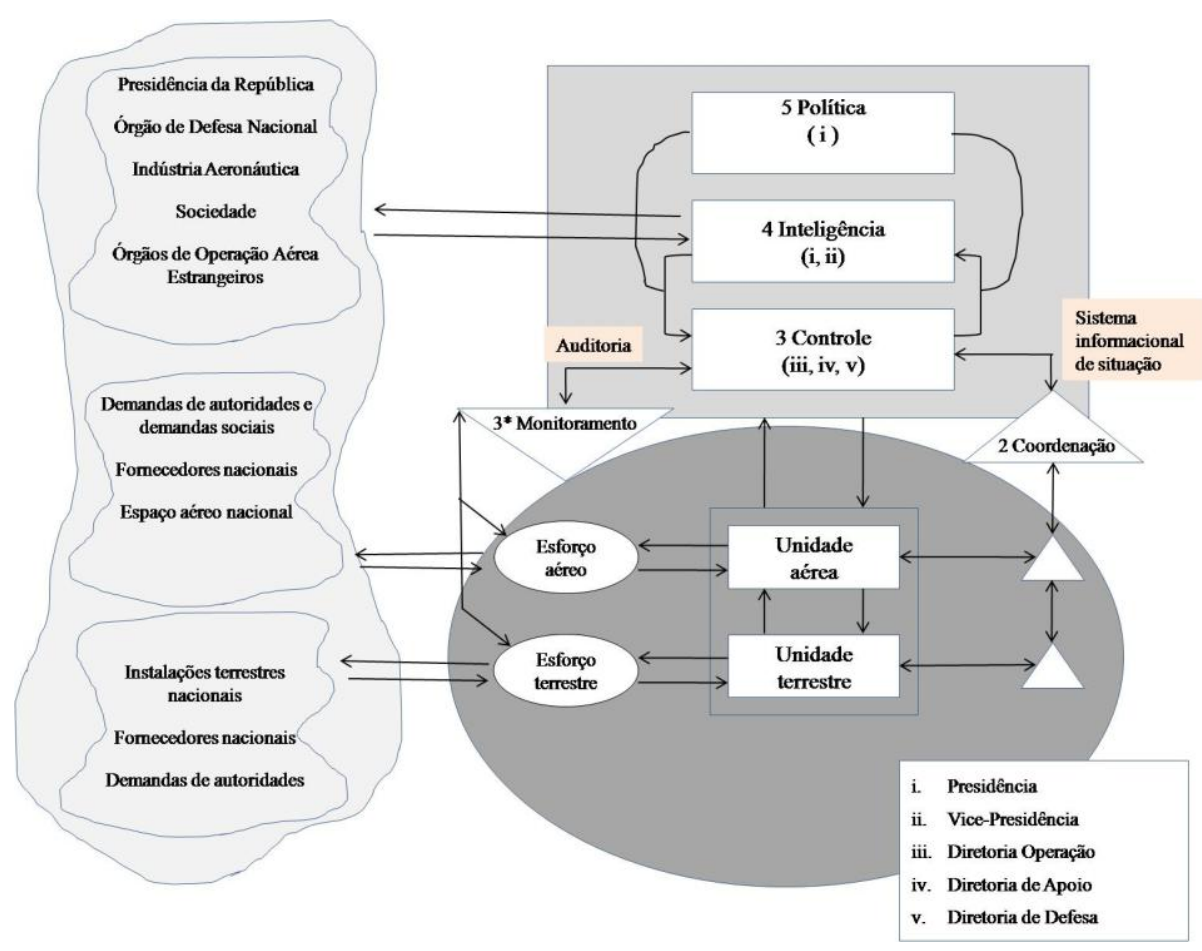

Figura 5.5 - Modelo de viabilidade de sistemas

(O autor, 2015)

Os resultados obtidos a partir das intervenções realizadas no contexto do sistema de atividade humana do Órgão de Operação Aérea permitiram delinear as ações programadas e as ações executadas, os benefícios e as dificuldades encontradas - Quadro 5.6.

\section{Ações para melhoria da situação-problema (Estágio 7 da SSM)}

A configuração do sistema organizacional do Órgão de Operação Aérea sinaliza para o sistema de coordenação uma função de viabilização do alinhamento entre o sistema de inteligência com o sistema de operação. Na medida em que se observam os princípios de 
auto-organização e adaptabilidade, qualquer função de regulação do sistema organizacional requer a atuação efetiva dos sistemas de controle e de monitoramento para manter uma condição de estabilidade. Mediante múltiplos ajustes na dinâmica do sistema de operação, por exemplo, alterando o ciclo de produção e operação, poderá melhorar o grau de atratividade dos sistemas.

Quadro 5.6 - Síntese dos resultados da ação executada: Projeto Alpha

(O autor, 2015)

\begin{tabular}{|c|c|c|}
\hline & \multicolumn{2}{|c|}{ Resultados Alcançados } \\
\hline \multirow{3}{*}{$\begin{array}{c}\text { Ações } \\
\text { Programadas } \\
\& \\
\text { Ações } \\
\text { Executadas }\end{array}$} & $\begin{array}{l}\text { Implementação de oficinas de } \\
\text { inquietação e ativação para as } \\
\text { chefias setoriais. }\end{array}$ & \\
\hline & $\begin{array}{l}\text { Implantação de metodologia de } \\
\text { mapeamento de processos de } \\
\text { negócios e de trabalho. }\end{array}$ & $\begin{array}{l}\text { Muitas dificuldades dos atores no emprego da } \\
\text { metodologia, devido a: conceitos novos, relutância e } \\
\text { indisponibilidade. }\end{array}$ \\
\hline & $\begin{array}{l}\text { Mapeamento e modelagem de } \\
\text { processos de negócio e de trabalho. }\end{array}$ & $\begin{array}{l}\text { Primeira versão dos processos de trabalho } \\
\text { mapeados. Baixa produtividade e pouco } \\
\text { envolvimento. }\end{array}$ \\
\hline & \multicolumn{2}{|c|}{$\begin{array}{l}\text { Potencializou a discussão interna sobre os fluxos de trabalho dos setores da organização. } \\
\text { Permitiu refletir sobre anomalias existentes: } \\
\text { - } \quad \text { Recursos mal empregados em algumas atividades; } \\
\text { - } \quad \text { Comunicação truncada entre atividades adjacentes de um mesmo processo, executadas } \\
\quad \text { por setores distintos; } \\
\text { - Possibilidade de definir metas e indicadores para os processos. } \\
\text { Inclusão do mapa de processos como apêndice das normas operacionais. }\end{array}$} \\
\hline $\begin{array}{l}\text { Dificuldades } \\
\text { Encontradas }\end{array}$ & \multicolumn{2}{|c|}{$\begin{array}{l}\text { Baixa maturidade em termos de emprego da notação de mapeamento de processos. } \\
\text { - } \quad \text { Processo mapeado incoerente com o processo real. } \\
\text { - } \quad \text { Lógica baseada na estrutura funcional. } \\
\text { - } \quad \text { Foco da Organização restringe o raciocínio baseado na visão processual. } \\
\text { - } \quad \text { Equipe de analistas de processos reduzida. } \\
\text { - } \quad \text { Requer preparo adequado para conduzir apoio aos especialistas. } \\
\text { - } \quad \text { Macroprocessos do Órgão encobertos. } \\
\text { - Percepção limitada dos processos, restringidos pela visão funcional (Regimentos e } \\
\quad \text { Procedimentos Operacionais). }\end{array}$} \\
\hline
\end{tabular}

A atratividade corresponde a um continuum, extremados pelos contextos de inteligência e contexto de operação. Quando os instrumentos de planejamento institucional e as atividades humanas estão em sintonia, entende-se que o alinhamento está convergente e é parte do mesmo sistema linguístico, de outra forma o alinhamento está divergente quando os domínios linguísticos tendem a se anular no horizonte de tempo. Já em relação ao princípio da estabilidade, o objeto de análise é o próprio do sistema de coordenação. Assim, haverá estabilidade positiva quando o contexto da inteligência for o principal condutor do processo decisório emanado para o contexto das operações, e na outra 
vertente, a estabilidade será negativa quando o domínio interno do sistema de operação for mais representativo e principal habilitador da inteligência do Órgão.

O esforço contínuo para desenvolver um vínculo dinâmico de inteligência e operação requer, necessariamente, um estilo intenso e cooperativo de interação baseado em experiências e conhecimento diferenciados, mas sobrepostos, dos líderes presentes em cada um dos contextos, apesar da existência de ciclos hierárquicos. O que se busca, em última análise, é o entrelaçamento virtuoso das contribuições em prol da promoção e fortalecimento de ambos, inteligência e operação.

Como resultado, há várias combinações possíveis que servirão de insumos para a análise e avaliação do sistema de coordenação que poderá fazer ajustes e correções reiteradamente até alcançar as condições de convivência favoráveis e a criação de um único sistema linguístico.

Àqueles que estiverem à frente do sistema de coordenação, vale ressaltar seu papel diante dos desafios e dilemas enfrentados nos sistemas de atividades humanas associados a cada um dos contextos.

Buscar o posicionamento estratégico e aprofundar a discussão interna para desenhar a configuração das estruturas sistêmicas, de modo a repercutir os eventos perturbadores do ambiente externo, é um esforço contínuo que é perseguido pela organização para se manter resiliente. Um dos grandes desafios nessa direção é suportar a "estrategização" e a "projetização", tão comuns no meio corporativo, mas pouco compreendido naquele cenário.

As unidades do sistema de operações aérea e terrestre, por outro lado, devem envidar esforços para subsidiar as decisões estratégicas do Órgão direcionadas ao sistema de coordenação, disponibilizando informações tempestivas, confiáveis e relevantes, assim como promovendo a aprendizagem organizacional. Paralelamente, ao atuar como apoiador, identificar pontos críticos, desenhar planos de atuação e alocar agentes multiplicadores para auxiliar a execução dos projetos e o cumprimento da missão.

Em síntese, as ações futuras para melhoria da situação-problema estão organizadas na forma de um roadmap, como pode ser observado na Figura 5.6. 


\section{PRÓXIMOS PASSOS}

\section{ROADMAP PARA DESENVOLVIMENTO \\ ORGANIZACIONAL - SisTEMA DE GESTÃo DE \\ OPERAÇÕES DO ÓRGÃo DE OPERAÇÃo AÉREA}
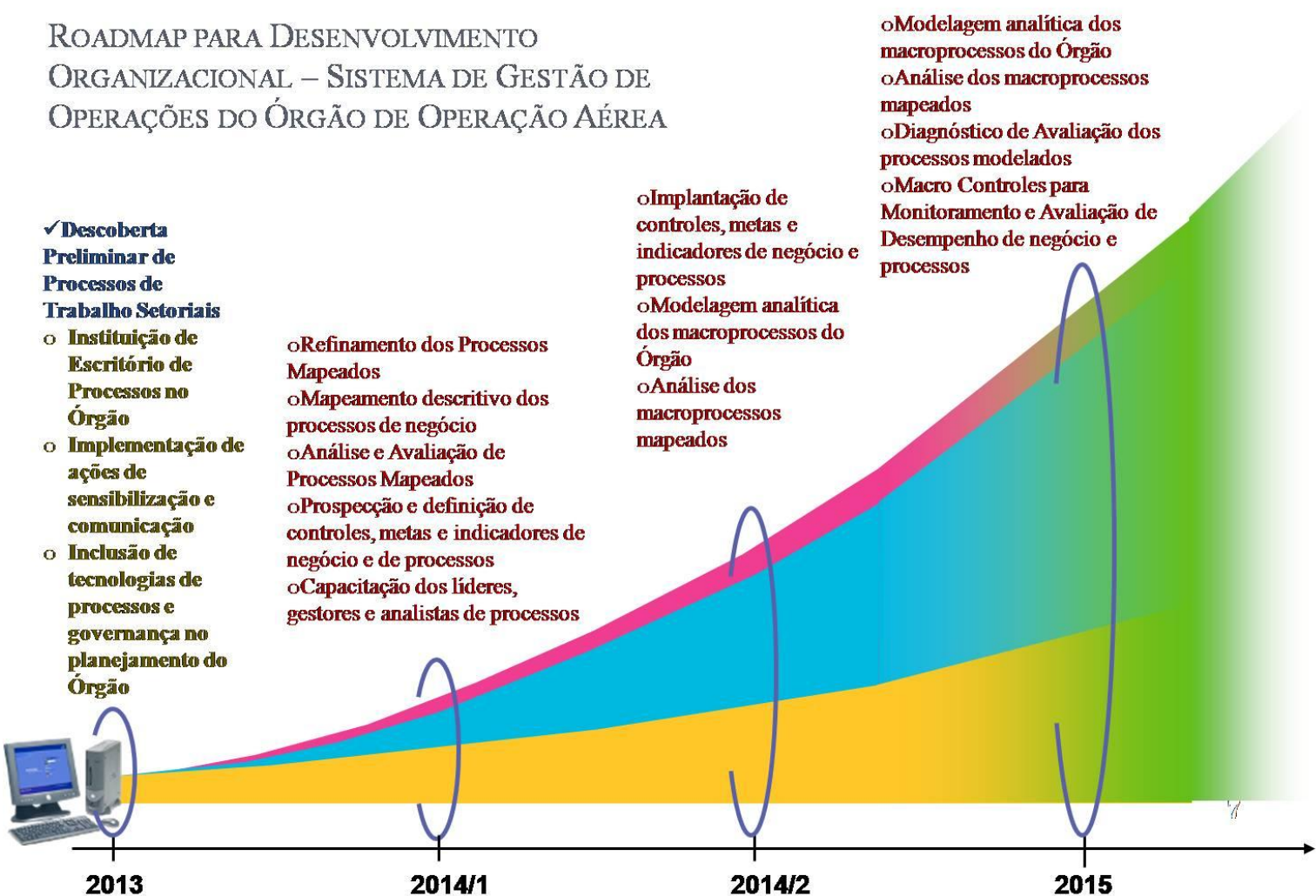

2013

oRefinamento dos Processos Mapeados

oMapeamento descritivo dos processos de negócio

oAnálise e Avaliação de

Processos Mapeados

oProspecção e definição de

controles, metas e indicadores de

negócio e de processos

oCapacitação dos líderes,

gestores e analistas de processos

Figura 5.6 - Ações para melhoria da situação-problema - Projeto Alpha

(O autor, 2015)

\section{6 - ESTÁGIO 4 - DISCUSSÃO E AVALIAÇÃO REFLEXIVA}

De acordo com Marconi e Lakatos (2010, p. 228),

A tese pode ser considerada como um teste de conhecimento para o candidato, que deve demonstrar capacidade de imaginação, de criatividade e habilidade não só para relatar o trabalho, mas também para apresentar soluções para determinado problema.

Com sucessivas implicações, o estudo partiu da definição dos temas de interesse que levaram à situação-problema de pesquisa, gerando a necessidade de se definir os cursos de ação da pesquisa e a orientação metodológica integrada e sistêmica, para então ser levada à experienciação nas três pesquisas de campo. Ao refletir sobre as mudanças decorrentes das ações pedagógicas empreendidas in loco e as análises do contexto de desenvolvimento organizacional, houve uma compreensão mais profunda dos muitos dilemas e paradoxos 
apresentados pelos sistemas de atividades humanas e a importância de se distinguir os domínios linguísticos existentes em cada cenário de pesquisa.

Ao longo das próximas seções serão expostos os argumentos relevantes que contribuíram para o aprofundamento das discussões e dos desencadeamentos observados. Para Marconi e Lakatos (2010, p. 232) a construção do conhecimento científico é habilitada pela técnica de exposição de argumentos no desenrolar do estudo, podendo assumir um dos três tipos, a saber: oposição, progressão ou cronologia. Na técnica de oposição, o pesquisador apresenta duas ou mais oposições fundamentais no enfoque do assunto, fator sugestivo e fecundo para o desenvolvimento de uma proposta temática. Na progressão, há relacionamento dos diferentes elementos, mas encadeados em sequência lógica, enquanto que a técnica cronologia baseia-se na sequência temporal dos acontecimentos para a constituição de uma proposta de concepção teórica.

Os resultados das análises descritiva e interpretativa obtidas nos estágios anteriores puderam revelar vestígios de situações prospectadas e discutidas com os sujeitos do conhecimento - atores sociais e pesquisadores - presentes nas três pesquisas de campo.

Com base nos estudos do físico e ciberneticista Heinz Von Foerster e do neurobiólogo Humberto Maturana, Vasconcellos (2013) destaca que o foco da Ciência no sujeito do conhecimento é um dos instrumentos chave para a nova epistemologia do pensamento sistêmico, já que a Ciência traz para seu domínio o sujeito do conhecimento, que outrora era considerado apenas um pesquisador passivo, incapaz de se posicionar e mantendo a todo custo a neutralidade diante das descobertas que ele mesmo produziu.

Em face da aplicação dos instrumentos de análise interpretativa em cada uma das três pesquisas de campo, as seguintes constatações foram obtidas após o exame das ações de intervenção pedagógicas empreendidas:

- Diante da realidade plural observada, é possível assumir que os sistemas de atividade humana convivem com situações inusitadas por conta de uma série de desarranjos de cunho social e técnico, de decisões equivocadas ou precipitadas e de consequências danosas provocadas por incertezas do ambiente externo de cada projeto. 
- Órgãos da Administração Pública Federal Brasileira são atores com alto poder de coerção e legitimação junto às demais partes interessadas dos três projetos. Não há clareza de ambas as partes quanto aos sistemas linguísticos existentes, refletindo na falta de coordenação e sintonia das atividades desenvolvidas e na alocação de recursos para o desenvolvimento organizacional.

- Em meio ás singularidades de cada projeto, cada sistema organizacional experienciado é subsidiado por instrumentos e mecanismos de governança e de gestão, implementados com base em modelos, arquétipos e metodologias, fortemente dependentes das tecnologias da informação, os quais são suportados por plataformas tecnológicas diversas, formando um mix singular que conduz a engrenagem corporativa.

\subsection{1 - Constituição do Mecanismo de Aprendizagem}

Uma vez posta à revista a base teórico-conceitual e uma vez oportunizados momentos de interação com outros sujeitos do conhecimento, três pontos de inflexão foram assimilados neste estudo: 1) o primeiro desencadeou os temas de interesse e o construto de visão multidimensional; 2) o segundo desencadeou as estratégias de pesquisa e a orientação metodológica baseada na abordagem integrada e sistêmica; e 3) o terceiro desencadeou o conhecimento teórico fundamentado na pesquisa-ação, que culminou com a proposta de um mecanismo de aprendizagem.

Em face da realidade observada em cada cenário de pesquisa e devido à compreensão holística das situações-problema desencadeadas tanto pela dinâmica dos sistemas de atividade humana como pelas ações intervencionistas, favoreceram a alocação de instrumentos e mecanismos disciplinares necessários para se buscar a resolução de cada problema. Todavia, somente após a distinção do sistema definido em torno de cada situação-problema e da construção de um único domínio linguístico para cada cenário investigado, foi possível prospectar métodos e abordagens tecnológicas para tornar realizável cada uma das soluções pleiteadas. Ao final, todo o processo de comunicação e avaliação sistêmica contribuiu para a adoção de medidas por parte dos gestores e dos demais sujeitos da pesquisa com papel de liderança nos respectivos projetos.

A realidade social percebida em cada contexto de pesquisa de campo coaduna com as manifestações políticas, culturais e tecnológicas prevalentes para formar um cenário 
complexo, mas ao mesmo tempo simbiótico. Para além das condições e restrições ambientais, Liker, Haddad e Karlin (1999) defendem que a própria realidade social da implementação de tecnologia é altamente complexa. Isso porque, diferentes tecnologias são apropriadas a diferentes contextos sociais por distintas razões, o que muitas vezes pode desencadear efeitos contrários. Assim sendo, concluem que são necessárias teorias complexas que reconheçam a emergência e a construção social da tecnologia.

Para dar forma ao mecanismo de aprendizagem com orientação metodológica para apoio à decisão em cenários complexos, as estratégias de argumentação foram empregadas longitudinalmente à medida que os estudos avançaram e os resultados emergiam das pesquisas empreendidas, permitindo esboçar a textura do mecanismo proposto, assim exposto na Figura 5.7.

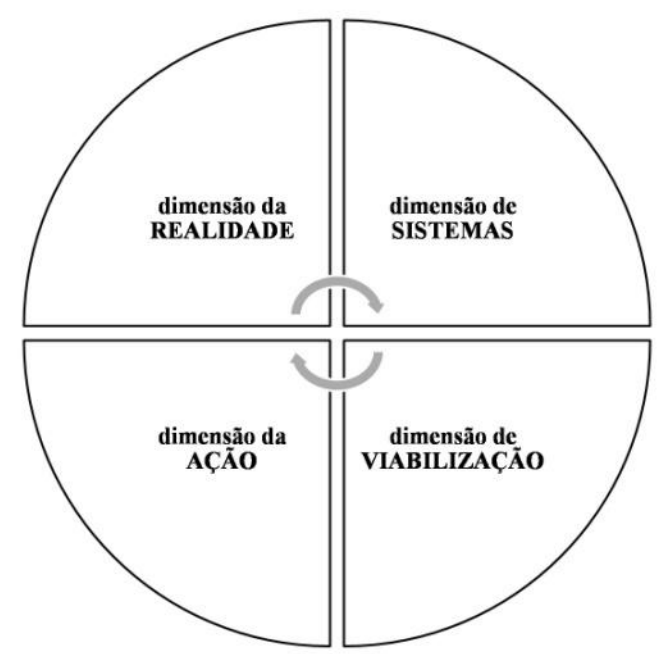

Figura 5.7 - Visão radial do Mecanismo de Aprendizagem

(O autor, 2015)

Após as análises interpretativas realizadas individualmente sobre cada um dos três projetos de pesquisa de campo, conseguimos identificar vestígios importantes que revelaram as principais dificuldades e acertos obtidos com as ações pedagógicas empreendidas. As análises sistêmicas permitiram dimensionar as condições e restrições de atuação, em termos funcionais, comportamentais, processuais e institucionais. Ao longo das próximas seções serão discutidos aspectos pontuais e chaves que levaram às reflexões avaliativas desta pesquisa. 
Adicionalmente, a interpretação com base na técnica de triangulação desencadeou novas possibilidades de aplicação do conhecimento teórico no processo de aprendizagem presente no contexto de análise descritiva e interpretativa, face à adoção da orientação metodológica. Portanto, as argumentações e implicações decorrentes dessa confrontação, permitiu elucidar algumas questões preponderantes da complexidade sistêmica:

- devido às análises multimetodológicas conseguimos compreender melhor a composição e a operação do sistema de atividade humana vinculado ao contexto da situação-problema;

- quanto mais complexo o cenário vivenciado em cada projeto, maiores foram as possibilidades de conexão e conversação com os atores e grupos sociais, facilitando a descoberta dos domínios linguísticos e por consequência a distinção do sistema definido em torno da situação-problema;

- a disposição enredada dos atores e elementos de cada sistema observado, mesmo quando se tratava de Órgão com estrutura funcional rígida, revelou a grande complexidade do sistema de atividade humana, que rompe com as barreiras da estrutura de comunicação formal e informal;

- a baixa percepção sistêmica que os atores e sujeitos da pesquisa apresentaram nos três projetos de campo contribuiu para a complexidade das análises. Especificamente quanto ao Projeto Charlie, o excessivo número de domínios linguísticos favorece a existência de uma grande quantidade de fluxos informações e processuais, com dinâmicas difusas e posicionamentos paradoxais, tornando a idealização do sistema de informação mais difícil ao utilizar os métodos tradicionais de desenvolvimento.

Os fenômenos sociais permeiam a atuação do profissional implicando seu modo de agir e de conduzir frentes de trabalho. Seja pela necessidade de dispor as ideias e afazeres de forma ordenada, coerente e metódica, seja pelo encadeamento de tarefas e uso de recursos, a função de coordenação se faz presente (Aun, Vasconcellos e Coelho, 2012). Com efeito, a consecução das dimensões exige momentos de reflexão e ação comunicativa entre os participantes, que deve contar com um coordenador que consiga ser o interlocutor dos domínios linguísticos e habilite a interconexão das redes de conhecimento, para minimizar os efeitos das "ilhas de conhecimento", que geralmente são desencadeadas pelos grupos sociais distintos. 
Para cada dimensão do mecanismo existe um conjunto de instrumentos de avaliação propostos para lidar com situações-problema, tipicamente encontradas em sistemas de atividade humana, em nível de mudanças e desenvolvimento organizacional, cujas proposições argumentativas presentes nas seções seguintes introduzirão os respectivos parâmetros de avaliação.

\subsubsection{1 - Dimensão da Realidade}

\section{Parâmetros de Avaliação:}

- De qual realidade se está falando afinal (Dietz, 2010)?

- Existe uma única realidade ou são várias realidades que emergem da observação dos stakeholders (Maturana, 1997)?

- Qual a realidade que nos importa (Maturana, 1997)?

- De onde emerge a realidade (Vasconcellos, 2013)?

Qualquer conhecimento de uma realidade absoluta é intrinsecamente impossível. O que se observa é uma suposta realidade transcendente, cuja descrição sempre implica em interações e, portanto, revela apenas uma realidade dependente do sujeito (Maturana, 1997, p. 162). Com isso, conclui o autor, o homem literalmente cria o mundo no qual vive, vivendo-o.

A dimensão da realidade é aquela que inicia o diálogo, que questiona e desperta o pesquisador para a realidade. Porquanto, é onde se encontra a face enigmática do mundo cibernético, os problemas perversos (termo originário do inglês, wicked problems), os discursos ambíguos, os domínios linguísticos contraditórios, as reflexões e posições paradoxais e o mundo na polissemia dos fenômenos que o constitui.

Para pensar em qualquer situação ou problema da realidade em particular, requer uma imagem ou um conceito, antes de se pensar em um modelo. Para pensar em algo tão complexo como um sistema de atividade humana, usamos modelos de sistemas similares, mais simples ou mais familiares (Checkland, 1993).

Para P. Checkland a representação da realidade observada é feita sobre conceitos construídos, desconstruídos e reconstruídos. Se os conceitos representam fatos, fenômenos ou seus aspectos investigados, Marconi e Lakatos (2010, p. 233) defendem que então ao 
formular uma proposição, eles serão utilizados como símbolos dos fenômenos que estão inter-relacionados.

Uma das situações-problema experienciadas nos três projetos de pesquisa de campo é a percepção da realidade. Para cada parte interessada, a existência da realidade é constituída com o que se observa, e o que se observa faz emergir objetos que se distinguem no processo de distinção que está atrelado à linguagem. A começar pelas distinções na linguagem empregada pelas partes envolvidas e partes afetadas de cada Projeto.

Não existe uma realidade independente de um observador nesse contexto (Vasconcellos, 2013), pois tudo é dito por um observador (Maturana, 1997) a outro observador (Von Foerster, 1991). A realidade, portanto, emerge na conversação (Vasconcellos, 2013), na interação social e na busca pela essência do fenômeno de pesquisa. Nesse contexto, conhecer a realidade como ela verdadeiramente se apresenta é uma condição metafísica. Destarte, Carneiro (2006) faz um resgate da obra do filósofo Hegel para reafirmar que o fenômeno esgota toda realidade, pois, a essência do fenômeno é o próprio fenômeno na sua manifestação. Para ele, a realidade é apreendida como se manifesta, não há essência por trás. A essência é simultânea à existência.

Ao reconhecer a inexistência da realidade independente do observador, devido à forma como somos biologicamente constituídos, Maturana (1997) destaca a inevitável impossibilidade de se fazer afirmações objetivas sobre o mundo e sobre o observador como parte desse mundo. De acordo com Vasconcellos (2013), ao questionar a possibilidade do conhecimento objetivo do mundo (epistemologia), os biólogos experimentalistas Humberto Maturana e Francisco Varela nos remetem ao reconhecimento de que constituímos o mundo ao distingui-lo (ontologia). Fez isso abordando cientificamente questões até então reservadas à filosofia e negligenciadas pela Ciência.

Ao propor uma ontologia para os sistemas, Dietz (2010) parte do pressuposto de que existe uma realidade subjacente ao sistema, cuja clareza da descrição e o dimensionamento do contexto real dependem da capacidade de distinção do sujeito-observador.

As ações pedagógicas - Estágio 4 da orientação metodológica - foram preparadas levando em consideração as realidades percebidas a partir da distinção dos principais domínios 
linguísticos em cada um dos três projetos de pesquisa de campo, conforme se observa no Quadro 5.7.

Quadro 5.7 - Principais domínios linguísticos identificados nas pesquisas de campo (O autor, 2015)

\begin{tabular}{|c|c|c|}
\hline PROJETO & DOMÍNIO LINGUÍSTICO & REALIDADE PERCEBIDA \\
\hline \multirow{4}{*}{ ALPHA } & $\begin{array}{l}\text { Domínio das condutas dos membros da Alta } \\
\text { Administração. }\end{array}$ & $\begin{array}{l}\text { Sistema de direcionamento } \\
\text { (comando e controle). }\end{array}$ \\
\hline & Domínio das condutas dos círculos hierárquicos. & Sistema de hierarquia. \\
\hline & $\begin{array}{l}\text { Domínio das condutas do corpo de especialistas } \\
\text { técnicos. }\end{array}$ & Sistema de suporte e metodológico. \\
\hline & Domínio de desenvolvimento organizacional. & Sistema de atividade humana. \\
\hline \multirow{4}{*}{$B R A V O$} & $\begin{array}{l}\text { Domínio das condutas dos membros da Alta } \\
\text { Administração. }\end{array}$ & Sistema de direcionamento. \\
\hline & Domínio das condutas do corpo de pessoal contratado. & Sistema de suporte e manutenção. \\
\hline & $\begin{array}{l}\text { Domínio das condutas do corpo de coordenadores e } \\
\text { analistas. }\end{array}$ & $\begin{array}{l}\text { Sistema de gestão e governança de } \\
\text { TI. }\end{array}$ \\
\hline & Domínio de desenvolvimento organizacional de TI. & Sistema de atividade humana. \\
\hline \multirow{4}{*}{ CHARLIE } & Domínio das condutas dos gestores públicos de cultura. & $\begin{array}{l}\text { Sistema de estímulo e apoio } \\
\text { governamental. }\end{array}$ \\
\hline & $\begin{array}{l}\text { Domínio das condutas do corpo de gestores dos } \\
\text { Escritórios de Articulação. }\end{array}$ & Sistema de gestão e operação. \\
\hline & $\begin{array}{l}\text { Domínio das condutas dos agentes da economia } \\
\text { criativa. }\end{array}$ & $\begin{array}{l}\text { Sistema de produção de cultura e } \\
\text { inclusão social. }\end{array}$ \\
\hline & $\begin{array}{l}\text { Domínio de desenvolvimento organizacional dos } \\
\text { Escritórios de Articulação. }\end{array}$ & Sistema de atividade humana. \\
\hline
\end{tabular}

Ao longo do processo de observação e das interações com os atores e grupos sociais pesquisados, os domínios das realidades emergiam mediante os momentos de conversação e discussão oportunizados pelas atividades de prospecção e ação na prática. Segundo Maturana (1997) cada domínio da realidade se constitui em um domínio de explicações da práxis de viver do observador.

De um modo geral, mas especialmente no Projeto Charlie, foi possível constatar a assimetria entre os agentes da economia criativa graças às grandes diferenças linguísticas observadas, o que naturalmente impedia uma maior aproximação dos grupos e coletivos de 
cultura com os empreendedores de cultura individuais, destes com as agências de fomento, dos gestores públicos e privados com os negócios criativos e assim por diante.

Fruto das análises realizadas nos Estágios 1 e 2 da orientação metodológica, tais situações puderam ser assimiladas. Do mesmo modo, a dimensão da realidade é coincidente com as duas primeiras etapas da metodologia SSM de Peter Checkland, ampliando as possibilidades de prospecção da realidade a partir dos métodos de estruturação de problemas, incluindo aqueles propostos pela Pesquisa Operacional (PO) Flexível. Desta última vem o instrumento de Análise e Desenvolvimento de Opções Estratégicas (SODA), operacionalizado pela técnica de mapeamento cognitivo. A Figura 5.8 ilustra os instrumentos sugeridos para compor a dimensão da realidade.

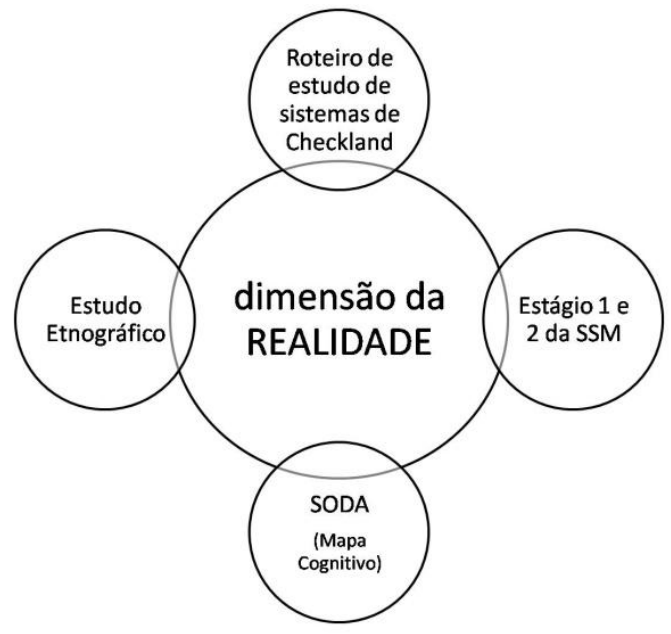

Figura 5.8 - Dimensão da realidade: Mecanismo de Aprendizagem (O autor, 2015)

O instrumento "estudo etnográfico" é fruto da aplicação no Projeto Charlie, onde o contexto e as circunstâncias ambientais do cenário de pesquisa favoreceram a adoção da etnografia, com cujas descrições dos grupos sociais e culturais estudados foi possível distinguir os costumes, as singularidades, as vocações e as peculiaridades de cada coletividade. Para casos em que existam situações parecidas, o estudo etnográfico é particularmente viável, dada a sua capacidade de evidenciar a história e as narrativas de um grupo social de interesse (Creswell, 2010).

À guisa de corolários, a dimensão da realidade se constitui a partir de métodos de estruturação de problemas (PO Flexível) e instrumentos de prospecção de problemas não 
estruturados ou pouco estruturados. As situações-problema emergem de realidades não acessíveis ou inapropriadas pelo observador, embora percebida, sentida e tida como palco de mudanças.

\subsubsection{2 - Dimensão de Sistemas}

Parâmetros de Avaliação:

- Qual é o sistema de interesse, ao reconhecer a existência de sistemas de sistemas (SoS) (ACKOFF, 1971)?

- Quais referências devem ser consideradas no momento de avaliação de um sistema (ULRICH, 1987)?

- O que importa considerar na distinção do sistema definido em torno de uma situação-problema (Anderson, Goolishian e Winderman, 1986)?

Durante a execução dos projetos de pesquisa de campo, a intensidade das interações e das conversações dos pesquisadores com os sujeitos da pesquisa, entre os próprios sujeitos e entre os pesquisadores-participantes determinaram o poder de percepção dos observadores em relação ao problema e à situação vivenciada. Dante (2006, p. 362) vai mais além ao argumentar que:

\footnotetext{
Em problemas de atividade humana, a própria ideia de um problema que pode ser resolvido deve ser substituída pela ideia do debate dialético, pela ideia de que resolver problemas é um processo contínuo, infindável, mas que pode ser orquestrado aplicando ideias sistêmicas: a realidade social não é um dado, mas um processo, no qual a realidade em contínua mudança é continuamente recriada pelos participantes.
}

Não é incomum considerar o sistema como domínio de aplicação e análise para resolução de problemas nas mais diversas áreas do conhecimento. Vimos, como exemplo, que o estudo das teses defendidas nos programas de doutorado em engenharia elétrica no Brasil revelou um percentual de pouco mais de $30 \%$ de trabalhos com essas características, sem, contudo, se preocupar com os princípios e conceitos que condicionam o pensar sistêmico. É graças a esta abordagem paradigmática que podemos discutir científica e criticamente sobre os sistemas (Maturana e Varela, 2001), distinguir sistemas de sistemas (Ackoff, 1971), analisar o sistema de referência (Ulrich, 1987), determinar o sistema em torno do 
problema (Anderson, Goolishian e Winderman, 1986), identificar as propriedades relevantes em um sistema intencional (Ackoff, 1971), projetar o sistema indagador (Churchman, 1971), construir sistemas de aprendizagem (Vasconcellos, 2013; Senge, 2013) e preparar metodologicamente para agir sobre sistemas (Checkland, 1993).

Ao reconhecer que um sistema possui um número ilimitado de propriedades, Ackoff (1971, p. 662) ressalta que o propósito da pesquisa sobre o sistema definirá quais propriedades são relevantes. Logo, o escopo do sistema de interesse poderá ser mais restrito ou mais amplo, dependendo das propriedades consideradas indispensáveis.

No Projeto Bravo, por exemplo, os atores da pesquisa pretendiam focalizar apenas uma das unidades operacionais de TI, por concentrar as atividades de coordenação geral da TI do Órgão - sem considerar as demais unidades operacionais do sistema de TI, nem outros setores do Órgão fortemente interdependentes da TI - no processo de desenvolvimento organizacional da TI. Visto que o sistema de referência restringia o escopo do sistema de TI, um exercício de reflexão sobre as análises sistêmicas feitas até aquele momento puderam identificar novos elementos e entidades essenciais na constituição do sistema de referência.

Na dimensão da realidade, uma das questões-chave é a descoberta dos diferentes domínios linguísticos. Já nesta dimensão (de sistemas) o que mais importa é identificar os parâmetros e os aspectos relevantes para distinguir o sistema determinado pelo problema (Anderson, Goolishian e Winderman, 1986), mediante a definição de um domínio linguístico em torno da situação-problema, possibilitando às pessoas interagirem e buscarem entendimentos sobre questões mal resolvidas, não estruturadas ou de difícil resolução. É por isso que as bases lançadas pelo trabalho sistêmico com redes sociais contribuíram para a noção de sistema determinado pelo problema (Aun, Vasconcellos e Coelho, 2012). 


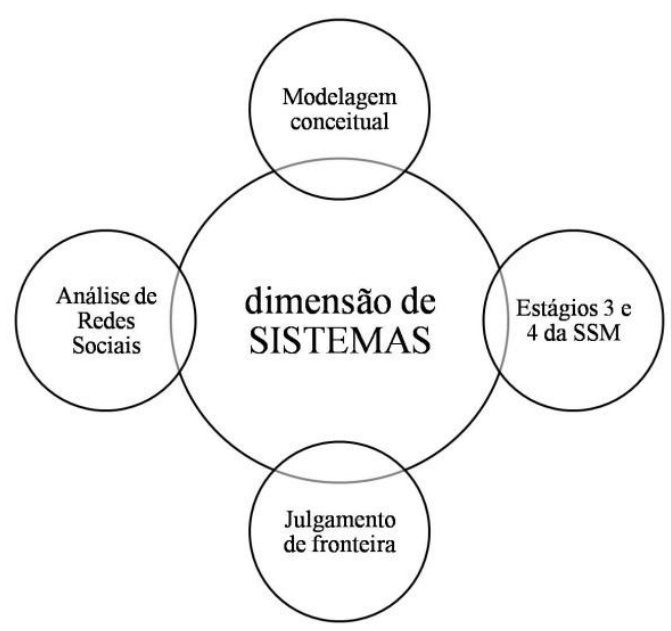

Figura 5.9 - Dimensão de sistemas: Mecanismo de Aprendizagem

(O autor, 2015)

O primeiro passo no sentido de compreender o sistema e seu ambiente é entender o conceito das diferentes perspectivas que foram passíveis de assimilação na dimensão da realidade. Já nesta dimensão, busca-se descrever as perspectivas intencionais e indispensáveis para representar as atividades do mundo real, utilizando a estrutura avaliativa da metodologia SSM, particularmente as etapas 3 e 4 , e a modelagem conceitual - assim representado na Figura 5.9.

Por ser fundamentalmente avaliativa (Checkland e Scholes, 1990), a SSM fornece uma base de valor para avaliar a situação-problema. A metodologia sendo empregada adequadamente pode resolver problemas e promover conflitos (Martinelli, 2006, p. 361).

Para definir os limites do sistema de referência, os demais instrumentos avaliativos recomendados para a dimensão de sistemas consistem na análise de julgamento de fronteira de Ulrich (1987) e análise de redes sociais, visto que o sistema de referência inclui os atores, os relacionamentos e a tipificação das redes constituídas pelo sistema de atividade humana.

$\mathrm{Na}$ medida em que o sistema de atividade humana consegue produzir os mesmos resultados de diferentes maneiras, seja mantendo o mesmo estado do sistema, seja alterando o seu estado, diz-se que ele é um sistema intencional. Ackoff (1971) argumenta que os sistemas intencionais podem ser discutidos e analisados com vistas a alcançar 
objetivos predeterminados. Esta condição dá ao sistema de atividade humana uma imprescindibilidade quando se pretende buscar o desenvolvimento organizacional.

Por definição, o sistema de atividade humana é um sistema social e intencional ao mesmo tempo (Checkland, 1993). Quanto mais complexo for o sistema social, mais complexos deverão ser os mapas mentais para refletir suas propriedades emergentes (Ackoff e Gharajedaghi, 1996).

No contexto de um sistema organizacional, onde há preponderância da atividade humana para alcançar os resultados esperados, Snowden e Boone (2007) caracterizam-no como sendo complexo, passível de ser investigado a partir do domínio da emergência. Como consequência, primeiro se deve investigar o problema até que haja uma tomada de consciência por parte dos envolvidos, para que ao final se busque uma resposta robusta, não necessariamente ótima ou sub-ótima.

Quadro 5.8-Contextos complexos das pesquisas de campo

(O autor, 2015)

\begin{tabular}{|c|c|}
\hline PROJETO & CONTEXTO \\
\hline \multirow{5}{*}{$A L P H A$} & Contexto das relações institucionais. \\
\hline & Contexto da administração do Órgão. \\
\hline & Contexto da estrutura de poder institucional. \\
\hline & Contexto da burocracia da administração pública brasileira. \\
\hline & Contexto de aplicação da tecnologia da informação. \\
\hline \multirow{4}{*}{$B R A V O$} & Contexto das relações institucionais. \\
\hline & Contexto de gestão e operação de TI do Órgão. \\
\hline & Contexto regulatório de TI do Governo Federal. \\
\hline & Contexto da burocracia da administração pública brasileira. \\
\hline \multirow{8}{*}{ CHARLIE } & Contexto da política pública de cultura no Brasil. \\
\hline & Contexto de implantação dos escritórios de articulação. \\
\hline & Contexto social dos agentes da economia criativa. \\
\hline & Contexto de desenvolvimento da economia criativa. \\
\hline & Contexto da burocracia da administração pública brasileira. \\
\hline & $\begin{array}{l}\text { Contexto institucional das instâncias de poder dos Órgãos } \\
\text { Públicos Federal, Estadual e Municipal }\end{array}$ \\
\hline & Contexto das relações institucionais. \\
\hline & Contexto da apropriação tecnológica. \\
\hline
\end{tabular}


Nos três projetos de pesquisa de campo, os contextos caracterizados como complexo, segundo a classificação de Snowden e Boone (2007), estão relacionados no Quadro 5.8.

À guisa de corolários, a dimensão de sistemas se constitui a partir da distinção do sistema definido em torno da situação-problema. Ao reconhecer a existência de sistemas de sistemas em cenários de desenvolvimento organizacional, os paradigmas da complexidade, instabilidade e intersubjetividade são consideradas no momento de avaliar o sistema de interesse. Não importa o número de sistemas identificados neste estágio, se as propriedades relevantes do sistema de interesse forem assimiladas e descritas.

\subsubsection{3 - Dimensão de viabilização}

Parâmetros de Avaliação:

- O que é possível/preciso ser feito para resolver a situação-problema (Churchman, 1971)?

- O que é preciso considerar para viabilizar o sistema de resolução do problema (Beer, 1984; Checkland e Scholes, 1990)?

- Quais os passos necessários para tornar realizável a solução pretendida (Checkland e Scholes, 1990)?

- Como descrever a organização e a estrutura de um sistema (Dietz, 2010; Maturana, 1997)?

De acordo com Cooley (1987, apud Dagnino e Novaes, 2009, p.107),

[...] ou nós teremos um futuro no qual, os seres humanos serão reduzidos a um tipo de comportamento de abelha, que apenas se adapta aos sistemas e equipamentos especificados para isso, ou nós teremos um futuro no qual as pessoas, consciente das suas habilidades tecno-políticas, decidam que vão ser os arquitetos de uma forma nova de desenvolvimento tecnológico que aumentará a criatividade humana e significará maior liberdade de expressão. (grifo nosso)

As dimensões da realidade e de sistemas têm como foco principal o problema, considerando sua natureza, entorno, abrangência, perversidade e partes envolvidas e afetadas. A dimensão de viabilização, por seu turno, parte dessa realidade reconhecida e 
analisada pelos aspectos de sua complexidade sistêmica, para tornar realizável uma proposta de mudança desejável.

Assim como ocorreu na Seção 5.5, as três últimas etapas da metodologia SSM serão utilizadas como instrumento de viabilização, por estarem orientadas à resolução do problema. Tais análises são capazes de criar percepções compartilhadas ou, pelo menos, uma acomodação entre pontos de vista e interesses conflitantes, de modo que possa ser implementada a mudança desejável (Martinelli, 2006).

Ao mesmo tempo em que é parte do problema, o sistema de atividade humana é indispensável no momento de idealização de soluções práticas para um problema complexo. A partir das definições essenciais do sistema de atividade humana - dimensão de sistemas - cabe neste momento buscar o modelo que viabilizará as ações de mudança naquela mesma realidade de outrora. A Figura 5.10 apresenta os instrumentos de avaliação para viabilização das mudanças desejáveis.

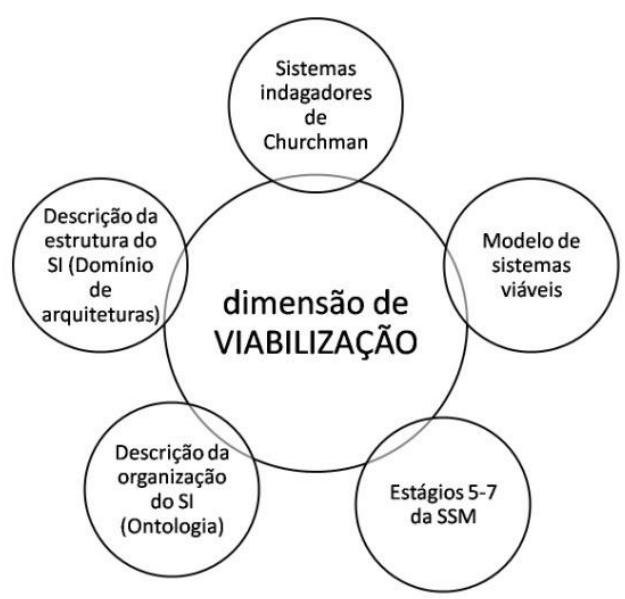

Figura 5.10 - Dimensão de viabilização: Mecanismo de Aprendizagem (O autor, 2015)

Para tornar as mudanças realizáveis no âmbito do desenvolvimento organizacional, para além das questões culturais, deverá ser observada também a capacidade dos meios de comunicação e de outras partes, que de alguma forma sofrerão os impactos daquela mudança (Morgan, 2005). Porquanto, os efeitos das ações sobre o sistema de atividade humana podem permanecer desconhecidos, cabe lembrar a lei dos efeitos das 
consequências não pretendidas de Senge (2013), que em última análise encerra as externalidades de uma ação sobre o sistema.

Para Pereira e Fonseca (2009) quando os decisores levam em conta apenas as variáveis que os afetam diretamente, sem analisar as consequências para os outros subsistemas ou o seu impacto no sistema maior, o risco de ruptura do sistema social torna-se muito grande. Corre-se o risco de resolver um problema criando outro maior em outros contextos.

Na prática da ação sobre o sistema, Churchman (1971) oferece um roteiro para o tratamento de problemas com base em cinco aspectos dos sistemas: seus objetivos, incluindo as medidas de desempenho, o ambiente (aquilo que está fora do controle da organização), os recursos (insumos), os componentes (missão, funções e atividades) e a administração (planejamento, controle e feedback).

Nessa mesma linha de ação, o modelo de sistema viável de Stafford Beer (1984) fundamenta-se na perspectiva cibernética com o propósito de avaliar a ligação entre sistemas e os objetivos da administração, tal como ocorreu na análise da Seção 5.5, tratando a viabilidade dos seguintes sistemas: sistema político (identidade), sistema de inteligência (estratégia), sistema de controle (função de controlador do sistema maior), sistema de monitoramento (auditoria - função de auditor do sistema maior), sistema de coordenação (função de coordenador dos sistemas de implementação) e sistema de operação (implementação - operador do sistema).

A partir das experiências neurobiológicas de Maturana (1997, p. 58), a comprovação de que a organização de um sistema é invariante e que a sua estrutura é mutável, faz toda diferença no momento de descrever os sistemas heterogêneos. Ainda segundo o autor (ibid.), organização e estrutura, portanto, não são sinônimos, pois a estrutura não determina suas propriedades enquanto uma unidade, e que uma unidade composta permanecerá a mesma somente na medida em que sua organização permanecer invariante (ibid., p.129).

Assim sendo, com base no trabalho de Maturana (1997) e de outros autores importantes, como Checkland e Holwell (1998), Dietz (2010), Vasconcellos (2013) e Morin (2011), a organização do Sistema de Informação (SI) aqui será descrita por meio de sua ontologia e a estrutura organizacional do SI por meio de suas arquiteturas. 
Diante da possibilidade de desconstruir os domínios linguísticos existentes e construir um novo sistema linguístico (Vasconcellos, 2013) - previsto para dimensão de sistemas - cabe à dimensão de viabilização descrever a organização (ontologia) e a estrutura (arquitetura) do novo sistema de resolução do problema. Logo, o novo domínio linguístico viabilizará a construção da ontologia do sistema de resolução do problema e de seus domínios de arquitetura.

Cada sistema tem uma arquitetura. Na prática, um sistema pode ter várias arquiteturas. Uma arquitetura é uma forma de concepção de um sistema. Logo, é possível existir várias concepções de um sistema, dependendo das possibilidades de visão e pontos de vista prospectados pelas partes interessadas na resolução da situação-problema.

Na concepção da visão ontológica (Dietz, 2010, p. 60), a construção do sistema consiste na formação conjunta de composição, ambiente e estrutura. As atividades dos elementos na composição e no ambiente são chamadas de operação do sistema. De acordo com o autor (ibid.), a organização dos sistemas de interesse - como exemplo, os sistemas de atividade humana - são combinações complexas de sistemas homogêneos que os tornarão heterogêneos.

A implantação de Sistemas de Apoio à Decisão (SAD) parte da premissa de que os tomadores de decisão e as partes interessadas compreendem o domínio do problema (dimensões da realidade e dimensão de sistemas) e concordam mutuamente com seus pontos de vista sobre o domínio e que as partes interessadas estão cientes dos recursos de informação que lhe estão disponíveis e necessárias para apoiá-los na realização de suas tarefas (Gaspoz e Wand, 2012).

Todavia, Gaspoz e Wand (2012) argumentam que muitas vezes, esses pressupostos podem não serem verdadeiros, e sua validade pode ser contestada pela crescente complexidade do ambiente empresarial moderno, pelo ritmo muito rápido de mudanças nesses ambientes, e pela grande dispersão das organizações modernas por apresentarem sistemas altamente heterogêneos. Em tais contextos, a implementação de avaliações sistêmicas, utilizando a metodologia SSM, deve preceder a concepção ontológica, de modo a refletir a estruturação do problema (ibid.). 
Em se tratando do Projeto Charlie, uma perspectiva visual ilustra a organização do sistema por meio da representação da Rede de Escritórios de Articulação (REA) da economia criativa - Figura 5.11. A organização em rede é particularmente desejável para o sistema de resolução do problema da economia criativa, mas os recursos e operações do sistema ainda não foram viabilizados.

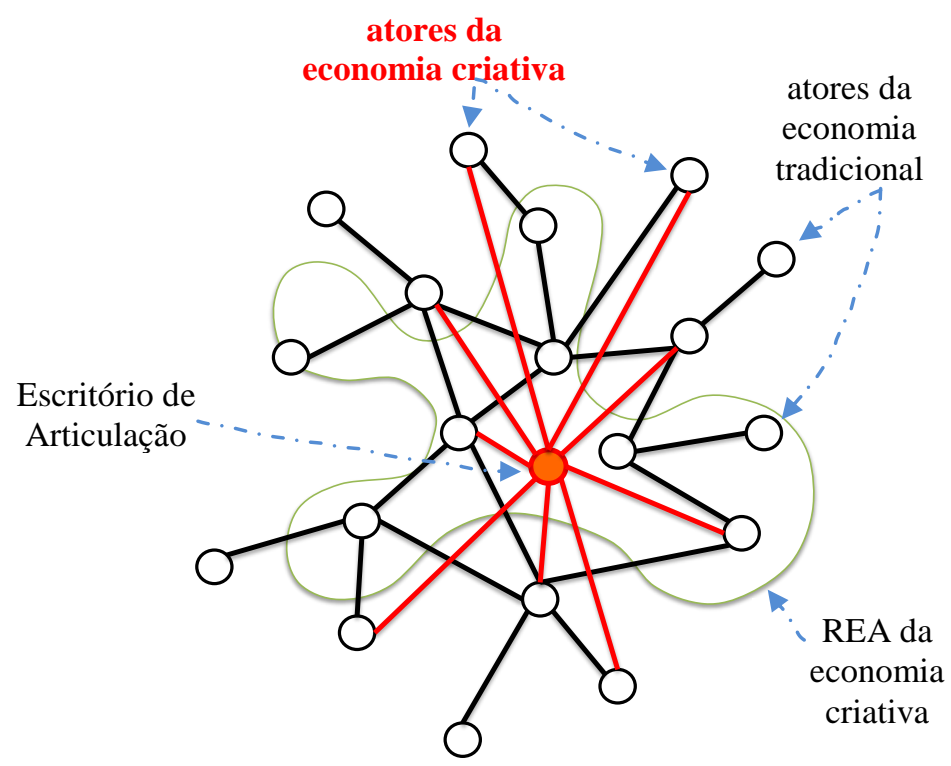

Figura 5.11 - Sistema construído em torno do problema: Projeto Charlie (O autor, 2015)

A descrição da estrutura do sistema consiste em mapear como as diferentes partes de um todo estão dispostas. Uma forma de fazê-lo é por meio das arquiteturas, as quais se ocupam em oferecer uma perspectiva de desenho técnico da estrutura. Se a visão e o ponto de vista modulam o tipo de arquitetura e a sua forma, quanto mais amplo e amplificado for o horizonte de avaliação, mais possibilidades de se criar novas arquiteturas. De outra forma, havendo mais arquiteturas, maiores serão as chances de se ter mais domínios linguísticos.

Como vimos na dimensão da realidade, os diferentes domínios linguísticos podem dificultar a estruturação do problema, cujo desafio posto na dimensão de sistemas é construir um sistema linguístico definido em torno da situação-problema para possibilitar a participação e o envolvimento das partes relevantes. Na dimensão de viabilização, o que se pretende é visualizar a estrutura organizacional do sistema por meio de arquiteturas, cuja solução de compromisso na constituição dos domínios de arquitetura é um fator chave que pode evitar soluções simplistas, correndo o risco de não incluir elementos críticos do SI, ou 
soluções totalitárias, que incluiriam todos os elementos do SI, inviabilizando a sua utilização.

Diante dessa situação, Zachman (1987) adverte que a arquitetura de sistemas de informação é um termo que pode perder o seu significado, pois dependendo da forma como estiver sendo empregada pode descrever muitas coisas diferentes por diferentes pessoas.

Um exemplo de arquitetura estratégica da Rede de Escritórios de Articulação do Projeto Charlie - conforme representado na Figura 5.12 - ilustra os blocos de construção de cada Escritório de Articulação e na camada superior o bloco de comunicação para harmonização geral.

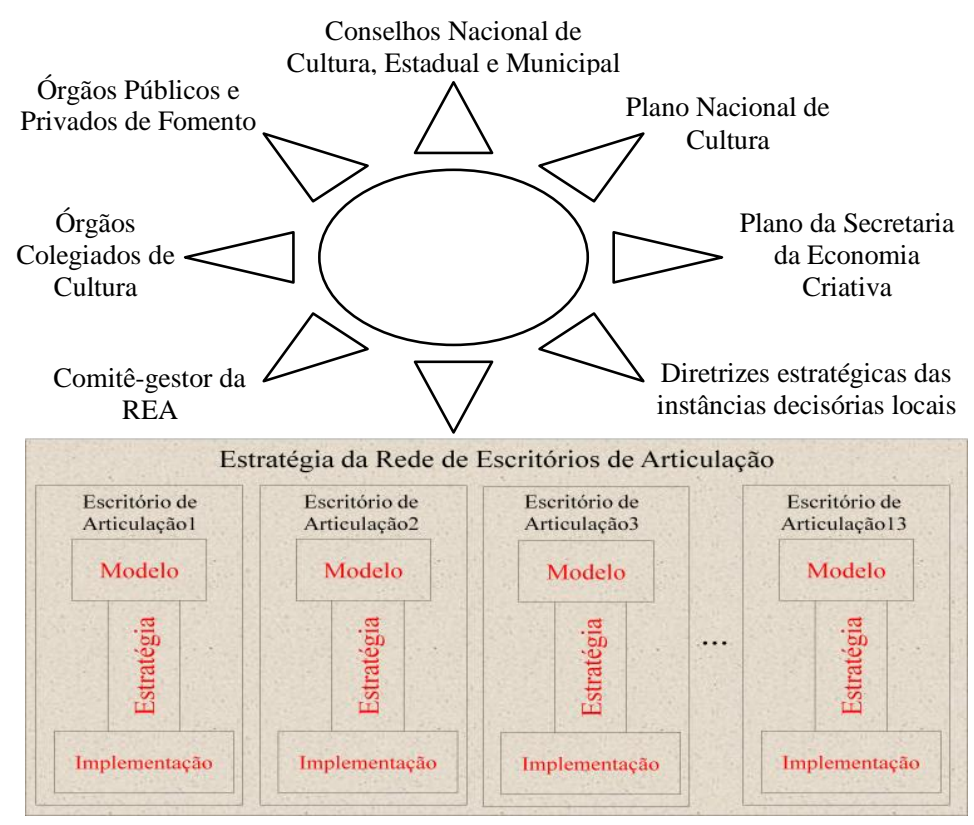

Figura 5.12 - Arquitetura da estratégia da REA: Projeto Charlie

(O autor, 2015)

Em termos gerais, nos três projetos de pesquisa de campo uma grande quantidade de informação foi gerada sobre os contextos de análise da situação-problema e do sistema determinado pelo problema. Assim, por meio do construto de visão multidimensional, foi possível reunir os fluxos de informação relacionados com estruturas, funções, processos e assim por diante, conforme pode ser observado no Quadro 5.9. 


\section{Quadro 5.9 - Status das pesquisas: Aplicação do Construto de Visão Multidimensional}

(O autor, 2015)

\begin{tabular}{|c|c|c|}
\hline PROJETO & DIMENSÃO & PARÂMETROS DE APRENDIZAGEM \\
\hline \multirow{7}{*}{$A L P H A$} & \multirow{2}{*}{$\begin{array}{l}\text { domínio } \\
\text { sistêmico }\end{array}$} & $\begin{array}{l}\text { 1. Situação-problema reconhecida } \\
\text { a. Visão dos envolvidos: estrutura de governança de processos insatisfatória. } \\
\text { b. Visão dos afetados: dinâmica interna das áreas disfuncionais, sem mecanismos de ligação } \\
\text { dos processos transversais. }\end{array}$ \\
\hline & & $\begin{array}{l}\text { 2. Sistema definido em torno do problema } \\
\text { a. Sistema de governança de processos de negócio. } \\
\text { b. Sistema de direcionamento estratégico. } \\
\text { c. Sistema de gestão de preparo e emprego. }\end{array}$ \\
\hline & \multirow{2}{*}{$\begin{array}{l}\text { perspectiva } \\
\text { interna e } \\
\text { externa }\end{array}$} & $\begin{array}{ll}\text { 3. } & \text { contexto - vide Quadro } 5.8 \\
\text { stakeholders - vide Quadro B.1 } \\
\text { modelo de negócio - reconhecido, mas não explicitado. }\end{array}$ \\
\hline & & $\begin{array}{l}\text { 4. função - lógica dominante do Órgão } \\
\text { processos - não reconhecido e não mapeado } \\
\text { estrutura - reconhecido e não mapeado }\end{array}$ \\
\hline & $\begin{array}{l}\text { escopo e } \\
\text { tempo }\end{array}$ & $\begin{array}{l}\text { 5. estratégico - formalizado no curto, no médio e no longo prazos } \\
\text { tático - formalizado }\end{array}$ \\
\hline & \multirow{2}{*}{$\begin{array}{l}\text { arquiteturas } \\
\text { e tomada de } \\
\text { decisão }\end{array}$} & $\begin{array}{l}\text { 6. } \begin{array}{l}\text { arquitetura de negócio - reconhecida e explicitada } \\
\text { arquitetura de } \mathbf{T I} \text { - não reconhecida } \\
\text { arquitetura social - reconhecida }\end{array} \\
\end{array}$ \\
\hline & & $\begin{array}{l}\text { 7. compreensão - atividade reconhecida e realizada de forma não estruturada } \\
\text { decisão - baseada na intuição e baseada em crenças conscientes } \\
\text { monitoramento - atividade reconhecida e realizada de forma estruturada }\end{array}$ \\
\hline \multirow{7}{*}{$B R A V O$} & \multirow[b]{2}{*}{$\begin{array}{l}\text { domínio } \\
\text { sistêmico }\end{array}$} & $\begin{array}{l}\text { 1. Situação-problema reconhecida } \\
\text { a. Visão dos envolvidos: operação de TI reativa. Estrutura de gestão insatisfatória. } \\
\text { b. Visão dos afetados: atendimento de TI insatisfatório. }\end{array}$ \\
\hline & & $\begin{array}{l}\text { 2. Sistema definido em torno do problema } \\
\text { a. Sistema de gestão de operações de TI. } \\
\text { b. Sistema de comunicação e controle de TI. } \\
\text { c. Sistema de gestão de serviços de TI. }\end{array}$ \\
\hline & \multirow{2}{*}{$\begin{array}{l}\text { perspectiva } \\
\text { interna e } \\
\text { externa }\end{array}$} & $\begin{array}{ll}\text { 3. } & \text { contexto - vide Quadro } 5.8 \\
\text { stakeholders - vide Quadro C.3 } \\
\text { modelo de negócio - reconhecido e explicitado }\end{array}$ \\
\hline & & $\begin{array}{l}\text { 4. função - lógica dominante do Órgão } \\
\text { processos - reconhecido e não mapeado } \\
\text { estrutura - reconhecida e não mapeada }\end{array}$ \\
\hline & $\begin{array}{l}\text { escopo e } \\
\text { tempo }\end{array}$ & $\begin{array}{l}\text { 5. estratégico - formalizado no curto prazo } \\
\text { tático - formalizado (PDTI) }\end{array}$ \\
\hline & \multirow{2}{*}{$\begin{array}{l}\text { arquiteturas } \\
\text { e tomada de } \\
\text { decisão }\end{array}$} & 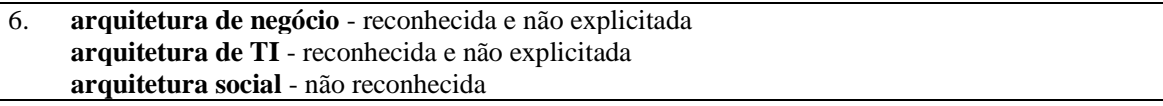 \\
\hline & & $\begin{array}{l}\text { 7. compreensão - atividade reconhecida e realizada de forma não estruturada } \\
\text { decisão - baseada na intuição e baseada em crenças conscientes } \\
\text { monitoramento - atividade reconhecida e não realizada }\end{array}$ \\
\hline \multirow{7}{*}{ CHARLIE } & \multirow[t]{2}{*}{$\begin{array}{l}\text { domínio } \\
\text { sistêmico }\end{array}$} & $\begin{array}{l}\text { 1. Situação-problema reconhecida } \\
\text { a. Visão dos envolvidos: comprometimento dos resultados devido ao ineditismo do projeto } \\
\text { com alto grau de incertezas, imprevisibilidades e cenários complexos, presentes no } \\
\text { processo de implantação da rede de Escritórios de Articulação. } \\
\text { b. Visão dos afetados: incertezas quanto ao modo de viabilização da participação dos } \\
\text { artistas, agentes da economia criativa, coletivos e empreendimentos criativos, de modo a } \\
\text { produzir resultados e gerar sinergias na rede. }\end{array}$ \\
\hline & & $\begin{array}{l}\text { 2. Sistema definido em torno do problema } \\
\text { a. Ecossistema da rede de espaços de articulação criativa. } \\
\text { b. Sistema de articulação da economia criativa. } \\
\text { c. Sistema de redes sociais criativas. }\end{array}$ \\
\hline & \multirow{2}{*}{$\begin{array}{l}\text { perspectiva } \\
\text { interna e } \\
\text { externa }\end{array}$} & $\begin{array}{ll}\text { 3. } & \text { contexto - vide Quadro } 5.8 \\
\text { stakeholders - vide Quadro D.3 } \\
\text { modelo de negócio - reconhecido e explicitado }\end{array}$ \\
\hline & & $\begin{array}{l}\text { 4. função - reconhecida e não mapeada } \\
\text { processos - não reconhecido e não mapeado } \\
\text { estrutura - reconhecida e não mapeada }\end{array}$ \\
\hline & $\begin{array}{l}\text { escopo e } \\
\text { tempo }\end{array}$ & $\begin{array}{l}\text { 5. estratégico - não previsto } \\
\text { tático - previsto para o médio prazo (Plano de trabalho) }\end{array}$ \\
\hline & \multirow{2}{*}{$\begin{array}{l}\text { arquiteturas } \\
\text { e tomada de } \\
\text { decisão }\end{array}$} & $\begin{array}{l}\text { 6. } \begin{array}{l}\text { arquitetura de negócio - não reconhecida } \\
\text { arquitetura de TI - não reconhecida } \\
\text { arquitetura social - não reconhecida }\end{array} \\
\end{array}$ \\
\hline & & $\begin{array}{l}\text { 7. compreensão - atividade não reconhecida } \\
\text { decisão - instintiva, baseada na intuição e baseada em crenças conscientes } \\
\text { monitoramento - atividade não reconhecida }\end{array}$ \\
\hline
\end{tabular}


À guisa de corolários, os pressupostos da dimensão de viabilização estão assentados na visão de consolidação do sistema linguístico para, desse ponto em diante, apropriar-se de instrumentos de constituição do SI que contribuirão para as análises de decisão subsequentes.

\subsubsection{4 - Dimensão da Ação}

\section{Parâmetros de Avaliação:}

- É possível tomar sempre uma decisão correta em um sistema de resolução de problemas (Shimizu, 2010)?

- Como avaliar alternativas e tomar a melhor decisão para ação (Hammond, Keeny e Raiffa, 1998)?

- Quais medidas de valor devem ser consideradas para tomada de decisão adequada (Hammond, Keeny e Raiffa, 1998)?

A resolução de um problema envolve a seleção de um ou mais cursos de ação na busca de um ou mais objetivos. Um objetivo é um resultado desejado. Identificar quais são os objetivos de uma organização é claramente importante na resolução do problema. Se outras partes se envolverem naquele problema, a mesma importância terá que ser dada para conhecer seus objetivos relevantes (Ackoff, 1979). Nesse contexto, a dimensão da ação visa avaliar os objetos de aprendizagem construídos na visão plural de uma organização, incluindo sua perspectiva estratégica, para subsidiar a maneira de observar, de julgar ou de agir do tomador de decisão - Figura 5.13.

A ação participativa é um dos elementos essenciais da orientação metodológica que suporta este mecanismo de aprendizagem. Para formar um sistema de aprendizagem participativo, outros elementos deverão ser observados. Por exemplo, Shrivastava (1983) destaca que o sistema de aprendizagem participativo refere-se a práticas organizações com a formação de comitês, comunidades de prática, grupos ou equipes de trabalho, para resolver problemas estratégicos e de gestão do sistema organizacional.

Para lidar com o modelo de tomada de decisão que manipula múltiplas opções estratégicas e opera sob incertezas em contextos instáveis e imprevisíveis, um dos conceitos essenciais que representam a essência da teoria de tomada de decisão é a aprendizagem (Shimizu, 
2010). O grau de representatividade em termos de participação na tomada de decisão pode representar um elemento facilitador de aprendizagem nas organizações (Shrivastava, 1983).

Ainda que se tenha a tendência de decidir subconscientemente o que fazer antes mesmo de descobrir a razão pela qual queremos fazê-lo (Hammond, Keeny e Raiffa, 1998), há que se ter clareza do valor proposto para compreender como os objetivos da organização e os objetivos das partes estão relacionados entre si (Ackoff, 1979). A dimensão de viabilização fornece os instrumentos e as tecnologias de suporte para alavancar o processo de aprendizagem. Desse modo, à avaliação precede o discernimento e sabedoria no momento da ação, ampliando o poder de assimilação e ciência das capacidades e potencialidades do sistema relevante.

Em relação ao planejamento interativo de Ackoff (1979), trata-se de um instrumento para desenvolver uma compreensão clara do que deve ser feito para mover a organização do seu estado atual, com problemas mal estruturados, em direção ao seu estado futuro, idealizado. É um processo interativo que visa projetar um futuro desejável para a organização e identificar as formas de realizá-la.

Além disso, o planejamento interativo envolve, para conseguir o desenvolvimento de todos, a participação ativa daqueles que possam ser diretamente afetados pelas decisões e, portanto, demanda contínua negociação e estabelecimento de algum tipo de consenso entre os participantes. Cada participante deve ter voz igual na tomada de decisão e deve ter compreensão clara de como se buscará o consenso e como se tomarão as decisões quando não for possível atingi-lo (Martinelli, 2006).

No processo de tomada de decisão, a compreensão parte do pressuposto de que o sistema de resolução do problema está estruturado com base nos instrumentos de avaliação da dimensão de viabilização. $\mathrm{O}$ ato da decisão é o instante de tempo em que o decisor faz a sua escolha de uma linha determinada de ação. Por meio do monitoramento se busca coletar e analisar os dados, informações e evidências para confrontar o estado anterior do sistema de interesse e o seu estado atual. Dependendo das condições encontradas, uma nova avaliação das dimensões do mecanismo de aprendizagem poderá ser realizada, de forma integral ou parcialmente. 
Para avaliar a realidade e o sistema relevante, o homem necessita de referenciais para tomar decisões, assim elencadas por Pereira e Fonseca (2009):

- ter uma espécie de radar para informá-lo das mudanças que estão ocorrendo no mundo, e isso a tecnologia moderna já lhe oferece;

- avaliar o impacto que essas mudanças vão exercer sobre ele, e isso depende de sua acuidade perceptiva e de seu nível de consciência;

- saber como responder a essas mudanças de maneira produtiva, e isso depende de decisões sábias.

Em relação os instrumentos de escopo e tempo, vale a mesma configuração do construto de visão multidimensional - Seção 5.2.1. O escopo define os cursos de ação estratégico e tático, enquanto que o tempo define os horizontes temporais das ações projetadas ou programadas.

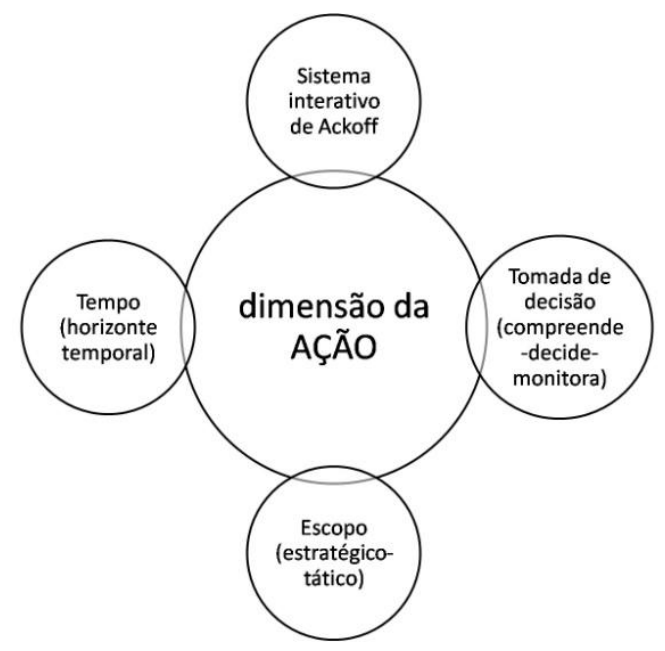

Figura 5.13 - Dimensão da ação: Mecanismo de Aprendizagem

(O autor, 2015)

À guisa de corolários, a idealização da dimensão da ação decorre da emancipação (autonomia) dos participantes que de alguma forma atuarão no momento de decidir, visto se tratar de uma condição circunstancial do acoplamento estrutural.

\subsection{2 - Avaliação Reflexiva}

Diante da possibilidade de se construir sistemas de aprendizagem a partir dos parâmetros de avaliação das múltiplas dimensões, uma nova perspectiva emerge no tocante ao modo 
com que se poderá utilizar o mecanismo. Considerando que as duas primeiras dimensões realidade e sistemas - estarem orientadas ao domínio do problema e que os problemas nessas condições tendem a estarem mal estruturados e de difícil compreensão, os métodos da pesquisa operacional flexível são os mais indicados para efeito de estruturação. Por outro lado, as dimensões de viabilização e de ação estão orientadas à solução do problema. Nessas condições, considerando que o problema já está estruturado e o modelo de sistemas reconhecido e compreendido, os métodos da pesquisa operacional tradicional poderão ser mais bem utilizados, conforme ilustrado na Figura 5.14.

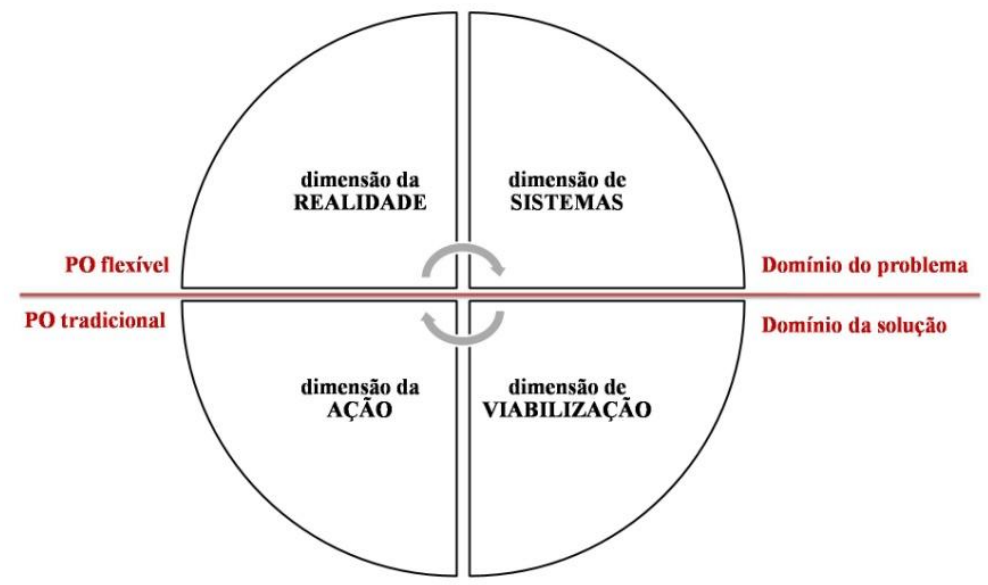

Figura 5.14 - Mecanismo de aprendizagem: quanto ao domínio do problema (O autor, 2015)

As abordagens prospectivas desempenham um papel fundamental na construção dialética e emancipatória do conhecimento oportunizado pela teia de relações e inter-relações dos interlocutores de um sistema de atividade humana. O método dialético, segundo Marconi e Lakatos (2010), busca a argumentação que faz clara distinção dos conceitos envolvidos na discussão. O princípio básico de que a realidade é contraditória ou dialética em si mesma favorece a passagem da quantidade à qualidade ou mudança qualitativa.

Decidir através dos paradoxos implica aprender a ampliar o contexto em que eles estão inseridos (Pereira e Fonseca, 2009). Inúmeros foram os eventos que revelaram situações de paradoxo nos três projetos de pesquisa de campo, principalmente no Projeto Charlie.

Ainda que se tenha um conjunto de circunstâncias esclarecedoras sobre a situaçãoproblema, não existe decisão perfeita porque não se podem analisar todas as alternativas e 
todas as consequências da ação. Ao optar por uma alternativa, Pereira e Fonseca (2009, p. 45) lembram que temos que renunciar às outras, e isso sempre gera um sentimento de perda, mesmo quando a decisão é eficaz, uma vez que qualquer decisão é um ato absolutamente individual e intransferível.

Portanto, o mecanismo de aprendizagem está centrado na definição de múltiplas dimensões de avaliação da situação-problema e do sistema construído em seu entorno para apoio à decisão em cenários complexos. A implicação do profissional como coordenador, portanto, é uma resposta à complexidade da atividade humana sob condições de incertezas, de dificuldades e de restrições ambientais. Trata-se, portanto, de um processo dinâmico e evolutivo na medida em que o coordenador interage com o sistema de informação e avança no processo construtivo em busca de conceitos e valores, que se inicia com a estruturação de um problema e culmina com a tomada de consciência e revelação de possíveis ideações.

Em termos práticos, o mecanismo se constitui em um corpo de conhecimento que servirá de inspiração e aprendizagem para os coordenadores de qualquer sistema de atividade humana, na medida em que se traçam os contornos da situação-problema que emerge dos cenários complexos, possibilitando a autonomia (emancipação) das partes interessadas e afetadas no processo de intervenção da realidade. As dimensões avaliadas atuam como vetores catalisadores, ampliando os espaços de análise e facilitando a síntese do processo decisório por meio das arquiteturas do sistema de informação.

Em face da orientação metodológica proposta para sustentar o mecanismo de aprendizagem, trata-se de um mecanismo social participativo. Num sistema de aprendizagem social a competência é histórica e socialmente definida (Wenger, 2014), consequência direta do acoplamento estrutural (Maturana e Varela, 2001).

Embora a concepção deste estudo não permita discutir as potenciais relações causais entre as dimensões, ao focar as quatro dimensões do mecanismo de aprendizagem, um corolário possível é a correspondência com as fases clássicas do processo decisório de Simon (1972), conforme mostrado no esquema do Quadro 5.10. 
Quadro 5.10 - Fases do processo decisório e as dimensões do mecanismo

(O autor, 2015)

\begin{tabular}{|l|l|l|}
\hline \multicolumn{1}{|c|}{$\begin{array}{c}\text { Fases do processo } \\
\text { decisório }\end{array}$} & \multicolumn{1}{|c|}{ Pergunta-chave } & \multicolumn{1}{c|}{ Dimensões do mecanismo } \\
\hline Estruturação & Qual é o problema? & Realidade - observada e experienciada \\
\hline Escolha & Quais são as alternativas? & Sistemas - concebidos e modelados \\
\hline Avaliação & Qual a melhor alternativa? & $\begin{array}{l}\text { Viabilização - tecnologias e meios de resolução } \\
\text { do problema }\end{array}$ \\
\hline Decisão & Qual ação tomar? & Ação - posição assumida pelo decisor \\
\hline
\end{tabular}

Em síntese, as quatro dimensões do mecanismo de aprendizagem estão caracterizadas na

Figura 5.15, ilustrando a noção de circularidade entre elas.

\begin{tabular}{|c|c|}
\hline $\begin{array}{l}\text { DIMENSÃO DA REALIDADE } \\
\text { Parâmetros de avaliação: } \\
\text { - } \quad \text { De qual realidade se está falando afinal (Dietz, } \\
\text { 2010)? } \\
\text { - } \quad \text { Existe uma única realidade ou são várias } \\
\text { realidades que emergem da observação dos } \\
\text { stakeholders (Maturana, 2007)? } \\
\text { - } \quad \text { Qual a realidade que nos importa (Maturana, } \\
\text { 2007)? } \\
\text { - De onde emerge a realidade (Vasconcellos, 2013)? } \\
\text { Descrição: } \\
\text { - Contexto de autonomia } \\
\text { - } \quad \text { Prospecção da situação-problema mal (pouco) } \\
\text { - } \quad \text { estruturada - momento de descoberta } \\
\text { - } \quad \text { Realidade não acessível ou inapropriada. } \\
\text { - } \quad \text { Existência de múltiplos domínios linguísticos } \\
\text { - } \quad \text { Atuação dos especialistas no problema (atores } \\
\text { - } \quad \text { sociais e pesquisadores) } \\
\text { Métodos de Estruturação de Problemas - PSM } \\
\text { Métodos da PO Flexível (Soft OR). }\end{array}$ & $\begin{array}{l}\text { Darâmetros de avaliação: } \\
\text { - } \quad \text { Qual é o sistema de interesse, ao reconhecer a existência } \\
\text { de sistemas de sistemas (SoS) (Ackoff, 1971)? } \\
\text { - } \quad \text { Quais referências devem ser consideradas no momento } \\
\text { de avaliação de um sistema (Ulrich, 1987)? } \\
\text { - } \quad \text { O que importa considerar na distinção do sistema } \\
\text { definido em torno de uma situação-problema } \\
\text { (Anderson, Goolishian e Winderman, 1986)? } \\
\text { Descrição: } \\
\text { - Avaliação da complexidade sistêmica } \\
\text { - } \quad \text { Atuação dos especialistas em sistemas (pensadores } \\
\text { - Momento de abstração (hólons) } \\
\text { - } \quad \text { Distinção do sistema (único) linguístico (SDTP) } \\
\text { - } \quad \text { SoS - Sistema de interesse } \\
\text { - Constituição do sistema relevante } \\
\text { - Framework Conceptagon } \\
\text { - } \quad \text { Framework Cynefin. }\end{array}$ \\
\hline $\begin{array}{l}\text { DIMENSÃO DA AÇÃO } \\
\text { Parâmetros de avaliação: } \\
\text { - É possível tomar sempre uma decisão correta em } \\
\text { um sistema de resolução de problemas (Shimizu, } \\
\text { 2010)? } \\
\text { - Como avaliar alternativas e tomar a melhor } \\
\text { decisão para ação (Hammond, Keeny e Raiffa, } \\
\text { 1998)? } \\
\text { - Quais medidas de valor devem ser consideradas } \\
\text { para tomada de decisão adequada? } \\
\text { Descrição: } \\
\text { - Decisão depende de múltiplos critérios e/ou } \\
\text { - } \quad \text { Dúltiplos objetivos. } \\
\text { - Decisão colegiada. } \\
\text { - } \quad \text { Atuaçaño dos Coordenadores } \\
\text { - } \quad \text { Momento de decisão } \\
\text { - } \quad \text { Métodos de análise multicritério: } \\
\text { - } \quad \text { Escola americana - AHP/ANP, } \\
\text { - } \quad \text { Escola europeia - Electre e Prométhée, } \\
\text { - Proposta híbrida - TODIM. }\end{array}$ & $\begin{array}{l}\text { DIMENSÃO DE VIABILIZAÇÃO } \\
\text { - } \quad \text { O quâme é possível/preciso ser feito para resolver a } \\
\text { situação-problema (Churchman, 1971)? } \\
\text { - } \text { O que é preciso considerar para viabilizar o sistema de } \\
\text { resolução do problema (Beer, 1984; Checkland e } \\
\text { Scholes, 1990)? } \\
\text { Quais os passos necessários para tornar realizável a } \\
\text { solução pretendida (Checkland e Scholes)? } \\
\text { - Como descrever a organização e a estrutura de um } \\
\text { sistema (Dietz, 2010; Maturana, 1997)? } \\
\text { Descrição: } \\
\text { Descrição da organização (ontologia) e da estrutura } \\
\text { (arquitetura) do sistema de resolução da situação- } \\
\text { problema. } \\
\text { Atuação dos especialistas técnicos (engenheiros, } \\
\text { analistas etc.) } \\
\text { Momento de modelagem da solução } \\
\text { - Métodos e tecnologias da Engenharia tradicional } \\
\text { (Engenharia de sistemas) } \\
\text { - Modelagem da dinâmica de sistemas (Jay Forrester, } \\
\text { John Sterman e Peter Senge). }\end{array}$ \\
\hline
\end{tabular}

Figura 5.15 - Dimensões do Mecanismo em Perspectiva

(O autor, 2015) 


\section{6 - CONCLUSÃO E RECOMENDAÇÕES}

A relação da força triádica tecnologia-prática-teoria nos sistemas de informação é a mola propulsora do desenvolvimento organizacional. O progresso de novas possibilidades tecnológicas tem sido muito mais rápido do que o progresso do pensamento sobre o sistema de informação, levando a desequilíbrio e confusão. Em qualquer campo onde a tecnologia é condutora do desenvolvimento, cujas mudanças são introduzidas na prática para depois serem percebidas pela teoria, o pressuposto é a existência de um sistema de aprendizagem orientado à ação.

O modelo de desenvolvimento e de apropriação tecnológica, empregado atualmente nas engenharias, não observa os impactos no ecossistema. Utilizam abordagens predominantemente analíticas, o que impossibilita lidar com a complexidade dos sistemas organizacionais - hajam vista os aspectos condicionantes da especialização exacerbada e da tecnoburocracia - dificultando às organizações transitarem do modelo burocrático para o gerencial e o governado.

Diante de cenários complexos, os problemas são mal estruturados e de difícil resolução. Não obstante a adoção de métodos, técnicas e ferramentas tradicionalmente aplicadas pela engenharia, pesquisa operacional e Ciências da Administração na resolução de problemas sob condições determinísticas e controladas, a mesma capacidade de resolução não é observada nos problemas encontrados em ambientes turbulentos, instáveis, imprevisíveis, com multiobjetivo, com alto grau de incertezas e complexidade. Uma forma de lidar com a complexidade é assimilando o princípio da multidimensionalidade para absorvê-la. Para se alcançar essa noção foi preciso discutir as faces da complexidade sistêmica à luz do marco teórico presente nas abordagens do pensamento sistêmico e das Ciências da Complexidade.

Os resultados das pesquisas empreendidas nesta tese permitiram embasar as discussões que culminaram com a proposta de um mecanismo de aprendizagem para apoio à decisão em cenários complexos. Em termos gerais, a preocupação com projetos ou processos de mudança complexos exige novos modos de pensamento que podem auxiliar os especialistas da engenharia tomar consciência da incerteza, volatilidade, ambiguidade e imprevisibilidade do ambiente, antes de decidir. 
Para existir uma ação, primeiro se identifica qual a viabilidade das mudanças desejadas no contexto do sistema de atividade humana, incluindo as partes envolvidas e afetadas. Antes disso, é preciso tomar consciência das semelhanças e diferenças entre as reais condições de existência de uma situação-problema e a distinção do sistema linguístico definido em seu entorno. Em meio a essa avaliação, surge a necessidade de se descrever a organização do sistema de resolução da situação-problema, por meio de uma ontologia, para depois descrever a sua estrutura organizacional, utilizando-se de domínios de arquitetura. Para tanto, foi preciso discutir a constituição dos sistemas de informação sob a ótica de arquiteturas e ontologias.

A elaboração de um construto de visão multidimensional foi a alternativa encontrada para servir de parâmetro para estudos prospectivos, partindo da compreensão das lógicas dominantes de um cenário de desenvolvimento organizacional. Apesar de as organizações estudadas disporem de um repertório de abordagens prescritivas e descritivas para alavancar seus próprios negócios, ainda assim, muitas questões mal resolvidas ou que sequer foram descobertas, comprometeram os resultados esperados pelos respectivos projetos.

Em tais cenários, qualquer decisão individual ou coletiva deve ser precedida de uma avaliação de alcance amplo ou restrito, a depender do grau de compreensão da realidade e do sistema relevante para a resolução do problema. Em se tratando de cenários complexos, várias são as possibilidades de decisão, seja porque existem múltiplos critérios de avaliação, seja porque o sistema relevante apresenta múltiplos objetivos, ou porque a decisão é colegiada. Tal discernimento foi alcançado após discutir as faces do processo decisório à luz do marco teórico que subjaz a tomada de decisão em cenários complexos.

O processo de desenvolvimento organizacional, prospectado nos três estudos de campo, raramente leva em conta a distinção entre o aspecto social e o aspecto tecnológico, embora seja comum encontrar maneiras de pensar sobre tais organizações que vai além do seu modo de operação. Assim, não é incomum encontrar nesse tipo de organização uma grande quantidade de abordagens, modelos, métodos e ferramentas prescritivas, que condicionam o modo de atuar das organizações, sem com isso observar a disposição do sistema de atividade humana presente. A sua condução é realizada pelos processos de governança e gestão que, de forma intencional ou não, estão estruturados e segregados. 
Dada a relevância dos sistemas de atividade humana, enquanto componente do sistema de resolução das respectivas situações-problema, àqueles deve se buscar uma melhor compreensão para se processar mudanças e ações de desenvolvimento organizacional. Ao assumir os preceitos de Thiollent (1997), os pesquisadores tiveram o cuidado de reproduzir os pontos de vista ou representações das diversas partes envolvidas nos projetos empreendidos, mesmo diante de situações conflituosos, em que não existe uma visão totalmente neutra.

Visto que os cenários de avaliação pertencem a um contexto real de desenvolvimento organizacional, para conhecer a realidade plural era preciso romper os limites do espaço in victro e experienciar na prática o teatro de operações reais. A viabilização dessa mudança exigiu uma concepção metodológica que permitisse não apenas observar um determinado cenário, mas, sobretudo, de construir um processo no qual os atores sociais implicados participassem, junto com os pesquisadores, para chegarem interativamente a elucidar a realidade em que estavam inseridos, identificando problemas coletivos, buscando e experimentando soluções em situação real. A pesquisa-ação-participante proporcionou essa condição, porém ainda faltava uma orientação metodológica que viabilizasse a operacionalização de uma pesquisa com tais características, de modo a identificar as atividades e os recursos necessários para análise dos dados, interpretação dos resultados e geração de novos conhecimentos teóricos fundamentos na prática.

No tocante aos procedimentos metodológicos, este trabalho permitiu mostrar a potencialidade das múltiplas abordagens aplicadas aos projetos de pesquisa de campo, já que possibilitou a distinção de contextos mais amplos onde as abordagens sistêmicas são mais bem praticadas.

Ainda que a orientação metodológica, proposta nesta tese (Capítulo 4), esteja estruturada para conformar a estratégia de pesquisa deliberada, nada impede que se empreguem outras combinações de abordagens multimetodológicas para conduzir pesquisas de campo na engenharia e em outras áreas do conhecimento.

Duas abordagens baseadas no método de pesquisa-ação tradicional foram discutidas abordagem antropopedagógica de André Morin e a metodologia de sistemas flexíveis de Peter Checkland - o que permitiu construir a proposta de orientação metodológica a partir 
da confluência de ambas. Por um lado a metodologia de Morin (2004) oferece os instrumentos para execução de uma ação pedagógica e por outro a metodologia de Checkland e Scholes (1990) contempla os estágios e as atividades de prospecção e análise sob enfoque sistêmico. Com isso, foi possível descobrir as abordagens descritivas e interpretativas da realidade para lidar com situações-problema.

As ações programadas e executadas nos três projetos de pesquisa de campo, uma vez operacionalizadas as análises e as interpretações preconizadas na orientação metodológica, permitiu a reflexão avaliativa triangulada com os pressupostos teórico-metodológicos e com o construto de visão multidimensional, culminado com a proposição do mecanismo de aprendizagem para avaliação de situação-problema com base na visão paradigmática da complexidade sistêmica.

Vale ressaltar, porém, que na avaliação de uma situação-problema, o pesquisador não necessariamente é o tomador de decisão. Posto isso, cabe ao pesquisador incluir a análise, a reflexão, a síntese, a preocupação em informar, explicar e descrever ao tomador de decisão determinado conjunto de elementos circunstanciais que condicionem, restrinjam e contornem o sistema relevante para a resolução da situação-problema.

\section{1 - DAS CONTRIBUIÇÕES E LIMITAÇÕES DA PESQUISA}

A tomada de decisão efetiva e a aprendizagem em um mundo de complexidade dinâmica crescente implicam os engenheiros a se tornarem pensadores sistêmicos, propiciando a expansão das fronteiras de seus modelos mentais e o desenvolvimento de ferramentas para compreender como a estrutura dos sistemas complexos cria o seu comportamento. $\mathrm{O}$ estudo bibliométrico realizado sinaliza uma tendência de crescimento no número de produções em Engenharias IV, mostrando que há uma preocupação em se discutir e fazer Ciência sob o paradigma da complexidade sistêmica para se buscar novas metodologias e processos de desenvolvimento de práticas e ações. Portanto, com este estudo se pretende estimular novas pesquisas científicas e novas práticas de desenvolvimento organizacional por meio de seu viés de orientação metodológica para a ação.

O método de pesquisa-ação possibilitou um contato mais próximo com os problemas reais e as situações inusitadas, suscitando novos conceitos e ideias sobre a formação dos 
sistemas construídos em torno das situações-problema. Isso remete aos argumentos dos Professores e metodologistas Pedro Demo e Michel Thiollent (Demo, 2014; Thiollent, 2002; 1997), segundo os quais essa capacidade de se aproximar da realidade constitui um alento às concepções de pesquisa de desenvolvimento organizacional de orientação positivista que recorrem a técnicas quantitativas sofisticadas, mas de pouca relevância para resolver os problemas concretos em termos práticos.

Cada um dos três projetos de pesquisa de campo gerou oportunidades de relacionar prática e teoria e de refletir sobre os valores humanistas e sociais que estavam em cena, desencadeando oportunidades de aprendizagem. Diante da possibilidade de aplicar ou construir novas tecnologias, o engenheiro poderá contar com o mecanismo de aprendizagem proposto para prospectar necessidades, demandas reprimidas ou desejos dos atores de um sistema de atividade humana, que fará a apropriação tecnológica. Do mesmo modo, ao desempenhar a função de coordenação o engenheiro estará inexoravelmente participando de um sistema de atividade humana, exigindo conhecimento astuto para poder lidar com as mais variadas situações-problema.

Diante dessa realidade, a atuação do coordenador exigirá o desenvolvimento de sua capacidade de visualizar o processo como um todo, ou seja, desenvolver um pensamento sistêmico, com o intuito de definir o problema, observar as circunstâncias nas quais este problema está envolvido, buscar alternativas de solução existentes para ele, refletir sobre as possibilidades de impactos e conseqüências globais, repercutir as implicações das ações sobre os resultados, e cientificar-se da capacidade de adaptação da solução frente às constantes mudanças ambientais. A esse conjunto de ações, uma arquitetura de sistemas de informação construída com base no mecanismo de aprendizagem aqui proposto, poderá, em tese, contribuir para a estruturação do problema e a viabilização da solução desejada.

O estudo bibliométrico empreendido permitiu constatar que a proposição de novos mecanismos, métodos ou soluções para problemas tipicamente tratados no domínio da engenharia elétrica, relativamente no escopo das teses publicadas nos repositórios dos Programas de Pós-Graduação em Engenharia Elétrica das Instituições de Ensino Superior (IES) no Brasil, mais de $60 \%$ das teses defendidas não apresentaram preocupação explícita de seus pesquisadores quanto à visão de mundo e à maneira como se propuseram a abordar 
o tema, com orientação metodológica nem sempre satisfatória para assegurar a discutibilidade e objetivação, nem tampouco explorando os princípios epistemológicos.

A natureza da Ciência é dependente do sujeito. Enquanto ser vivo, constitui-se em um sistema dinâmico determinado estruturalmente, e tudo o que acontece nele é determinado a cada instante por sua estrutura. $\mathrm{O}$ meio não pode especificar o que acontece em um sistema vivo, ele pode apenas desencadear em sua estrutura mudanças determinadas por sua estrutura (Maturana, 1997). Portanto, a contribuição do sujeito do conhecimento à Ciência dependerá do seu acoplamento estrutural naquele instante. Ao assumir esse postulado, esperamos que esta tese possa ser lida e evoluída como uma obra inacabada, sujeita aos desígnios dos novos acoplamentos estruturais.

Uma vez que o projeto da tese está no prelo, levará algum tempo para rever o que foi bem sucedido e o que precisa ser melhorado. Por hora, ao avaliar cada projeto de pesquisa de campo, em retrospecto, cada novo pesquisador interessado no assunto será capaz de aplicar os mesmos métodos ou outros que sejam mais adequados para analisar a situação problemática e o rastro de vestígios que venham a emergir, de tal sorte que consiga implicar as suposições desta investigação e encontrar novas percepções que coadunem com as dimensões do mecanismo proposto.

Não se pretende generalizar a relevância do mecanismo de aprendizagem para apoio à decisão em contextos organizacionais em geral, ainda que seu propósito principal seja aplicá-lo em cenários complexos em particular. As dimensões de avaliação e aprendizagem podem ser apropriadas e repercutidas nos contextos ambientais e nos sistemas constituídos em torno das situações-problema pertinentes a cada projeto de pesquisa empreendido, ou quando muito a cenários similares. De outro modo, não há garantias de que os resultados alcançados sejam os mesmos.

Existe inexoravelmente a possibilidade de erros não arbitrários neste estudo, seja do ponto de vista formal-lógico, seja pela própria condição processual, o que o torna suscetível de ser superado ou rebatido por outrem, assegurando, consequentemente, o seu caráter de discutibilidade. A presunção do erro é a marca registrada de qualquer produção científica, permitindo sua continuidade, renovação, retomada, abandono ou reinvenção (Demo, 2014, p. 54; Marconi e Lakatos, 2010). 
A proposta de mecanismo de aprendizagem fundamentada na visão multidimensional não pretende esgotar todas as possibilidades, exaurindo os argumentos para análise decisória; nem tampouco sugere um modelo prescritivo a ser empregado em situações do cotidiano dos sistemas organizacionais. De sorte, não se deseja que os pesquisadores se limitem a elas (dimensões); pelo contrário, que se sintam estimulados a alcançar um sistema de aprendizagem para lidar com as questões preponderantes de uma situação problemática, a qual deve ser debatida sob diferentes aspectos das realidades que emergem segundo as visões e os pontos de vista das partes interessadas.

Ainda que a complexidade inerente aos sistemas de atividade humana de cada projeto de pesquisa de campo tenha dificultado o dimensionamento de suas externalidades, os depoimentos e as manifestações dos atores da pesquisa e dos pesquisadores que participaram nos projetos sinalizam uma assimilação conscientizadora por parte dos grupos e indivíduos envolvidos e afetados pelas ações pedagógicas executadas em cada projeto. Thiollent (1997, p. 24) argumenta que em condições adversas, experiências de pesquisaação nem sempre conseguem alcançar a fase de conclusão, mas, pelo menos dão início a um efeito conscientizador ou um efeito de autodefinição dos grupos. O processo não desemboca em uma ação transformadora, mas pode abrir um leque de possibilidades para o futuro.

Não se pretende enunciar suposições ou modelos que contenham os preceitos estabelecidos para lidar com situações problemáticas, uma vez que as distinções do sistema determinado pelo problema emergem circunstancialmente e de acordo com a nossa capacidade perceptiva, que depende do nosso domínio linguístico naquele momento. Destarte, quando estamos emancipados, por meio de uma abordagem sensitiva e aproximativa, temos mais clareza acerca de muitas dimensões do problema.

Por fim, não há uma bala de prata para lidar com problemas em cenários complexos, porque sua resolução envolve outros conhecimentos, além do científico: a criatividade, a condição cognoscente dos envolvidos, a perícia na análise da natureza sistêmica do problema e as questões axiológicas e culturais, assim como a experiência prolongada com projetos de pesquisa orientada para a ação. 
Cientes das contribuições destacadas, cabe salientar algumas limitações importantes da pesquisa:

- quanto ao solipsismo: possíveis vieses nas interpretações e inferências do pensamento individual do pesquisador no sentido de reforçar os pressupostos teórico-empíricos que fundamentam este estudo;

- quanto à estratégia de pesquisa: a adoção de múltiplas metodologias pode gerar sobreposição e confusão, complexificando por demais as análises e interpretações.

- quanto à proposta de modelo teórico: por se tratar de uma abordagem construcionista e interpretativista, mesmo trilhando o caminho percorrido pelo pesquisador, resultados diferentes poderão ser encontrados, uma vez que a realidade é plural e isso vale tanto para as unidades de pesquisa, como para o acoplamento estrutural de cada pesquisador.

- quanto aos procedimentos metodológicos: uma única aplicação da SSM em cada projeto, já que segundo seu criador - Peter Checkland - os benefícios do método podem ser mais bem percebidos perfazendo-se três ou quatro ciclos de execução.

\section{2 - RECOMENDAÇÕES E CONSIDERAÇÕES FINAIS}

\footnotetext{
A preocupação central do filósofo Jean-Jacques Rousseau é a de que mesmo tendo sucesso em suas investigações científicas, nada garante o uso adequado dos conhecimentos adquiridos [...] qual de nós saberá dar-lhes bom uso? [...] não basta o conhecimento, não basta o poder governamental; é preciso que os governos se dignem a incorporar os saberes úteis em suas práticas. (Becker, 2012, p. 56-57).
}

Lidar com pensamento e prática sistêmica pressupõe análises e atuações tão intensas e participativas quanto for o nível de complexidade inerente. A mesma situação é percebida no sistema de aprendizagem que progride proporcionalmente à complexidade sistêmica. Nesse sentido, são várias as possibilidades de trabalhos futuros partindo desta base de conhecimento, das quais destaco:

- o viés prático é tradicionalmente mais desenvolvido na formação dos engenheiros, o que pode favorecer a implementação de abordagens de aprendizagem baseada em problema (termo originário do inglês, Problem Based Learning - PBL). Diante dessa possibilidade, e tendo em vista a aplicabilidade do mecanismo de 
aprendizagem com orientação metodológica, vislumbra-se um estudo original que proponha empregá-lo como um framework de referência;

- os estudos realizados nas teses de doutorado em engenharia elétrica mostram a baixa propensão em se discutir novas possibilidades paradigmáticas e metodológicas. Nesse sentido, uma pesquisa robusta poderia ser empreendida com o objetivo de propor um arquétipo para pesquisa de campo nas engenharias;

- diante da motivação em discutir o modo como a engenharia produz Ciência, um estudo mais denso que permita refletir sobre os principais problemas que contribuem para o atual status em termos de avanços científicos da área, permitindo discutir as realidades dos programas stricto sensu tanto em relação à realidade brasileira, como na perspectiva de outros países como Estados Unidos, Israel, China e Alemanha - importantes atores mundiais na produção de conhecimento em engenharia;

- estudar as implicações do engenheiro eletricista desempenhando o papel de pesquisador na sociedade brasileira, com o propósito de traçar um quadro sobre o status atual da engenharia enquanto Ciência, repercutindo o desempenho da produção de novas tecnologias da informação, nível de participação nas publicações internacionais e as tendências de desenvolvimento científico dos grupos de pesquisa brasileiros.

- desenvolver pesquisa sobre o sistema energético brasileiro, utilizando como estratégia de pesquisa a orientação metodológica integrada e sistêmica para refletir sobre as situações-problema que atualmente afligem as políticas e estratégias governamentais e os usuários de energia;

- realizar pesquisa de campo sob orientação metodológica de pesquisa-ação integrada e sistêmica, com o propósito de repercutir as questões essenciais, os principais problemas enfrentados e as armadilhas encontradas nos processos de gestão e operação da tecnologia da informação em organizações públicas complexas, para viabilizar sua atuação resiliente e sustentável. Organizações resilientes podem se auto-organizar em resposta a mudanças que não podem ser previstas de forma antecipada (Jackson, 2013).

- estudar e realizar experienciações no ensino de graduação para avaliar a viabilidade de incluir o mecanismo de aprendizagem na cadeira de pesquisa operacional ou sistemas de informação; 
- analisar o impacto real da aplicação do mecanismo de aprendizagem combinado com uma abordagem de sistemas enxuta (Lean Systems Approach), para suportar momentos de recursos reduzidos, mantendo a entrega dos serviços essenciais de uma organização; e

- avaliar a possibilidade de aprimoramento das abordagens ágeis de desenvolvimento de sistemas de software, mais especificamente $S_{c r u m}{ }^{14}$ e $F D D^{15}$, a partir das dimensões do mecanismo de aprendizagem.

Nossa expectativa reside no despertar de novos pesquisadores, comprometidos em agregar, a cada novo desencadeamento científico, a práxis sobre o processo formativo e a atuação profissional dos engenheiros em cenários complexos que exijam a sua intervenção em sistemas de atividade humana. Ciente que muitos são os passos da caminhada desse profissional, preparado e instrumentalizado pelas Instituições de Ensino para a função de produção, porque não desenvolver competências que lhe habilite a atuar desempenhando a função de coordenação. Reforçamos, portanto, a esperança de que esta tese ofereça uma trilha para orientar o desenvolvimento de novos conhecimentos teóricos fundamentos na prática, e que contribua para o sistema de aprendizagem orientado à estruturação de problemas.

\footnotetext{
${ }^{14}$ Scrum - framework para desenvolver e manter sistemas de software complexos. Acesso em 15 Out. 2014. Disponível em <<http://www.scrumguides.org/>>.

${ }^{15}$ FDD - Desenvolvimento orientado a aspectos (termo originário do inglês, Feature Driven Development). Acesso em 15 Out. 2014. Disponível em <<http://www.featuredrivendevelopment.com/〉>.
} 


\section{REFERÊNCIAS BIBLIOGRÁFICAS}

Ackoff, R. L. (1987). Art of problem solving, John Wiley \& Sons, Nova Iorque, E.U.A. . (1979). "Resurrecting the future of operational research". In: Journal of the Operational Research Society, 30(3): 189-199. . (1971). Pesquisa Operational, LTC, São Paulo.

Ackoff, R. L. e Gharajedaghi, J. (1996). "Reflections on Systems and Their Models". In: Systems Research, vol. 13, n.1, 13-23.

Ackoff, R. L. e Sasieni, M. W. (1968). Fundamentals of Operations Research, Wiley, Universidade de Michigan.

Affeldt, F. S. e Vanti, A. A. (2009). "Alinhamento Estratégico de Tecnologia da Informação: Análise de Modelos e Propostas para Pesquisas Futuras". In: Journal of Information Systems and Technology Management, 6(2): 203-226.

Allen, P. M. (2001). “A Complex Systems Approach to Learning in Adaptative Networks". In: International Journal of Innovation Management, Vol. 5, No. 2, 149-180.

Ashby, W. R. (1970). Uma Introdução a Cibernética, Editora Perspectiva, São Paulo.

Anderson, H.; Goolishian, H. e Winderman, L. (1986). "Problem determined systems: towards transformation in family therapy". In: Journal of Strategic and Systemic Therapies, 5: 1-14.

Aun, J. G., Vasconcellos, J., Coelho, S. V. (2012). Atendimento Sistêmico de Famílias e Redes Sociais, Ophicina de Arte \& Prosa, Belo Horizonte, $3^{\mathrm{a}}$ ed., vol. 1 - fundamentos teóricos e epistemológicos.

Becker, E. (2012). “Natureza X Sociedade: Percursos e Percalços de Nossa Trajetória Científico-Civilizacional". In: Santos, A. C. e Becker, E. (Orgs.). Entre o Homem e a Natureza: Abordagens Teórico-Metodológicas, Redes Editora, Porto Alegre, 129-140.

Beer, S. (1984). “The Viable System Model: Its Provenances, Development, Methodology and Pathology". In: Journal of the Operational Research Society.

. (1968). Cibernética e Administração Industrial, Zahar editores, Rio de

Janeiro.

Bernroider, E. W. N. e Schmollerl, P. (2013). "A technological, organisational, and environmental analysis of decision making methodologies and satisfaction in the context of IT induced business transformations". In: European Journal of Operational Research, 224, 141-153. 
Bertalanffy, L. (1969). General Systems Theory: Foundations, Development, Applications, George Braziller Inc.

Boardman, J. T., et al. (2009). "The Conceptagon: A Framework for Systems Thinking and Systems Practice". In: IEEE, International Conference on Systems, Man and Cybernetics. Borgatti Neto, R. (2008). Perspectivas da Complexidade Aplicadas à Gestão de Empresas, Tese de Doutorado, Escola Politécnica da Universidade de São Paulo, 309p.

Bringhurst, R. (2006). A Forma Sólida da Linguagem: um ensaio sobre escrita e significado, Edições Rosari, São Paulo.

Brodbeck, A. F. (2001). Alinhamento estratégico entre os planos de negócio e de tecnologia de informação: um modelo operacional para a implementação, Tese de Doutorado, Programa de Pós-Graduação em Administração, Escola de Administração, Universidade Federal do Rio Grande do Sul, Porto Alegre.

Bui, H. e Baruch, Y. (2010). "Creating Learning Organizations in Higher Education: Applying a Systems Perspective". In: The Learning Organization, Vol. 17 No. 3, 228-242.

Capes. (2014). Cursos de Doutorado Recomendados e Reconhecidos pela Capes, Coordenação de Aperfeiçoamento de Pessoal de Nível Superior, Disponível em: <http://www.capes.gov.br/cursos-recomendados>, Acesso em: 10 Abr 2014. . (2014). Sistema Integrado WebQualis, Coordenação de Aperfeiçoamento de

Pessoal de Nível Superior, Disponível em: <http://qualis.capes.gov.br/webqualis/principal.seam>, Acesso em: 14 Fev 2014.

Capra, F. (1996). A Teia da Vida: uma nova compreensão científica dos sistemas vivos, Cultrix, São Paulo, Tradução de Newton Roberval Eichemberg. (1982). O Ponto de Mutação, Cultrix, São Paulo.

Carneiro, A. M. C. G. (2006). "Hegel e a Fenomenologia: Reflexões Preliminares sobre Mundo e Sujeito”. In: Revista Eletrônica Estudos Hegelianos, 3(5).

Castro, M. S. (2011). Análise do Perfil do Profissional de Tecnologia da Informação e Comunicação a Partir da Percepção Interna do Setor, Tese de Doutorado, Programa de Pós-Graduação em Engenharia Elétrica, Universidade de Brasília, Brasília-DF.

Chan, Y. e Reich, B. (2007). "IT alignment: what have we learned?", In: Journal of Information Technology, 22, 297-315.

Checkland, P. B. (1993). Systems Thinking, Systems Practice, Wiley, Chichester, Inglaterra. 
Checkland, P. B. e Holwell, S. (1998). Information, Systems and Information Systems: Making Sense of the Field, Wiley, Chichester, Inglaterra.

Checkland, P. B. e Scholes J. (1990). Soft Systems Methodology in Action, Wiley, Chichester, Inglaterra.

Churchman, C.W. (1971). The design of inquiring systems, Basic Books, Nova Iorque, E. U. A.

Clutterbuck, J. (2001). “Is Complementary Strategy the Way Forward?”, In: Key Note Address at the OA Techniques for the Future Workshop 31 January (DERA and UK Operational Research Society).

Coelho, C. C. S. R. (2001). Complexidade e Sustentabilidade nas Organizações, Tese de Doutorado, Universidade Federal de Santa Catarina, 189p.

Corbin, J., \& Strauss, A. (2008). Basics of qualitative research: Techniques to developing grounded theory, (3rd Ed.), CA: Sage, Los Angeles, E.U.A.

Correia, M. F. B. (2009). "Indeterminação, Multidimensionalidade e Relevância do Processo de Construção de Significados". In: Psicologia em Estudo, Maringá, v. 14, n. 2, p. 251-258, abr.jun.

Courtney, J. F. (2001). "Decision Making and Knowledge Management in Inquiring Organizations: toward a new Decision-Making Paradigm for DSS". In: Decision Support Systems, 31: 17-38.

Creswell, J. W. (2010). Projeto de Pesquisa: Métodos Qualitativo, Quantitativo e Misto,

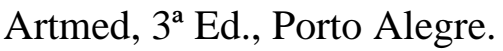

Dagnino, R. e Novaes, H. T. (2009). "O Papel do Engenheiro na Sociedade". In: Revista Tecnologia e Sociedade, p. 95-112.

Demo, P. (2014). Metodologia Científica em Ciências Sociais, Atlas, $3^{\text {a }}$ ed., São Paulo.

Dietz, J. L. G. (2010). Enterprise Ontology - Theory and Methodology, Springer, Berlin, Alemanha.

Espejo, R., et al. (1996), Organizational transformation and learning: a cybernetic approach to management, John Wiley \& Sons, Chichester, Inglaterra.

Findlay, J. e Straus, A. (2013). "Resolvendo Problemas de Gerenciamento de Stakeholder Utilizando Abordagem de Sistemas Adaptativos a Complexidade", In: Revista Mundo Project Management, 50 (9), abr/mai, 9-15. 
Freyle, J. D. H.; Florez, L. C. G. e Rincón, E. C. (2013). "Investigación-acción aplicada a la gestión del conocimiento a través de la Metodología de sistemas blandos". In: Information Systems and Technologies (CISTI), IEEE.

Garrossini, F. D. (2010). As Tecnologias da Informação e Comunicação como vetores catalisadores de participação cidadã na construção de políticas públicas: o caso dos conselhos de saúde brasileiros, Tese de Doutorado, Faculdade de Comunicação, Universidade de Brasília, 235p.

Gaspoz, C. e Wand, Y. (2012). "Using Ontologies and Soft Systems Methodology to Provide Multi-user Support in Problem Structuring". In: IEEE Computer Society, 45th Hawaii International Conference on System Sciences, 658-667.

Georgiou, I. (2012). "Messing about in transformations: Structured systemic planning for systemic solutions to systemic problems". In: European Journal of Operational Research, $223,392-406$.

Gerritsen et al. (2013). "Knowledge Governance: An Exploration of Principles, Impact, and Barriers". In: Science and Public Policy 40, 604-615.

Gharajedaghi, J. (2011). Systems Thinking: Managing Chaos and Complexity: A Platform for Designing Business Architecture, $3^{\mathrm{a}}$ Ed., Morgan Kaufmann Publishers Inc., São Francisco, E. U. A.

. (2007). "Systems thinking: a case for second-order-learning". In: The

Learning Organization, Vol. 14, no. 6, Emerald Group Publishing Limited, pp. 473-479. . (2004). "Systems methodology - A Holistic Language of Interaction And

Design Seeing Through Chaos and Understanding Complexities", In: University of Pennsylvania, Managing Complexity in Defence Projects.

Gil, A. C. (2010). Como Elaborar Projetos de Pesquisa, 5a ed., Atlas, São Paulo.

Gomes, L. F. A. M. (2007). Teoria da Decisão, Thomson Learning, São Paulo.

Gomes, L. F. A. M., Araya, G. e Carignano, M. C. (2011). Tomada de decisões em cenários complexos: introdução aos métodos discretos do apoio multicritério à decisão, Cengage Learning, São Paulo.

Gonzalez, R.; Gasco, J. e Llopis, J. (2006). "Information Systems Outsourcing: A Literature Analysis". In: Information \& Management 43(7), 821-834.

Hammond, J. S., Keeney, R. L. e Raiffa, H. (1998). "The Hidden Traps in Decision Making". In: Harvard Business Review, Best of HBR. 
Hartmann, T., Fischer, M. e Haymaker, J. (2009). “Implementing Information Systems with Project Team Using Ethnographic-Action Research". In: Advanced Engineering Informatics, 23, 57-67.

Henderson, J. C.; Venkatraman, N. (1993). "Strategic Alignment: Leveraging Information Technology for Transforming Organizations”. In: IBM Systems Journal, 32( 1), 4-16.

Holloway, C. A. (1979). "Introduction to the Analysis of Decisions". In: Decision Making under Uncertainty: Models and Choices, Prentice Hall, Nova Iorque, E.U.A.

Howick, S. e Ackerman, F. (2011). “Mixing OR Methods in Practice: Past, Present and Future Directions". In: European Journal of Operational Research, vol. 215, pp. 503-511. Hrebiniak, L. G. (2005). Making Strategy Work: Leading Effective Execution and Change, Wharton School, Nova Jersey, E. U. A.

Isidro-Filho, A. e Guimarães, T. A. (2008). "Estilos de Liderança e Mecanismos de Aprendizagem em Organizações: Análise de suas Relações em uma Organização Financeira". In: Revista de Gestão Organizacional, 6(3): 361-378.

Ison, R. L. (2008). "Systems thinking and practice for action research", In: Reason, P. W. e Bradbury, H. The Sage Handbook of Action Research Participative Inquiry and Practice, $2^{a}$ ed., Sage Publications, Londres, Inglaterra, 139-158.

Jackson, M. C. (2013). “Pensamento Sistêmico Holístico: Prática Essencial em Projetos de Larga Escala”. In: Revista Mundo Project Management, 50 (9), abr/mai, 22-26.

(2003). Systems Thinking: Creative Holism for Managers, Wiley, Chichester, Inglaterra.

(1991). Systems Methodology for the Management Sciences, Plenum Press,

Nova Iorque.

Johnson, G.; Scholes, K.; Whittington, R. (2007). Explorando a Estratégia Corporativa, Tradução de Luciana de Oliveira da Rocha. Bookman, Porto Alegre:, $7^{\mathrm{a}}$. ed.

Jonkers, H.; et al. (2004). "Concepts for modeling enterprise architectures". In: International Journal of Cooperative Information Systems, 13(03): 257-287.

Juarreiro, A. (2010). "Complex Dynamical Systems Theory". In: Cognitive-edge, disponível em: <www.cognitive-edge.com>, acesso aos: 20 Out. 2012.

Kant, I. (2005). “Resposta a Pergunta: Que é Esclarecimento?”. In: Textos Seletos. Tradução Floriano de Sousa Fernandes. $3^{\text {a }}$ ed., Editora Vozes, Petrópolis, RJ, p. 63-71. 
Karcanias, N. e Hessami, A. G. (2011). "System of Systems and Emergence". In: IEEE Computer Society, 2011 Fourth International Conference on Emerging Trends in Engineering \& Technology, 27-32.

Kasper, H. (2000). O Processo de Pensamento Sistêmico: Um Estudo das Principais Abordagens a partir de um Quadro de Referência Proposto. Dissertação de Mestrado apresentada ao PPGEP/UFRGS, Porto Alegre.

Kaufmann, A. (1968). A Ciência da Tomada de Decisão, McGraw-Hill, Nova Iorque, E.U.A.

Kreher, H. (1994). "Some Recurring Themes in Using Soft Systems Methodology". In: Journal of the Operational Research Society, 45(11): 1293-1303.

Lankhorst, M. et al. (2006). "Enterprise architecture: Management tool and blueprint for the organisation”. In: Information Systems Frontiers, 8(2): 63-66.

Larrère, R. (2012). “Como Avaliar as Novas Tecnologias”. In: Santos, A. C. e Becker, E. (Orgs.). Entre o Homem e a Natureza: Abordagens Teórico-Metodológicas, Redes Editora, Porto Alegre, 129-140.

Liker, J. K.; Haddad, C. J. e Karlin, J. (1999). "Perspectives on technology and work organization". In: Annual Review of Sociology, n. 25, 575-596.

Lima, E. A. (2009). Factores habilitadores de gestão do conhecimento: estudo de caso no Sector de Educação Superior brasileiro, Dissertação de Mestrado, ISCTE, Instituto Universitário de Lisboa, Lisboa, Portugal.

Lima, E. A., Alves, J. B. e Molinaro, L. F. R. (2014). "Proposta de Elementos Arquiteturais para o Sistema de Gestão de um Espaço Organizativo: Desenvolvimento da economia criativa no Brasil sob o enfoque sistêmico". In: Revista Redes.com - Estudios para el Desarollo Social de la Comunicación, 9: 85-111.

Lima, E. A., Silva, F. K. P. e Molinaro, L. F. R. (2013). “Fatores Habilitadores para Decisão de Terceirização de TI: Um Estudo de Caso no Setor Público Brasileiro". In: Temas de Administração Pública, Unesp, v. 8, n. 2.

Lima-Marques, M. e Lacerda, F. (2006). “Arquitetura da Informação: Base para a Gestão do Conhecimento". In: Tarapanoff, K. (Ed.). Inteligência, informação e conhecimento. Brasília: Ibict - Unesco, p. 241-256.

Lipshitz, R., Popper, M., and Friedman,V. A. (2002). "Multi-facet model of organizational learning". In: Journal of Applied Behavioral Science, 38(1): 78-98. 
Lira, W. S. et al. (2007). "Processo de Decisão do Uso da Informação". In: Perspectivas em Ciência da Informação, 12(2): 64-80, mai./ago.

López, S. P., Peón, J. M. M. e Ordás, C. J. V. (2005). “Organizational learning as a determining factor in business performance". In: The Learning Organization, 12 (3): 227 245.

Magnani, J. G. C. (2009). "Etnografia como Prática e Experiência". In: Horizontes Antropológicos, Porto Alegre, ano 15, n. 32, p. 129-156, jun/dez.

Marconi, M. A. e Lakatos, E. M. (2010). Fundamentos de Metodologia Científica, $7^{\text {a }}$ Ed., Atlas, São Paulo.

Maricato, J. M. e Noronha, D. P. (2012). “Indicadores bibliométricos e cientométricos em CT\&I: apontamentos históricos, metodológicos e tendências de aplicação". In: Hayashi, M. C. P. I. e Leta, J. (Org.). Bibliometria e Cientometria: reflexões teóricas e interfaces. Pedro \& João, São Carlos, v. 1, p. 21-41.

Martinelli, D. P., et al. (2012). Teoria Geral dos Sistemas, $2^{\mathrm{a}}$ ed., Saraiva, São Paulo.

Martinelli, D. P.; Ventura, C. A. A. (org.). (2006). Visão sistêmica e administração: conceitos, metodologias e aplicações, Saraiva, São Paulo.

Martinelli, D. P. (2006). "Negociação, administração e sistemas: três níveis a serem interrelacionados”. In: R.Adm., São Paulo, 41(4): 353-368, out./nov./dez.

Martins, G. A. e Theóphilo, C. R. (2009). Metodologia da Investigação Científica para Ciências Sociais Aplicadas, Atlas, $2^{\mathrm{a}}$ ed., São Paulo.

Maturana, H. R. (1997). A Ontologia da Realidade, Editora UFMG, Belo Horizonte.

Maturana, H. R. e Varela, F. J. (2001). A Árvore do Conhecimento: As Bases Biológicas da Compreensão Humana, Palas Athena, São Paulo.

McDonald, C. (2005). "Research as an Information Systems Domain”. In: Hart, D. N. e Gregor, D. (Eds.). Information Systems Foundations: Constructing and Criticising, ANU E Press, Universidade Nacional da Austrália, Canberra, Austrália.

Mele, C., et al. (2010). "A Brief Review of Systems Theories and Their Managerial Applications", In: Service Science Journal, 2(1/2), pp. 126 - 135.

Mingers, J. (2011). "Soft OR comes of age - but not everywhere!”. In: International Journal of Management Science, 39, 729-741.

(1997). "Multimethodology: for Mixing Towards a Framework Methodologies". In: Omega, Int. J. Mgmt Sci. 25(5): 489-509. 
Mingers, J. e Brocklesby, J. (1997). “Multimethodology: for Mixing Towards a Framework Methodologies". In: Omega, Int. J. Mgmt Sci. V. 25, No. 5, pp. 489-509.

Mingers, J. e Rosenhead, J. (2004). "Problem Structuring Methods in Action". In: European Journal of Operational Research, 152, 530-554.

Mingers, J. e White, L. (2010). "A Review of the Recent Contribution of System Thinking to Operational Research and Management Science". In: European Journal of Operational Research.

Mintzberg, H. (2000). Safari de Estratégia, Editora Bookman, São Paulo.

Molinaro, L. F. R. e Ramos, K. H. C. (2011). Gestão de Tecnologia da Informação: Governança de TI: Arquitetura e Alinhamento entre Sistemas de Informação e o Negócio, LTC, Rio de Janeiro.

Moraes, M. C. (2004). Pensamento Eco-Sistêmico: Educação, Aprendizagem e Cidadania no Século XXI, Vozes, Petrópolis, RJ.

Moraes, M. C. e Torre, S. (2006). "Pesquisando a partir do Pensamento Complexo Elementos para uma Metodologia de Desenvolvimento Eco-sistêmico". In: Revista Educação, Porto Alegre-RS, ano XXIX, 1(58): 145-172, jan./abr.

Moraes, M. C. e Valente, J. (2008). Como pesquisar em educação a partir da complexidade e da transdisciplinaridade?, Paulus, São Paulo.

Morgan, G. (1982). “Cybernetics and Organization Theory: Epistemology or Technique?”. In: Human Relations, 35, 521-537.

Morgan, P. (2005). "The idea and practice of systems thinking and their relevance for capacity development". In: European Centre for Development Policy Management, mar.

Morin, A. (2004). Pesquisa-Ação Integral e Sistêmica: uma Antropopedagogia Renovada, DP\&A, Rio de Janeiro.

Morin, E. (2011). Introdução Ao Pensamento Complexo, Sulina, Porto Alegre, RS, $4^{\mathrm{a}}$ Ed. Munro, I. e Mingers, J. C. (2002). "The Use of Multimethodology in Practice: Results of a Survey of Practitioners". In: Journal of the Operational Research Society, 53, 369-378.

Neves, J. L. (1996). "Pesquisa qualitativa: características, usos e possibilidades". In: Cadernos de Pesquisas em Administração, 1(3). $2^{\circ}$ Sem.

O'Brien, J. A. e Marakas, G. M. (2007). Administração de Sistemas de Informação: Uma Introdução, McGrawHill, São Paulo, $13^{\mathrm{a}}$ ed.

Oslon, D. L. (2001). “Rationality in Information Systems Support to Decision Making”. In: Information Systems Frontier, 3:2, 239-248. 
Pereira, B. A. D., Lobler, M. L. e Simonetto, E. O. (2010). "Análise dos Modelos de Tomada de Decisão sob o Enfoque Cognitivo". In: Rev. Adm. UFSM, Santa Maria, 3(2): 260-268, mai./ago.

Pereira, M. J. L. B. e Fonseca, J. G. M. (2009). Faces da Decisão: Abordagem Sistêmica do Processo Decisório, LTC, Rio de Janeiro.

Popper, M. and Lipshitz, R. (2000). "Organizational learning: mechanisms, culture and feasibility". In: Journal of Management Learning, 31(2): 181-196.

Renner, B., Stair, R. M. e Hanna, M. E. (2012). Quantitative analysis for management, Pearson, Nova Jersey, E.U.A.

Rizzoli, A. L. e Schlindwein, S. L. (2012). "Modelo do Sistema Viável no Brasil: Um Levantamento Sobre sua Aplicação". In: Revista Gestão e Conhecimento, edição especial, nov, 104-122.

Rummler, G. A. e Brache, A. P. (1994). Melhores desempenhos das empresas: Uma abordagem prática para transformar as organizações através da reengenharia, Tradução de Kátia A. Roque. 2a. ed., Makron Books, São Paulo.

Seagriff, T. e Lord, S. (2009). "Soft Operational Research Techniques: current and future uses”. In: Defense Science an Technology Laboratory. Operational Research Journal. Acesso em 20 de janeiro de 2014. Disponível em: http://www.theorsociety.com/Media/Documents/Users/CaraQuinton01011978/OriginalDoc ument/13_09_2011-09_48_11.pdf.

Senge, P. M. (2013). A Quinta Disciplina - Arte e Prática da Organização que Aprende, $29^{a}$ ed., BestSeller, Rio de Janeiro.

Senge, P. M. e Sterman, J. D. (1992). "Systems thinking and organizational learning: Acting locally and thinking globally in the organization of the future". In: European Journal of Operational Research, 59: 137-150.

Shimizu, T. (2010). Decisão nas Organizações, $3^{\text {a }}$ ed., Atlas, São Paulo.

Shrivastava, P. (1983). “The Tipology of Organizational Learning Systems”. In: Journal of Management Studies, 20(1): 7-28.

Silva, F. K. P., Lima, E. A. e Molinaro, L. F. R. (2013) "Impact Factors on the IT Outsourcing Decision: A Case Study in the Brazilian Public Sector". In: International Journal of Advances in Engineering Sciences, Vol.3 (3), Jul.

Silvino, A. M. D. (2007). "Epistemologia Positivista: Qual a Sua Influência Hoje?”. In: Psicologia, Ciência e Profissão, 27(2): 276-289. 
Simon, H. A. (1979). Comportamento administrativo: estudo dos processos decisórios nas organizações administrativas, $3^{\text {a }}$ ed., Fundação Getúlio Vargas, Rio de Janeiro.

. (1972). A capacidade de decisão e de liderança, $2^{\mathrm{a}}$ ed. brasileira, Fundo de

Cultura, Rio de Janeiro, traduzida de The new science of management decision; Harper and Brothers Publishers, Nova Iorque, E.U.A.

Simonsson, M. e Ekstedt, M. (2005). "Prioritizing IT Governance: Literatura vs Practice". In: Department of Industrial Information and Control Systems Royal Institute of Technology (KTH), Stockholm, Sweden, WP.

Small, A. e Wainwright, D. (2014). "SSM and Technology Management: Developing Multimethodology Through Practice". In: European Journal of Operational Research, $233,660-673$.

Snowden, D. (1999). “The Paradox of Story: Simplicity and Complexity in Strategy". In: Scenario and Strategy Planning, 1(5): 16-20, Nov.

Snowden, D. J. e Boone, M. E. (2007). “A leader's framework for decision making”. In: Harvard BusinessReview, Nov.

Soares, A. (2009). Towards Ontology-Driven Information Systems: Guidelines to the Creation of new Methodologies to Build Ontologies, Tese de Doutorado em Ciências e Tecnologia da Informação, Universidade de Pensilvânia, E.U.A.

Soares, A. e Fonseca, F. (2009). "Building Ontologies for Information Systems: What we have, what we need". In: iConference, Universidade de Illinois, E.U.A.

SOBRAPO. (2014). "Pesquisa Operacional". Sociedade Brasileira de Pesquisa Operacional, disponível em: < http://www.sobrapo.org.br/o_que_e_po.php>, acesso em: 05 fev. 2014.

Stanicek, Z.; et al. (2010). "Service Systems Through the Prism of Conceptual Modeling". In: Service Science 2(1/2), pp. 112 - 125.

Sterman, J. (2000). Business Dynamics: Systems thinking and modeling for a complex world, Massachusetts Institute of Technology, Sloan School of Management, Mcgraw-Hill, E.U.A.

Stevens, R. (2008). "Profiling Complex Systems". In: IEEE International Systems Conference, SysCon 2008, Montreal, Canadá, Abril 7-10.

Thiollent, M. (2011). "Action Research and Participatory Research: An Overview". In: International Journal of Action Research, 7(2): 160-174.

. (2002). Metodologia de Pesquisa-Ação, Cortez, São Paulo. 
(1997). Pesquisa-Ação nas Organizações, Atlas, São Paulo.

Turoff, M. (1975). “The Policy Delphi”. In: Delphi method - Techniques and Applications, Linston, H.A. e Turoff, M. (eds.) p. 80-96.

. (1970). "The design of a policy Delphi". In: Technological Forecasting and Social Change, 2-2, p. 149-171.

Ulrich, W. (1987). “Critical Heuristics of Social Systems Design”. In: European Journal of Operational Research, 276-283.

Van Waarden, F. (1992). "Dimensions and Types of Policy Networks". In: European Journal of Political Research, 21, 29-52.

Vasconcelos, E. M. (2002). Complexidade e Pesquisa Interdisciplinar: Epistemologia e Metodologia Operativa, Editora Vozes, Rio de Janeiro.

Vasconcellos, M. J. (2013). Pensamento Sistêmico: O Novo Paradigma da Ciência, Papirus, Campinas-SP, $10^{\mathrm{a}}$ ed. rev. e atual.

Vasconcelos, A.; Sousa, P. e Tribolet, J. (2003). "Information System Architectures: Representation, Planning and Evaluation”. In: Systemics, Cybernetics and Informatics, Proceedings of International Conference on Computer, Communication and Control Technologies, Orlando, E.U.A.

Vieira, S. (2008). Como Escrever uma Tese, $6^{\mathrm{a}}$ ed., Atlas, São Paulo.

Von Foerster, H. (1991). "Cibernetica de la cibernetica". In: Pakman, Marcelo. Las semillas de cibernetica. Obras escogidas de Heinz von Foerster. Barcelona: Gedisa, 1991, p. 89-93. Artigo original inglês 1974.

Von Winterfeldt, D. E Fasolo, B. (2009). "Structuring Decision Problems: A Case Study and Reflections for Practitioners". In: European Journal of Operational Research, 199, $857-866$.

Wenger, E. (2000). "Communities of Practice and Social Learning Systems". In: Organization, 7(2): 225-246.

White, L. (2009) "Understanding Problem Structuring Methods Interventions". In: European Journal of Operational Research, 199, 823-833.

Wooldridge, J. M. (2011). "A Natureza da Econometria e os Dados Econômicos". In: Introdução À Econometria: Uma Abordagem Moderna, 4 ${ }^{\mathrm{a}}$ Ed., Pioneira Thompson Learning.

Zachman, J. (1987). "A framework for information systems architecture”. In: IBM Systems Journal, Vol. 26. No. 3. 


\section{APÊNDICES}




\section{A- APÊNDICE A: ARTEFATOS DE APOIO À COMUNICAÇÃO E AO PROCESSO DE DESENVOLVIMENTO DA TESE}

Este apêndice compreende os seguintes artefatos:

- glossário

- cronograma do projeto de pesquisa

- guia de tópicos para a Seção Policy Delphi

- concepção metodológica da tese 


\section{Glossário}

Acoplamento estrutural - é uma forma de interação entre o sistema e o meio, caracterizado pelo fato de que a interação entre esses elementos gera fenômenos que são particularmente recorrentes ou repetitivos e que são relevantes para a manutenção da organização do sistema. Assim, o acoplamento estrutural é condição de existência dos sistemas.

Antropopedagógica - perspectiva metodológica que consiste na aplicação e adaptação de métodos de observação participante da antropologia e de princípios da pedagogia aberta, que é baseada na autonomia dos educandos, atualizando as propostas de investigação do tipo emancipatório.

Ator - é um membro de um grupo (p.ex. uma rede social) que integra um sistema social que desempenha atividades e/ou consome recursos, relacionando-se com outros atores dos propósitos do sistema e de seu conjunto de valores que o motiva.

Construtivismo social - é uma filosofia de pesquisa em que a investigação é centrada na suposição de que os indivíduos procuram entender o mundo em que vivem e trabalham. Os indivíduos desenvolvem significados subjetivos de suas experiências, significados direcionados para alguns objetos ou coisas.

Discutibilidade - é a predisposição em estar aberto à discussão e que vale a pena ser discutido, incluindo tanto características formais como políticas.

Distinção - o ato de designar qualquer ente, objeto, coisa ou unidade, está ligado à realização de um ato de distinção que separa o designado e o distingue de um fundo.

Externalidade - impacto das ações de alguém sobre o bem-estar dos que estão em torno. Trata-se de um importante indicador para dimensionar a relevância de uma ação executada. 
Incerteza - é uma situação de dúvida ou insegurança de se obter um resultado, sem forma de quantificar as possibilidades de ocorrências das situações positivas ou negativas.

Objetivação - significa a tentativa, nunca completa, de descobrir a realidade assim como ela é, mais do que como gostaríamos que fosse. Cabe ao pesquisador preservar os traços originais e as singularidades do ecossistema observado e capturar as idiossincrasias dos atores envolvidos.

Pensamento sistêmico - quadro de referência conceitual, conjunto de conhecimentos e ferramentas desenvolvido para esclarecer os padrões como um todo e ajudar a ver como modificá-los efetivamente.

Sistema determinado pelo problema - consiste na definição do sistema constituído em torno da situação-problema de interesse.

Sistema organizacional - todo e qualquer sistema que organiza e tem a capacidade para se organizar em torno de objetivos, metas e ações intencionais, com forte participação do sistema de atividade humana em nível de direcionamento estratégico, tático e operacional.

Solipsismo - concepção filosófica que afirma nada existir fora do pensamento individual e que tudo aquilo que se percebe não passa de uma espécie de sonho que se tem. 
Quadro A.1 - Cronograma do projeto de pesquisa

\begin{tabular}{|c|c|c|c|c|c|c|c|c|c|c|c|c|}
\hline \multicolumn{13}{|c|}{ CRONOGRAMA DE ATIVIDADES DA PESQUISA } \\
\hline & \multicolumn{2}{|c|}{2011} & \multicolumn{2}{|c|}{2012} & \multicolumn{2}{|c|}{2013} & \multicolumn{5}{|c|}{2014} & \multirow{2}{*}{ 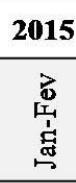 } \\
\hline & 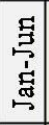 & 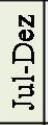 & 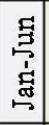 & $\begin{array}{l}\mathbf{N} \\
\stackrel{8}{9} \\
\stackrel{1}{\Xi}\end{array}$ & 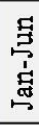 & $\begin{array}{l}\mathbf{N} \\
\stackrel{\mathbf{D}}{9} \\
\frac{1}{\Xi} \\
\end{array}$ & 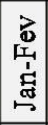 & 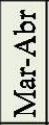 & 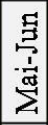 & 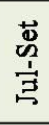 & 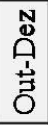 & \\
\hline \multicolumn{13}{|l|}{ Proposta de Pré-Projeto de Pesquisa } \\
\hline \multicolumn{13}{|l|}{ Proposta de Projeto de Pesquisa } \\
\hline Revisão Bibliográfica & $\bullet$ & $\bullet$ & $\diamond$ & $\diamond$ & $\bullet$ & $\bullet$ & $\bullet$ & $\bullet$ & $\bullet$ & $\bullet$ & & \\
\hline \multicolumn{13}{|l|}{ Definição dos Objetivos de Pesquisa } \\
\hline \multicolumn{13}{|c|}{ Definição das Estratégias de Pesquisa } \\
\hline \multicolumn{13}{|c|}{ Aplicação dos Instrumentos de Pesquisa-Projeto Alpha: Etapa 1} \\
\hline \multicolumn{13}{|c|}{ Aplicação dos Instrumentos de Pesquisa-Projeto Alpha: Etapa 2} \\
\hline \multicolumn{13}{|c|}{ Aplicação dos Instrumentos de Pesquisa-Projeto Bravo: Etapa 1} \\
\hline \multicolumn{13}{|c|}{ Aplicação dos Instrumentos de Pesquisa-Projeto Bravo: Etapa 2} \\
\hline \multicolumn{13}{|c|}{ Aplicação dos Instrumentos de Pesquisa-Projeto Charlie: Etapa 1} \\
\hline \multicolumn{13}{|c|}{ Aplicação dos Instrumentos de Pesquisa-Projeto Charlie: Etapa 2} \\
\hline \multicolumn{13}{|c|}{ Aplicação dos Instrumentos de Pesquisa-Casos 1, 2 e 3: Etapa 3} \\
\hline \multicolumn{13}{|l|}{ Redação e Revisão Final da Tese } \\
\hline \multicolumn{13}{|l|}{ Qualificação da Tese (Pré-Tese) } \\
\hline Ajustamento da Proposta de Tese & & & & & & & & & & & 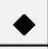 & $\nabla$ \\
\hline Defesa da Tese & & & & & & & & & & & & \\
\hline
\end{tabular}


Quadro A.2 - Guia de tópicos para a Seção Policy Delphi

(O autor, 2015)

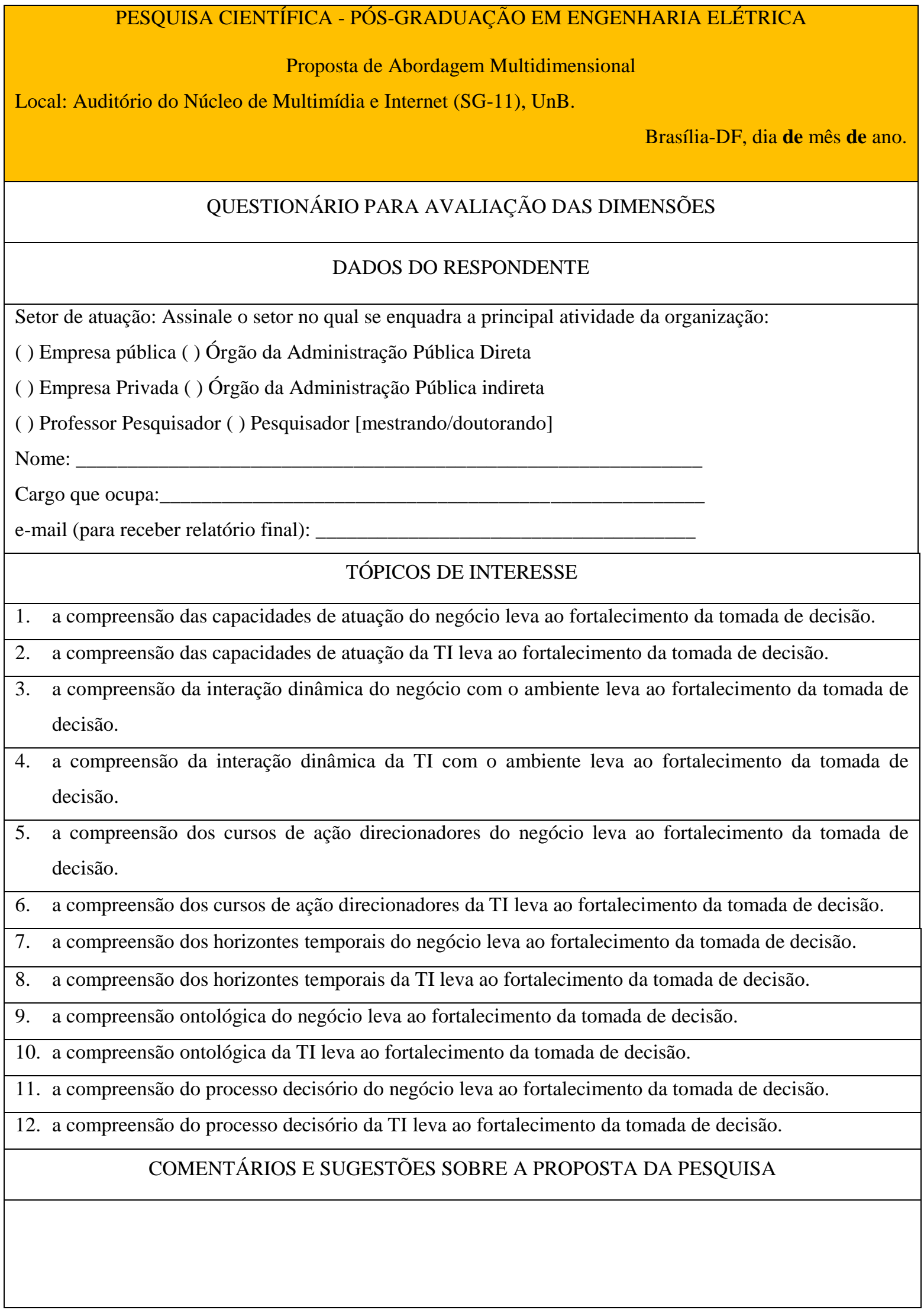




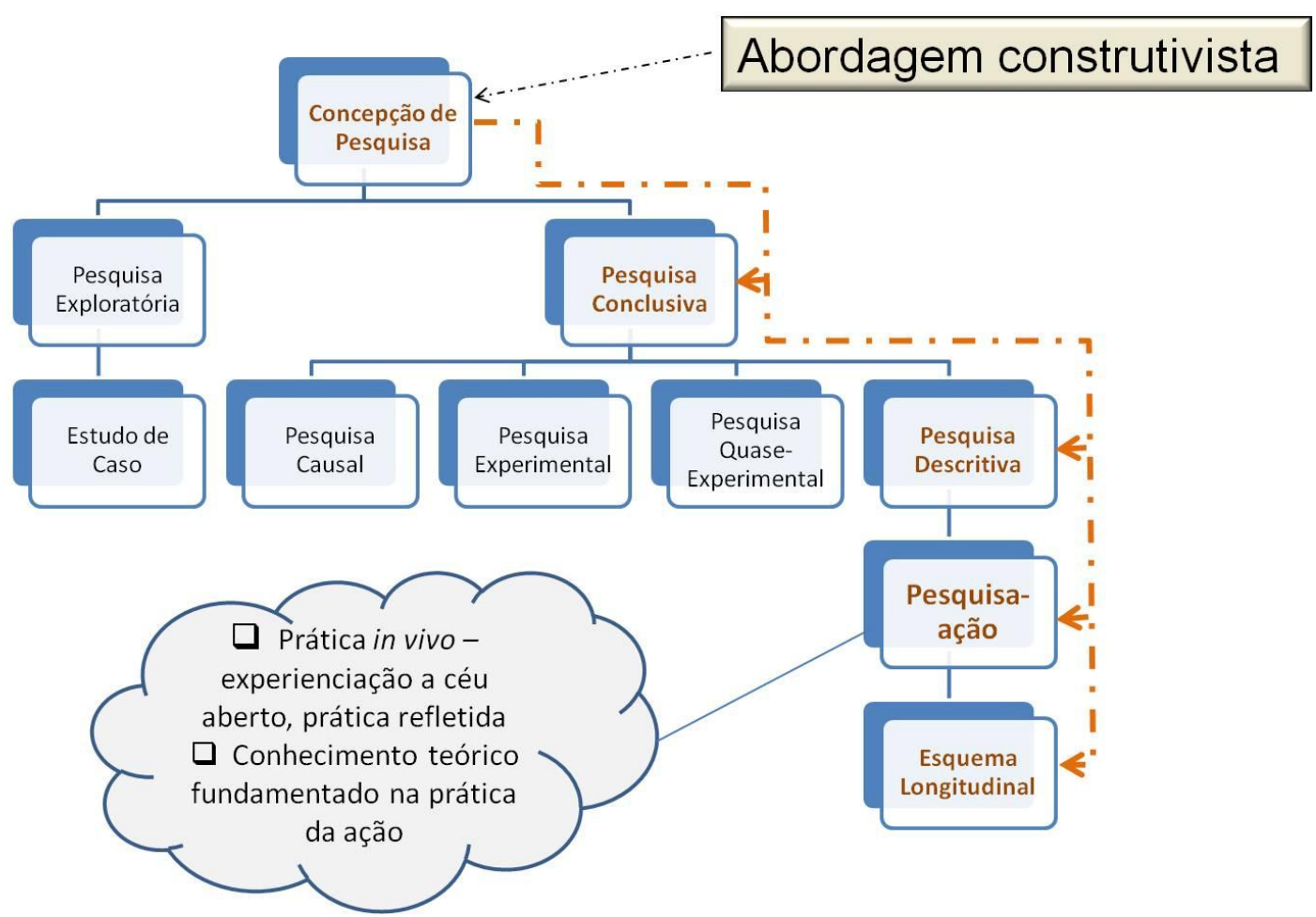

Figura A.1 - Concepção metodológica da tese

(O autor, 2015) 


\section{B- APÊNDICE B: ARTEFATOS DO PROJETO ALPHA}

Este apêndice compreende os seguintes instrumentos de análise:

- organograma do Órgão de Operação Aérea

- aspectos da análise de fronteira de Ulrich,

- dimensões da tipologia de rede,

- matriz de atribuição de responsabilidades RACI,

- prospecção da capacidade de atuação do sistema de TI,

- categorias avaliativas da análise de fronteira.

A Figura B.1 apresenta uma perspectiva do organograma para melhor ilustrar o posicionamento do Órgão de Operação Aérea.

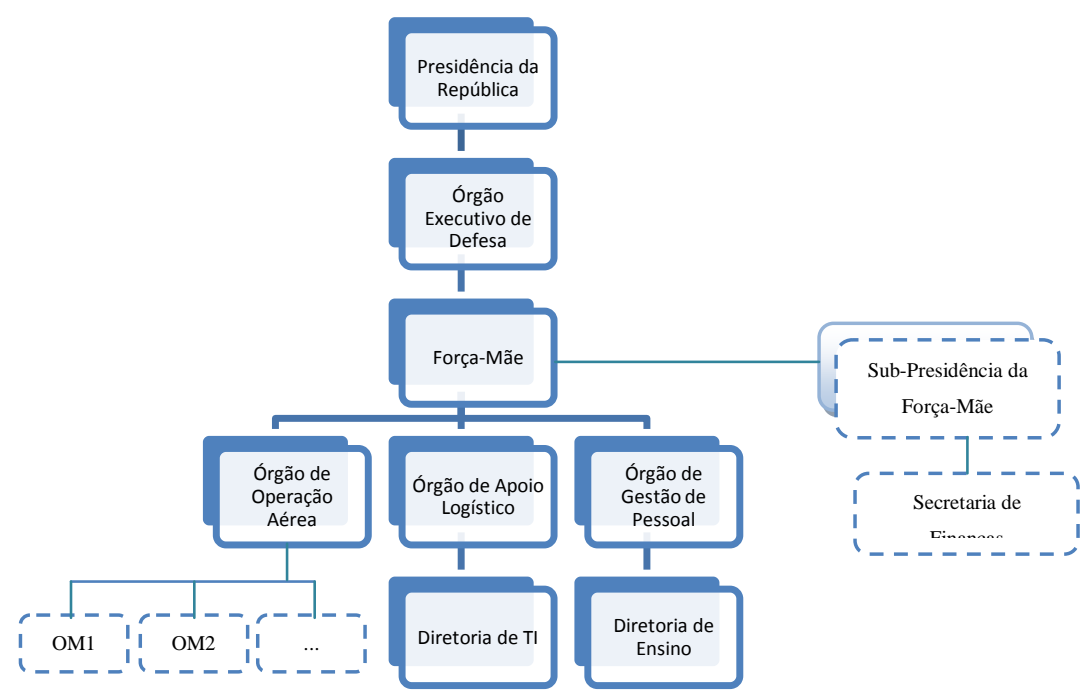

Figura B.1 - Perspectiva do Organograma do Órgão de Operação 


\section{Quadro B.1 - Aspectos da análise de fronteira de Ulrich: Projeto Alpha}

(Ulrich, 1987, modificado)

\begin{tabular}{|c|c|}
\hline \multicolumn{2}{|r|}{ ASPECTOS } \\
\hline \multicolumn{2}{|c|}{$\begin{array}{l}\text { PROPÓSITO [INTENÇÕES, DESEJOS, INTERESSES GERAIS] } \\
\text { [De onde vem a noção de propósito e valor? Quais propósitos são servidos; de quem são esses propósitos?] }\end{array}$} \\
\hline \multicolumn{2}{|l|}{ Inteligência tático-operacional } \\
\hline \multicolumn{2}{|l|}{ - $\quad$ Preparo e emprego da força } \\
\hline \multicolumn{2}{|l|}{ - $\quad$ Excelência operacional } \\
\hline \multicolumn{2}{|c|}{$\begin{array}{l}\text { PODER [GRUPOS DE INTERESSE E INSTÂNCIAS DECISÓRIAS DO SISTEMA DE GESTÃO DE PROCESSOS] } \\
\text { [Quem controla os meios e os recursos? Quem controla a situação e quem é necessário para o sucesso?] }\end{array}$} \\
\hline \multicolumn{2}{|c|}{ • $\quad$ Presidência da República (PR) } \\
\hline \multicolumn{2}{|c|}{ - $\quad$ Presidência do Órgão Executivo de Defesa (OED) } \\
\hline \multicolumn{2}{|c|}{ - $\quad$ Comitê Representativo das Forças Conjuntas } \\
\hline \multicolumn{2}{|l|}{ - $\quad$ Presidência da Força-Mãe } \\
\hline \multicolumn{2}{|c|}{ • $\quad$ Presidência do ÓRGÃO DE OPERAÇÃO AÉREA } \\
\hline \multicolumn{2}{|c|}{ - $\quad$ Alta Administração do ÓRGÃO DE OPERAÇÃO AÉREA } \\
\hline \multicolumn{2}{|c|}{ - $\quad$ Chefias de Divisão do ÓRGÃO DE OPERAÇÃO AÉREA } \\
\hline \multicolumn{2}{|c|}{ - $\quad$ Chefias setoriais do ÓRGÃO DE OPERAÇÃO AÉREA } \\
\hline \multicolumn{2}{|c|}{ - $\quad$ Equipe de especialistas do ÓRGÃO DE OPERAÇÃO AÉREA } \\
\hline \multicolumn{2}{|c|}{ • $\quad$ Equipe de apoio do ÓRGÃO DE OPERAÇÃO AÉREA } \\
\hline \multicolumn{2}{|c|}{$\begin{array}{l}\text { CONHECIMENTO [EIXOS TEMÁTICOS E DOMÍNIOS DE CONHECIMENTO] } \\
\text { [Quais experiências e conhecimentos apoiam a tomada de decisão? Qual a fonte de perícia contribui com a informação necessária?] }\end{array}$} \\
\hline EIXOS & DESCRIÇÃO \\
\hline \multirow{2}{*}{ - $\quad$ Competências em Operações Aéreas } & Empreender meios e tecnologias para gerir as operações aéreas. \\
\hline & Empreender meios e tecnologias para preparo e emprego da inteligência. \\
\hline \multirow{2}{*}{ - $\quad$ Competências em Comando e Controle } & Empreender meios e tecnologias para ordenamento do teatro de operações. \\
\hline & Empreender meios e tecnologias para assegurar o cumprimento da missão. \\
\hline - $\quad$ Competências em Gestão de Pessoal & $\begin{array}{l}\text { Empreender meios e tecnologias para doutrinamento de pessoal e preparo } \\
\text { técnico. }\end{array}$ \\
\hline \multirow[t]{2}{*}{$\begin{array}{l}\text { - Competências em Gestão de Apoio e } \\
\text { Logística }\end{array}$} & $\begin{array}{l}\text { Empreender meios e tecnologias para suportar os processos administrativos e } \\
\text { os sistemas de informação. }\end{array}$ \\
\hline & $\begin{array}{l}\text { Empreender meios e tecnologias para apoiar logisticamente as operações e } \\
\text { instalações aéreas. }\end{array}$ \\
\hline $\begin{array}{l}\text { - Competências em Planejamento e } \\
\text { Inteligência }\end{array}$ & $\begin{array}{l}\text { Empreender meios e tecnologias para estabelecer objetivos estratégicos e } \\
\text { definição de planos de ação programática. }\end{array}$ \\
\hline \multirow[t]{2}{*}{ - $\quad$ Competências em Segurança e Defesa } & $\begin{array}{l}\text { Empreender meios e tecnologias para proteger e manter a ordem nas } \\
\text { instalações aéreas. }\end{array}$ \\
\hline & Empreender meios e tecnologias para aprestar as instalações aéreas. \\
\hline \multicolumn{2}{|c|}{$\begin{array}{l}\text { LEGITIMAÇÃO [LINHAS DE ATUAÇÃO E AGENTES LEGITIMADORES] } \\
\text { [O que provê a legitimação?] }\end{array}$} \\
\hline - $\quad$ Constituição Federal do Brasil & Legalidade constitucional da atuação das Forças Conjuntas - PR, OED. \\
\hline - $\quad$ Atuação institucional do Órgão & $\begin{array}{l}\text { Presidência da Força-Mãe - prestação de contas em termos de desempenho e } \\
\text { produtividade. }\end{array}$ \\
\hline - $\quad$ Orçamento e Finanças & $\begin{array}{l}\text { Presidência da Força-Mãe, Sub-Presidência da Força-Mãe, Secretaria de } \\
\text { Finanças, Administração Direta do Governo Federal. }\end{array}$ \\
\hline $\begin{array}{l}\text { - } \quad \text { Quadro de pessoal e remuneração dos } \\
\text { servidores }\end{array}$ & $\begin{array}{l}\text { Diretoria de Ensino, Presidência da Força-Mãe, Administração Direta do } \\
\text { Governo Federal. }\end{array}$ \\
\hline $\begin{array}{l}\text { - Adoção de práticas de gestão e governança } \\
\text { de TI }\end{array}$ & Órgão de Apoio Logístico (Diretoria de TI), TCU, SLTI/MP. \\
\hline $\begin{array}{l}\text { - Processo de aquisição, contratação e } \\
\text { contratos }\end{array}$ & Sub-Presidência da Força-Mãe, Secretaria de Finanças, CGU, SLTI, TCU. \\
\hline $\begin{array}{l}\text { - Políticas e práticas de segurança da } \\
\text { informação }\end{array}$ & Comitê de SIC, TCU, DSIC/GSI-PR. \\
\hline - $\quad$ Definição tecnológica de TI & $\begin{array}{l}\text { Órgão de Apoio Logístico (Diretoria de TI), Empresas Públicas de TI } \\
\text { (SERPRO, DATAPREV E TELEBRÁS), Fornecedores privados de TI. }\end{array}$ \\
\hline
\end{tabular}




\section{Quadro B.2 - Dimensões da tipologia de rede: Projeto Alpha}

\section{(Van Waarden, 1992, modificado)}

\begin{tabular}{|c|c|}
\hline \multicolumn{2}{|r|}{ DIMENSÕES } \\
\hline \multicolumn{2}{|c|}{$\begin{array}{c}\text { TEMPORALIDADE } \\
\text { [Comunicação em rede em tempo real, mas permite a conexão de tempos sociais distintos] }\end{array}$} \\
\hline $\begin{array}{l}\text { Recursos tecnológicos } \\
\text { disponíveis }\end{array}$ & $\begin{array}{l}\text { Correio eletrônico corporativo. } \\
\text { Correio eletrônico seguro. } \\
\text { Telefonia fixa e móvel (segura). } \\
\text { Intranet do Órgão. } \\
\text { Sistema de help-desk institucional } \\
\text { Atendimento direto presencial. } \\
\text { Videoconferência. } \\
\text { Correio Aéreo Nacional. }\end{array}$ \\
\hline $\begin{array}{c}\text { Regras de conduta } \\
\text { [Elementos indutores para } \\
\text { definição das normas/regras de } \\
\text { convivência] }\end{array}$ & $\begin{array}{l}\text { Obediência à estrutura hierárquica. } \\
\text { Prestação de contas setoriais à Presidência do Órgão. } \\
\text { Princípios de hierarquia e disciplina. } \\
\text { Notas de serviço. } \\
\text { Matriz de comunicação com os envolvidos em operações, missões e exercícios. } \\
\text { Relatórios de gestão. } \\
\text { Códigos de ética e de conduta militar. }\end{array}$ \\
\hline Como atender as demandas? & $\begin{array}{l}\text { Pelo Alta Administração do Órgão: } \\
\text { - chamados intempestivos e inopinados da PR, OED, Presidência da Força-Mãe e } \\
\text { - Orgãos congêneres; } \\
\text { - } \quad \text { solicitações dos Órgãos subordinados; } \\
\text { Pelas instâncias deliberativas, seguindo cadeia de comando: } \\
\text { - tramitação de processos, documentos e correspondências oficiais; } \\
\text { - cumprimento do ordenamento militar e dos atos administrativos. }\end{array}$ \\
\hline \multicolumn{2}{|c|}{$\begin{array}{c}\text { ESPACIALIDADE } \\
\text { [Criação de territorialidade de novo tipo, virtuais e presenciais, e a conexão entre ambas] }\end{array}$} \\
\hline Determinação dos espaços & $\begin{array}{l}\text { Espaço físico das instalações do Órgão. } \\
\text { Espaço físico das unidades operacionais de TI. } \\
\text { Espaços de reunião e auditórios. } \\
\text { Atuação em campo (OM apoiadas). } \\
\text { Salas de segurança. } \\
\text { Apoio físico aos órgãos da PR, do OED e da Presidência da Força-Mãe. } \\
\text { Correio eletrônico corporativo. } \\
\text { Sistema de processamento eletrônico dos documentos. } \\
\text { Estações de trabalho. }\end{array}$ \\
\hline Determinação dos atores & $\begin{array}{l}\text { Presidência do Órgão. } \\
\text { Alta Administração do Órgão. } \\
\text { Chefia de Divisão. } \\
\text { Chefia de Área Setorial. } \\
\text { Corpo de especialistas. } \\
\text { Pessoal de apoio. } \\
\text { Especialista contratado. } \\
\text { Pessoal de apoio terceirizado. } \\
\text { Analista de negócio. } \\
\text { Analista de processo. } \\
\text { Autoridades da PR, OED, Presidência da Força-Mãe e Presidências dos Órgãos Congêneres. } \\
\text { Chefia de Órgão apoiado. } \\
\text { Parceiro institucional. } \\
\text { Fornecedor de tecnologia do setor aeroespacial. }\end{array}$ \\
\hline $\begin{array}{l}\text { Determinação dos tipos de } \\
\text { relação }\end{array}$ & $\begin{array}{l}\text { Demandas/Consultas institucionais da PR, OED, Presidência da Força-Mãe, Órgãos } \\
\text { congêneres e Órgãos apoiados. } \\
\text { Solicitações/Consultas junto a PR, OED, Presidência da Força-Mãe e Órgãos congêneres. } \\
\text { Ordenamentos/Inspeções aos Órgãos apoiados. } \\
\text { Eventos que envolvem a proteção da Força; } \\
\text { Estratégias deliberadas (Planos setoriais, operacionais); } \\
\text { Legislação e código militar; } \\
\text { Notas de serviço. }\end{array}$ \\
\hline
\end{tabular}




\section{SOCIABILIDADE}

[Novas formas de relações sociais, em intensidade, abrangência, intencionalidade e, em especial, seu significado e alcance em um novo tipo de esfera pública]

\begin{tabular}{|c|l|}
\hline $\begin{array}{c}\text { O que e como? } \\
\text { [dentificar os principais tópicos } \\
\text { de interesse do Órgão que } \\
\text { induzem a operação das } \\
\text { atividades essenciais] }\end{array}$ & $\begin{array}{l}\text { Operações Aéreas. } \\
\text { Comando e Controle. } \\
\text { Gestão de Pessoal. } \\
\text { Gestão de Apoio e Logística. } \\
\text { Planejamento e Inteligência. } \\
\text { Segurança e Defesa. } \\
\text { Sistema de gestão integrada. }\end{array}$ \\
\hline $\begin{array}{c}\text { Quais os processos com cada } \\
\text { ator? }\end{array}$ & \\
$\begin{array}{c}\text { [Dentre as atividades essenciais } \\
\text { levantadas, quais as participações } \\
\text { dos atores, em quais processos e } \\
\text { os formatos possíveis] }\end{array}$ & Vide matriz de responsabilidade RACI - Quadro B.3 \\
\hline $\begin{array}{c}\text { O que se espera a partir de uma } \\
\text { comunicação em Rede? }\end{array}$ & $\begin{array}{l}\text { Melhorar a dinâmica das operações e de comando e controle. } \\
\text { Aproximação com Autoridades internas/externas à Força-Mãe, OM apoiadas, parceiros } \\
\text { institucionais, fornecedores de tecnologia do setor aeroespacial. } \\
\text { Firmação de parcerias. }\end{array}$ \\
\hline
\end{tabular}


Quadro B.3 - Matriz de atribuição de responsabilidades RACI: Projeto Alpha

\begin{tabular}{|c|c|c|c|c|c|c|c|c|c|c|c|c|c|c|}
\hline & 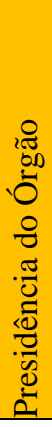 & 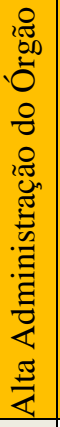 & 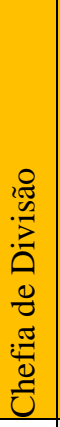 & 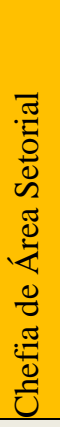 & 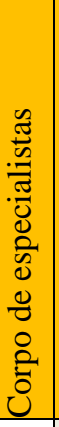 & $\begin{array}{l}0 \\
0 \\
0 \\
\tilde{\sigma} \\
0 \\
0 \\
\tilde{0} \\
0 \\
0 \\
0 \\
0\end{array}$ & 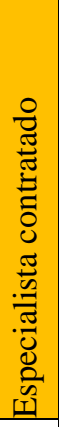 & 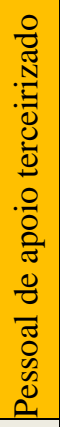 & 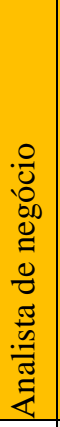 & 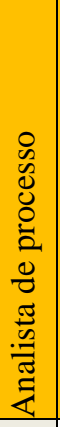 & 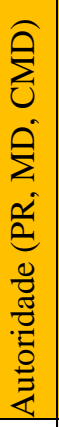 & 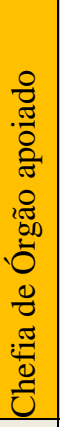 & 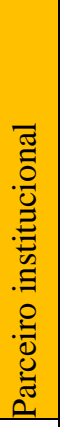 & 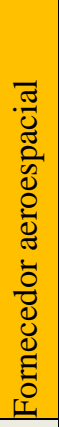 \\
\hline Operações Aéreas & $\mathrm{R}$ & $\mathrm{C}$ & $\mathrm{R}$ & $\mathrm{R}$ & $\mathrm{R}$ & $\mathrm{C}$ & $\mathrm{C}$ & $\mathrm{C}$ & $\mathrm{C}$ & $\mathrm{C}$ & A & $\mathrm{R}$ & $\mathrm{C}$ & $\mathrm{C}$ \\
\hline Comando e Controle & $\mathrm{R}$ & $\mathrm{C}$ & $\mathrm{R}$ & $\mathrm{R}$ & $\overline{\mathrm{R}}$ & $\mathrm{C}$ & $\mathrm{C}$ & $\mathrm{C}$ & $\mathrm{C}$ & $\mathrm{C}$ & A & $\mathrm{R}$ & $\mathrm{C}$ & $\mathrm{C}$ \\
\hline Gestão de Pessoal & A & $\mathrm{R}$ & $\mathrm{R}$ & $\mathrm{R}$ & $\mathrm{R}$ & $\mathrm{C}$ & $\mathrm{C}$ & $\mathrm{C}$ & $\mathrm{C}$ & $\mathrm{C}$ & I & $\mathrm{R}$ & $\mathrm{C}$ & $\mathrm{C}$ \\
\hline Gestão de Apoio e Logística & A & $\mathrm{R}$ & $\mathrm{R}$ & $\mathrm{R}$ & $\mathrm{R}$ & $\mathrm{C}$ & $\mathrm{C}$ & $\mathrm{C}$ & $\mathrm{C}$ & $\mathrm{C}$ & I & $\mathrm{R}$ & $\mathrm{C}$ & $\mathrm{C}$ \\
\hline Planejamento e Inteligência & A & $\mathrm{R}$ & $\mathrm{R}$ & $\mathrm{R}$ & $\mathrm{R}$ & $\mathrm{C}$ & $\mathrm{C}$ & $\mathrm{C}$ & $\mathrm{C}$ & $\mathrm{C}$ & $\mathrm{I}$ & $\mathrm{R}$ & $\mathrm{C}$ & $\mathrm{C}$ \\
\hline Segurança e Defesa & A & $\mathrm{R}$ & $\mathrm{R}$ & $\mathrm{R}$ & $\mathrm{R}$ & $\mathrm{C}$ & $\mathrm{C}$ & $\mathrm{C}$ & $\mathrm{C}$ & $\mathrm{C}$ & I & $\mathrm{R}$ & $\mathrm{C}$ & $\mathrm{C}$ \\
\hline Sistema de gestão integrada & A & $\mathrm{R}$ & $\mathrm{R}$ & $\mathrm{R}$ & $\mathrm{R}$ & $\mathrm{C}$ & $\mathrm{C}$ & $\mathrm{C}$ & $\mathrm{C}$ & $\mathrm{C}$ & I & $\mathrm{R}$ & $\mathrm{C}$ & $\mathrm{C}$ \\
\hline
\end{tabular}

Legenda:

- R:Responsável por executar uma atividade (o executor);

- A: Autoridade, quem deve responder pela atividade, o dono (apenas uma autoridade pode ser atribuída por atividade);

- C: Consultado, quem deve ser consultado e participar da decisão ou atividade no momento que for executada;

- I: Informado, quem deve receber a informação de que uma atividade foi executada. 


\section{Quadro B.4 - Prospecção da capacidade do sistema de interesse: Projeto Alpha}

(Morgan, 2006, modificado)

\begin{tabular}{|c|c|c|c|}
\hline $\begin{array}{l}\text { Perspectiva } \\
\text { [tópicos de } \\
\text { interesse] }\end{array}$ & $\begin{array}{l}\text { Dificuldades encontradas } \\
\text { [limitações - deficiências e } \\
\text { restrições] }\end{array}$ & $\begin{array}{l}\text { Políticas e Planos } \\
\text { [(boas) práticas, procedimentos] }\end{array}$ & $\begin{array}{c}\text { O que deve ser feito } \\
\text { minimamente para trazer o } \\
\text { impacto desejado para cada } \\
\text { perspectiva relevante? }\end{array}$ \\
\hline $\begin{array}{l}\text { Operações } \\
\text { Aéreas }\end{array}$ & $\begin{array}{l}\text { Contingenciamento de meios } \\
\text { insatisfatório } \\
\text { Ecossistema aeroespacial brasileiro } \\
\text { Condicionantes e restrições do } \\
\text { Governo Federal }\end{array}$ & $\begin{array}{l}\text { Instrumentos de Doutrinamento } \\
\text { Princípios de hierarquia e disciplina } \\
\text { Teatro de operações reais, } \\
\text { exercícios e manobras }\end{array}$ & $\begin{array}{l}\text { Implantar arquitetura de } \\
\text { Sistemas de Informação } \\
\text { (ASI) } \\
\text { Implantar arquitetura de } \\
\text { processos }\end{array}$ \\
\hline $\begin{array}{l}\text { Comando e } \\
\text { Controle (C2) }\end{array}$ & $\begin{array}{l}\text { Estrutura de C2 insatisfatória } \\
\text { Ecossistema aeroespacial brasileiro } \\
\text { Condicionantes e restrições do } \\
\text { Governo Federal }\end{array}$ & $\begin{array}{l}\text { Instrumentos de Doutrinamento } \\
\text { Princípios de hierarquia e disciplina } \\
\text { Teatro de operações reais, } \\
\text { exercícios e manobras }\end{array}$ & $\begin{array}{l}\text { Implantar ASI } \\
\text { Implantar arquitetura de } \\
\text { processos de C2 }\end{array}$ \\
\hline $\begin{array}{c}\text { Gestão de } \\
\text { Pessoal (GP) }\end{array}$ & $\begin{array}{l}\text { Contingenciamento de recursos } \\
\text { insuficiente } \\
\text { Falta de mecanismos motivacionais e } \\
\text { de recompensa } \\
\text { Condicionantes e restrições do } \\
\text { Governo Federal }\end{array}$ & $\begin{array}{l}\text { Instrumentos de Doutrinamento } \\
\text { Princípios de hierarquia e disciplina } \\
\text { Teatro de operações reais, } \\
\text { exercícios e manobras }\end{array}$ & $\begin{array}{l}\text { Implantar ASI } \\
\text { Implantar arquitetura social } \\
\text { Implantar arquitetura de } \\
\text { processos de GP }\end{array}$ \\
\hline $\begin{array}{l}\text { Gestão de Apoio } \\
\text { e Logística } \\
\text { (GAL) }\end{array}$ & $\begin{array}{l}\text { Contingenciamento de recursos } \\
\text { insuficiente } \\
\text { Modelos e metodologias } \\
\text { insatisfatórios } \\
\text { Condicionantes e restrições do } \\
\text { Governo Federal }\end{array}$ & $\begin{array}{l}\text { Instrumentos de Doutrinamento } \\
\text { Princípios de hierarquia e disciplina } \\
\text { Teatro de operações reais, } \\
\text { exercícios e manobras }\end{array}$ & $\begin{array}{l}\text { Implantar ASI } \\
\text { Implantar arquitetura de } \\
\text { processos de GAL }\end{array}$ \\
\hline $\begin{array}{l}\text { Planejamento e } \\
\text { Inteligência (PI) }\end{array}$ & $\begin{array}{l}\text { Sistema de governança não } \\
\text { percebido } \\
\text { Arquitetura de processos não } \\
\text { intencional }\end{array}$ & $\begin{array}{l}\text { Instrumentos de Doutrinamento } \\
\text { Princípios de hierarquia e disciplina } \\
\text { Teatro de operações reais, } \\
\text { exercícios e manobras }\end{array}$ & $\begin{array}{l}\text { Implantar ASI } \\
\text { Implantar arquitetura de } \\
\text { processos de PI }\end{array}$ \\
\hline $\begin{array}{l}\text { Segurança e } \\
\text { Defesa (SD) }\end{array}$ & $\begin{array}{l}\text { Contingenciamento de recursos } \\
\text { insuficiente } \\
\text { Condicionantes e restrições do } \\
\text { Governo Federal }\end{array}$ & $\begin{array}{l}\text { Instrumentos de Doutrinamento } \\
\text { Princípios de hierarquia e disciplina } \\
\text { Teatro de operações reais, } \\
\text { exercícios e manobras }\end{array}$ & $\begin{array}{l}\text { Implantar ASI } \\
\text { Implantar arquitetura de } \\
\text { processos de SD }\end{array}$ \\
\hline $\begin{array}{c}\text { Sistema de } \\
\text { Gestão Integrada } \\
\text { (SGI) }\end{array}$ & $\begin{array}{l}\text { Arquitetura de processos não } \\
\text { intencional } \\
\text { Tecnologias de gestão insatisfatórias }\end{array}$ & & $\begin{array}{l}\text { Implantar ASI } \\
\text { Implantar arquitetura de } \\
\text { processos de SGI }\end{array}$ \\
\hline
\end{tabular}




\section{Quadro B.5 - Categorias avaliativas da análise de fronteira: Projeto Alpha}

\section{(Ulrich, 1987, p. 279, modificado)}

\begin{tabular}{|c|c|}
\hline \multicolumn{2}{|c|}{ Relacionamento com os Públicos Internos e Externos } \\
\hline $\begin{array}{l}\text { - Quais os tipos de relações do Órgão com o } \\
\text { público interno? Quais indivíduos/agentes a } \\
\text { compõem? }\end{array}$ & $\begin{array}{l}\text { - } \quad \text { Cumprimento da missão e ordenamento militar } \\
\circ \quad \text { Cadeia de comando e círculos militares }\end{array}$ \\
\hline $\begin{array}{l}\text { - E com o público externo, como se dá o } \\
\text { relacionamento com as partes envolvidas e } \\
\text { afetadas pela atuação do Órgão? Quais } \\
\text { indivíduos/agentes a compõem? }\end{array}$ & 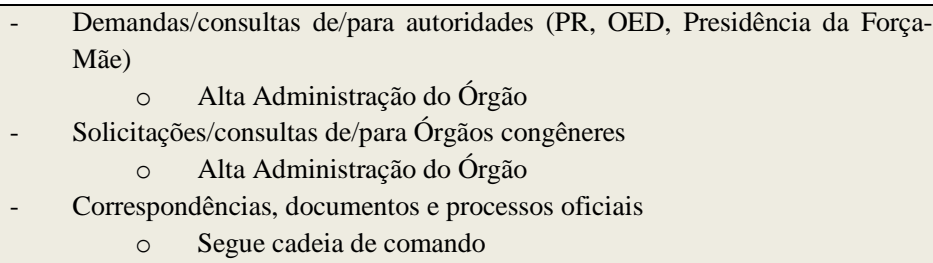 \\
\hline $\begin{array}{l}\text { - Quais os tipos de relações do Órgão com seus } \\
\text { Órgãos apoiados? Quais indivíduos/agentes a } \\
\text { compõem? }\end{array}$ & 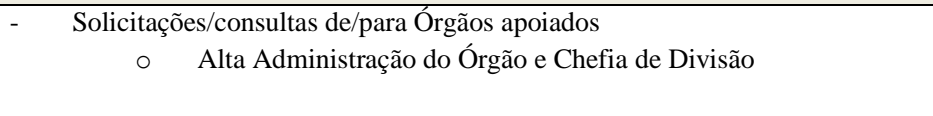 \\
\hline $\begin{array}{l}\text { - Como público interno percebe a ideia de valor } \\
\text { do Órgão? }\end{array}$ & Missão dada, missão cumprida \\
\hline $\begin{array}{l}\text { - Como seus Órgãos apoiados percebem a ideia } \\
\text { de valor do Órgão? }\end{array}$ & Imagem e semelhança tático-operacional \\
\hline $\begin{array}{l}\text { - O que o público externo espera do } \\
\text { serviço/missão que o Órgão está entregando? }\end{array}$ & $\begin{array}{ll} & \text { Precisão e pontualidade no atendimento } \\
\text { - } & \text { Facilidade de acesso ao serviço prestado }\end{array}$ \\
\hline $\begin{array}{l}\text { - Há alguma ação de engajamento com o público } \\
\text { interno e/ou externo? }\end{array}$ & $\begin{array}{ll}\text { - } & \text { Comprometimento militar } \\
\text { - } & \text { Atuação conjunta com as demais Forças }\end{array}$ \\
\hline - Qual a expectativa de qualidade do Órgão? & Excelência operacional \\
\hline $\begin{array}{l}\text { - Qual a tendência de inovação e } \\
\text { desenvolvimento? Como a organização está se } \\
\text { preparando para as novas fronteiras } \\
\text { tecnológicas? }\end{array}$ & $\begin{array}{ll}- & \text { Investimento (tímido) em PD\&I } \\
- & \text { Troca de experiências e conhecimentos com as demais Forças } \\
\text { - } & \text { Aprendizado contínuo }\end{array}$ \\
\hline $\begin{array}{l}\text { - Os canais de comunicação com os públicos } \\
\text { internos e externos são efetivos? }\end{array}$ & $\begin{array}{ll}\text { - } & \text { Sim, atendem as necessidades de comunicações operacionais. } \\
\text { - } & \text { As necessidades de comunicações administrativas carecem de melhorias }\end{array}$ \\
\hline $\begin{array}{l}\text { - Como se mede a satisfação e fidelidade dos } \\
\text { envolvidos e afetados? }\end{array}$ & $\begin{array}{ll}- & \text { Cumprimento da missão } \\
- & \text { Excelência operacional }\end{array}$ \\
\hline
\end{tabular}


Tabela B.1 - Matriz de relacionamento dos atores: Projeto Alpha

\begin{tabular}{|c|c|c|c|c|c|c|c|c|c|c|c|c|c|c|}
\hline $\begin{array}{l}\quad \underline{\text { LEGENDA }} \\
0=\text { não se relaciona } \\
1=\text { relação fraca } \\
2=\text { relação forte } \\
3=\text { relação muito forte }\end{array}$ & 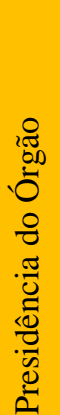 & 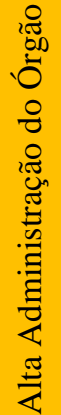 & 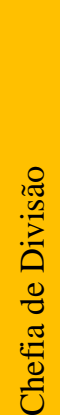 & 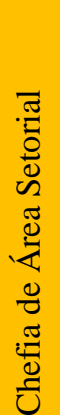 & 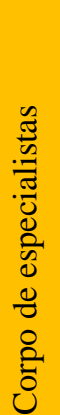 & 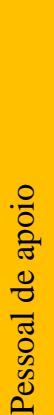 & 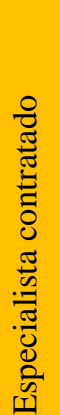 & 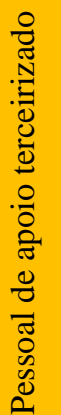 & 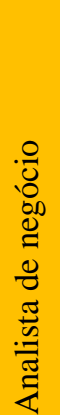 & 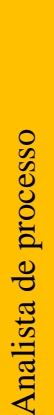 & 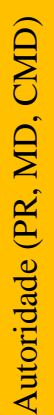 & 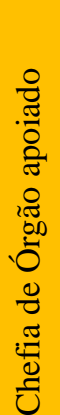 & 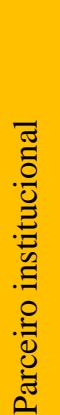 & 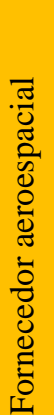 \\
\hline Presidência do Órgão & $\overline{0}$ & 3 & 2 & 1 & 1 & 1 & 1 & 0 & 1 & 1 & 3 & 3 & 3 & 3 \\
\hline Alta Administração do Órgão & 3 & 0 & 3 & 2 & 1 & 1 & 2 & 1 & 1 & 0 & 2 & 3 & 2 & 3 \\
\hline Chefia de Divisão & 2 & 3 & 0 & 3 & 3 & 1 & 3 & 2 & 2 & 1 & 1 & 2 & 2 & 2 \\
\hline Chefia de Área Setorial & 1 & 2 & 3 & 0 & 3 & 3 & 2 & 2 & 2 & 2 & 0 & 0 & 1 & 2 \\
\hline Corpo de especialistas & 1 & 1 & 2 & 3 & 0 & 3 & 1 & 0 & 1 & 0 & 0 & 0 & 0 & 2 \\
\hline Pessoal de apoio & 0 & 0 & 1 & 2 & 1 & 0 & 0 & 2 & 0 & 0 & 0 & 0 & 0 & 0 \\
\hline Especialista contratado & 1 & 1 & 2 & 1 & 1 & 0 & 0 & 0 & 1 & 0 & 0 & 0 & 0 & 0 \\
\hline Pessoal de apoio terceirizado & 0 & 0 & 1 & 1 & 1 & 1 & 0 & 0 & 0 & 0 & 0 & 0 & 0 & 0 \\
\hline Analista de negócio & 1 & 1 & 1 & 2 & 1 & 0 & 0 & 0 & 0 & 2 & 0 & 0 & 0 & 0 \\
\hline Analista de processo & 1 & 1 & 1 & 2 & 1 & 0 & 0 & 0 & 2 & 0 & 0 & 0 & 0 & 0 \\
\hline Autoridade (PR, MD e CMD) & 2 & 1 & 0 & 0 & 0 & 0 & 0 & 0 & 0 & 0 & 0 & 0 & 0 & 0 \\
\hline Chefia de Órgão apoiado & 3 & 3 & 2 & 1 & 0 & 0 & 0 & 0 & 0 & 0 & 0 & 0 & 1 & 2 \\
\hline Parceiro institucional & 2 & 2 & 1 & 0 & 0 & 0 & 0 & 0 & 0 & 0 & 0 & 0 & 0 & 0 \\
\hline Fornecedor aeroespacial & 3 & 3 & 2 & 2 & 2 & 0 & 0 & 0 & 0 & 0 & 0 & 0 & 0 & 0 \\
\hline
\end{tabular}




\section{C- APÊNDICE C: ARTEFATOS DO PROJETO BRAVO}

Este apêndice compreende os seguintes instrumentos de análise:

- roteiro para iniciar os estudos de sistemas,

- figura rica do sistema de gestão de operações de TI,

- definições-chave do sistema relevante

- aspectos da análise de fronteira,

- dimensões da tipologia de rede,

- matriz de atribuição de responsabilidades RACI,

- prospecção da capacidade de atuação do sistema de TI,

- categorias avaliativas da análise de fronteira,

- matriz de relacionamento dos atores, e

- $\quad$ síntese dos resultados da ação executada.

A implementação das fases de diagnóstico, ação e reflexão, previstas para o caso 2, contou com a participação de pesquisadores e estagiários, vinculados ao projeto de pesquisa, desenvolvimento e inovação sob a coordenação técnica do Laboratório NMI. A condução das atividades investigativas foi realizada pelo próprio pesquisador participante, incluindo o seguinte cenário de pesquisa:

- atividades de campo realizadas na sede do próprio Órgão, localizado na cidade de Brasília-DF;

- participação de dois ou três pesquisadores especialistas e/ou doutorandos, além de estagiários em nível de graduação;

- as atividades do primeiro projeto de PD\&I foram executadas no período de janeiro a novembro de 2013;

- $\quad$ as atividades do segundo projeto de PD\&I estão sendo executadas desde o mês de janeiro de 2013 e continuam em fase de execução, enquanto este material está sendo produzido; $\mathrm{e}$

- todas as entrevistas foram registradas em ata, além de apresentar os seguintes componentes de coleta de dados. 


\section{Quadro C.1 - Roteiro para iniciar os estudos de sistemas: Projeto Bravo}

(Checkland, 1993, p. 294-298)

\begin{tabular}{|c|c|}
\hline \multicolumn{2}{|r|}{ Considerar o Cliente } \\
\hline Quem é o cliente? & Unidades organizacionais do Órgão, Presidência da República, cidadãos. \\
\hline 2. $\quad$ Quais são suas aspirações? & $\begin{array}{l}\text { Acesso à informação útil, confiável e tempestiva. Interação com sistemas de } \\
\text { informação gerencial, de apoio à decisão e executivos. Compartilhamento de } \\
\text { conhecimento técnico e de gestão. }\end{array}$ \\
\hline \multicolumn{2}{|c|}{ Considerar o sistema constituído em torno do problema } \\
\hline $\begin{array}{l}\text { 3. Quem são os detentores do papel de } \\
\text { conhecedor do problema? }\end{array}$ & $\begin{array}{ll}- & \text { Coordenador de TI. } \\
\text { - } & \text { Equipe de TI das unidades operacionais. } \\
\text { - } & \text { Coordenação de desenvolvimento de soluções. } \\
\text { - } & \text { Coordenação de infraestrutura e suporte. } \\
\text { - } & \text { Fornecedores contratados de soluções de TI. }\end{array}$ \\
\hline $\begin{array}{l}\text { 4. Quem são os detentores do papel de } \\
\text { tomador de decisão? }\end{array}$ & $\begin{array}{ll}- & \text { Alta administração do Órgão Integrador } \\
\text { - } & \text { Comitê estratégico de TI. } \\
\text { - } & \text { Coordenador de TI. } \\
\text { - } & \text { Coordenação de desenvolvimento de soluções. } \\
\text { - } & \text { Coordenação de infraestrutura e suporte. } \\
\end{array}$ \\
\hline $\begin{array}{l}\text { 5. A versão consensuada dos tomadores de } \\
\text { decisão sobre a natureza do problema, é: }\end{array}$ & - $\quad$ Estrutura de gestão insatisfatória. \\
\hline $\begin{array}{l}\text { 6. As razões consensuadas dos tomadores de } \\
\text { decisão para considerar "o problema" } \\
\text { como o problema, são: }\end{array}$ & $\begin{array}{ll} & \text { Alta dependência de fornecedores de TI. } \\
\text { - } & \text { Alta rotatividade de pessoal. } \\
\text { - } & \text { Ausência de indicadores de TI. } \\
\text { - } & \text { Ausência de segregação de funções nas áreas de testes qualidade, } \\
\text { administração de banco de dados. } \\
\text { - } \quad \text { Baixa capacidade de inovação. } \\
\text { - } \quad \text { Baixo nível de competências de gestão de TI por parte dos servidores da } \\
\text { Unidade de Coordenação de TI. } \\
\text { - } \quad \text { Canais de atendimento ineficientes. } \\
\text { - } \quad \text { Competências técnicas de pessoal insatisfatórias. } \\
\text { - } \quad \text { Quadro de pessoal reduzido. }\end{array}$ \\
\hline $\begin{array}{l}\text { 7. As expectativas consensuadas dos } \\
\text { tomadores de decisão sobre o sistema de } \\
\text { resolução de problemas, são: }\end{array}$ & $\begin{array}{ll}- & \text { Reposicionar TI hierarquicamente para a condição de Diretoria (no } \\
\text { momento é uma Coordenação). } \\
\text { - } \\
\text { Estruturar sistema de governança de TI (em termos de estrutura, } \\
\text { processos e políticas). } \\
\text { - } \quad \text { Atualizar regimento interno da Coordenação de TI. }\end{array}$ \\
\hline $\begin{array}{l}\text { 8. A resposta para o item 6. sugere a seguir as } \\
\text { que são altamente avaliadas pelos } \\
\text { tomadores de decisão. }\end{array}$ & $\begin{array}{ll}- & \text { Alta dependência de fornecedores de TI. } \\
- & \text { Quadro de pessoal reduzido. } \\
\text { - } & \text { Baixa capacidade de inovação. }\end{array}$ \\
\hline $\begin{array}{l}\text { 9. A versão consensuada dos conhecedores } \\
\text { do problema sobre a natureza do problema, } \\
\text { é: }\end{array}$ & - $\quad$ Operação de TI reativa. \\
\hline $\begin{array}{l}\text { 10. As razões dos conhecedores do problema } \\
\text { para considerar "o problema" como o } \\
\text { problema, são: }\end{array}$ & 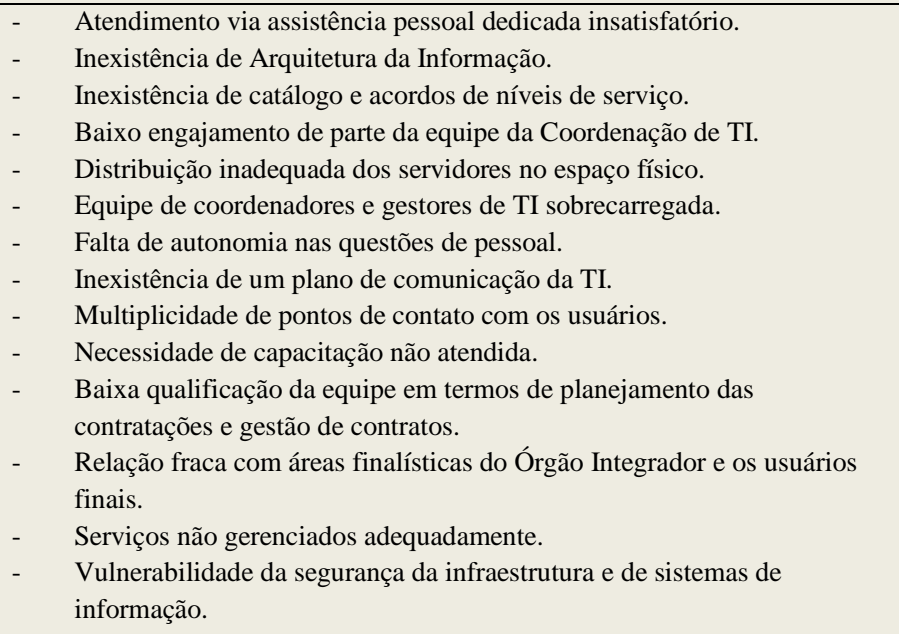 \\
\hline 11. As expectativas consensuadas dos & - $\quad$ Elaborar catálogo de serviços de TI. \\
\hline
\end{tabular}




\begin{tabular}{|c|c|c|}
\hline & $\begin{array}{l}\text { conhecedores do problema sobre o sistema } \\
\text { de resolução de problemas, são: }\end{array}$ & $\begin{array}{ll}\text { - } & \text { Revisar competências da Coordenação de TI. } \\
\text { - } & \text { Implantar processos de gestão de serviços de TI. } \\
\text { - } & \text { Implantar processos de gestão de projetos. } \\
\text { - } & \text { Implantar plano de capacitação de pessoal de TI. } \\
\text { - } & \text { Implantar processos de gestão de Segurança da Informação e } \\
& \text { Comunicações (SIC). } \\
\text { - } & \text { Criar setor de Riscos e SIC na Coordenação de TI. }\end{array}$ \\
\hline 12. & $\begin{array}{l}\text { A resposta para o item } 10 \text {. sugere a seguir } \\
\text { os que são altamente avaliados pelos } \\
\text { conhecedores do problema. }\end{array}$ & $\begin{array}{ll}- & \text { Inexistência de Arquitetura da Informação. } \\
\text { - } & \text { Inexistência de um plano de comunicação da TI. } \\
\text { - } & \text { Multiplicidade de pontos de contato com os usuários. }\end{array}$ \\
\hline 13. & $\begin{array}{l}\text { Alguns nomes possíveis para o sistema que } \\
\text { contém o problema, são: }\end{array}$ & $\begin{array}{ll}- & \text { Sistema de gestão de operações de TI. } \\
\text { - } & \text { Sistema de comunicação e controle de TI. } \\
\text { - } & \text { Sistema de gestão de serviços de TI. }\end{array}$ \\
\hline & \multirow{2}{*}{$\begin{array}{l}\text { Ao descrever inicialmente o sistema } \\
\text { determinado pelo problema, os seguintes } \\
\text { elementos parecem propensos a serem } \\
\text { relevantes: }\end{array}$} & $\begin{array}{l}\text { Substantivos - terceirização, sistema, arquitetura, projeto, serviço, } \\
\text { competência, capacidade, fornecedor, cliente, infraestrutura, tecnologia, } \\
\text { gestão, governança, processo. }\end{array}$ \\
\hline & & $\begin{array}{l}\text { Verbos - planejar, gerir, medir, implantar, projetar, sistematizar, valorizar, } \\
\text { incentivar, reconhecer, reunir, controlar, comunicar, habilitar, facilitar, } \\
\text { colaborar, coordenar. }\end{array}$ \\
\hline & $\begin{array}{l}\text { Restrições ambientais sobre o sistema } \\
\text { determinado pelo problema, são: }\end{array}$ & $\begin{array}{l}\text { Inexistência de estrutura de governança de TI. Influência das empresas } \\
\text { públicas de TI. Sistema regulatório de TI do Governo Federal. Modelo de } \\
\text { desenvolvimento de TI adotado pelo Governo Federal. }\end{array}$ \\
\hline \multicolumn{3}{|c|}{ Considerar o sistema de resolução de problema } \\
\hline & $\begin{array}{l}\text { Os detentores do papel de solucionadores } \\
\text { do problema, são: }\end{array}$ & Coordenadores e analistas de TI. \\
\hline 17. & $\begin{array}{l}\text { As outras pessoas (papéis) no sistema de } \\
\text { resolução de problema, são: }\end{array}$ & Comitê de TI, equipe técnica de TI. \\
\hline 18. & \multicolumn{2}{|c|}{$\begin{array}{l}\text { Os recursos do sistema de resolução do problema são: } \\
\text { a. Pessoas (papéis) - terceiros contratados para operar TI, instituições de cooperação e consultoria em gestão e } \\
\text { governança de TI. } \\
\text { b. Recursos físicos - dependências da Coordenação de TI e das unidades operacionais de TI, salas seguras para } \\
\text { acomodação dos equipamentos de retaguarda (backend). } \\
\text { c. Capacidades distintivas - estrutura de relações da coordenação de TI com seus pares, superiores e } \\
\text { colaboradores subordinados, bem como parceiros e fornecedores. } \\
\text { d. Financeiro - orçamento e financeiro definidos pela União e executados pelo Órgão. } \\
\text { e. Horizonte temporal - prevalência dos objetivos de curto prazo (operações de atendimento e suporte) e dos } \\
\text { objetivos de médio prazo (plano diretor de TI e projetos de iniciação e contratação de TI) em detrimento de } \\
\text { objetivos de longo prazo. }\end{array}$} \\
\hline 19. & $\begin{array}{l}\text { Restrições ambientais prováveis ou conheci } \\
\text { sobre o sistema de resolução de problema, sã }\end{array}$ & \begin{tabular}{l|ll} 
as & - & Falta de continuidade das políticas de gestão, estrutura de \\
& governança não intencional, alta rotatividade de pessoal, pressão \\
& institucional por resultados.
\end{tabular} \\
\hline 20. & $\begin{array}{l}\text { Os solucionadores do problema saberão qua } \\
\text { o problema poderá ser solucionado: }\end{array}$ & $\begin{array}{l}\text { - Quando houver uma compreensão do ecossistema de TI do governo } \\
\text { federal. }\end{array}$ \\
\hline
\end{tabular}




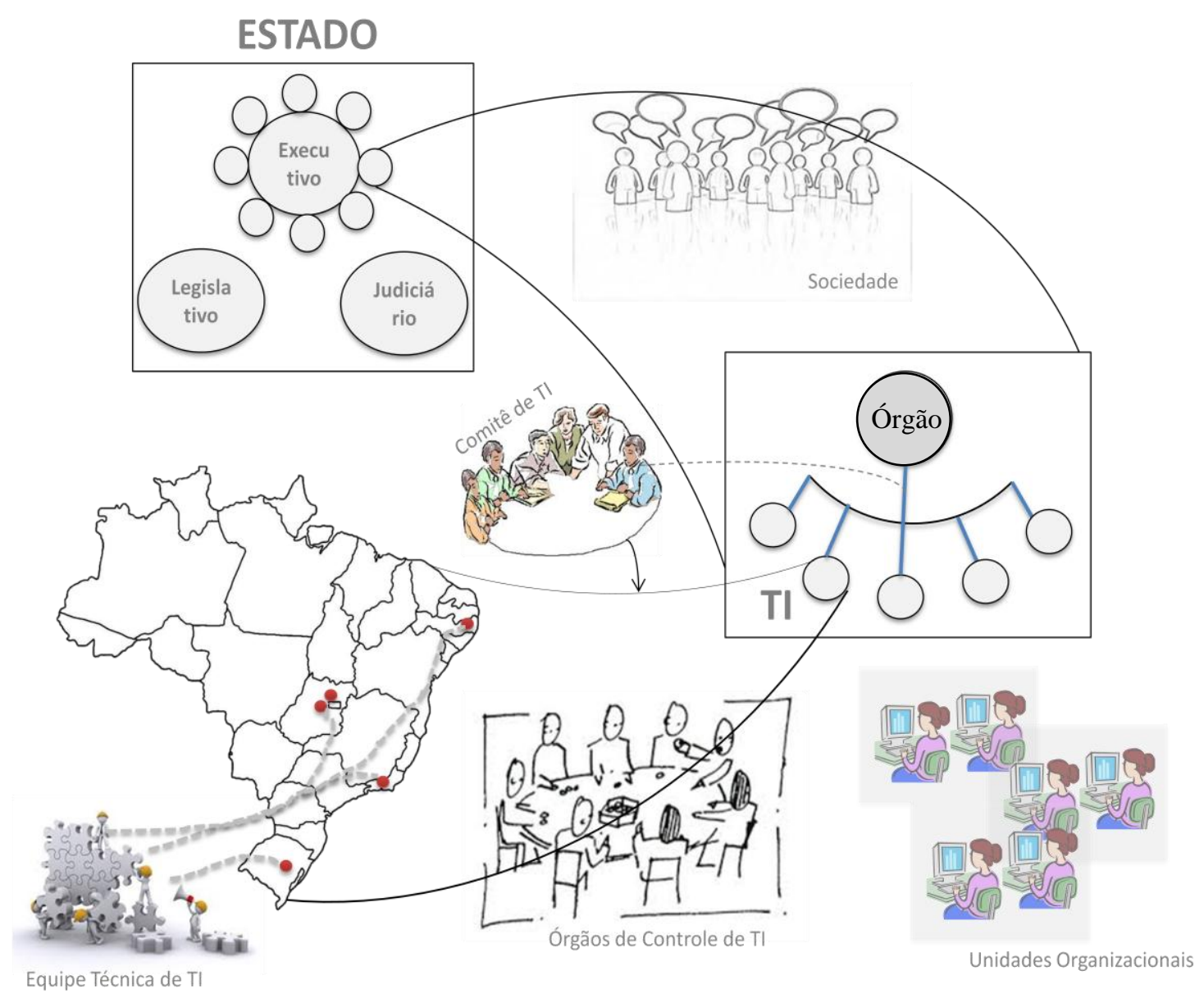

Figura C.1 - Figura rica do sistema de gestão de operações de TI: Projeto Bravo

(O autor, 2015) 
Quadro C.2 - Definições-chave do sistema relevante: Projeto Bravo

(Checkland e Scholes, 1990, p. 35, modificado)

\begin{tabular}{|c|c|c|}
\hline Transformações & Abordagens & Definições \\
\hline Visão de mundo & CATWOE & $\begin{array}{l}\text { Provimento de meios e recursos de tecnologia da informação para } \\
\text { habilitar a atuação do órgão no tocante à promoção da política de } \\
\text { integração nacional. }\end{array}$ \\
\hline Atores & $\begin{array}{l}\text { CATWOE, } \\
\text { TASCOI }\end{array}$ & $\begin{array}{l}\text { Membros do Comitê Estratégico de } \text { TI. Coordenadores e } \\
\text { especialistas das Unidades de } \\
\text { Administração da Instituição. }\end{array}$ \\
\hline Fornecedores & TASCOI & Contratados (terceirizados). Fornecedores públicos e privados de TI. \\
\hline Clientes & $\begin{array}{l}\text { CATWOE, } \\
\text { TASCOI }\end{array}$ & Unidades organizacionais. Servidores do Órgão. Sociedade. \\
\hline Proprietários & $\begin{array}{l}\text { CATWOE, } \\
\text { TASCOI }\end{array}$ & O Estado e a sociedade brasileira. \\
\hline Interventores & TASCOI & $\begin{array}{l}\text { O Estado, por meio do sistema jurídico e dos princípios } \\
\text { constitucionais dirigidos à Administração Pública. }\end{array}$ \\
\hline $\begin{array}{l}\text { Restrições } \\
\text { ambientais }\end{array}$ & CATWOE & $\begin{array}{l}\text { Inexistência de estrutura de governança de TI. Influência das } \\
\text { empresas públicas de TI. Sistema regulatório de TI do Governo } \\
\text { Federal. Modelo de desenvolvimento de TI adotado pelo Governo } \\
\text { Federal. }\end{array}$ \\
\hline
\end{tabular}




\section{Quadro C.3 - Aspectos da análise de fronteira de Ulrich: Projeto Bravo}

(Ulrich, 1987, modificado)

\begin{tabular}{|c|c|}
\hline \multicolumn{2}{|c|}{ ASPECTOS } \\
\hline \multicolumn{2}{|c|}{$\begin{array}{l}\text { PROPÓSITO [INTENÇÕES, DESEJOS, INTERESSES GERAIS] } \\
\text { [De onde vem a noção de propósito e valor? Quais propósitos são servidos; de quem são esses propósitos?] }\end{array}$} \\
\hline \multicolumn{2}{|l|}{ Atuação estratégica } \\
\hline \multicolumn{2}{|l|}{ - $\quad$ Parceria confiável } \\
\hline \multicolumn{2}{|l|}{ - $\quad$ Referência em termos de gestão e governança de TI } \\
\hline \multicolumn{2}{|l|}{ - $\quad$ Excelência operacional } \\
\hline \multicolumn{2}{|c|}{$\begin{array}{l}\text { PODER [GRUPOS DE INTERESSE E INSTÂNCIAS DECISÓRIAS DO SISTEMA DE TI] } \\
\text { [Quem controla os meios e os recursos? Quem controla a situação e quem é necessário para o sucesso?] }\end{array}$} \\
\hline \multicolumn{2}{|c|}{ - $\quad$ Alta administração do órgão } \\
\hline \multicolumn{2}{|l|}{ - $\quad$ Comitê estratégico de TI } \\
\hline \multicolumn{2}{|l|}{ - $\quad$ Comitê de segurança da informação e comunicações } \\
\hline \multicolumn{2}{|l|}{ - $\quad$ Coordenador de TI } \\
\hline \multicolumn{2}{|l|}{ - $\quad$ Equipe de TI das unidades operacionais } \\
\hline \multicolumn{2}{|l|}{ - $\quad$ Coordenação de desenvolvimento de soluções } \\
\hline \multicolumn{2}{|l|}{ - $\quad$ Coordenação de infraestrutura e suporte } \\
\hline \multicolumn{2}{|l|}{ - $\quad$ Fornecedores contratados de soluções de TI } \\
\hline \multicolumn{2}{|c|}{$\begin{array}{l}\text { CONHECIMENTO [EIXOS TEMÁTICOS E DOMÍNIOS DE CONHECIMENTO] } \\
\text { [Quais experiências e conhecimentos apoiam a tomada de decisão? Qual a fonte de perícia contribui com a informação necessária?] }\end{array}$} \\
\hline \multicolumn{2}{|c|}{\begin{tabular}{|c|c|} 
EIXOS & DESCRIÇ̃̃O \\
\end{tabular}} \\
\hline \multirow{2}{*}{ - Conhecimento técnico de TIC } & Desenvolvimento de soluções (software) \\
\hline & Infraestrutura de TI \\
\hline \multirow{5}{*}{ - $\quad$ Competências em Gestão } & Gestão de serviços \\
\hline & Gestão de processos e projetos \\
\hline & Gestão do conhecimento \\
\hline & Gestão de contratação e de contratos \\
\hline & Gestão estratégica \\
\hline \multirow[t]{3}{*}{ - $\quad$ Competências sociais } & Competências conversacionais \\
\hline & Liderança \\
\hline & Negociação \\
\hline \multirow[t]{4}{*}{ - $\quad$ Visão sistêmica da TI } & Sistema definido pelo problema \\
\hline & $\begin{array}{l}\text { Lidar com complexidade, instabilidade, imprevisibilidade e } \\
\text { interpessoalidade }\end{array}$ \\
\hline & Conhecimento de métodos sistêmicos \\
\hline & Conhecimento do framework COBIT 5 \\
\hline \multicolumn{2}{|c|}{$\begin{array}{l}\text { LEGITIMAÇÃO [LINHAS DE ATUAÇÃO E AGENTES LEGITIMADORES] } \\
\text { [O que provê a legitimação?] }\end{array}$} \\
\hline - $\quad$ Estratégia deliberada e realizada. & Comitê Estratégico de TI, Ministro e Secretário-Executivo. \\
\hline - $\quad$ Planejamento da TI & Comitê Estratégico de TI, Ministro e Secretário-Executivo. \\
\hline - $\quad$ Orçamento de TI & $\begin{array}{l}\text { Presidência da República, SOF/MP, Comitê Estratégico de } \\
\text { TI, Ministro e Secretário-Executivo. }\end{array}$ \\
\hline - $\quad$ Quadro de pessoal e remuneração dos servidores & Ministério do Planejamento. \\
\hline - $\quad$ Adoção de práticas de gestão e governança de TI & TCU, SLTI/MP. \\
\hline - $\quad$ Processo de contratação e de contratos de TI & CGU, SLTI, TCU. \\
\hline - $\quad$ Políticas e práticas de segurança da informação & Comitê de SIC, TCU. \\
\hline - $\quad$ Definição tecnológica de TI & $\begin{array}{l}\text { Empresas Públicas de TI (SERPRO, DATAPREV E } \\
\text { TELEBRÁS), Fornecedores privados de TI. }\end{array}$ \\
\hline
\end{tabular}




\section{Quadro C.4 - Dimensões da tipologia de rede: Projeto Bravo}

\section{(Van Waarden, 1992, modificado)}

\begin{tabular}{|c|c|}
\hline \multicolumn{2}{|r|}{ DIMENSÕES } \\
\hline \multicolumn{2}{|c|}{$\begin{array}{c}\text { TEMPORALIDADE } \\
\text { [Comunicação em rede em tempo real, mas permite a conexão de tempos sociais distintos] }\end{array}$} \\
\hline Recursos tecnológicos disponíveis & $\begin{array}{ll}\text { - } & \text { Correio eletrônico. } \\
\text { - } & \text { Telefonia fixa e móvel (coordenadores). } \\
\text { - } & \text { Rede social corporativa (intranet). } \\
\text { - } & \text { Sistema de help-desk da Coordenação de TI. } \\
\text { - } & \text { Atendimento direto presencial. } \\
\text { - } & \text { Videoconferência. }\end{array}$ \\
\hline $\begin{array}{c}\text { Regras de conduta } \\
\text { [elementos indutores para definição das } \\
\text { normas/regras de convivência] }\end{array}$ & $\begin{array}{l}\text { - } \text { Obediência à estrutura hierárquica. } \\
\text { - } \quad \text { Documento de oficialização da demanda (DoD). } \\
\text { - } \quad \text { Ordem de serviço. } \\
\text { - } \quad \text { Chatriz de comunicação com os contratados (relação direta com Preposto). } \\
\text { - } \quad \text { Prestação de contas das demandas estratégicas (Secretário Executivo e } \\
\text { Gabinete do Órgão Integrador). } \\
\text { - } \quad \text { Relatório de gestão e governança de TI (anual). } \\
\text { - } \quad \text { Recisões em nível de coordenação pautadas pelo suporte técnico. } \\
\text { - } \quad \text { Reuniões ordinárias anuais (duas) do Comitê de TI (portaria interna). } \\
\text { Encontros anuais com os Órgãos Vinculados de TI do Órgão Integrador } \\
\text { (seminários). } \\
\text { Reuniões do Comitê de SIC. }\end{array}$ \\
\hline Como atender as demandas? & $\begin{array}{l}\text { - Procedimento da IN SLTI } 04 \text { para formalização de demanda. } \\
\text { - Atendimento ad hoc das demandas de TI. } \\
\text { - Memorando de solicitação de levantamento de demandas junto às áreas } \\
\text { - Ae negócio. } \\
\text { - Chamados de suporte direcionados para Central de Atendimento. }\end{array}$ \\
\hline \multicolumn{2}{|r|}{ ESPACIALIDADE } \\
\hline Determinação dos espaços & $\begin{array}{ll}\text { - } & \text { Espaço físico da Coordenação de TI. } \\
\text { - } & \text { Espaço físico da TI das unidades operacionais. } \\
\text { - } & \text { Rede social corporativa do órgão. } \\
\text { - } & \text { Atendimento de campo (unidades organizacionais apoiadas). } \\
\text { - } & \text { Salas cofre. } \\
\text { - } & \text { Espaços de reunião dos Comitês de TI e SIC. } \\
\text { - } & \text { Espaço de reunião da comissão de coordenação do SISP. } \\
\text { - } & \text { Apcritórios regionais no Estados: RJ, RS e PE. } \\
\text { - } & \text { Correio eletrônico coroororonativo. } \\
\text { - } & \text { Processo eletrônico (implantação futura). } \\
\text { - } & \text { Estações de trabalho. }\end{array}$ \\
\hline Determinação dos atores & $\begin{array}{l}\text { - } \quad \text { Alta administração (Presidente, Secretário-Executivo e demais Secretários do } \\
\text { Orgão Integrador). } \\
\text { - } \quad \text { Comitês de TI. } \\
\text { - } \quad \text { Consultoria Jurídica. } \\
\text { - } \quad \text { Coordenação de Gestão de Pessoal. } \\
\text { - } \quad \text { Coordenação de Logística. } \\
\text { - } \quad \text { Coorsessoria de Comunicação. } \\
\text { - } \quad \text { Coordenação de desenvolvimento de soluções. } \\
\text { - } \quad \text { Coordenação de infraestrutura e suporte. } \\
\text { - } \quad \text { Equipe da Coordenação de TI. } \\
\text { - } \quad \text { Usuaipe contratada. } \\
\text { - } \\
\text { Dirigentes de TI das Unidades Vinculadas. }\end{array}$ \\
\hline
\end{tabular}




\begin{tabular}{|c|c|}
\hline & $\begin{array}{ll}\text { - } & \text { Unidades operacionais de TI. } \\
\text { - } & \text { Orgãos de Controle. } \\
\text { - } & \text { SLTI/MP. } \\
\text { - } & \text { Dirigentes de TI do SISP. } \\
\text { - } & \text { GSI/PR. } \\
\text { - } & \text { ENCOMAP. } \\
\text { - } & \text { Empresas Públicas de TI. } \\
\text { - } & \text { Fornecedores Privados. }\end{array}$ \\
\hline Determinação dos tipos de relação & $\begin{array}{ll}\text { - } & \text { Demandas institucionais da TI. } \\
\text { - } & \text { Eventos climáticos e naturais. } \\
\text { - } & \text { Estratégias deliberadas (Planejamento Estratégico de TI, Planejamento } \\
\text { - } & \text { Estratégico Institucional, Plano-Diretor de TI). } \\
\text { - } & \text { Adoção de boas práticas de gestão e governança de TI. } \\
\text { - } & \text { Contratos de TI. } \\
\text { - } & \text { Atendimento aos usuários. } \\
\text { - } & \text { Definição de SLAs com usuários (intenção). } \\
\text { Ordens de serviço. }\end{array}$ \\
\hline \multicolumn{2}{|c|}{$\begin{array}{c}\text { SOCIABILIDADE } \\
\text { [Novas formas de relações sociais, em intensidade, abrangência, intencionalidade e, em especial, seu significado e alcance em um } \\
\text { novo tipo de esfera pública] }\end{array}$} \\
\hline $\begin{array}{l}\text { O que e como? } \\
\text { [Identificar os principais tópicos de interesse } \\
\text { da TI que induzem a operação das } \\
\text { atividades essenciais] }\end{array}$ & $\begin{array}{ll}\text { - } & \text { Governança de TI e Estratégia de TI. } \\
\text { - } & \text { Gestão de TI. } \\
\text { - } & \text { Conformidade Legal. } \\
\text { - } & \text { Operações de TI. } \\
\text { - } & \text { Sesenvolvimento e evoluçãão de soluções. } \\
\text { - } & \text { Atendimento. } \\
\text { - } & \text { Motivação e desenvolvimento de Pessoal. } \\
\text { - } & \text { Comunicação. }\end{array}$ \\
\hline $\begin{array}{l}\text { Quais os processos com cada ator? } \\
\text { [Dentre as atividades essenciais levantadas, } \\
\text { quais as participações dos atores, em quais } \\
\text { processos e os formatos possíveis] }\end{array}$ & Vide matriz de responsabilidade RACI - Quadro C.5. \\
\hline $\begin{array}{l}\text { O que se espera a partir de uma } \\
\text { comunicação em Rede? }\end{array}$ & $\begin{array}{l}\text { - } \quad \text { Criação e compartilhamento do conhecimento. } \\
\text { - Inovação. } \\
\text { - Criação de valor para as áreas clientes do Órgão Integrador e para a } \\
\text { - } \quad \text { Apciedade. } \\
\text { - } \quad \text { Firmação de parcerias. }\end{array}$ \\
\hline
\end{tabular}


Quadro C.5 - Matriz de atribuição de responsabilidades RACI: Projeto Bravo

\begin{tabular}{|c|c|c|c|c|c|c|c|c|c|c|c|c|c|c|c|c|c|c|c|c|c|c|}
\hline & 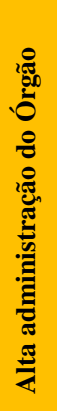 & 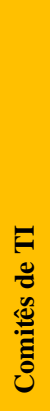 & 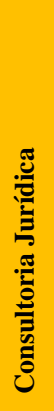 & 苞 & चે & $\sum_{0}^{\sum}$ & 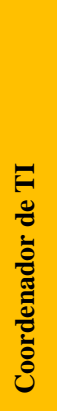 & $\stackrel{0}{\tilde{S}}$ & $\frac{\mathbf{z}}{8}$ & 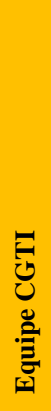 & 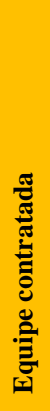 & 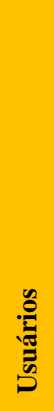 & 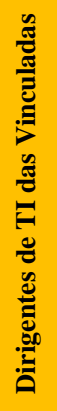 & 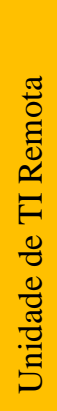 & 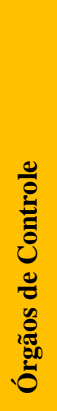 & $\underset{⿱ 乛}{\mid}$ & 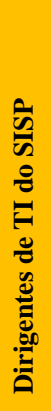 & : & 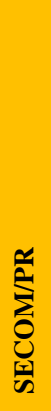 & $\sum_{i=1}^{i}$ & 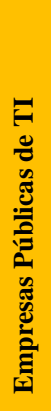 & 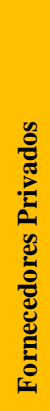 \\
\hline Governança de TI e Estratégia & $\mathrm{A}$ & $\mathrm{R}$ & $\mathrm{C}$ & $\mathrm{C}$ & $\mathrm{C}$ & I & $\mathrm{R}$ & $\mathrm{C}$ & $\mathrm{C}$ & $\mathrm{C}$ & $\mathrm{I}$ & $\mathrm{I}$ & $\mathrm{I}$ & $\mathrm{C}$ & $\mathrm{C}$ & $\mathrm{C}$ & $\mathrm{C}$ & $\mathrm{C}$ & $\mathrm{C}$ & I & I & $\mathrm{I}$ \\
\hline Gestão de TI & $\mathrm{A}$ & $\mathrm{C}$ & $\mathrm{C}$ & $\mathrm{C}$ & $\mathrm{C}$ & $\mathrm{C}$ & $\mathrm{R}$ & $\mathrm{R}$ & $\mathrm{R}$ & $\mathrm{C}$ & $\mathrm{C}$ & $\mathrm{I}$ & I & $\mathrm{R}$ & $\mathrm{C}$ & $\mathrm{C}$ & I & $\mathrm{C}$ & $\mathrm{C}$ & $\mathrm{C}$ & $\mathrm{C}$ & $\mathrm{C}$ \\
\hline Conformidade Legal & A & $\mathrm{R}$ & $\mathrm{C}$ & $\mathrm{C}$ & $\mathrm{C}$ & $\mathrm{C}$ & $\mathrm{R}$ & $\mathrm{R}$ & $\mathrm{R}$ & $\mathrm{C}$ & $\mathrm{C}$ & $\mathrm{C}$ & I & $\mathrm{R}$ & $\mathrm{C}$ & $\mathrm{C}$ & $\mathrm{I}$ & $\mathrm{C}$ & $\mathrm{C}$ & $\mathrm{I}$ & $\mathrm{I}$ & $\mathrm{I}$ \\
\hline Operações de TI & $\mathrm{I}$ & $\mathrm{I}$ & $\mathrm{I}$ & $\mathrm{I}$ & $\mathrm{I}$ & I & A & $\mathrm{R}$ & $\mathrm{R}$ & $\mathrm{R}$ & $\mathrm{R}$ & $\mathrm{C}$ & $\mathrm{I}$ & $\mathrm{C}$ & $\mathrm{I}$ & $\mathrm{I}$ & $\mathrm{I}$ & $\mathrm{I}$ & $\mathrm{I}$ & I & $\mathrm{C}$ & $\mathrm{C}$ \\
\hline Desenvolvimento e evolução de soluções & $\mathrm{I}$ & $\mathrm{I}$ & $\mathrm{I}$ & $\mathrm{I}$ & $\mathrm{I}$ & $\mathrm{I}$ & $\mathrm{A}$ & $\mathrm{R}$ & $\mathrm{R}$ & $\mathrm{R}$ & $\mathrm{R}$ & $\mathrm{C}$ & $\mathrm{I}$ & $\mathrm{C}$ & $\mathrm{I}$ & $\mathrm{I}$ & $\mathrm{I}$ & $\mathrm{I}$ & $\mathrm{I}$ & $\mathrm{I}$ & $\mathrm{C}$ & $\mathrm{C}$ \\
\hline Segurança da Informação e Comunicações & A & $\mathrm{R}$ & $\mathrm{R}$ & $\mathrm{R}$ & $\mathrm{R}$ & $\mathrm{R}$ & $\mathrm{R}$ & $\mathrm{R}$ & $\mathrm{R}$ & $\mathrm{R}$ & $\mathrm{R}$ & $\mathrm{R}$ & $\mathrm{I}$ & $\mathrm{R}$ & $\mathrm{C}$ & $\mathrm{C}$ & $\mathrm{C}$ & $\mathrm{C}$ & $\mathrm{C}$ & $\mathrm{C}$ & $\mathrm{R}$ & $\mathrm{R}$ \\
\hline Atendimento & $\mathrm{I}$ & $\mathrm{I}$ & $\mathrm{C}$ & $\mathrm{C}$ & $\mathrm{C}$ & I & A & $\mathrm{R}$ & $\mathrm{R}$ & $\mathrm{R}$ & $\mathrm{R}$ & $\mathrm{C}$ & I & $\mathrm{R}$ & $\mathrm{C}$ & $\mathrm{I}$ & $\mathrm{I}$ & $\mathrm{I}$ & $\mathrm{I}$ & $\mathrm{I}$ & $\mathrm{C}$ & $\mathrm{C}$ \\
\hline Motivação e desenvolvimento de Pessoal & $\mathrm{A}$ & $\mathrm{R}$ & I & $\mathrm{R}$ & I & I & $\mathrm{R}$ & $\mathrm{R}$ & $\mathrm{R}$ & $\mathrm{C}$ & $\mathrm{C}$ & $\mathrm{C}$ & I & $\mathrm{R}$ & I & I & I & I & I & $\mathrm{C}$ & I & I \\
\hline Comunicação & $\mathrm{C}$ & $\mathrm{C}$ & $\mathrm{C}$ & $\mathrm{C}$ & $\mathrm{C}$ & $\mathrm{R}$ & A & $\mathrm{R}$ & $\mathrm{R}$ & $\mathrm{R}$ & $\mathrm{C}$ & $\mathrm{C}$ & $\mathrm{C}$ & $\mathrm{R}$ & $\mathrm{C}$ & $\mathrm{C}$ & $\mathrm{C}$ & $\mathrm{C}$ & $\mathrm{C}$ & $\mathrm{C}$ & $\mathrm{C}$ & $\mathrm{C}$ \\
\hline
\end{tabular}

\section{Legenda:}

- R:Responsável por executar uma atividade (o executor);

- A: Autoridade, quem deve responder pela atividade, o dono (apenas uma autoridade pode ser atribuída por atividade);

- C: Consultado, quem deve ser consultado e participar da decisão ou atividade no momento que for executada;

- I: Informado, quem deve receber a informação de que uma atividade foi executada. 


\section{Quadro C.6 - Prospecção da capacidade do sistema de interesse: Projeto Bravo}

(Morgan, 2006, modificado)

\begin{tabular}{|c|c|c|c|}
\hline $\begin{array}{l}\text { Perspectiva } \\
\text { [tópicos de } \\
\text { interesse] }\end{array}$ & $\begin{array}{l}\text { Dificuldades encontradas } \\
\text { [limitações - deficiências e restrições] }\end{array}$ & $\begin{array}{l}\text { Políticas e Planos } \\
\text { [(boas) práticas, } \\
\text { procedimentos] }\end{array}$ & $\begin{array}{c}\text { O que deve ser feito } \\
\text { minimamente para trazer o } \\
\text { impacto desejado para cada } \\
\text { perspectiva relevante? }\end{array}$ \\
\hline $\begin{array}{l}\text { Governança de } \\
\text { TI e Estratégia }\end{array}$ & $\begin{array}{l}\text { - arquitetura de informação não definida } \\
\text { - processos de governança não } \\
\text { implementados (avaliar, direcionar e } \\
\text { monitorar) - ad hoc } \\
\text { - deficiência em termos de políticas e } \\
\text { normatização interna da TI } \\
\text { - baixa implementação em termos de } \\
\text { elementos facilitadores e habilitadores de } \\
\text { governança de TI } \\
\text { - ausência da definição de SLAs } \\
\text { - atribuições da TI excessivamente } \\
\text { operacionais }\end{array}$ & $\begin{array}{l}\text { - patrocínio da Alta } \\
\text { Administração } \\
\text { (direcionamento, } \\
\text { monitoramento, avaliação, } \\
\text { relacionamento, orçamento) } \\
\text { - PEI } \\
\text { - PDTI } \\
\text { - POSIC } \\
\text { - PGRSIC } \\
\text { - Comitês de TI e SIC } \\
\text { - PETI }\end{array}$ & $\begin{array}{l}\text { - reposicionar TI } \\
\text { hierarquicamente para a } \\
\text { condição de Diretoria } \\
\text { - estruturar um sistema de } \\
\text { governança de TI (em termos } \\
\text { de estrutura, processos e } \\
\text { políticas) } \\
\text { - atualizar regimento interno } \\
\text { da Coordenação de TI } \\
\text { - elaborar o catálogo de } \\
\text { serviços de TI }\end{array}$ \\
\hline Gestão de TI & $\begin{array}{l}\text { - gerenciamento insatisfatório das demandas } \\
\text { de TI } \\
\text { - visão não orientada a serviços } \\
\text { - multiplicidade de canais de atendimento, } \\
\text { com requisições intempestivas } \\
\text { - baixa cultura de processos (não } \\
\text { implementados) } \\
\text { - atribuições da TI bastante operacionais } \\
\text { - foco dos Coordenadores de TI no âmbito } \\
\text { operacional, concentrando os esforços nas } \\
\text { atividades ligadas à aplicação e } \\
\text { infraestrutura } \\
\text { - baixa implementação em termos de } \\
\text { elementos facilitadores e habilitadores de } \\
\text { governança de TI } \\
\text { - dificuldade na definição de SLAs (interno) } \\
\text { - espaço físico mal distribuído } \\
\text { - falta de capacitação do pessoal da área de } \\
\text { compra quanto à IN04, para fiscalização de } \\
\text { contratos de TI } \\
\text { - ausência de unidade para tratar riscos } \\
\text { - ausência de unidade para tratar SIC } \\
\text { - equipe de TI da Unidade Operacional } \\
\text { Remota não formalizada; } \\
\text { - ausência de catálogo de serviços }\end{array}$ & $\begin{array}{l}\text { - patrocínio da alta } \\
\text { administração } \\
\text { (direcionamento, } \\
\text { monitoramento, avaliação, } \\
\text { relacionamento, orçamento) } \\
\text { - PEI } \\
\text { - PDTI } \\
\text { - POSIC } \\
\text {-PGRSIC } \\
\text { - Comitês de TI e SIC } \\
\text { - PETI } \\
\text { - assunção dos novos } \\
\text { Analistas de TI na } \\
\text { Coordenação de TI }\end{array}$ & $\begin{array}{l}\text { - atualizar regimento interno } \\
\text { - revisar competências da } \\
\text { Coordenação de TI } \\
\text { - implantar processos de } \\
\text { gestão de serviços de TI } \\
\text { - implantar processos de } \\
\text { gestão de projetos } \\
\text { - elaborar catálogo de } \\
\text { serviços de TI } \\
\text { - estruturar um sistema de } \\
\text { governança de TI (em termos } \\
\text { de estrutura, processos e } \\
\text { políticas) } \\
\text { - implantar plano de } \\
\text { capacitação de pessoal de TI } \\
\text { - implantar processos de } \\
\text { gestão de SIC } \\
\text { - criar setor de Riscos e SIC } \\
\text { na Coordenação de TI } \\
\text { - revisar ocupação do espaço } \\
\text { físico da TI }\end{array}$ \\
\hline $\begin{array}{l}\text { Conformidade } \\
\text { Legal }\end{array}$ & - governo eletrônico & $\begin{array}{l}\text { - norma interna para } \\
\text { contratações } \\
\text { - PEI } \\
\text { - PDTI }\end{array}$ & $\begin{array}{l}\text { - plano de capacitação de } \\
\text { pessoal de TI }\end{array}$ \\
\hline $\begin{array}{l}\text { Operações de } \\
\text { TI }\end{array}$ & $\begin{array}{l}\text { - quadro de pessoal reduzido } \\
\text { - limitação da privacidade da equipe de } \\
\text { servidores da Coordenação de TI } \\
\text { - equipe de TI de uma unidade operacional } \\
\text { não formalizada }\end{array}$ & $\begin{array}{l}\text { - infraestrutura de TI voltada } \\
\text { para gestão de TI }\end{array}$ & $\begin{array}{l}\text { - atualizar regimento interno, } \\
\text { revisando as competências da } \\
\text { Coordenação de TI } \\
\text { - revisar ocupação do espaço } \\
\text { físico da TI } \\
\text { - articular projetos e ações } \\
\text { REM rede com outros órgãos }\end{array}$ \\
\hline $\begin{array}{l}\text { Desenvolvi- } \\
\text { mento e } \\
\text { evolução de } \\
\text { soluções }\end{array}$ & $\begin{array}{l}\text { - falta de segregação de funções (teste, } \\
\text { desenvolvimento e pontos de função, } \\
\text { auditoria) } \\
\text { - atividades de sustentação pela } \\
\text { Coordenação de Desenvolvimento de } \\
\text { Soluções }\end{array}$ & $\begin{array}{l}\text { - metodologia de } \\
\text { desenvolvimento de sistemas }\end{array}$ & $\begin{array}{l}\text { - atualizar regimento interno, } \\
\text { revisando as competências da } \\
\text { Coordenação de TI } \\
\text { - contratar fornecedores para } \\
\text { exercer as funções de } \\
\text { desenvolvimento de sistemas }\end{array}$ \\
\hline $\begin{array}{l}\text { Segurança da } \\
\text { Informação e } \\
\text { Comunicações }\end{array}$ & $\begin{array}{l}\text { - baixa cultura de segurança } \\
\text { - ausência de normativos e políticas de SIC } \\
\text { interna }\end{array}$ & $\begin{array}{l}\text { - POSIC } \\
\text { - PGRSIC }\end{array}$ & $\begin{array}{l}\text { - implantar processos de } \\
\text { gestão de SIC } \\
\text { - criar um setor de riscos e }\end{array}$ \\
\hline
\end{tabular}




\begin{tabular}{|c|c|c|c|}
\hline $\begin{array}{l}\text { Perspectiva } \\
\text { [tópicos de } \\
\text { interesse] }\end{array}$ & $\begin{array}{c}\text { Dificuldades encontradas } \\
\text { [limitações - deficiências e restrições] }\end{array}$ & $\begin{array}{l}\text { Políticas e Planos } \\
\text { [(boas) práticas, } \\
\text { procedimentos] }\end{array}$ & $\begin{array}{c}\text { O que deve ser feito } \\
\text { minimamente para trazer o } \\
\text { impacto desejado para cada } \\
\text { perspectiva relevante? }\end{array}$ \\
\hline & $\begin{array}{l}\text { - ausência de unidade para tratar riscos } \\
\text { - ausência de unidade para tratar SIC } \\
\text { - aquisição de TI não assistida pela } \\
\text { Coordenação de TI }\end{array}$ & & SIC na Coordenação de TI \\
\hline Atendimento & $\begin{array}{l}\text { - multiplicidade de canais de atendimento, } \\
\text { com requisições intempestivas } \\
\text { - alta rotatividade de pessoal } \\
\text { - equipe de TI de uma unidade operacional } \\
\text { não formalizada }\end{array}$ & $\begin{array}{l}\text { - central de serviços } \\
\text { - infraestrutura de TI voltada } \\
\text { para gestão de TI }\end{array}$ & $\begin{array}{l}\text { - atualizar regimento interno, } \\
\text { revisando as competências da } \\
\text { Coordenação de TI } \\
\text { - implantar processos de } \\
\text { gestão de serviços de TI } \\
\text { - identificar e capacitar } \\
\text { pessoas para exercer o papel } \\
\text { de "gerente de contas" }\end{array}$ \\
\hline $\begin{array}{l}\text { Motivação e } \\
\text { desenvolvi- } \\
\text { mento de } \\
\text { Pessoal }\end{array}$ & - baixo desenvolvimento de competências & & $\begin{array}{l}\text { Plano de capacitação de } \\
\text { pessoal de TI }\end{array}$ \\
\hline $\begin{array}{l}\text { Comunicação } \\
\text { (interna e } \\
\text { externa) }\end{array}$ & $\begin{array}{l}\text { - ausência de planos de comunicação } \\
\text { institucional da TI }\end{array}$ & - Assessoria de Comunicação & $\begin{array}{l}\text { - desenvolver treinamento dos } \\
\text { usuários }\end{array}$ \\
\hline
\end{tabular}




\title{
Quadro C.7 - Categorias avaliativas da análise de fronteira: Projeto Bravo
}

\author{
(Ulrich, 1987, p. 279, modificado)
}

\begin{tabular}{|c|c|}
\hline \multicolumn{2}{|c|}{ Relacionamento com os Públicos Internos e Externos } \\
\hline $\begin{array}{l}\text { - quais os tipos de relações da TI com as demais } \\
\text { áreas de negócio e público interno do Órgão? } \\
\text { Quais indivíduos/agentes a compõem? }\end{array}$ & $\begin{array}{l}\text { - provedor de soluções - Secretaria Executiva, demais Secretarias } \\
\text { - suporte aos sistemas e usuários - Secretaria Executiva, demais Secretarias } \\
\text { - assessoria técnica à Alta Administração do Órgão Integrador }\end{array}$ \\
\hline $\begin{array}{l}\text { - e com o público externo, como se dá o } \\
\text { relacionamento com as partes envolvidas e } \\
\text { afetadas pela TI? Quais indivíduos/agentes a } \\
\text { compõem? }\end{array}$ & $\begin{array}{l}\text { - órgãos de controle (TCU, CGU): monitoramento e auditoria de conformidade } \\
\text { regulatória e da gestão e governança de TI e segurança da informação } \\
\text { - SISP: SLTI - normatização de TI e da distribuição do quadro de pessoal técnico; } \\
\text { direcionamento da estratégias de TI; participação em grupos de trabalho do SISP } \\
\text { - órgãos integrantes do SISP: comissão de coordenação (órgãos setoriais), } \\
\text { parcerias e trocas de experiências } \\
\text { - fornecedores privados: contratos de prestação de serviços e aquisição de bens } \\
\text { - empresas públicas de TI (INFOVIA, SERPRO): serviços de rede e telecom } \\
\text { - GSI/PR: normatização de SIC } \\
\text { - SECOM/PR: normatização de comunicação institucional } \\
\text { - ENAP: capacitação e formação de pessoal técnico de TI } \\
\text { - sociedade: SI corporativo (exemplo: cartão do bolsa estiagem), SI de inteligência } \\
\text { ambiental (sistemas de predição, prevenção e contingência), projetos de } \\
\text { infraestrutura hídrica }\end{array}$ \\
\hline $\begin{array}{l}\text { - quais os tipos de relações da TI com os órgãos } \\
\text { vinculados do Órgão? Quais indivíduos/agentes } \\
\text { a compõem? }\end{array}$ & $\begin{array}{l}\text { - comitê de TI } \\
\text { - fóruns e parcerias com as unidades de TI }\end{array}$ \\
\hline $\begin{array}{l}\text { - como as áreas de negócio do Órgão/público } \\
\text { interno percebem a ideia de valor da TI? }\end{array}$ & $\begin{array}{l}\text { - disponibilidade dos sistemas de TIC } \\
\text { - capacidade de resposta às demandas } \\
\text { qualidade e utilidade da informação }\end{array}$ \\
\hline $\begin{array}{l}\text { - como os órgãos vinculados do Órgão percebem } \\
\text { a ideia de valor da TI? }\end{array}$ & - por meio de aprendizado \\
\hline $\begin{array}{l}\text { - o que o público externo espera do sistema ou } \\
\text { serviço que a TI está entregando? }\end{array}$ & $\begin{array}{l}\text { - órgãos de controle e SLTI: conformidade legal e efetividade da gestão e da } \\
\text { governança } \\
\text { - órgãos integrantes do SISP: aprendizado } \\
\text { - fornecedores privados e empresas públicas de TI: retorno financeiro, visibilidade } \\
\text { (projeção); adoção de tecnologias } \\
\text { - GSI/PR: conformidade legal e proteção das informações } \\
\text { - SECOM/PR: conformidade legal em relação aos padrões de comunicação do } \\
\text { governo federal } \\
\text { - ENAP: avaliação do aprendizado }\end{array}$ \\
\hline $\begin{array}{l}\text { - há alguma ação de engajamento com o público } \\
\text { interno e/ou externo? }\end{array}$ & $\begin{array}{l}\text { - página da Coordenação de TI na Intranet } \\
\text { - levantamento de necessidades de TI (via memorando) }\end{array}$ \\
\hline - qual a expectativa de qualidade da TI? & $\begin{array}{l}\text { - vinculada à disponibilidade de TI } \\
\text { - responsividade às demandas de TI }\end{array}$ \\
\hline $\begin{array}{l}\text { - qual a tendência de inovação e } \\
\text { desenvolvimento? Como o Sistema de TI do } \\
\text { Órgão está se preparando para as novas } \\
\text { fronteiras de TI (nexus de forças da Gartner): } \\
\text { redes e mídias sociais, mobilidade, computação } \\
\text { em nuvem e big data }\end{array}$ & $\begin{array}{l}\text { - rede social interna (portal de rede social interna) } \\
\text { - coordenação de TI com foco operacional }\end{array}$ \\
\hline $\begin{array}{l}\text { - os canais de comunicação com os públicos } \\
\text { internos e externos são efetivos? }\end{array}$ & $\begin{array}{l}\text { - não são satisfatórios e nem efetivos, não há plano de comunicação, não há ações } \\
\text { estruturadas, prevalecendo a estrutura informal }\end{array}$ \\
\hline $\begin{array}{l}\text { - como se mede a satisfação e fidelidade dos } \\
\text { envolvidos e afetados? }\end{array}$ & $\begin{array}{l}\text { - não se emprega métodos sistematizados, embora o número de chamados } \\
\text { resolvidos seja um indicador importante. }\end{array}$ \\
\hline
\end{tabular}


Tabela C.1 - Matriz de relacionamento dos atores: Projeto Bravo

\begin{tabular}{|c|c|c|c|c|c|c|c|c|c|c|c|c|c|c|}
\hline $\begin{array}{l}\quad \underline{\text { LEGENDA }} \\
0=\text { não se relaciona } \\
1=\text { relação fraca } \\
2=\text { relação forte } \\
3=\text { relação muito forte }\end{array}$ & 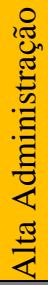 & 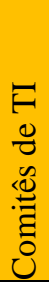 & 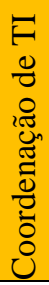 & 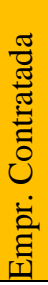 & 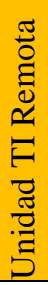 & 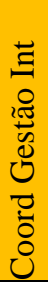 & 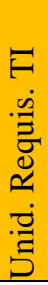 & 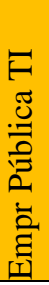 & 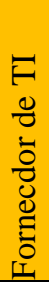 & $\underset{\text { Z }}{\stackrel{Q}{Z}}$ & 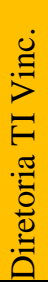 & 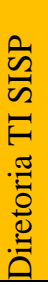 & 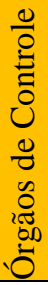 & $\underset{⿱ ⺊}{\sum_{二}}$ \\
\hline Alta Administração & 0 & 1 & 3 & 0 & 0 & 0 & 0 & 1 & 1 & 0 & 1 & 0 & 2 & 0 \\
\hline Comitês de TI & 2 & 0 & 2 & 0 & 1 & 1 & 0 & 0 & 0 & 0 & 0 & 0 & 1 & 1 \\
\hline Coordenação de TI & 3 & 1 & 0 & 2 & 2 & 1 & 3 & 1 & 3 & 1 & 1 & 1 & 3 & 2 \\
\hline Empr. contratada & 0 & 0 & 2 & 0 & 0 & 0 & 3 & 0 & 0 & 0 & 0 & 0 & 0 & 0 \\
\hline Unid TI Remota & 3 & 1 & 2 & 0 & 0 & 0 & 0 & 2 & 3 & 1 & 1 & 0 & 3 & 2 \\
\hline Coord Gestão Int & 1 & 1 & 1 & 0 & 0 & 0 & 0 & 0 & 0 & 0 & 0 & 0 & 0 & 0 \\
\hline Unid. Requisit. TI & 0 & 0 & 3 & 3 & 0 & 0 & 0 & 0 & 0 & 0 & 0 & 0 & 0 & 0 \\
\hline Empr. Pública TI & 1 & 0 & 1 & 0 & 1 & 0 & 0 & 0 & 0 & 0 & 0 & 0 & 0 & 0 \\
\hline Fornecedor de TI & 1 & 1 & 3 & 1 & 3 & 0 & 0 & 0 & 0 & 0 & 3 & 0 & 0 & 1 \\
\hline ENAP & 0 & 0 & 1 & 0 & 1 & 0 & 0 & 0 & 0 & 0 & 0 & 0 & 2 & 3 \\
\hline Diretoria TI Vinc. & 1 & 1 & 1 & 0 & 1 & 0 & 0 & 1 & 3 & 1 & 0 & 0 & 1 & 1 \\
\hline Diretoria de TI SISP & 0 & 0 & 2 & 0 & 0 & 0 & 0 & 0 & 0 & 1 & 0 & 0 & 0 & 3 \\
\hline Órgãos de Controle & 2 & 0 & 1 & 0 & 0 & 0 & 0 & 1 & 1 & 0 & 1 & 0 & 0 & 1 \\
\hline SLTI/MP & 1 & 0 & 1 & 0 & 0 & 0 & 0 & 1 & 0 & 3 & 1 & 1 & 0 & 0 \\
\hline
\end{tabular}




\section{Quadro C.8 - Síntese dos resultados da ação executada: Projeto Bravo}

(O autor, 2015)

\begin{tabular}{|c|c|c|}
\hline Tópicos & \multicolumn{2}{|c|}{ Resultados Alcançados } \\
\hline \multirow{3}{*}{$\begin{array}{l}\text { Ações } \\
\text { Programadas } \\
\qquad \& \\
\text { Ações } \\
\text { Executadas }\end{array}$} & $\begin{array}{l}\text { Implementação de oficinas de } \\
\text { inquietação e ativação para os } \\
\text { coordenadores e analistas de TI }\end{array}$ & $\begin{array}{l}\text { Trocas intensas de conhecimento e percepções } \\
\text { entre atores sociais e pesquisadores envolvidos. }\end{array}$ \\
\hline & $\begin{array}{l}\text { Diagnóstico e avaliação do subsistema } \\
\text { de TI com enfoque sistêmico. }\end{array}$ & $\begin{array}{l}\text { Desafios e oportunidades levantadas, } \\
\text { decorrentes da ação comunicativa e apreciativa } \\
\text { da realidade experienciada; baixa consciência } \\
\text { sistêmica, visão essencialmente analítica. }\end{array}$ \\
\hline & Proposta de plano estratégico de TI. & $\begin{array}{l}\text { Envolvimento de áreas de negócio na formação } \\
\text { do plano estratégico de TI; } \\
\text { Inclusão de declarações de modelo de negócio, } \\
\text { serviços e processos sob enfoque sistêmico. }\end{array}$ \\
\hline $\begin{array}{l}\text { Benefícios } \\
\text { Alcançados }\end{array}$ & \multicolumn{2}{|c|}{$\begin{array}{l}\text { Possibilitou a ampliação do horizonte de avaliação das situações-problema típicas da TI } \\
\text { para o nível de sistema de TI. Permitiu refletir sobre anomalias existentes: } \\
\text { - } \quad \text { tratamento de problemas com soluções apressadas ou precárias; } \\
\text { - } \quad \text { fatores desfavoráveis à ação de deriva de metas; } \\
\text { - } \quad \text { bloqueio de crescimento por fator limitante. } \\
\text { Inclusão de roadmap de ações a desenvolver no curto prazo. }\end{array}$} \\
\hline $\begin{array}{l}\text { Dificuldades } \\
\text { Encontradas }\end{array}$ & \multicolumn{2}{|c|}{$\begin{array}{l}\text { Solução apressada de situações problemáticas tornam os respectivos problemas crônicos, } \\
\text { afastando perspectivas de soluções fundamentais. } \\
\text { - tendência de adotar sempre a solução mais rápida e econômica, a solução } \\
\text { sintomática. } \\
\text { Inexistência de uma política de governança de TI } \\
\text { - ausência de políticas, diretrizes e procedimentos orientativos e coercitivos. }\end{array}$} \\
\hline
\end{tabular}




\section{D- APÊNDICE D: ARTEFATOS DO PROJETO CHARLIE}

Este apêndice compreende os seguintes instrumentos de análise:

- mapa contendo os escritórios de articulação,

- roteiro para iniciar os estudos de sistemas,

- figura rica do ecossistema da economia criativa,

- definições-chave do sistema relevante

- aspectos da análise de fronteira,

- dimensões da tipologia de rede,

- matriz de atribuição de responsabilidades RACI,

- prospecção da capacidade de atuação do sistema de TI,

- categorias avaliativas da análise de fronteira,

- matriz de relacionamento dos atores,

- guia de pesquisa etnográfica, e

- $\quad$ síntese dos resultados da ação executada.

A pesquisa não é sobre redes e formação de redes sociais em geral. Mais exatamente, a pesquisa-ação participante é sobre como a criatividade é sustentada pelos gestores públicos e os agentes da economia criativa, sob a coordenação de cada Escritório de Articulação. O estudo etnográfico foi conduzido de forma intersubjetiva, envolvendo detalhada e atenta observação participante junto aos gestores públicos e agentes da economia criativa.

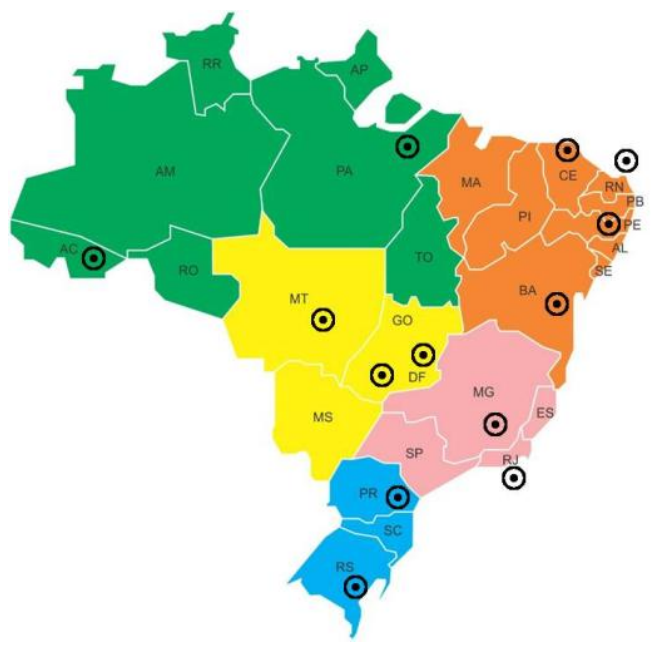

Figura D.1 - Unidades da Federação com Escritórios de Articulação 


\section{Quadro D.1 - Roteiro para iniciar os estudos de sistemas: Projeto Charlie}

(Checkland, 1993, p. 294-298)

\begin{tabular}{|c|c|}
\hline \multicolumn{2}{|r|}{ Considerar Cliente } \\
\hline 1. Quem é o cliente? & $\begin{array}{l}\text { Agentes da economia criativa. Organizações, redes e coletivos da } \\
\text { sociedade civil. Empreendedores criativos. Gestores públicos de cultura. } \\
\text { Associações, cooperativas e arranjos produtivos locais, pontos de cultura. } \\
\text { Sociedade. }\end{array}$ \\
\hline 2. Quais são suas aspirações? & $\begin{array}{l}\text { Acesso à informação, capacitação, consultorias e assessorias técnicas, } \\
\text { entre outros serviços voltados para a qualificação da gestão de projetos, } \\
\text { produtos e negócios de micro e pequenos empreendimentos criativos. }\end{array}$ \\
\hline \multicolumn{2}{|c|}{ Considerar o sistema constituído em torno do problema } \\
\hline $\begin{array}{l}\text { 3. Quem são os detentores do papel de } \\
\text { conhecedor do problema? }\end{array}$ & $\begin{array}{l}\text { Agentes da economia criativa. Gestores públicos de cultura. Instituições } \\
\text { de Ensino Superior e Técnico. Pastas do Órgão Fomentador. }\end{array}$ \\
\hline $\begin{array}{l}\text { 4. Quem são os detentores do papel de tomador de } \\
\text { decisão? }\end{array}$ & $\begin{array}{l}\text { Pasta de Economia Criativa do Órgão Fomentador, Conselhos de Cultura, } \\
\text { Instituições Estaduais Convenentes com o Órgão Fomentador para } \\
\text { implantação dos escritórios. }\end{array}$ \\
\hline $\begin{array}{l}\text { 5. A versão consensuada dos tomadores de } \\
\text { decisão sobre a natureza do problema é: }\end{array}$ & $\begin{array}{l}\text { Comprometimento dos resultados devido ao ineditismo do projeto com } \\
\text { alto grau de incertezas, imprevisibilidades e cenários complexos, } \\
\text { presentes no processo de implantação da rede de Escritórios de } \\
\text { Articulação. }\end{array}$ \\
\hline $\begin{array}{l}\text { 6. As razões consensuadas dos tomadores de } \\
\text { decisão para considerar "o problema" como o } \\
\text { problema são: }\end{array}$ & $\begin{array}{l}\text { Ausência de mecanismos e parâmetros de medição e avaliação de } \\
\text { desempenho dos Escritórios de Articulação. } \\
\text { Ausência de mecanismos e parâmetros de medição e avaliação de } \\
\text { desempenho da rede dos escritórios. } \\
\text { Indefinições e interpretações dúbias do conceito de economia criativa. } \\
\text { Indefinições quanto à configuração dos Espaços de Articulação Criativa } \\
\text { Desconhecimento da estrutura de processos de negócio e de trabalho } \\
\text { necessária para viabilizar a plataforma operacional dos escritórios. } \\
\text { Heterogeneidade e assimetria dos ecossistemas locais de economia } \\
\text { criativa. }\end{array}$ \\
\hline $\begin{array}{l}\text { 7. As expectativas consensuadas dos tomadores } \\
\text { de decisão sobre o sistema de resolução de } \\
\text { problemas são: }\end{array}$ & $\begin{array}{l}\text { Inauguração e implantação dos escritórios dentro do prazo previsto no } \\
\text { plano de trabalho. } \\
\text { Execução orçamentária conforme plano de trabalho e descentralização de } \\
\text { recursos financeiros. } \\
\text { Mapeamento dos contextos ambientais de cada ecossistema local da } \\
\text { economia criativa. } \\
\text { formação de rede de trocas e interação entre os escritórios. }\end{array}$ \\
\hline $\begin{array}{l}\text { 8. A resposta para o item } 6 \text {. sugere a seguir as que } \\
\text { são altamente avaliadas pelos tomadores de } \\
\text { decisão. }\end{array}$ & $\begin{array}{l}\text { Ausência de mecanismos e parâmetros de medição e avaliação de } \\
\text { desempenho da rede dos escritórios. } \\
\text { Indefinições e interpretações dúbias do conceito de economia criativa. } \\
\text { Heterogeneidade e assimetria dos ecossistemas locais de economia } \\
\text { criativa. }\end{array}$ \\
\hline $\begin{array}{l}\text { 9. A versão consensuada dos conhecedores do } \\
\text { problema sobre a natureza do problema é: }\end{array}$ & $\begin{array}{l}\text { Incertezas quanto ao modo de viabilização da participação dos artistas, } \\
\text { agentes da economia criativa, coletivos e empreendimentos criativos, de } \\
\text { modo a produzir resultados e gerar sinergias na rede. }\end{array}$ \\
\hline $\begin{array}{l}\text { 10. As razões dos conhecedores do problema para } \\
\text { considerar "o problema" como o problema são: }\end{array}$ & $\begin{array}{l}\text { Conflitos desencadeados pela atuação conjunta dos coordenadores e } \\
\text { equipe de apoio contratados para gerir os escritórios. } \\
\text { Dificuldades para especificar as competências da equipe gestora dos } \\
\text { escritórios. } \\
\text { Repercussões imprevisíveis da atuação dos escritórios e da possibilidade } \\
\text { de formação de rede. } \\
\text { Cenário de convivência dos atores da economia criativa altamente } \\
\text { turbulento. } \\
\text { Atuação intempestiva dos agentes e gestores públicos. } \\
\text { Assimetria entre os tempos dos tomadores de decisão, dos parceiros } \\
\text { cooperados e das instâncias de poder. } \\
\text { Empreendedores e criativos na informalidade. }\end{array}$ \\
\hline $\begin{array}{l}\text { 11. As expectativas consensuadas dos } \\
\text { conhecedores do problema sobre o sistema de } \\
\text { resolução de problemas são: }\end{array}$ & $\begin{array}{l}\text { Redes articuladas para mapeamento da economia criativa, troca de } \\
\text { experiências e interações. } \\
\text { Empoderamento dos agentes e gestores públicos de cultura. } \\
\text { Emancipação dos atores e empreendedores criativos para contribuir na }\end{array}$ \\
\hline
\end{tabular}




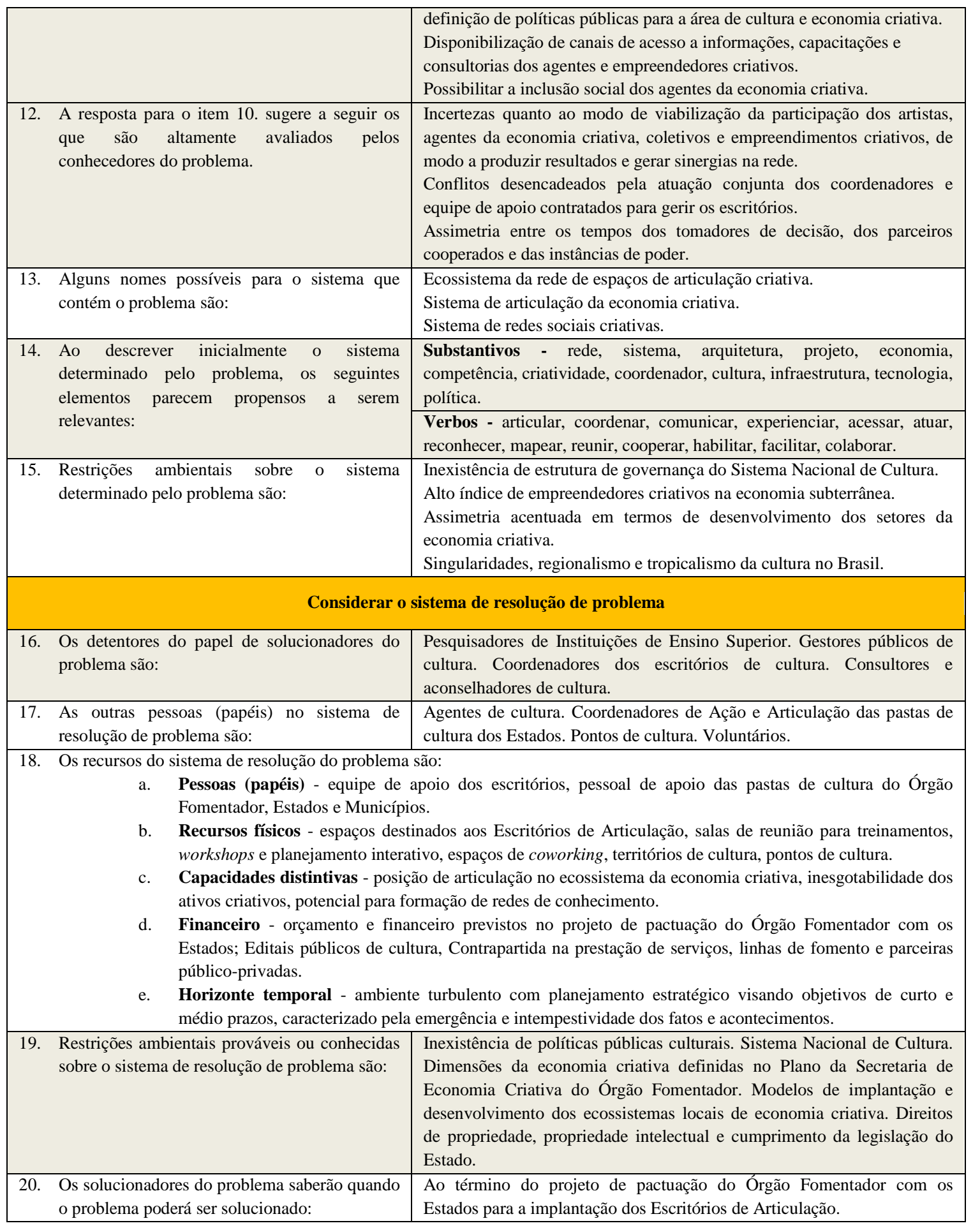




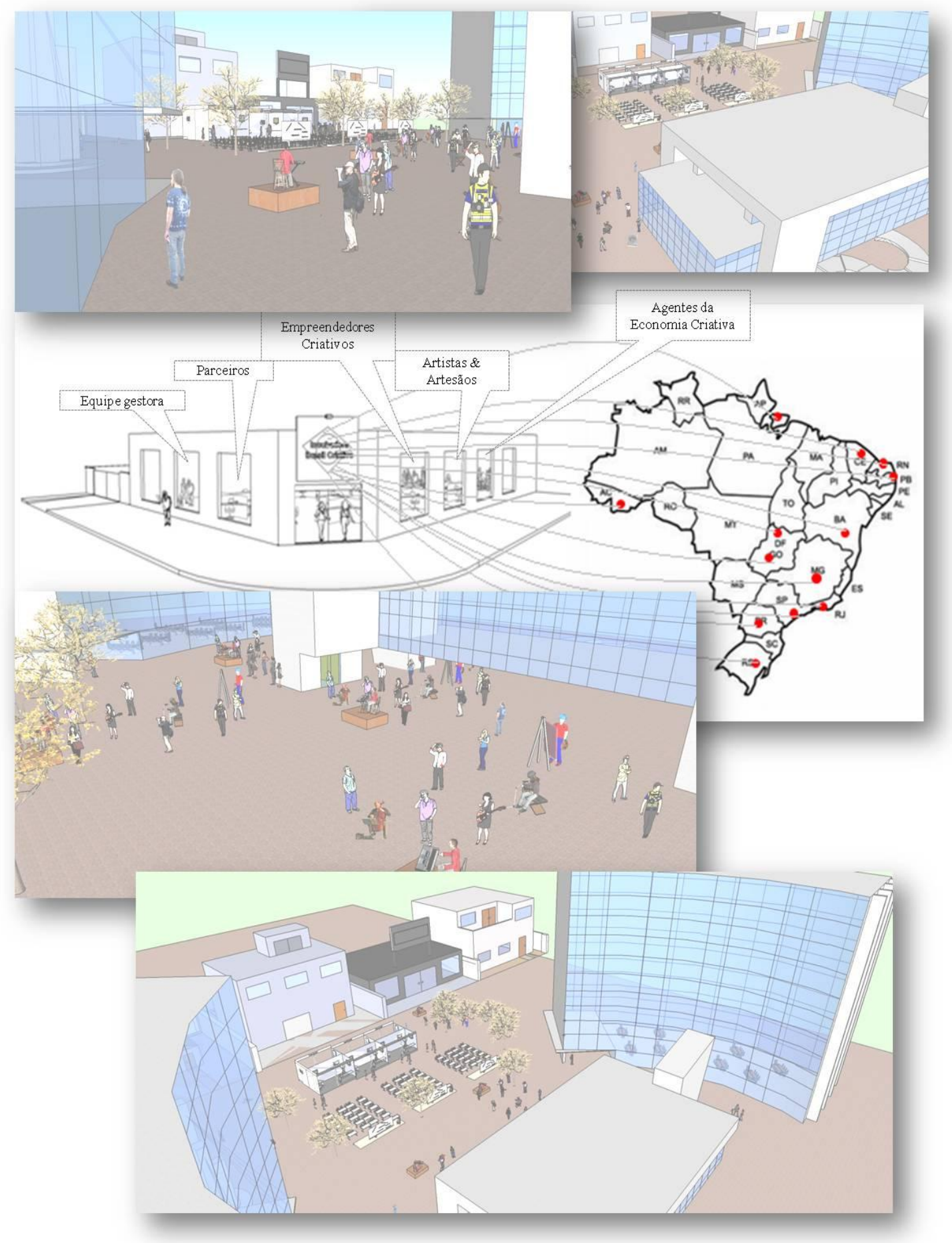

Figura D.2 - Figura rica do ecossistema da economia criativa: Projeto Charlie (O autor, 2015) 


\section{Quadro D.2 - Definições-chave do sistema relevante: Projeto Charlie}

(Checkland e Scholes, 1990, p. 35, modificado)

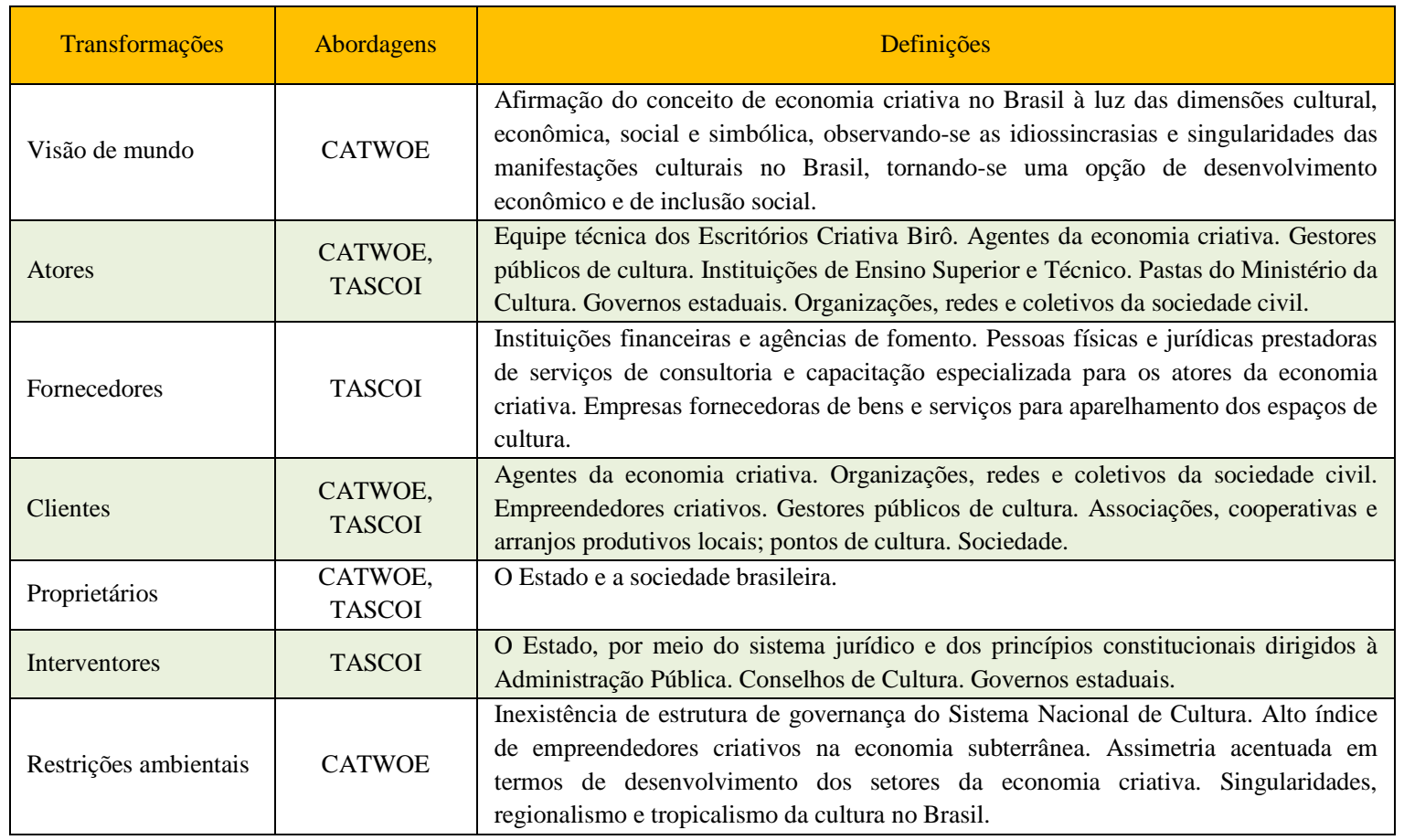




\section{Quadro D.3 - Aspectos da análise de fronteira de Ulrich: Projeto Charlie}

(Ulrich, 1987, modificado)

\begin{tabular}{|c|c|}
\hline \multicolumn{2}{|c|}{ ASPECTOS } \\
\hline \multicolumn{2}{|c|}{$\begin{array}{l}\text { PROPÓSITO [INTENÇÕES, DESEJOS, INTERESSES GERAIS] } \\
\text { [De onde vem a noção de propósito e valor? Quais propósitos são servidos; de quem são esses propósitos?] }\end{array}$} \\
\hline \multicolumn{2}{|l|}{ Geração e difusão de informação } \\
\hline \multicolumn{2}{|l|}{ - $\quad$ Fomento a empreendimentos criativos } \\
\hline \multicolumn{2}{|l|}{ - $\quad$ Formação para profissionais criativos } \\
\hline \multicolumn{2}{|l|}{ - $\quad$ Promoção de negócios criativos } \\
\hline \multicolumn{2}{|c|}{$\begin{array}{l}\text { PODER [GRUPOS DE INTERESSE E INSTÂNCIAS DECISÓRIAS DA REDE DE ESCRITÓRIOS DE ARTICULAÇÃO] } \\
\text { [Quem controla os meios e os recursos? Quem controla a situação e quem é necessário para o sucesso?] }\end{array}$} \\
\hline \multicolumn{2}{|l|}{ - $\quad$ Órgão Fomentador } \\
\hline \multicolumn{2}{|l|}{ - $\quad$ Conselho Consultivo } \\
\hline \multicolumn{2}{|l|}{ - $\quad$ Conselho Administrativo } \\
\hline \multicolumn{2}{|l|}{ - $\quad$ Comitê gestor dos Escritórios de Articulação } \\
\hline \multicolumn{2}{|l|}{ - $\quad$ Equipe gestora dos Escritórios de Articulação } \\
\hline \multicolumn{2}{|l|}{ - $\quad$ Órgãos convenentes nos Estados } \\
\hline \multicolumn{2}{|c|}{$\begin{array}{l}\text { CONHECIMENTO [EIXOS TEMÁTICOS E DOMÍNIOS DE CONHECIMENTO] } \\
\text { [Quais experiências e conhecimentos apoiam a tomada de decisão? Qual a fonte de perícia contribui com a informação necessária?] }\end{array}$} \\
\hline EIXOS & DESCRIÇÃO \\
\hline \multirow{4}{*}{ - Competências em articulação institucional/redes } & $\begin{array}{l}\text { Coordenar levantamento de informações e dados do } \\
\text { ecossistema local da economia criativa. }\end{array}$ \\
\hline & $\begin{array}{l}\text { Articular e conduzir o processo de mapeamento do ecossistema } \\
\text { local da economia criativa com o objetivo de identificar } \\
\text { vocações e oportunidades de desenvolvimento local e regional. }\end{array}$ \\
\hline & $\begin{array}{l}\text { Planejar, propor, formular e implementar ações de ativação e } \\
\text { sensibilização sobre o ecossistema local da economia criativa. }\end{array}$ \\
\hline & $\begin{array}{l}\text { Prospecção de necessidades dos setores criativos do } \\
\text { ecossistema local da economia criativa. }\end{array}$ \\
\hline \multirow{6}{*}{ - Competências em empreendedorismo e inovação } & $\begin{array}{l}\text { Liderar com atitude empreendedora os processos pertinentes ao } \\
\text { seu cargo dentro dos Escritórios de Articulação. }\end{array}$ \\
\hline & $\begin{array}{l}\text { Contribuir ativamente, dentro de suas competências, para o } \\
\text { cumprimento do Planejamento Estratégico dos Escritórios de } \\
\text { Articulação. }\end{array}$ \\
\hline & $\begin{array}{l}\text { Exercer atividades de planejamento, coordenação, organização, } \\
\text { controle e avaliação de ações pertinentes à sua área. }\end{array}$ \\
\hline & $\begin{array}{l}\text { Articular parceiras com instituições públicas, empresas } \\
\text { privadas e com os empreendedores criativos. }\end{array}$ \\
\hline & $\begin{array}{l}\text { Buscar parcerias que possam inserir o trabalho dos Escritórios } \\
\text { de Articulação no meio acadêmico do Estado. }\end{array}$ \\
\hline & $\begin{array}{l}\text { Contribuir para que as ações/projetos sejam comunicados de } \\
\text { forma positiva para o público interno e externo. }\end{array}$ \\
\hline \multirow{4}{*}{ - $\quad$ Competências em formação } & $\begin{array}{l}\text { Exercer atividades de planejamento, coordenação, organização, } \\
\text { controle e avaliação de ações pertinentes à sua área. }\end{array}$ \\
\hline & $\begin{array}{l}\text { Contribuir ativamente, dentro de suas competências, para o } \\
\text { cumprimento do Planejamento Estratégico dos Escritórios de } \\
\text { Articulação. }\end{array}$ \\
\hline & $\begin{array}{l}\text { Propor, planejar e organizar, ações de formação, como cursos, } \\
\text { workshops, seminários, palestras referentes à Economia } \\
\text { Criativa e aos agentes criativos envolvidos nos setores } \\
\text { criativos. }\end{array}$ \\
\hline & $\begin{array}{l}\text { Acompanhar as ações de formação, com o intuito de garantir a } \\
\text { disseminação dos conceitos referentes à Economia Criativa } \\
\text { entre os agentes criativos no Estado. }\end{array}$ \\
\hline \multirow{3}{*}{ - Competências em Administração/Financeiro } & $\begin{array}{l}\text { Coordenar as rotinas administrativas, o planejamento } \\
\text { estratégico e a gestão dos recursos organizacionais: materiais, } \\
\text { patrimoniais, financeiros, tecnológicos. }\end{array}$ \\
\hline & $\begin{array}{l}\text { Coordenar a equipe, as atividades, o controle, a análise e o } \\
\text { planejamento do fluxo operacional da área. }\end{array}$ \\
\hline & Desenhar os processos criando os fluxos da área, elaborar e \\
\hline
\end{tabular}




\begin{tabular}{|c|c|}
\hline & $\begin{array}{l}\text { implantar procedimentos e políticas administrativas, garantir a } \\
\text { realização de todas as atividades e operações da área. }\end{array}$ \\
\hline & $\begin{array}{l}\text { Acompanhar os pagamentos, a partir de análise crítica sobre os } \\
\text { dados e valores envolvidos. }\end{array}$ \\
\hline \multicolumn{2}{|c|}{$\begin{array}{l}\text { LEGITIMAÇÃO [LINHAS DE ATUAÇÃO E AGENTES LEGITIMADORES] } \\
\text { [O que provê a legitimação?] }\end{array}$} \\
\hline - Pasta de Economia Criativa/Órgão Fomentador & $\begin{array}{l}\text { Acordo de pactuação celebrado entre Órgão Fomentador e } \\
\text { Estados para implantação do projeto de Escritórios de } \\
\text { Articulação }\end{array}$ \\
\hline $\begin{array}{l}\text { - Estado, por meio do sistema jurídico e dos princípios } \\
\text { constitucionais dirigidos à Administração Pública }\end{array}$ & $\begin{array}{l}\text { Atuação da equipe contratada para gerir os Escritórios de } \\
\text { Articulação enquanto agentes públicos. }\end{array}$ \\
\hline - Conselhos Consultivo e Deliberativo & $\begin{array}{l}\text { Atendimento das diretivas emanadas pelos Conselhos, } \\
\text { traduzindo os interesses e necessidades manifestadas em } \\
\text { objetivos estratégicos e ações de articulação. }\end{array}$ \\
\hline - $\quad$ Comitê Gestor & $\begin{array}{l}\text { Instância decisória interna aos Escritórios de Articulação, } \\
\text { constituída pelos coordenadores contratados e representante do } \\
\text { Órgão convenente do Estado. }\end{array}$ \\
\hline - $\quad$ Sociedade & $\begin{array}{l}\text { Percepção da proposta de valor por parte dos agentes da } \\
\text { economia criativa, dos empreendedores e grupos informais de } \\
\text { cultura, artistas e atores sociais. }\end{array}$ \\
\hline
\end{tabular}




\section{Quadro D.4 - Dimensões da tipologia de rede: Projeto Charlie}

(Van Waarden, 1992, modificado)

\begin{tabular}{|c|c|}
\hline \multicolumn{2}{|r|}{ DIMENSÕES } \\
\hline \multicolumn{2}{|c|}{$\begin{array}{c}\text { TEMPORALIDADE } \\
\text { [Comunicação em rede em tempo real, mas permite a conexão de tempos sociais distintos] }\end{array}$} \\
\hline Recursos tecnológicos disponíveis & $\begin{array}{l}\text { - } \quad \text { Sede física de atendimento dos Escritórios de Articulação. } \\
\text { - } \\
\text { - } \\
\text { - } \\
\text { - } \\
\text { - }\end{array}$ \\
\hline $\begin{array}{c}\text { Regras de conduta } \\
\text { [Elementos indutores para definição das } \\
\text { normas/regras de convivência] }\end{array}$ & $\begin{array}{l}\text { - Respeito à estrutura de governança - Comitês Consultivo e Administrativo e } \\
\text { Comitê Gestor instituídos. } \\
\text { Desenvolver o conceito e o modelo de economia criativa para o ecossistema } \\
\text { local, promovendo e participando de cursos, palestras, seminários, } \\
\text { workshops, treinamentos, debates e consultas públicas referentes ao tema } \\
\text { economia criativa. } \\
\text { - Agir e proceder de forma ética e proba a fim de garantir bom andamento da } \\
\text { gestão pública, observando prazos, normais e procedimentos legais. } \\
\text { Observar princípios constitucionais dirigidos à Administração Pública. } \\
\text { Agir com parcimônia e tolerância com os conflitos de interesse e } \\
\text { divergências de ideias e posturas que emergem das relações com o público } \\
\text { interno e externo. } \\
\text { Estar disposto a conviver com as diferenças e aceitar o próximo. }\end{array}$ \\
\hline Como atender as demandas? & $\begin{array}{l}\text { - } \text { Por meio do mapeamento de redes e articulação dos territórios. } \\
\text { - Capacitando e apoiando os agentes da economia criativa. } \\
\text { - Informando os agentes da economia criativa sobre oportunidades. } \\
\text { - Captando parcerias e informações dos atores locais. }\end{array}$ \\
\hline \multicolumn{2}{|c|}{$\begin{array}{c}\text { ESPACIALIDADE } \\
\text { [Criação de territorialidade de novo tipo, virtuais e presenciais, e a conexão entre ambas] }\end{array}$} \\
\hline Determinação dos espaços & 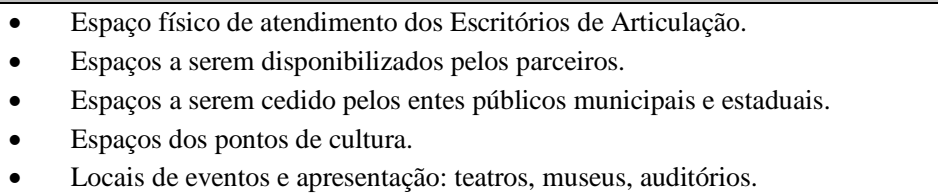 \\
\hline Determinação dos atores & $\begin{array}{ll}\text { - } & \text { Instituições financeiras. } \\
\text { - } & \text { Instituições de fomento. } \\
\text { - } & \text { Entes públicos Municipais e Estaduais. } \\
\text { - } & \text { Instituições de Ensino Superior e Técnico (IES). } \\
\text { - } & \text { Instituições de Ensino Técnico (IET). } \\
\text { - } & \text { Entidades do Sistema S. } \\
\text { - } & \text { Agências de turismo. } \\
\text { - } & \text { Fundações. } \\
\text { - } & \text { Organizações do terceiro setor. } \\
\text { - } & \text { Veículos de comunicação. } \\
\text { - } & \text { Associações e cooperativas. } \\
\text { - } & \text { Organizações da sociedade civil. } \\
\text { - } & \text { Produtores culturais; APLs. } \\
\text { - } & \text { Centros culturais. } \\
\text { - } & \text { Agentes da Economia Criativa. } \\
\text { - } & \text { Fornecedores. } \\
\text { - } & \text { Pontos de cultura. } \\
\text { - } & \text { Equipe contratada. } \\
\text { - } & \text { Órgão Fomentador. } \\
\text { - } & \text { Órgão convenente. } \\
\text { - } & \text { Conselhos Consultivo/Administrativo }\end{array}$ \\
\hline Determinação dos tipos de relação & 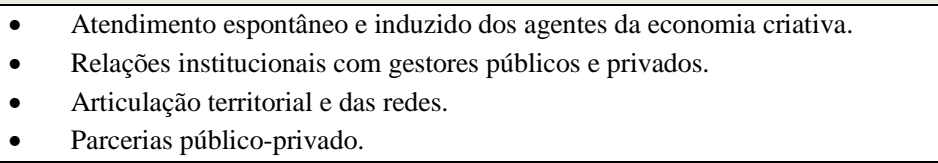 \\
\hline
\end{tabular}




\begin{tabular}{|c|c|}
\hline & - $\quad$ Execução do convênio pactuado com o Órgão Fomentador. \\
\hline \multicolumn{2}{|c|}{$\begin{array}{c}\text { SOCIABILIDADE } \\
\text { [Novas formas de relações sociais, em intensidade, abrangência, intencionalidade e, em especial, seu significado e alcance em um } \\
\text { novo tipo de esfera pública] }\end{array}$} \\
\hline $\begin{array}{l}\text { O que e como? } \\
\text { [Identificar os principais tópicos de interesse } \\
\text { da TI que induzem a operação das } \\
\text { atividades essenciais] }\end{array}$ & $\begin{array}{ll}\text { - } & \text { Geração e difusão de informação. } \\
\text { - } & \text { Fomento a empreendimentos criativos. } \\
\text { - } & \text { Formação para profissionais criativos. } \\
\text { - } & \text { Promoção de negócios criativos. }\end{array}$ \\
\hline $\begin{array}{l}\text { Quais os processos com cada ator? } \\
\text { [Dentre as atividades essenciais levantadas, } \\
\text { quais as participações dos atores, em quais } \\
\text { processos e os formatos possíveis] }\end{array}$ & - Vide matriz de responsabilidade RACI - Quadro D.5. \\
\hline $\begin{array}{l}\text { O que se espera a partir de uma } \\
\text { comunicação em Rede? }\end{array}$ & $\begin{array}{l}\text { - } \quad \text { Estimular o desenvolvimento da economia criativa no Brasil. } \\
\text { - } \quad \text { Mapear os territórios criativos e as expressões da cultura popular brasileira. } \\
\text { - } \quad \text { Viabilizar a articulação de agentes e grupos informais não mapeados. } \\
\text { Ponto de encontro e trocas de experiências entre empreendedores, coletivos e } \\
\text { negócios criativos para comercializar e/ou integralizar cadeias produtivas. }\end{array}$ \\
\hline
\end{tabular}


Quadro D.5 - Matriz de atribuição de responsabilidades RACI: Projeto Charlie

\begin{tabular}{|c|c|c|c|c|c|c|c|c|c|c|}
\hline & 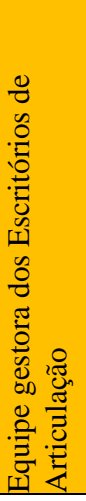 & 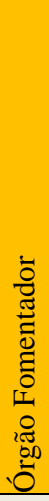 & 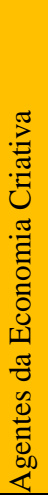 & 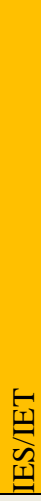 & 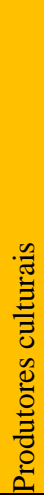 & 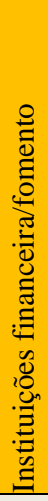 & 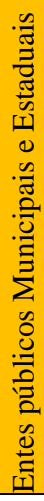 & 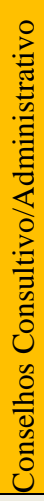 & 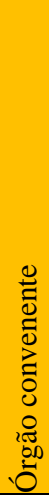 & 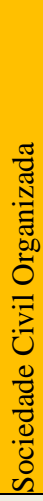 \\
\hline Geração e difusão de informação & $\mathrm{R}$ & $\mathrm{C}$ & $\mathrm{R}$ & $\mathrm{C}$ & $\mathrm{C}$ & $\mathrm{C}$ & $\mathrm{C}$ & A & $\mathrm{R}$ & I \\
\hline Fomento a empreendimentos criativos & $\mathrm{R}$ & $\mathrm{R}$ & $\mathrm{C}$ & I & I & $\mathrm{C}$ & $\mathrm{R}$ & A & $\mathrm{R}$ & $\mathrm{C}$ \\
\hline Formação para profissionais criativos & $\mathrm{R}$ & $\mathrm{R}$ & $\mathrm{R}$ & $\mathrm{R}$ & $\mathrm{C}$ & I & $\mathrm{R}$ & A & $\mathrm{R}$ & $\mathrm{C}$ \\
\hline Promoção de negócios criativos & $\mathrm{R}$ & $\mathrm{R}$ & $\mathrm{R}$ & $\mathrm{C}$ & $\mathrm{R}$ & $\mathrm{C}$ & $\mathrm{R}$ & A & $\mathrm{R}$ & I \\
\hline
\end{tabular}

Legenda:

- R:Responsável por executar uma atividade (o executor);

- A: Autoridade, quem deve responder pela atividade, o dono (apenas uma autoridade pode ser atribuída por atividade);

- C: Consultado, quem deve ser consultado e participar da decisão ou atividade no momento que for executada;

- I: Informado, quem deve receber a informação de que uma atividade foi executada. 


\section{Quadro D.6 - Prospecção da capacidade do sistema de interesse: Projeto Charlie}

(Morgan, 2006, modificado)

\begin{tabular}{|c|c|c|c|}
\hline $\begin{array}{l}\text { Perspectiva } \\
\text { [tópicos de } \\
\text { interesse] }\end{array}$ & $\begin{array}{c}\text { Dificuldades encontradas } \\
\text { [limitações - deficiências e restrições] }\end{array}$ & $\begin{array}{l}\text { Políticas e Planos } \\
\text { [(boas) práticas, } \\
\text { procedimentos] }\end{array}$ & $\begin{array}{c}\text { O que deve ser feito } \\
\text { minimamente para trazer } \\
\text { o impacto desejado para } \\
\text { cada perspectiva } \\
\text { relevante? }\end{array}$ \\
\hline \multirow{2}{*}{$\begin{array}{l}\text { Geração e } \\
\text { difusão de } \\
\text { informação }\end{array}$} & $\begin{array}{l}\text { - Inexistência de plano de comunicação que defina } \\
\text { critérios e canais apropriados para divulgação dos } \\
\text { objetos de informação. }\end{array}$ & \multirow{8}{*}{$\begin{array}{l}\text { - Sistema Nacional de } \\
\text { Cultura. } \\
\text { - Plano Nacional de } \\
\text { Cultura. } \\
\text { - Pontos de cultura } \\
\text { - Plano da Secretaria de } \\
\text { Economia Criativa do } \\
\text { Órgão Fomentador. } \\
\text { - Plano de trabalho do } \\
\text { convênio de pactuação } \\
\text { do Órgão Fomentador } \\
\text { com os Estados. } \\
\text { - Artefatos produzidos } \\
\text { nos Seminários com a } \\
\text { Universidade de Brasília, } \\
\text { incluindo: planejamento } \\
\text { estratégico, modelo de } \\
\text { negócio e modelo de } \\
\text { gestão. } \\
\text { - Mapeamentos } \\
\text { existentes nas } \\
\text { Instituições públicas de } \\
\text { cultura. }\end{array}$} & \multirow{8}{*}{$\begin{array}{l}\text { - Atuação articulada com } \\
\text { IES, agentes da economia } \\
\text { criativa, parceiros } \\
\text { públicos e privados, } \\
\text { sistema Órgão } \\
\text { Fomentador e Pastas de } \\
\text { cultura municipal e } \\
\text { estadual. } \\
\text { - Desenvolvimento de } \\
\text { plataforma de diálogo e } \\
\text { interação com partes } \\
\text { interessadas. }\end{array}$} \\
\hline & $\begin{array}{l}\text { - Falta pessoal qualificado para modelar atividades de } \\
\text { geração e difusão de informação. }\end{array}$ & & \\
\hline \multirow{2}{*}{$\begin{array}{l}\text { Fomento a } \\
\text { empreendiment } \\
\text { os criativos }\end{array}$} & $\begin{array}{l}\text { - Inexistência de plataforma de diálogo e interação } \\
\text { com parceiros e instituições de fomento. }\end{array}$ & & \\
\hline & $\begin{array}{l}\text { - Dificuldades em participar de editais e convênios } \\
\text { devido à falta de conhecimento técnico para elaborar } \\
\text { e gerar projetos. }\end{array}$ & & \\
\hline \multirow{2}{*}{$\begin{array}{l}\text { Formação para } \\
\text { profissionais } \\
\text { criativos }\end{array}$} & $\begin{array}{l}\text { - Dificuldade em encontrar especialistas preparados } \\
\text { para orientar e formar profissionais criativos no } \\
\text { contexto da economia criativa. }\end{array}$ & & \\
\hline & $\begin{array}{l}\text { - Ausência de metodologia (ou não apropriação de) } \\
\text { para mapear e articular redes e coletivos. }\end{array}$ & & \\
\hline \multirow[b]{2}{*}{$\begin{array}{l}\text { Promoção de } \\
\text { negócios } \\
\text { criativos }\end{array}$} & $\begin{array}{l}\text { - Impossibilidade de mapear a extensão e amplitude } \\
\text { dos negócios criativos e as cadeias produtivas neste } \\
\text { momento. }\end{array}$ & & \\
\hline & $\begin{array}{l}\text { - Dificuldade na articulação de diferentes canais de } \\
\text { difusão, circulação e comercialização para promoção } \\
\text { de bens e serviços criativos junto a parceiros públicos } \\
\text { e privados e empreendedores criativos (feira, rodadas } \\
\text { de negócio, plataformas de comercialização, } \\
\text { catálogo). }\end{array}$ & & \\
\hline
\end{tabular}




\section{Quadro D.7 - Categorias avaliativas da análise de fronteira: Projeto Charlie}

\section{(Ulrich, 1987, p. 279, modificado)}

\begin{tabular}{|c|c|c|c|}
\hline \multicolumn{4}{|c|}{ Relacionamento com os Públicos Internos e Externos } \\
\hline & $\begin{array}{l}\text { Quais os tipos de relações dos Escritórios de } \\
\text { Articulação (ECB) com seu público interno? } \\
\text { Quais indivíduos/agentes a compõem? }\end{array}$ & - & $\begin{array}{l}\text { Processo de implantação e aparelhamento dos ECB } \\
\circ \quad \text { Contratação da equipe gestora, incluindo coordenadores e } \\
\text { pessoal de apoio. } \\
\text { Coordenação da Ação do Órgão convenente, responsável pela } \\
\text { gestão dos recursos pactuados. }\end{array}$ \\
\hline 2. & $\begin{array}{l}\text { E com o público externo, como se dá o } \\
\text { relacionamento com as partes envolvidas e } \\
\text { afetadas pelos ECB? Quais } \\
\text { indivíduos/agentes a compõem? }\end{array}$ & - & $\begin{array}{l}\text { Oferta/captação de informações sobre a conjuntura socioeconômica e } \\
\text { política que interessa ao ecossistema da economia criativa } \\
\text { agentes da economia criativa, equipe gestora dos ECB, } \\
\text { parceiros institucionais, entes públicos e privados. } \\
\text { Articulação territorial e de redes } \\
\text { coordenação de articulação dos ECB, agentes e coletivos de } \\
\text { cultura, pontos de cultura, parceiros institucionais, entes } \\
\text { públicos e privados. } \\
\text { Oferta de capacitação e orientação } \\
\text { agentes da economia criativa, gestores públicos e privados de } \\
\text { cultura, empreendedores e negócios criativos. } \\
\text { Promoção de negócios criativos } \\
\text { empreendedores e negócios criativos, segmentos empresariais } \\
\text { das cadeias produtivas pertinentes aos setores da economia } \\
\text { criativa. }\end{array}$ \\
\hline & $\begin{array}{l}\text { Quais os tipos de relações dos ECB com os } \\
\text { Órgãos convenentes do Órgão Fomentador? } \\
\text { Quais indivíduos/agentes a compõem? }\end{array}$ & - & $\begin{array}{l}\text { Manutenção da equipe gestora dos ECB } \\
\circ \quad \text { Coordenadora da Ação do Órgão convenente } \\
\circ \quad \text { Definição de perfis da equipe gestora por parte da Secretaria de } \\
\text { Economia Criativa do Órgão Fomentador } \\
\text { Repasse e prestação de contas dos recursos financeiros pactuados e } \\
\text { cumprimento do plano de trabalho } \\
\circ \quad \text { Coordenadora da Ação do Órgão convenente } \\
\circ \quad \text { Ordenador de despesa do Órgão convenente } \\
\circ \quad \text { Órgão Fomentador }\end{array}$ \\
\hline & $\begin{array}{l}\text { Como o público interno percebe a ideia de } \\
\text { valor dos ECB? }\end{array}$ & - & $\begin{array}{l}\text { Oportunidade de contribuir para o desenvolvimento socioeconômico dos } \\
\text { agentes da economia criativa e dos grupos informais de cultura. }\end{array}$ \\
\hline & $\begin{array}{l}\text { Como os Órgãos convenentes do Órgão } \\
\text { Fomentador percebem a ideia de valor dos } \\
\text { ECB? }\end{array}$ & - & $\begin{array}{l}\text { Instrumento de fomento à cultura regional e mecanismo de captação de } \\
\text { recursos financeiros para atendimento das demandas reprimidas. }\end{array}$ \\
\hline & $\begin{array}{l}\text { O que o público externo espera dos serviços } \\
\text { que os ECB estão entregando? }\end{array}$ & - & $\begin{array}{l}\text { Novo alento para desenvolvimento e implementação de políticas públicas } \\
\text { culturais para suprir carências, necessidades e demandas reprimidas da } \\
\text { sociedade. } \\
\text { Desenvolvimento de uma agenda pública/privada para o setor de cultura. }\end{array}$ \\
\hline & $\begin{array}{l}\text { Há alguma ação de engajamento com o } \\
\text { público interno e/ou externo? }\end{array}$ & - & $\begin{array}{l}\text { Promoção de eventos de ativação e de estímulo à participação dos agentes } \\
\text { da economia criativa e parceiros institucionais. } \\
\text { Visitas de campo nos territórios criativos. }\end{array}$ \\
\hline & Qual a expectativa de qualidade dos ECB? & & $\begin{array}{l}\text { Contemplar as ações e iniciativas previstas no plano de trabalho do } \\
\text { convênio pactuado. }\end{array}$ \\
\hline & $\begin{array}{l}\text { Qual a tendência de inovação e } \\
\text { desenvolvimento? Como o Sistema de redes } \\
\text { dos ECB está se preparando para as novas } \\
\text { fronteiras tecnológicas? }\end{array}$ & & $\begin{array}{l}\text { A atuação articulada e prospectiva da equipe dos ECB junto às partes } \\
\text { interessadas poderá trazer dividendos em termos de projetos viáveis, } \\
\text { formação de parceiras e novos estímulos às cadeias produtivas no setor } \\
\text { cultural, além de desencadear novas possibilidades com a presença das } \\
\text { redes dos ECB. }\end{array}$ \\
\hline & $\begin{array}{l}\text { Os canais de comunicação com os públicos } \\
\text { internos e externos são efetivos? }\end{array}$ & - & $\begin{array}{l}\text { Carecem de um plano de comunicação integrativo e da idealização de uma } \\
\text { plataforma de acesso aos públicos de interesse. }\end{array}$ \\
\hline & $\begin{array}{l}\text { Como se mede a satisfação e fidelidade dos } \\
\text { envolvidos e afetados? }\end{array}$ & & $\begin{array}{l}\text { Com base na percepção de valor agregada dos agentes de economia } \\
\text { criativa, parceiros institucionais, entes públicos e privados e da sociedade. }\end{array}$ \\
\hline
\end{tabular}


Tabela D.1 - Matriz de relacionamento dos atores: Projeto Charlie

\begin{tabular}{|c|c|c|c|c|c|c|c|c|c|c|}
\hline $\begin{array}{l}0 \text { LEGENDA } \\
0=\text { não se relaciona } \\
1=\text { relação fraca } \\
2=\text { relação forte } \\
3=\text { relação muito forte }\end{array}$ & 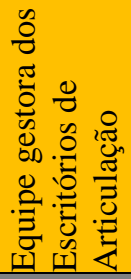 & 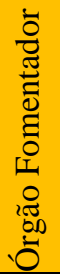 & 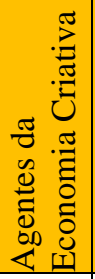 & 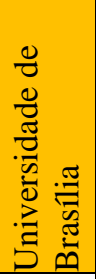 & 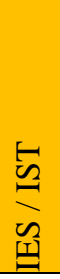 & 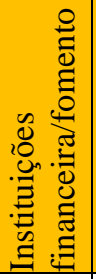 & 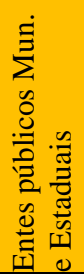 & 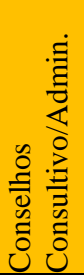 & $\begin{array}{l}0 \\
0 \\
0 \\
0 \\
0 \\
0 \\
0 \\
0 \\
0 \\
0 \\
00 \\
0\end{array}$ & 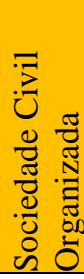 \\
\hline $\begin{array}{l}\text { Equipe gestora dos } \\
\text { Escritórios de Articulação }\end{array}$ & 0 & 2 & 3 & 2 & 1 & 1 & 2 & 0 & 3 & 1 \\
\hline Órgão Fomentador & 2 & 0 & 2 & 2 & 1 & 1 & 1 & 0 & 3 & 1 \\
\hline $\begin{array}{l}\text { Agentes da Economia } \\
\text { Criativa }\end{array}$ & 3 & 1 & 0 & 1 & 2 & 2 & 2 & 1 & 3 & 3 \\
\hline Universidade de Brasília & 2 & 3 & 1 & 0 & 0 & 0 & 0 & 0 & 1 & 0 \\
\hline IES/IET & 1 & 1 & 2 & 1 & 0 & 1 & 2 & 1 & 2 & 2 \\
\hline $\begin{array}{l}\text { Instituições } \\
\text { financeira/fomento }\end{array}$ & 1 & 1 & 1 & 0 & 0 & 0 & 0 & 0 & 1 & 0 \\
\hline $\begin{array}{l}\text { Entes públicos Mun. e } \\
\text { Estaduais }\end{array}$ & 1 & 1 & 1 & 0 & 0 & 1 & 0 & 0 & 1 & 1 \\
\hline $\begin{array}{l}\text { Conselhos } \\
\text { Consultivo/Admin. } \\
\end{array}$ & 1 & 0 & 1 & 0 & 0 & 0 & 0 & 0 & 3 & 1 \\
\hline Órgão convenente & 3 & 3 & 3 & 1 & 1 & 1 & 2 & 3 & 0 & 2 \\
\hline $\begin{array}{l}\text { Sociedade Civil } \\
\text { Organizada }\end{array}$ & 1 & 0 & 2 & 0 & 0 & 0 & 1 & 1 & 2 & 0 \\
\hline
\end{tabular}




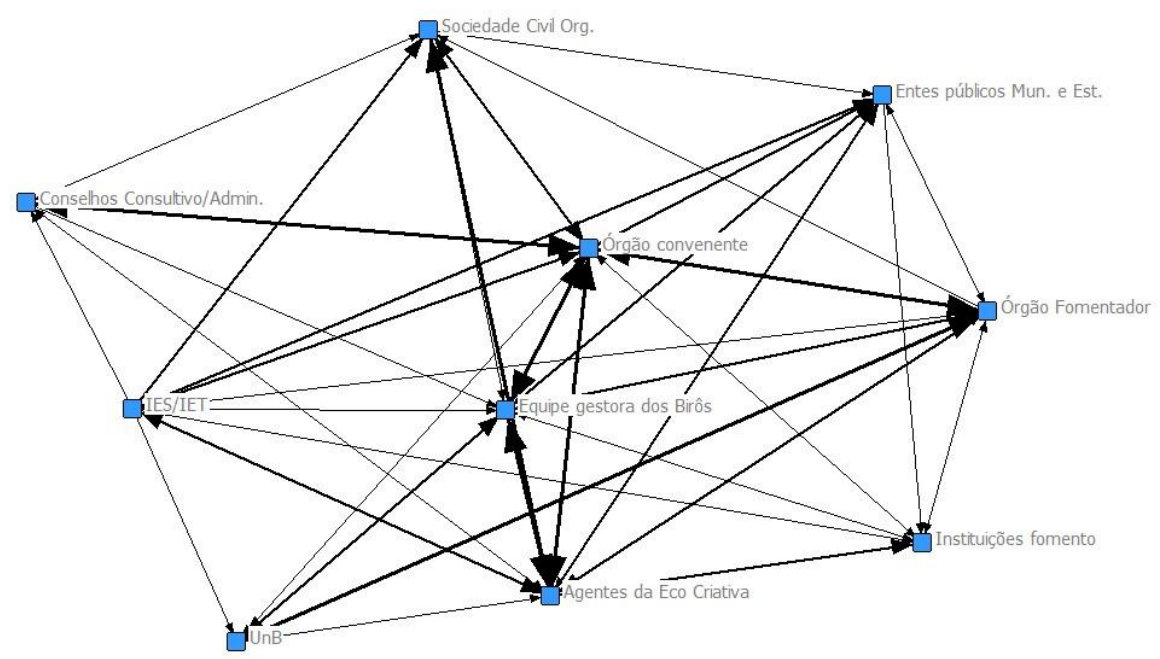

Figura D.3 - Mapa de Relações Sociais: Projeto Charlie 


\section{Quadro D.8 - Guia de tópicos do estudo etnográfico: Projeto Charlie}

\section{(Grupo de Trabalho UnB ${ }^{16}, 2013$ )}

\begin{tabular}{|c|c|}
\hline OBJETIVOS & $\begin{array}{l}\text { 1. Contato dos informantes chaves. } \\
\text { 2. Coleta dos dados primários. } \\
\text { 3. Conhecimento do modelo de Escritório de Articulação. }\end{array}$ \\
\hline INFORMANTES & $\begin{array}{l}\text { Preferencialmente, as entrevistas devem procurar explorar o nível interno (gestores, técnicos, } \\
\text { coordenadores, gênese do Escritório de Articulação, modelo de negócio e etc.), de modo a } \\
\text { caracterizar a constituição, o funcionamento e a operação do ESCRITÓRIO DE } \\
\text { ARTICULAÇÃO. Em um segundo nível, procuraremos entrevistar os empreendedores e os } \\
\text { parceiros que deram suporte ao desenvolvimento do ESCRITÓRIO DE ARTICULAÇÃO. }\end{array}$ \\
\hline METODOLOGIA & $\begin{array}{l}\text { As ferramentas técnicas a aplicar na primeira visita: } \\
\text { 1. Ficha de Estudo de Caso. O objetivo deve ser criar laboratórios locais. } \\
\text { 2. Etnografia. Diário de bordo para uma aproximação cultural a partir de observações pessoais. } \\
\text { Todos os membros da equipe deverão realizar essas anotações para triangular resultados } \\
\text { (notas e olhares). } \\
\text { 3. Entrevistas enfocadas. Aqui distinguimos três tipologias: } \\
\text { a. Técnicos (coordenador, gestor, formadores) - identificação de elementos } \\
\text { direcionadores do ESCRITÓRIO DE ARTICULAÇÃO, elementos descritores do } \\
\text { formato de design e desenvolvimento e dos elementos condicionadores da operação e } \\
\text { entrega. } \\
\text { Empreendedores - modelo de organização, dinâmica de trabalho, percepção do } \\
\text { Escritório de Articulação, rotinas entre outros, etc. } \\
\text { Representante dos principais parceiros institucionais - modelo de desenvolvimento, } \\
\text { formato de suporte para o ESCRITÓRIO DE ARTICULAÇÃO, percepção do } \\
\text { Escritório de Articulação, entre outros, etc. } \\
\text { Todas as entrevistas deverão ser gravadas e deve ter duração entre } 1 \text { hora e } 1 \text { hora e meia. }\end{array}$ \\
\hline & GUIA DE TÓPICOS TÉCNICOS \\
\hline I - ATORES & $\begin{array}{l}\text { 1. História do informante. Formação, interesses no Escritório de Articulação, como passou a } \\
\text { formar parte do projeto. } \\
\text { 2. Relações pessoais com outros agentes culturais. } \\
\text { 3. Percepção da economia criativa e do Escritório de Articulação. } \\
\text { 4. Pertinência? se aplica? como funciona? solução esperada? } \\
\text { 5. Experiências do trabalho no Escritório de Articulação. }\end{array}$ \\
\hline III - REDES SOCIAIS & $\begin{array}{l}\text { 1. Comunicação e informação: quanto à rede, qual o modelo, como o Escritório de Articulação } \\
\text { se estrutura para estar na rede do Ecossistema local da Economia Criativa? } \\
\text { 2. Dados para mapear as dimensões: quais os atores e os coletivos mapeados? Atores? } \\
\text { Relações com os grupos (mapeados ou não), relações entre atores. } \\
\text { 3. Processo de informação e divulgação. } \\
\text { 4. Como é a estrutura de participação da sociedade no processo de construção do Escritório de } \\
\text { Articulação. Existe algum instrumento de participação (diálogo, acesso, riscos e } \\
\text { transparência)? } \\
\text { Como se articulam os encontros, as estruturas de rede, de comunicação, em nível } \\
\text { local/regional e em nível nacional. }\end{array}$ \\
\hline $\begin{array}{l}\text { IV - CULTURA E } \\
\text { IDENTIDADE. }\end{array}$ & $\begin{array}{l}\text { Qual sua visão sobre o Escritório de Articulação, o que atende? Quais os objetivos } \\
\text { percebidos? Quais os pontos fortes? Quais os problemas e fragilidades observadas? }\end{array}$ \\
\hline
\end{tabular}

16 Grupo de trabalho da UnB vinculado ao projeto de cooperação técnica com o Órgão de Cultura responsável pela coordenação técnica das atividades do projeto e das atividades da pesquisa de campo. 


\begin{tabular}{|c|c|}
\hline & $\begin{array}{l}\text { 2. De que forma o Escritório de Articulação pode contribuir ao Plano Estratégico da Economia } \\
\text { Criativa e ao Plano Nacional de Cultura. } \\
\text { 3. Que participação se contempla da cidadania, e que grau de conhecimento considera ter os } \\
\text { empreendedores e agentes culturais. Metodologias colaborativas o participativas com a } \\
\text { cidadania. } \\
\text { 4. Qual a visão de futuro para o Escritório de Articulação para o desenvolvimento local. } \\
\text { 5. Em sentido prospectivo: como se imagina o funcionamento do Escritório de Articulação, os } \\
\text { setores que se destacam ou os setores que teriam destaque. }\end{array}$ \\
\hline \multicolumn{2}{|r|}{ GUIA DE TÓPICOS - EMPRENDEDORES } \\
\hline $\begin{array}{c}\mathrm{V} \text { - PARTICIPAÇÃO DOS } \\
\text { EMPREENDEDORES }\end{array}$ & $\begin{array}{l}\text { 1. História do informante. Formação, interesses no Escritório de Articulação, trajetória } \\
\text { profissional. } \\
\text { 2. Relações pessoais com outros agentes culturais. } \\
\text { 3. Percepção da economia criativa e do Escritório de Articulação. Como entrou em contato } \\
\text { com o Escritório de Articulação. } \\
\text { 4. Experiência no Escritório de Articulação como empreendedor. } \\
\text { 5. Descrição do projeto e empresa e iniciativa cultural. Elementos inovadores, modelo de } \\
\text { negócio, estudo de demanda. } \\
\text { 6. Análise SWOT do empreendimento e do Escritório de Articulação. Debilidades, Ameaças, } \\
\text { Fortalezas e Oportunidades do Escritório de Articulação. } \\
\text { 7. Redes Sociais. Percepção da rede de redes de Escritórios de Articulação do Ecossistema } \\
\text { Brasil Criativo. } \\
\text { 8. Valoração de informações e difusão da Economia Criativa. } \\
\text { 9. Redes culturais de seu projeto. } \\
\text { 10. Prospectiva. Visão de futuro para seu negócio e de desenvolvimento local do Escritório de } \\
\text { Articulação. }\end{array}$ \\
\hline \multicolumn{2}{|r|}{ GUIA DE TÓPICOS REPRESENTANTE - GESTOR LOCAL } \\
\hline $\begin{array}{l}\text { VI - PARTICIPAÇÃO DO } \\
\text { REPRESENTANTE - } \\
\text { GESTOR LOCAL }\end{array}$ & $\begin{array}{l}\text { 1. História (trajetória) da Gênese em termos de Desenvolvimento de empreendimentos } \\
\text { criativos. } \mathbf{N}^{\circ} \text { de empreendimentos atendidos, modelo de desenvolvimento. } \\
\text { 2. Formato de parceria com o Escritório de Articulação. Quando se iniciou, como se } \\
\text { desenvolveu a relação e qual o status atual. Tipo de suporte dado. } \\
\text { 3. Qual a percepção em relação ao Escritório de Articulação. } \\
\text { 4. Qual a visão da economia criativa. De que forma contribui o Gestor Local do Escritório de } \\
\text { Articulação. }\end{array}$ \\
\hline
\end{tabular}




\section{Quadro D.9 - Síntese dos resultados da ação executada: Projeto Charlie}

(O autor, 2015)

\begin{tabular}{|c|c|c|}
\hline Tópicos & \multicolumn{2}{|r|}{ Resultados Alcançados } \\
\hline \multirow{3}{*}{$\begin{array}{l}\text { Ações } \\
\text { Programadas } \\
\quad \& \\
\text { Ações } \\
\text { Executadas }\end{array}$} & $\begin{array}{l}\text { Implementação de oficinas de } \\
\text { comunicação social e } \\
\text { formação de redes }\end{array}$ & $\begin{array}{l}\text { Compreensão dos fundamentos sobre a construção do } \\
\text { conceito de economia criativa no Brasil. } \\
\text { Propostas de políticas públicas envolvendo a economia } \\
\text { criativa. } \\
\text { Plano da Secretaria da Economia Criativa. Territórios, } \\
\text { Cidades, Polos e Bacias Criativas. }\end{array}$ \\
\hline & $\begin{array}{l}\text { Proposta de modelo de gestão } \\
\text { e de governança dos } \\
\text { escritórios da economia } \\
\text { criativa }\end{array}$ & $\begin{array}{l}\text { Viabilização de instâncias decisórias baseadas nos } \\
\text { comitês-gestor e conselhos executivo e consultivo. } \\
\text { Projetos e operações correntes desdobrados em pacotes } \\
\text { de trabalho. }\end{array}$ \\
\hline & $\begin{array}{l}\text { Suporte técnico e } \\
\text { metodológico para a } \\
\text { implantação de escritórios da } \\
\text { economia criativa }\end{array}$ & $\begin{array}{l}\text { Estudos etnográficos junto aos grupos sociais envolvidos } \\
\text { nos ecossistemas locais de economia criativa no Brasil. } \\
\text { Análise de redes sociais do ecossistema da economia } \\
\text { criativa. }\end{array}$ \\
\hline $\begin{array}{l}\text { Benefícios } \\
\text { Alcançados }\end{array}$ & \multicolumn{2}{|c|}{$\begin{array}{l}\text { Construção de um modelo de gestão compartilhada, potencializando o processo de co- } \\
\text { construção do consenso, com } \\
\text { - } \quad \text { propósitos em torno de um mesmo tema; } \\
\text { - } \quad \text { prioridade ao diálogo no trabalho em equipe; } \\
\text { - } \quad \text { crença e valorização das pessoas/instituições que participam do processo; } \\
\text { - } \quad \text { consideração, reconhecimento, validação das particularidades de cada um; } \\
\text { - } \quad \text { perseverança no propósito de priorizar o contexto dialógico }\end{array}$} \\
\hline $\begin{array}{l}\text { Dificuldades } \\
\text { Encontradas }\end{array}$ & \multicolumn{2}{|c|}{$\begin{array}{l}\text { Inexistência de plataforma de diálogo e interação com parceiros e instituições de fomento. } \\
\text { Dificuldade em encontrar especialistas com consciência sistêmica, preparados para } \\
\text { orientar e formar profissionais criativos no contexto da economia criativa. }\end{array}$} \\
\hline
\end{tabular}




\section{E- APÊNDICE E: ARTEFATOS DO PROJETO DE PESQUISA}

Este apêndice compreende os seguintes instrumentos de análise:

- roteiro para iniciar os estudos de sistemas,

- definições-chave do sistema relevante

- aspectos da análise de fronteira,

- dimensões da tipologia de rede,

- matriz de atribuição de responsabilidades RACI,

- prospecção da capacidade de atuação do sistema de TI,

- categorias avaliativas da análise de fronteira,

- matriz de relacionamento dos atores. 


\section{Quadro E.1 - Roteiro para iniciar os estudos de sistemas: Projeto de Pesquisa}

(Checkland, 1993, p. 294)

\begin{tabular}{|c|c|c|}
\hline \multicolumn{3}{|r|}{ Considerar Clientes } \\
\hline & Quem é o cliente? & Comunidade científica. Sociedade. \\
\hline & Quais são suas aspirações? & $\begin{array}{l}\text { Lidar com problemas em cenários complexos dimensionando } \\
\text { adequadamente a sua extensão e natureza, de modo a buscar soluções } \\
\text { robustas que assegurem a sustentabilidade de suas decisões. }\end{array}$ \\
\hline \multicolumn{3}{|c|}{ Considerar o sistema constituído em torno do problema } \\
\hline & $\begin{array}{l}\text { Quem são os detentores do papel de } \\
\text { conhecedor do problema? }\end{array}$ & $\begin{array}{l}\text { - } \quad \text { Autores da literatura acadêmica e especializada. Sujeitos que lidam } \\
\text { com problemas reais em contextos complexos. }\end{array}$ \\
\hline & $\begin{array}{l}\text { Quem são os detentores do papel de tomador de } \\
\text { decisão? }\end{array}$ & $\begin{array}{l}\text { - } \quad \text { Pesquisador-autor da tese. } \\
\text { - } \quad \text { Orientador da tese. }\end{array}$ \\
\hline & $\begin{array}{l}\text { A versão consensuada dos tomadores de } \\
\text { decisão sobre a natureza do problema é: }\end{array}$ & $\begin{array}{l}\text { - A falta de interesse na estruturação de situações problemáticas } \\
\text { comprometem a avaliação da complexidade sistêmica, ocasionando } \\
\text { soluções enviesadas pela conjuntura política, de poder e tecnológica. }\end{array}$ \\
\hline & $\begin{array}{l}\text { As razões consensuadas dos tomadores de } \\
\text { decisão para considerar "o problema" como o } \\
\text { problema são: }\end{array}$ & 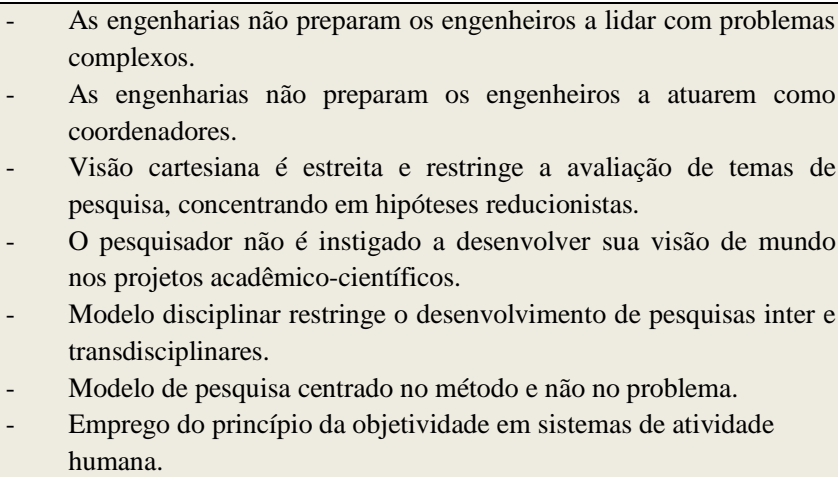 \\
\hline & $\begin{array}{l}\text { As expectativas consensuadas dos tomadores } \\
\text { de decisão sobre o sistema de resolução de } \\
\text { problemas são: }\end{array}$ & 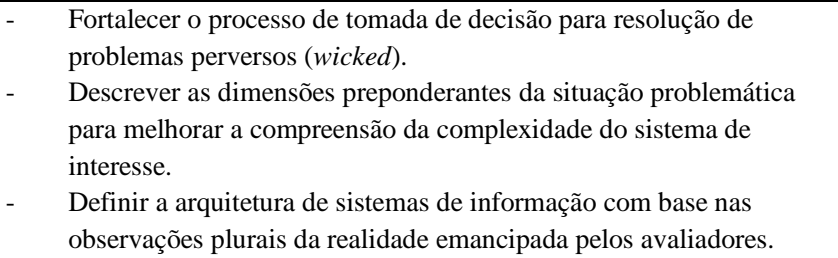 \\
\hline & $\begin{array}{l}\text { A resposta para o item } 6 \text {. sugere a seguir as que } \\
\text { são altamente avaliadas pelos tomadores de } \\
\text { decisão. }\end{array}$ & $\begin{array}{l}\text { - As engenharias não preparam os engenheiros a lidar com problemas } \\
\text { complexos. } \\
\text { - As engenharias não preparam os engenheiros a atuarem como } \\
\text { coordenadores. } \\
\text { - O pesquisador não é instigado a desenvolver sua visão de mundo } \\
\text { nos projetos acadêmico-científicos. }\end{array}$ \\
\hline & $\begin{array}{l}\text { A versão consensuada dos conhecedores do } \\
\text { problema sobre a natureza do problema, é: }\end{array}$ & $\begin{array}{l}\text { - } \text { A abordagem tradicional com enfoque no pensamento mecanicista } \\
\text { privilegia as partes em detrimento do todo para lidar com qualquer } \\
\text { tipo de problema, do mais simples ao mais complexo. }\end{array}$ \\
\hline & $\begin{array}{l}\text { As razões dos conhecedores do problema para } \\
\text { considerar "o problema" como o problema, são: }\end{array}$ & 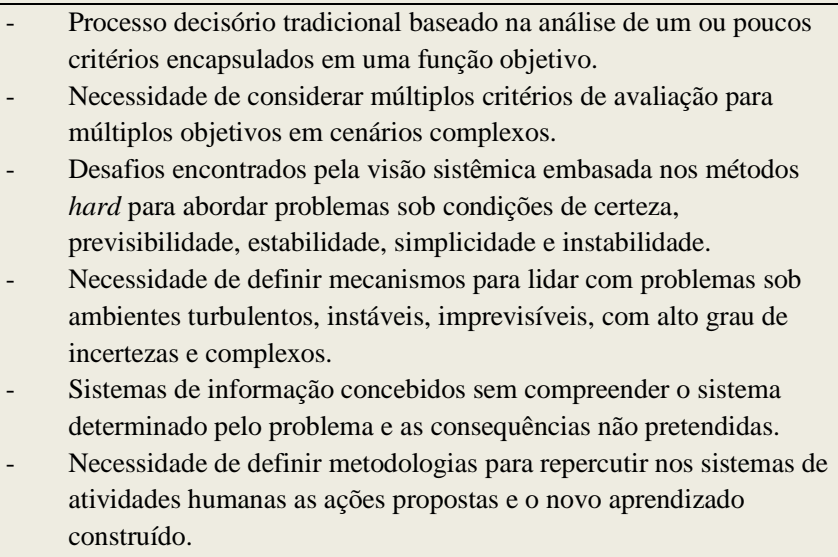 \\
\hline & $\begin{array}{l}\text { As expectativas consensuadas dos } \\
\text { conhecedores do problema sobre o sistema de }\end{array}$ & $\begin{array}{l}\text { - } \quad \text { Dimensionar o problema sob várias perspectivas para compreendê- } \\
\text { lo, absorvendo a complexidade ao invés de simplificá-la. }\end{array}$ \\
\hline
\end{tabular}




\begin{tabular}{|c|c|c|c|}
\hline & resolução de problemas, são: & \multicolumn{2}{|c|}{ 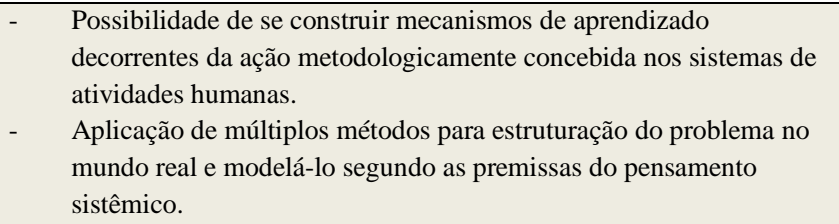 } \\
\hline 12. & $\begin{array}{l}\text { A resposta para o item 10. } \text { sugere a seguir os } \\
\text { que são altamente avaliados pelos } \\
\text { conhecedores do problema. }\end{array}$ & \multicolumn{2}{|c|}{$\begin{array}{l}\text { - } \quad \text { Necessidade de considerar múltiplos critérios de avaliação para } \\
\text { múltiplos objetivos em cenários complexos. } \\
\text { - } \quad \text { Necessidade de definir mecanismos para lidar com problemas sob } \\
\text { ambientes turbulentos, instáveis, imprevisíveis, com alto grau de } \\
\text { incertezas e complexos. } \\
\text { Sistemas de informação concebidos sem compreender o sistema } \\
\text { determinado pelo problema e as consequências não pretendidas. }\end{array}$} \\
\hline & $\begin{array}{l}\text { Alguns nomes possíveis para o sistema que } \\
\text { contém o problema são: }\end{array}$ & \multicolumn{2}{|r|}{$\begin{array}{l}\text { Sistema de informação de aprendizado. } \\
\text { Sistema de informação de atividade humana. } \\
\text { Sistema sócio-técnico. } \\
\text { Sistema de avaliação de situações problemáticas. } \\
\text { Sistema determinado pelo problema. }\end{array}$} \\
\hline & \multirow{2}{*}{$\begin{array}{l}\text { Ao descrever inicialmente o } r \text { sistema } \\
\text { determinado pelo problema, os } \\
\text { elementos parecem propensos a serem } \\
\text { relevantes: }\end{array}$} & \multicolumn{2}{|c|}{$\begin{array}{l}\text { Substantivos - tese, sistema, arquitetura, projeto, teoria, prática, } \\
\text { capacidade, ação, problema, aprendizado, tecnologia, sociedade, rede, } \\
\text { domínio, dimensão, linguística. }\end{array}$} \\
\hline & & \multicolumn{2}{|c|}{$\begin{array}{l}\text { Verbos - discutir, direcionar, emancipar, aprender, desaprender, } \\
\text { reaprender, comunicar, reconhecer, compreender, reunir, sintetizar, } \\
\text { decidir, facilitar, coordenar. }\end{array}$} \\
\hline & $\begin{array}{llll}\text { Restrições ambientais sobre } & \text { o } & \text { sistema } \\
\text { determinado pelo problema são: } & & \\
\end{array}$ & \multicolumn{2}{|c|}{$\begin{array}{l}\text { Área de concentração e linha de pesquisa do PPGEE; Regras para defesa } \\
\text { da tese; Créditos (44) a cumprir; Tempo de duração do doutorado. }\end{array}$} \\
\hline \multicolumn{4}{|c|}{ Considerar o sistema de resolução de problema } \\
\hline 16. & \multicolumn{2}{|c|}{$\begin{array}{l}\text { Os detentores do papel de solucionadores do problema } \\
\text { são: }\end{array}$} & $\begin{array}{l}\text { Pesquisador-autor da tese. Orientador da tese. Pesquisadores do } \\
\text { grupo de pesquisa NMI. }\end{array}$ \\
\hline 17. & \multicolumn{2}{|c|}{$\begin{array}{l}\text { As outras pessoas (papéis) no sistema de resolução de } \\
\text { problema são: }\end{array}$} & \\
\hline 18. & \multicolumn{3}{|c|}{$\begin{array}{l}\text { a. Pessoas (papéis) - coordenador do PPGEE, estagiários e pessoal de apoio do laboratório NMI; } \\
\text { b. Recursos físicos - dependências do laboratório NMI, Biblioteca Central da UnB; salas de aula. } \\
\text { c. Capacidades distintivas - abordagem dialógica e interacionista, práticas multi e interdisciplinares; } \\
\text { d. Financeiro - orçamento baseado em bolsa de apoio a pesquisa e no desenvolvimento de projetos de pes } \\
\text { e inovação para despesas de deslocamento, aquisição de material didático e livros, participação em ev } \\
\text { (congressos, workshops, encontros e seminários); } \\
\text { e. Horizonte temporal - projetado para desenvolvimento dentro do período regulamentar do doutorado. }\end{array}$} \\
\hline 19. & \multicolumn{2}{|c|}{$\begin{array}{l}\text { Restrições ambientais prováveis ou conhecidas sobre o } \\
\text { sistema de resolução de problema são: }\end{array}$} & 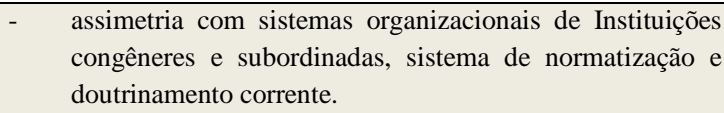 \\
\hline 20. & \multicolumn{2}{|c|}{$\begin{array}{l}\text { Os solucionadores do problema saberão quando o } \\
\text { problema poderá ser solucionado: }\end{array}$} & ao término da atual gestão da Instituição. \\
\hline
\end{tabular}


Quadro E.2 - Definições-chave do sistema relevante: Projeto de Pesquisa

(Checkland e Scholes, 1990, p. 35, modificado)

\begin{tabular}{|c|c|c|}
\hline Visão de mundo & CATWOE & $\begin{array}{l}\text { A visão da complexidade sistêmica em um mundo de instabilidade, de sistemas } \\
\text { autônomos, de imprevisibilidade e de incontrolabilidade, cuja preocupação está } \\
\text { centrada na compreensão da realidade e não no método. }\end{array}$ \\
\hline Atores & $\begin{array}{c}\text { CATWOE, } \\
\text { TASCOI }\end{array}$ & $\begin{array}{l}\text { Pesquisador-autor da tese; Orientador da tese. Coordenação do PPGEE. Professores } \\
\text { do PPGEE. Membros do grupo de pesquisa do Laboratório NMI. Alunos do mestrado } \\
\text { e doutorado. Sujeitos dos projetos de pesquisa-ação. Capes. }\end{array}$ \\
\hline Fornecedores & TASCOI & BCE-UNB; Periódico Capes. Laboratório NMI. \\
\hline Clientes & $\begin{array}{c}\text { CATWOE, } \\
\text { TASCOI }\end{array}$ & Comunidade científica. Sociedade. \\
\hline Proprietários & $\begin{array}{c}\text { CATWOE, } \\
\text { TASCOI }\end{array}$ & Pesquisador; Orientador da tese. \\
\hline
\end{tabular}




\title{
Quadro E.3 - Aspectos da análise de fronteira de Ulrich: Projeto de Pesquisa
}

\author{
(Ulrich, 1987, modificado)
}

\begin{tabular}{|c|c|}
\hline \multicolumn{2}{|c|}{$\begin{array}{l}\text { PROPÓSITO [INTENÇÕES, DESEJOS, INTERESSES GERAIS] } \\
\text { [De onde vem a noção de propósito e valor? Quais propósitos são servidos; de quem são esses propósitos?] }\end{array}$} \\
\hline \multicolumn{2}{|l|}{ Engenheiro enquanto coordenador. } \\
\hline \multicolumn{2}{|l|}{ - $\quad$ Sistema de atividade humana. } \\
\hline \multicolumn{2}{|l|}{ - $\quad$ Mecanismo de avaliação emancipatório. } \\
\hline \multicolumn{2}{|c|}{$\begin{array}{l}\text { PODER [GRUPOS DE INTERESSE E INSTÂNCIAS DECISÓRIAS DO SISTEMA DE PESQUISA CIENTÍFICA] } \\
\text { [Quem controla os meios e os recursos? Quem controla a situação e quem é necessário para o sucesso?] }\end{array}$} \\
\hline \multicolumn{2}{|c|}{ - $\quad$ Pesquisador-autor da tese } \\
\hline \multicolumn{2}{|l|}{ - $\quad$ Orientador da tese } \\
\hline \multicolumn{2}{|l|}{ - $\quad$ Coordenador do PPGEE } \\
\hline \multicolumn{2}{|c|}{$\begin{array}{l}\text { CONHECIMENTO [EIXOS TEMÁTICOS E DOMÍNIOS DE CONHECIMENTO] } \\
\text { [Quais experiências e conhecimentos apoiam a tomador de decisão? Qual a fonte de perícia contribui com a informação necessária?] }\end{array}$} \\
\hline EIXOS & DESCRIÇÃO \\
\hline \multirow{3}{*}{ - $\quad$ Estruturação de problema } & $\begin{array}{l}\text { Abordagens tradicionais de pesquisa operacional (métodos hard) - } \\
\text { orientados à solução. }\end{array}$ \\
\hline & $\begin{array}{l}\text { Abordagens flexíveis de pesquisa operacional (métodos soft) - } \\
\text { orientados ao problema. }\end{array}$ \\
\hline & Sistema determinado pelo problema. \\
\hline - $\quad$ Análise de decisão multicritério & Abordagens tradicionais da teoria da decisão. \\
\hline - $\quad$ Complexidade sistêmica & Sistema adaptativo complexo. \\
\hline \multicolumn{2}{|c|}{$\begin{array}{l}\text { LEGITIMAÇÃO [LINHAS DE ATUAÇÃO E AGENTES LEGITIMADORES] } \\
\text { [O que provê a legitimação?] }\end{array}$} \\
\hline $\begin{array}{l}\text { - } \quad \text { Organização, estrutura e formatação da tese. } \\
\text { - } \quad \text { Publicação científica. }\end{array}$ & 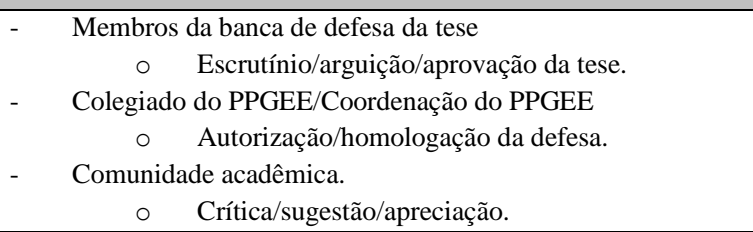 \\
\hline - $\quad$ Preparação e projeto da tese. & $\begin{array}{ll}\text { - } & \text { Orientador da tese. } \\
\text { - } & \text { Pesquisadores do grupo de pesquisa do NMI. } \\
\text { - } & \text { Pesquisadores/Professores voluntários. }\end{array}$ \\
\hline - $\quad$ Fundamentação teórica. & 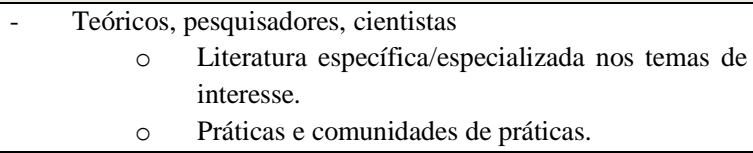 \\
\hline - $\quad$ Pesquisa-ação etnográfica/Abordagem prospectiva. & 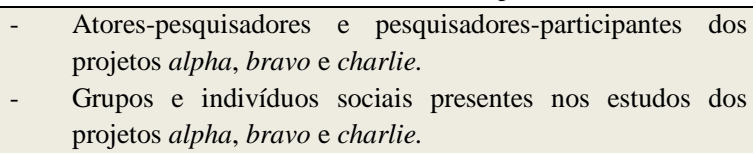 \\
\hline
\end{tabular}




\section{Quadro E.4 - Dimensões da tipologia de rede: Projeto de Pesquisa}

\section{(Van Waarden, 1992, modificado)}

\begin{tabular}{|c|c|}
\hline \multicolumn{2}{|r|}{ DIMENSÕES } \\
\hline \multicolumn{2}{|c|}{$\begin{array}{c}\text { TEMPORALIDADE } \\
\text { [Comunicação em rede em tempo real, mas permite a conexão de tempos sociais distintos] }\end{array}$} \\
\hline Recursos tecnológicos disponíveis & 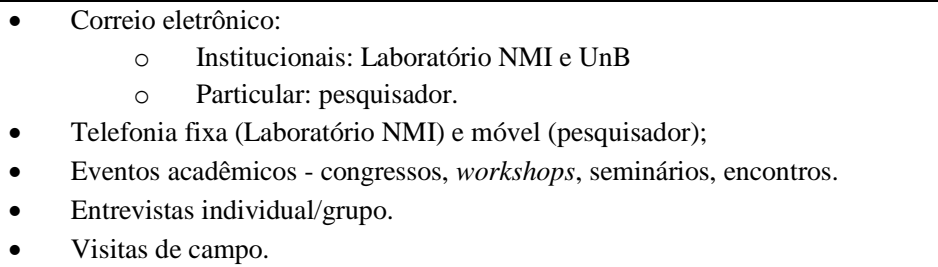 \\
\hline $\begin{array}{l}\text { Regras de conduta } \\
\text { [elementos indutores para definição das } \\
\text { normas/regras de convivência] }\end{array}$ & $\begin{array}{l}\text { - } \\
\text { - } \quad \text { Rito da defesa de qualificação/tese. } \\
\text { - } \quad \text { Normas da Faculdade de Tecnologia/ABNT para formatação da tese. } \\
\text { - } \quad \text { Planos de ensino das disciplinas cursadas. } \\
\text { - } \quad \text { Orientação/direcionamento do Professor Orientador da tese. }\end{array}$ \\
\hline Como atender as demandas? & $\begin{array}{l}\text { - Matrícula semestral no PPGEE. } \\
\text { - } \text { Aprovação nas disciplinas cursadas. } \\
\text { Levantamento da literatura específica/especializada nos temas de } \\
\text { interesse. } \\
\text { Participação em eventos acadêmicos - congressos, workshops, } \\
\text { seminários, encontros. } \\
\text { - Recorrendo a especialistas de tecnologia da informação/negócio e } \\
\text { pesquisadores para repercutir os temas de interesse e o problema de } \\
\text { pesquisa. } \\
\text { Construindo, desconstruindo e reconstruindo preconceitos, ideias, } \\
\text { posições e propostas. } \\
\text { Observando as práticas e os fenômenos que emergem dos projetos } \\
\text { alpha, bravo e charlie. }\end{array}$ \\
\hline \multicolumn{2}{|c|}{$\begin{array}{c}\text { ESPACIALIDADE } \\
\text { [Criação de territorialidade de novo tipo, virtuais e presenciais, e a conexão entre ambas.] }\end{array}$} \\
\hline Determinação dos espaços & 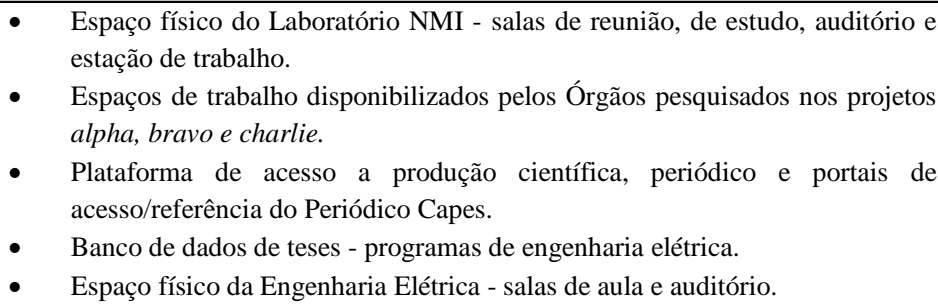 \\
\hline Determinação dos atores & $\begin{array}{ll}\text { - } & \text { Pesquisador-autor da tese. } \\
\text { - } & \text { Orientador da tese. } \\
\text { - } & \text { Coordenador do PPGEE. } \\
\text { - } & \text { Pessoal de apoio da Secretaria do PPGEE. } \\
\text { - } & \text { Colegiado do PPGEE. } \\
\text { - } & \text { Pesquisadores/estagiários do grupo de pesquisa do NMI. } \\
\text { - } & \text { Professores do PPGEE. } \\
\text { - } & \text { Atores-pesquisadores e pesquisadores-participantes dos projetos alpha, bravo } \\
& \text { e charlie. }\end{array}$ \\
\hline Determinação dos tipos de relação & $\begin{array}{l}\text { - } \quad \text { Demandas institucionais da coordenação do PPGEE. } \\
\text { - } \quad \text { Eventos acadêmicos relacionados com os temas de interesse da tese. } \\
\text { - } \quad \text { Orientação/direcionamento do Orientador da tese. } \\
\text { - } \quad \text { Dinâmica das atividades executivas dos projetos alpha, bravo e charlie. }\end{array}$ \\
\hline \multicolumn{2}{|c|}{$\begin{array}{c}\text { SOCIABILIDADE } \\
\text { [Novas formas de relações sociais, em intensidade, abrangência, intencionalidade e, em especial, seu significado e alcance em um } \\
\text { novo tipo de esfera pública] }\end{array}$} \\
\hline $\begin{array}{c}\text { O que e como? } \\
\text { [Identificar os principais tópicos de interesse } \\
\text { que induzem a operação das atividades } \\
\text { essenciais] }\end{array}$ & $\begin{array}{ll}\text { - } & \text { Planejamento e execução do projeto da tese. } \\
\text { - } & \text { Definição do problema e dos objetivos de pesquisa. } \\
\text { - } & \text { Estrategização dos métodos e procedimentos metodológicos. } \\
\text { - } & \text { Construção do mecanismo de avaliação emancipatório. }\end{array}$ \\
\hline
\end{tabular}


Quais os processos com cada ator? [Dentre as atividades essenciais levantadas, quais as participações dos atores, em quais processos e os formatos possíveis

O que se espera a partir de uma comunicação em Rede?
Vide matriz de responsabilidade RACI - Quadro E.5.

- Aprendizado e reforço dos pressupostos epistemológicos e ontológicos, e das propostas metodológica e do modelo teórico da tese.

- Criação de valor para a comunidade acadêmico-científica em geral, e para as engenharias em particular.

- Aproximação e fortalecimento de vínculos com grupos de pesquisa e pesquisadores dentro e fora do Brasil. 
Quadro E.5 - Matriz de atribuição de responsabilidades RACI: Projeto de Pesquisa

\begin{tabular}{|c|c|c|c|c|c|c|c|c|c|}
\hline & 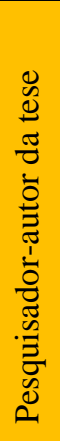 & 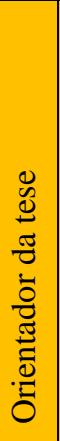 & 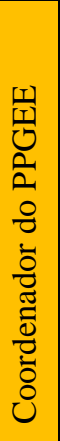 & 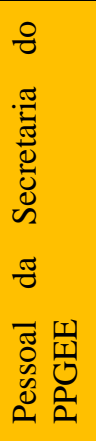 & $\begin{array}{l}\text { 崩 } \\
0 \\
0 \\
0 \\
0 \\
0 \\
\frac{0}{0} \\
\frac{0}{60} \\
\frac{0}{0} \\
0\end{array}$ & 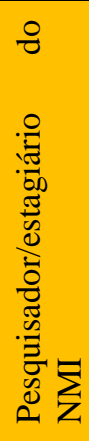 & 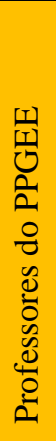 & 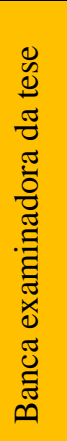 & 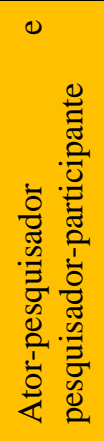 \\
\hline Planejamento e execução do projeto da tese & $\mathrm{R}$ & A & $\mathrm{C}$ & I & $\mathrm{C}$ & $\mathrm{C}$ & $\mathrm{C}$ & I & I \\
\hline $\begin{array}{l}\text { Definição do problema e dos objetivos de } \\
\text { pesquisa }\end{array}$ & $\mathrm{R}$ & A & I & I & I & I & I & I & I \\
\hline $\begin{array}{lll}\text { Estrategização dos métodos } & \mathrm{e} \\
\text { procedimentos metodológicos } & \end{array}$ & $\mathrm{R}$ & A & I & I & I & $\mathrm{C}$ & $\mathrm{C}$ & I & $\mathrm{C}$ \\
\hline $\begin{array}{l}\text { Construção do mecanismo de avaliação } \\
\text { emancipatório (defesa da tese) }\end{array}$ & $\mathrm{R}$ & $\mathrm{R}$ & $\mathrm{C}$ & I & A & $\mathrm{C}$ & $\mathrm{C}$ & $\mathrm{R}$ & $\mathrm{C}$ \\
\hline
\end{tabular}

\section{Legenda:}

- R:Responsável por executar uma atividade (o executor);

- A: Autoridade, quem deve responder pela atividade, o dono (apenas uma autoridade pode ser atribuída por atividade);

- C: Consultado, quem deve ser consultado e participar da decisão ou atividade no momento que for executada;

- I: Informado, quem deve receber a informação de que uma atividade foi executada. 


\section{Quadro E.6 - Prospecção da capacidade do sistema de interesse: Projeto de Pesquisa}

(Morgan, 2006, modificado)

\begin{tabular}{|c|c|c|c|}
\hline $\begin{array}{l}\text { Perspectiva } \\
\text { [tópicos de } \\
\text { interesse] }\end{array}$ & $\begin{array}{l}\text { Dificuldades encontradas } \\
\text { [limitações - deficiências e restrições] }\end{array}$ & $\begin{array}{c}\text { Políticas e Planos } \\
\text { [(boas) práticas, } \\
\text { procedimentos] }\end{array}$ & $\begin{array}{c}\text { O que deve ser feito } \\
\text { minimamente para trazer o } \\
\text { impacto desejado para } \\
\text { cada perspectiva relevante? }\end{array}$ \\
\hline $\begin{array}{l}\text { Planejamento e } \\
\text { execução do } \\
\text { projeto da tese }\end{array}$ & 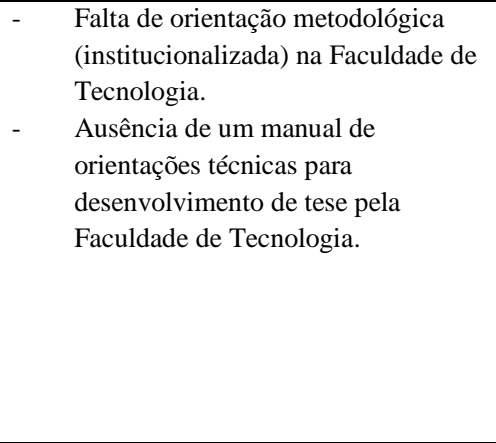 & \multirow{4}{*}{ 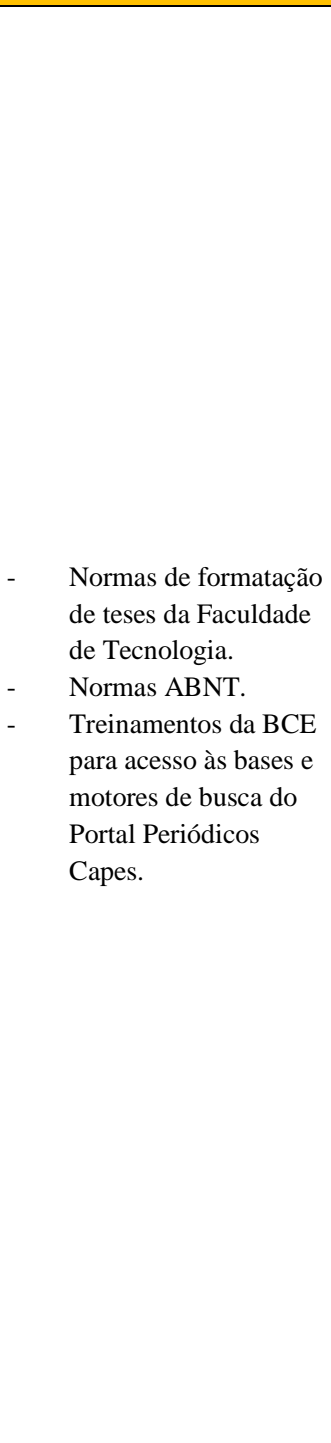 } & $\begin{array}{ll}\text { - } & \text { Buscar apoio } \\
\text { metodológico noutras } \\
\text { faculdades e/ou } \\
\text { professores/ } \\
\text { epistemólogos. } \\
\text { Buscar referências } \\
\text { bibliográficas } \\
\text { especializadas em } \\
\text { epistemologia e } \\
\text { métodos/ } \\
\text { procedimentos de } \\
\text { pesquisa. }\end{array}$ \\
\hline $\begin{array}{l}\text { Definição do } \\
\text { problema e dos } \\
\text { objetivos de } \\
\text { pesquisa }\end{array}$ & 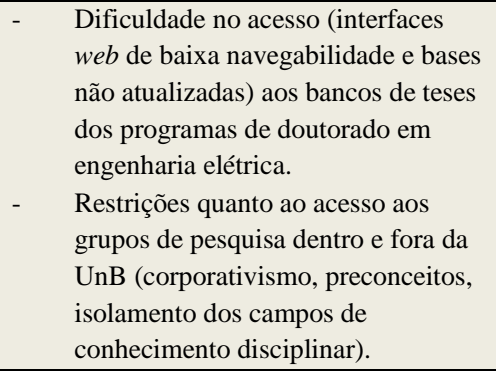 & & 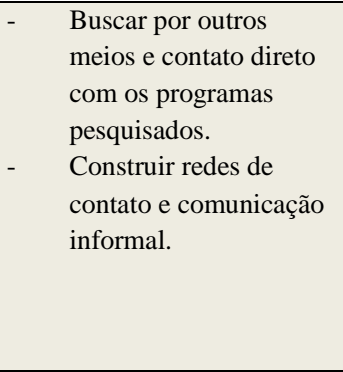 \\
\hline $\begin{array}{l}\text { Estrategização } \\
\text { dos métodos e } \\
\text { procedimentos } \\
\text { metodológicos }\end{array}$ & $\begin{array}{l}\text { - } \quad \text { Dificuldade em encontrar } \\
\text { Organizações públicas e/ou privadas } \\
\text { dispostas a colaborar com a pesquisa } \\
\text { científica. } \\
\text { Dificuldade em encontrar } \\
\text { mecanismos para instrumentalizar e } \\
\text { operacionalizar as pesquisas em } \\
\text { ambientes reais. }\end{array}$ & & $\begin{array}{l}\text { Escolher projetos de } \\
\text { PD\&I aptos e } \\
\text { convenientes para } \\
\text { desenvolver pesquisas } \\
\text { prospectivas e } \\
\text { intervenções em } \\
\text { ambientes reais. }\end{array}$ \\
\hline $\begin{array}{l}\text { Construção do } \\
\text { mecanismo de } \\
\text { avaliação } \\
\text { emancipatório } \\
\text { (modelo teórico) }\end{array}$ & 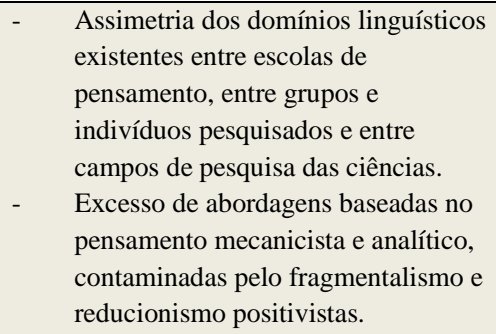 & & $\begin{array}{l}\text { Revista dos trabalhos } \\
\text { seminais e } \\
\text { fundamentação dos } \\
\text { polos epistemológico, } \\
\text { metodológico e teórico- } \\
\text { conceitual. }\end{array}$ \\
\hline
\end{tabular}




\section{Quadro E.7 - Categorias avaliativas da análise de fronteira: Projeto de Pesquisa}

\section{(Ulrich, 1987, p. 279, modificado)}

\begin{tabular}{|c|c|}
\hline \multicolumn{2}{|c|}{ Relacionamento com os Públicos Internos e Externos } \\
\hline $\begin{array}{l}\text { - O que o público externo espera do sistema de } \\
\text { avaliação de situações problemáticas que está } \\
\text { sendo pensado? }\end{array}$ & $\begin{array}{l}\text { - Que haja contribuições teóricas e pragmáticas para a academia e para os } \\
\text { grupos de prática. }\end{array}$ \\
\hline $\begin{array}{l}\text { - Há alguma ação de engajamento com o público } \\
\text { interno e/ou externo? }\end{array}$ & 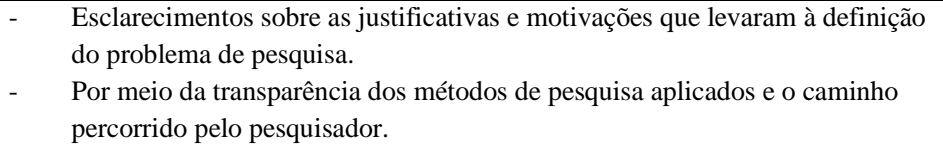 \\
\hline $\begin{array}{l}\text { - Qual a expectativa de qualidade do trabalho de } \\
\text { pesquisa? }\end{array}$ & $\begin{array}{l}\text { - } \quad \text { Alinhamento com as orientações da tese e do PPGEE. } \\
\text { - Nível de contribuições para as comunidades acadêmico-científicas e } \\
\text { comunidades de prática. } \\
\text { - Ética na pesquisa. }\end{array}$ \\
\hline $\begin{array}{l}\text { - Qual a tendência de inovação e } \\
\text { desenvolvimento? Como o sistema de avaliação } \\
\text { de situações problemáticas está adequado para as } \\
\text { novas fronteiras tecnológicas? }\end{array}$ & $\begin{array}{l}\text { - Por meio do mecanismo de avaliação que permitirá aprender com a situação } \\
\text { problemática e repercutindo os desencadeamentos e emergências } \\
\text { tecnológicas. }\end{array}$ \\
\hline $\begin{array}{l}\text { - Os canais de comunicação com os públicos } \\
\text { internos e externos são efetivos? }\end{array}$ & $\begin{array}{l}\text { - } \quad \text { São adequados para o cenário de pesquisa empreendido. Maior intercâmbio } \\
\text { com grupos de pesquisa interdisciplinares poderiam ter sido implementados } \\
\text { para melhor a comunicação do projeto de pesquisa. }\end{array}$ \\
\hline $\begin{array}{l}\text { - Como se mede a satisfação e fidelidade dos } \\
\text { envolvidos e afetados? }\end{array}$ & $\begin{array}{l}\text { - } \quad \text { por meio de sessões de conversação e verbalização da proposta de trabalho } \\
\text { da tese, as motivações da pesquisa e os principais resultados esperados. }\end{array}$ \\
\hline
\end{tabular}


Tabela E.1 - Matriz de relacionamento dos atores: Projeto de Pesquisa

\begin{tabular}{|c|c|c|c|c|c|c|c|c|}
\hline $\begin{array}{l}0=\text { LEGENDA } \\
1=\text { relação frace raca } \\
2=\text { relação forte } \\
3=\text { relação muito forte }\end{array}$ & 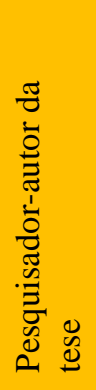 & 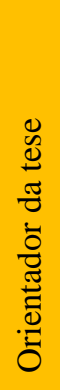 & 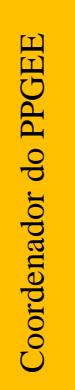 & 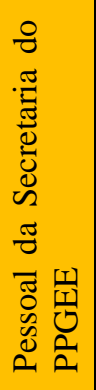 & 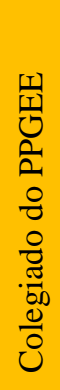 & 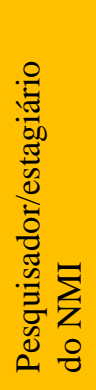 & 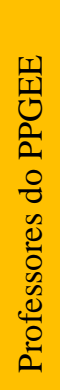 & 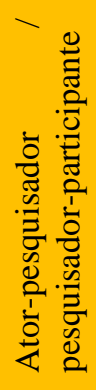 \\
\hline Pesquisador-autor da tese & 0 & 3 & 1 & 1 & 0 & 2 & 1 & 2 \\
\hline Orientador da tese & 2 & 0 & 1 & 2 & 2 & 0 & 2 & 1 \\
\hline Coordenador do PPGEE & 1 & 1 & 0 & 1 & 1 & 0 & 2 & 0 \\
\hline Pessoal da Secretaria do PPGEE & 1 & 2 & 2 & 0 & 2 & 0 & 3 & 0 \\
\hline Colegiado do PPGEE & 0 & 1 & 2 & 2 & $\overline{0}$ & 0 & 2 & 0 \\
\hline Pesquisador/estagiário do NMI & 2 & 2 & 0 & 0 & 0 & 0 & 1 & 1 \\
\hline Professores do PPGEE & 1 & 2 & 3 & 3 & 3 & 0 & 0 & 0 \\
\hline Ator-pesquisador/pesquisador-participante & 2 & 1 & 0 & 0 & 0 & 2 & 0 & 0 \\
\hline
\end{tabular}


ANEXOS 


\title{
F- ANEXO A: ARTEFATOS DA HEURÍSTICA CRÍTICA SISTÊMICA
}

\author{
Quadro F.1 - Categorias e aspectos da CSH
}

(Ulrich, 1987)

\begin{tabular}{|c|c|c|c|}
\hline $\begin{array}{c}\text { CATEGORIAS DE } \\
\text { FRONTEIRA }\end{array}$ & & & ASPECTOS \\
\hline $\begin{array}{l}\text { 1. Cliente } \\
\text { 2. Propósito } \\
\text { 3. Medida de melhoria }\end{array}$ & Motivação & \multirow{3}{*}{ Envolvidos } & \multirow{4}{*}{$\begin{array}{l}\text { É o sistema de referência que determina } \\
\text { quais observações (fatos) e avaliações } \\
\text { (valores) são considerados relevantes } \\
\text { quando avaliamos os méritos e deficiências } \\
\text { de uma proposição. }\end{array}$} \\
\hline $\begin{array}{l}\text { 4. Responsável pela tomada } \\
\text { de decisão } \\
\text { 5. Recursos } \\
\text { 6. Ambiente de decisão }\end{array}$ & Poder & & \\
\hline $\begin{array}{l}\text { 7. Profissional } \\
\text { 8. Perícia } \\
\text { 9. Garantia }\end{array}$ & Conhecimento & & \\
\hline $\begin{array}{l}\text { 10. Testemunha } \\
\text { 11. Emancipação } \\
\text { 12. Visão de mundo }\end{array}$ & Legitimação & Afetados & \\
\hline
\end{tabular}




\section{Quadro F.2 - As doze categorias críticas que compõem a heurística}

(Ulrich, 1987)

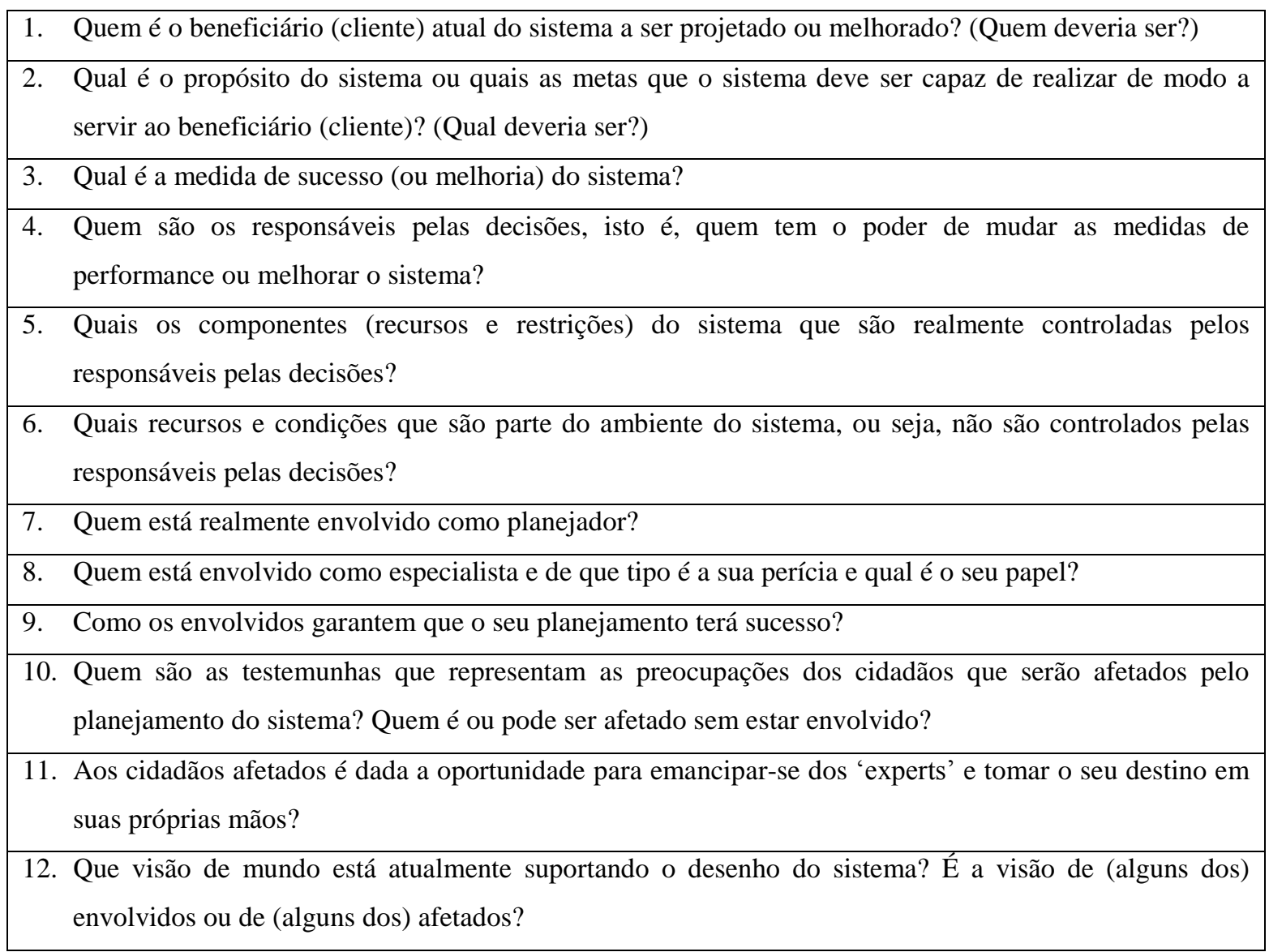

